\title{
Ideas, Institutions and Interests:
}

\section{The Politics of China's Energy Policy Change 1996-2015}

\author{
By \\ Yang Gao
}

(高 旸)

\author{
A Thesis \\ submitted to Victoria University of Wellington \\ in fulfilment of the requirements for the \\ Degree of Doctor of Philosophy
}

School of History, Philosophy, Political Science \& International Relations

Victoria University of Wellington 


\section{Abstract}

This study investigates and explains the shift of the relative priority in China's energy policy in the 1990s and 2000s. Between 1996 and 2015, the priority of China's national energy policy had shifted from an emphasis on energy supply security to energy demand efficiency. A central question this study seeks to answer is: what forces led to this shift of policy priority?

To answer the question, this study proposes a multi-layered and cross-sectoral analytical framework based on Historical Institutionalism theory. It focuses on the complex interaction between ideas, institutions and interests to understand the politics of China's energy policy change. This study establishes a model of policy change as a means of institutional adaptation to manage an emerging mismatch between evolving ideational patterns at the national level, and the persistence of certain interest-seeking behaviour shaped by historically-formulated institutions at the subnational level.

With the introduction of the "Socialist Market Economy" idea in the early 1990s, China began to deepen its reform on two sets of fundamental institution that define China's state-industry relations and central-local intergovernmental relations. Over time, the reforms profoundly impacted the development of China's two major energy-based industrial value chains, namely the Coal-Metallurgical Value Chain (CMVC) and the Oil-Petrochemical Value Chain (OPVC), by shaping their asymmetrical institutional connections with Chinese government at central and local levels. At the national level, the 1990s reforms helped to build strong institutional connections between the central government and the OPVC, which greatly contributed to China's energy security in the 2000s. However, decentralising and marketising most heavy industries allowed interest-seeking local governments to build strong institutional connections with the CMVC, causing the 1990s reforms to produce an unintended consequence of heavy industrialisation that has significantly changed China's economic structure. Such uncontrolled heavy industrialisation, revealed by the country's declining energy efficiency in the early 2000s, had increasingly went against a new generation of Chinese top leadership's "Scientific Development" idea. A major energy policy shift was therefore initiated and utilised by the central government to curb the heavy industrialisation. The central government's institutional connections with the coalbased heavy industries, especially those in the CMVC, were rebuilt and strengthened.

Overall, this study provides a more sophisticated understanding of how ideas, institutions and interests dynamically interact to produce major policy change in the context of a transitional state. 


\section{Acknowledgements}

I am most indebted to my primary supervisor, Professor Xiaoming Huang, whom I first met six years ago as a young university graduate. From the beginning of my Masters study all the way to the end of my $\mathrm{PhD}$ study, this interesting and challenging intellectual endeavour would never have been possible without his kind guidance and invaluable help. Professor Huang's hard work to establish and promote the New Zealand Contemporary China Research Centre has in particular benefited this study by connecting me with some of the world's most influential Sinologists, such as Professor Barry Naughton and Professor Dali Yang, who have all offered priceless advice to my study.

My two co-superviors, Dr. Jason Young and Dr. Marc Lanteigne, contributed significantly to this study. Dr. Young is the most generous and the most patient scholar I have encountered. He is always ready to help his students with his rich knowledge on Chinese politics. He has inspired me throughout my thesis writing and has offered numerous brilliant ideas and insightful comments. I also owe thanks to Dr. Lanteigne for giving me much support at the early stage of my thesis writing.

Many insights with Chinese energy policy and energy sectors that played a crucial role in building the very foundation this study were attainable only through the generosity of some individuals and institutes across China's academic, government and industry. I would like to thank Mr. WEN Hao of Beijing Municipal Government, and Dr. ZHU Mingzhe of China University of Political Science and Law, who introduced me to two precious internship opportunities offered by China National Offshore Oil Corporation (CNOOC) and China Shenhua Group. My colleagues at CNOOC and China Shenhua Group taught me much about energy technology, energy markets and China's evolving industrial institutions. I owe these individuals a debt of gratitude for opening their doors to me and for guiding me patiently through the dense labyrinth of China's energy policy and energy sector.

I am also indebted to many other friendly and helpful staff of Victoria University of Wellington. Special thanks go to Professor Stephen Levine for his generosity in offering much help and advice during my Masters and PhD studies. I also greatly value my friendship with Dr. LUO Hui, the founding director of the Confucius Institute at Victoria University of Wellington. Participating in the numerous cultural, musical and language projects organised by Dr. Luo was a major source of inspiration to my study. Most importantly, I owe an enormous debt to my parents and my sister for their enduring love, support and patience. I am especially grateful that I could meet my fiancee toward the end of my $\mathrm{PhD}$ study. She is an inimitable source of inspiration and motivation in my life. 


\section{Table of Contents}

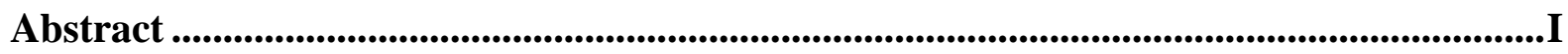

Acknowledgements .................................................................................................................................... II

List of Figures ....................................................................................................................................... VII

List of Tables..............................................................................................................................................VIII

List of Abbreviations ...........................................................................................................................IX

Chapter One: Introduction.................................................................................................................. 1

1.1 The Puzzle of China's National Energy Policy Change 1996-2015 ........................1

1.2 China's Energy Policy Change - Questions, Explanations and Gaps ...................... 3

1.2.1 Existing Explanations of Policy Change ..............................................

1.2.2 Growing Explanatory Deficits ............................................................. 10

1.3 Understanding Policy Change - A Historical Institutionalism Approach.............15

1.3.1 Historical Institutionalism and Policy Studies ....................................15

1.3.2 Ideas, Institutions and Interests - A HI-based Framework for Policy

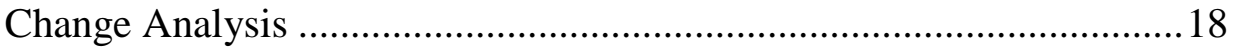

1.4 Research Design and Methodology ………………………………………...... 19

1.4.1 Multi-Layered and Cross-Sectoral Institutional Analysis ...................20

1.4.2 Research Methods ...............................................................................24

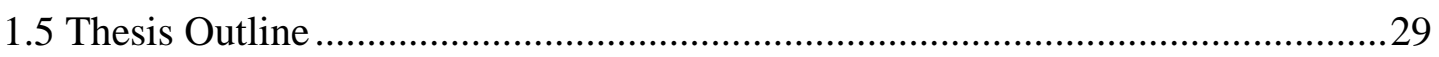

Chapter Two: Priorities of China's Energy Policy and their Industrial Basis................. 32

2.1 The Two Energy Policy Priorities in China's FYPs 1996-2015............................32

2.1.1 The FYP Policy System and China's National Energy Policy ............32

2.1.2 Priorities of China's Energy Policy 1996-2015 .....................................34

2.2 Energy Security, Energy Efficiency and China's Two Major Energy-based Industrial Value Chains .......................................................................................

2.2.1 China's Energy Situation and the Concept of Industrial Value Chain39

2.2.2 China's Energy Policy Priorities and Two Energy-Based Industrial

Value Chains .......................................................................................... 42

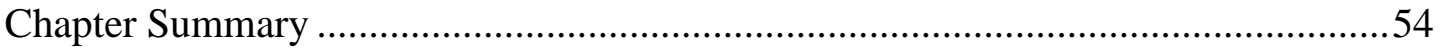

Chapter Three: Ideational Dynamism in China's National Policymaking......................... 55

3.1 Chinese Party-State Leadership and Their Ideational Systems ..............................55 
3.1.1 Institutionalisation of the Party-State Leadership in the Post-Reform Era

3.1.2 Deng's Legacy: Socialist Market Economy Theory and Ideational Innovation .58

3.2 Reform-to-Grow: The Jiang-Zhu Leadership's Strategy in the 1990s 60

3.2.1 Growth-Oriented Institutional Reforms. .60

3.2.2 Passing-on Ideational Innovation: the 'Three Represents' .63

3.3 Scientific Development: Hu-Wen Leadership's Updated Strategy in the 2000s..65

3.3.1 Hu-Wen's Scientific Development Outlook in the 2000s .65

3.3.2 Scientific Development: Development Model and Economic Structure .68

3.4 Turning Ideas into FYPs - Evolving Policymaking Actors and Process at the National Level .71

3.4.1 Streamlining Central Government Policy Bureaucracies .72

3.4.2 Top Party-State Leadership's Increasing Control over Policymaking76

Chapter Summary ..... .81

\section{Chapter Four: Institutional Reforms and an Imbalanced Structure of Industrial} Development

4.1 SOE Reform and Central Government Control over 'Strategic Sectors' .84

4.1.1 China's SOE-based Industrial Sector and Early Reforms . .84

4.1.2 "Grasping the large" and the Formation of Centrally-Controlled SOE Fleet 88

4.1.3 Yangqi as means of Controlling Strategic Sectors .93

4.2 Central-Local Institution Reform and Local Government's 'Growth Imperative'

4.2.1 The Political \& Economic Dimensions of Central-Local Relation ....99

4.2.2 Fiscal Reform and 'Growth Imperative' at Subnational Level ........ 104

4.3 Emerging Post-Reform Heavy-Industrialisation at Subnational Level

4.3.1 SOE reform and Local Proliferation of Energy-Intensive Industries 109

4.3.2 SOE Reform, Central-Local Institution Reform and Changing

Dynamics of Local industrialisation 1980s-2010s 112

Chapter Summary 117

\section{Chapter Five: Case Study I - CMVC Restructure in the 1990s and China's} Energy Efficiency in the 2000s .

5.1 Formation of China's CMVC and Industrial Energy Efficiency in the 1980s ... 120 
5.1.1 Formation and Development of China's Centralised CMVC 1950s$1980 \mathrm{~s}$

5.1.2 Central Government Control over Industrial Energy Intensity in the $1980 \mathrm{~s}$

5.2 1990s Institutional Reforms and Decentralisation of CMVC.

5.2.1 The Coalmining Sector Reform

5.2.2 The Power Sector Reform

5.2.3 The Metallurgy Sector Reform

5.3 Local Government Interests and CMVC Growth in the 2000s 136

5.3.1 Iron \& Steel Capacity Expansion

5.3.2 Decentralised Aluminium Industry and Local Manipulation of Energy

Supply

5.4 FYPs' Energy Efficiency Policy as Institutional Adaptation toward Scientific

Development

5.4.1 The Failure of Conventional Industrial Policy 2003-2005

5.4.2 Introduction of Energy Efficiency Target Responsibility System in the 11th and 12th FYPs. 151

Chapter Summary 155

Chapter Six: Case Study II - OPVC Restructure in the 1990s and China's Energy Security in the 2000s

6.1 Formation and Early Reform of China's OPVC. 157

6.1.1 Formation and Development of OPVC in the Planned Economy .... 157

6.1.2 Decentralisation and Marketisation 1981-1997. 160

6.2 'Grasping the Large' - Institutional Connections between the State and the OPVC 168

6.2.1 Restructuring the OPVC 169

6.2.2 'Squeezing Out' the Non-Central Players ....................................... 172

6.2.3 Putting China's OPVC under the State Council SASAC ..................176

6.3 Restructured OPVC and China's Energy Security in the 2000s........................180

Chapter Summary 186

Chapter Seven: Discussion and Conclusion

7.1 Research Questions and Research Design Revisit.

7.2 Major Findings

7.2.1 Emerging Ideational Dynamism on the National Level 189 
7.2.2 Imbalanced Structure of Energy Development and Institution-Shaped Interest-seeking Behaviour on the Subnational Level ......................... 190

7.2.3 Idea-Interest Mismatch and Idea-Guided Structural Rebalance .......193

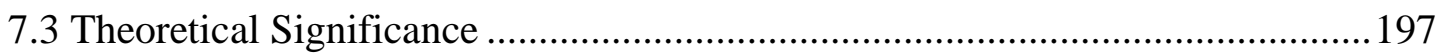

7.3.1 The Role of Ideational Innovation in Policy Formulation ................197

7.3.2 Multi-layered and Cross-Sectoral Institutional Analysis..................198

7.3.3 An Idea-Guided Institutional Adaptation Model of China's Energy

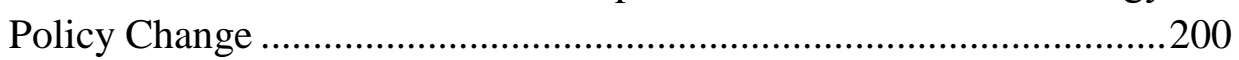

7.4 Conclusion and Future Research ..................................................................202

Appendix: Formation of Vertically-Integrated NOCs in 1998 ......................................... 206

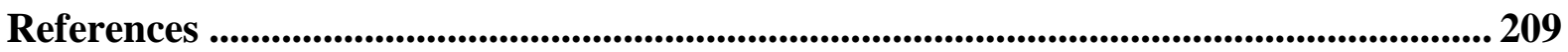




\section{List of Figures}

Figure 1 China's Energy Intensity and Overall Energy Dependence 1982-2011 .............5

Figure 2 China's Oil Dependence and Overall Energy Dependence 1982-2011............ 11

Figure 3 A Multi-Layered, Cross-Sectoral Analytical Framework ................................20

Figure 4 Average Energy Intensity of China's Major Industrial Subsectors between

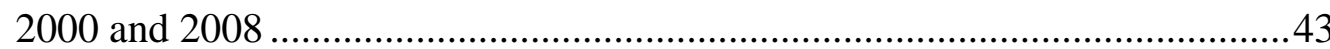

Figure 5 Mix of Industrial Enterprises in China's Top-1,000 Project ...........................47

Figure 6 Overview of China's Two Energy-based Industrial Value Chains ...................53

Figure 7 Chinese Local Government Revenue \& Expenditure as Percentage of National

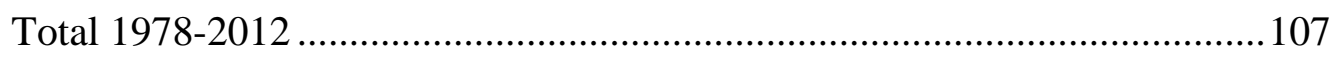

Figure 8 Structure of Top-10 World Steel Producers (as of 2010) .............................137

Figure 9 China's Steel Production by Provinces as Percentage of National Total (as of

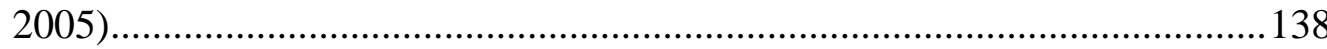

Figure 10 Output of the World's Top-10 Aluminum Producers (as of 2010).............. 143

Figure 11 China's Electrolytic Aluminum Production by Provinces as Percentage of

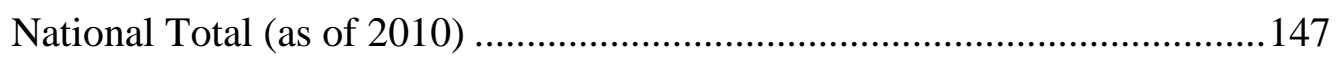

Figure 12 The Three Sectors' Contribution to China's Annual GDP Growth 1995-2013

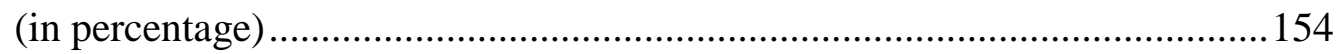

Figure 13 China's Petroleum Products Distribution System - the example of diesel

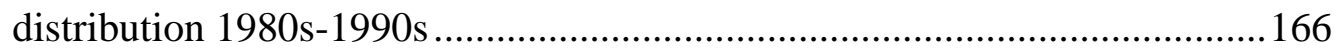

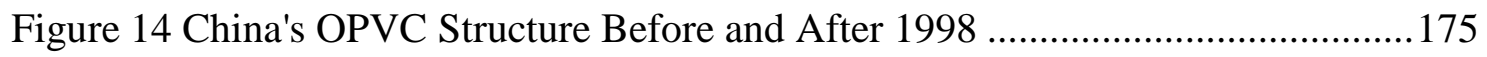

Figure 15 The Central Party-State's Control over China's NOCs ...............................178

Figure 16 An Imbalanced Structure of Energy Development .....................................191

Figure 17 Energy Policy Change: Rebalancing the Imbalanced Structure of Energybased Industrial Development .................................................................... 194

Figure 18 An Idea-Guided Institutional Adaptation Model of China's Energy Policy

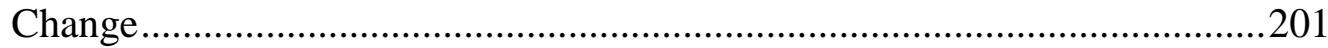




\section{List of Tables}

Table 1 Overview of China's Macro-Economic Objectives 1993-2011 .......................70

Table 2 Formulation and Implementation of Energy Efficiency Target Responsibility

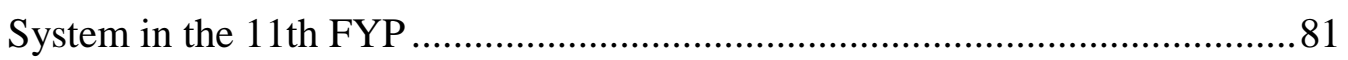

Table 3 Ownership of China's Top-20 Steelmakers (as of 2010) ...............................139

Table 4 Energy Efficiency Work Evaluation System for Chinese Provincial

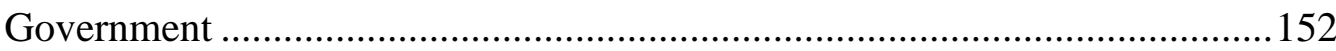

Table 5 Major Joint-Venture Petrochemical Projects Under Planned in the Late 1990s 164

Table 6 Matrix of Government-Industry institutional Connections and Interest

Alignment 


\section{List of Abbreviations}

ACEWC

CHALCO

CMVC

CNOOC

CNPC

CPC

EBF

EIA

EIT

GDP

GHG

IOC

IPP

kgsce

Kwh

LAT

MOC

MOF

MCI

$\mathrm{mmt}$

Mtce

NDRC

NOC

NPC

OECD/IEA

OPVC

PIT
Annual Central Economic Working Conference

China Aluminium Corporation

Coal-based Metallurgical Value Chain

China National Offshore Oil Company

China National Petroleum Corporation

Communist Party of China

Extra-Budgetary Funds

(U.S.) Energy Information Administration (EIA)

Enterprise Income Tax

Gross Domestic Product

Green House Gas

International Oil Company

Independent Power Producer

kilogram standard coal equivalent

Kilowatt Hours

(China) Local Administration of Tax

(China) Ministry Of Commerce

(China) Ministry Of Finance

(China) Ministry of Coal Industry

Million metric tons

Million tons of coal equivalent

(China) National Development and Reform Commission

National Oil Company

(China) National People's Congress

Organization for Economic Co-operation and

Development/ International Energy Agency

Oil-based Petrochemical Value Chain

Personal Income Tax 
PRC

SASAC

SAT

SCECO

SDPC

SESRC

SEZ

SETC

Sinopec

SOE

SPCC

Tce

TVE

VAT
People's Republic of China

(China) State Assets Supervision and Administration

Commission

(China) State Administration of Taxation

(China) State Council Energy Conservation Office

(China) State Development and Planning Agency

State Economic System Reform Commission

Special Economic Zone

(China) State Economic and Trade Commission

China National Petrochemical Corporation

State-Owned Enterprise

State Power Corporation of China

Ton(s) of coal equivalent

Township-and-Village Enterprise

Value-Added Tax 


\section{Chapter One: Introduction}

\subsection{The Puzzle of China's National Energy Policy Change 1996-2015}

In general, the objectives of a country's energy policy fall into several categories, including security of supply, efficiency, equity, financial, and macro-economic (Andrews-Speed 2004, p.42). Over the last decade, the dramatic shift of the relative priority of China's national energy policy objectives in its recent four Five-Year Plans (1996-2015) has captured the world's attention. Energy supply security, with a focus on oil supply security that had been the top priority of China's energy policy in the 9th and 10th Five-Year Plans (FYPs) (1996-2005), was suddenly replaced by energy efficiency targets, especially industrial energy intensity targets, as the new top priority of China's energy policy in the 11th and 12th Five-Year Programmes (also FYPs hereafter) (20062015). ${ }^{1}$ As the world's second largest economy, the second largest energy producer and consumer today, China's energy policy and its change have a profound impact on the global economy and environment issues. To study the mechanism of China's energy policymaking and the underlying forces that led to the policy change over the past two decades is very important for us to understand the country's transitional political economy and its implications for the world.

China's energy policy regime has its roots in the Soviet-style planned economy. National energy policy has been primarily embodied in the FYPs since 1953. From the 1950s, the building and development of a strong energy industry was identified as one of the top national development objectives. By 1963, the discovery of major oil reserves in eastern China, together with the country's abundant coal reserve, enabled the country to achieve energy self-sufficiency. In the following decades, China's

\footnotetext{
${ }^{1}$ Energy efficiency of an economy is commonly defined and measured as GDP per unit of energy input. Energy intensity is measured as energy consumed per unit of output. It is often used as a key indicator of energy efficiency. In those countries where the industrial sector represents a considerable share of the whole economy, like China, the state of industrial energy intensity could profoundly impact the whole economy's energy efficiency. See Bhattacharyya (2011).
} 
industrialisation under the planned economy was made possible thanks to the stateowned energy sectors, such as the oil-petrochemical sectors and the coal-based power sectors. From the late 1970s, as China began its political and economic transition, the Chinese economy started to recover rapidly from the Cultural Revolution. The power of the market unleashed by economic reforms pushed the country's energy demand to quickly outstrip energy supply. Depleting domestic oil fields and sluggish electric power capacity-building made China in constant power shortage throughout the 1980s. However, it was China's turning from a major oil exporter on a net oil importer in the early 1990s that had the most profound impact on the country's energy policy making.

In the 1990s, the increasing dependence on foreign oil seemed to particularly worry the Chinese policymakers at the time, as it rapidly turned the country from a net energy exporter to a net energy importer and exposed China to the supply risks and price volatility of the global energy market. China at the time perceived itself as very vulnerable in getting stable and affordable energy supply from foreign energy producers, especially those major energy producers in geopolitically unstable regions such as the Middle East and Africa. Under such circumstances, China's energy development policies in the 9th and 10th FYPs (1996-2005) were made with unprecedented emphasis on the security of energy supply. Although China's energy deficits increased rapidly in the following decade, its national energy policy was updated and reoriented to emphasize industrial energy efficiency from the 11th FYP (2006-2010), and such change was continued in the 12th FYP period (2011-2015). Marked by a "20 percent" industrial energy intensity reduction target in the 11th FYP period and a "16 percent" target in the 12th FYP period, the priority of China's energy policy has shifted away from energy supply security to industrial energy efficiency for a whole decade. During the decade 2006-2015, energy efficiency improvement, focusing on industrial energy intensity reduction, has not only become the top priority of China's national energy policy, but has also constituted a cornerstone in China's overall development strategy, summarised as the "Scientific Development Outlook" (kexue fazhan guan). ${ }^{2}$

\footnotetext{
${ }^{2}$ See Chapter Three for detailed analyses on the nature and origins of the "Scientific Development Outlook".
} 
As a major economy with increasing influence in the world, such significant energy policy change has brought profound impacts to the global energy market and environmental governance. It has led policymakers and academics around the world to ask how and why such drastic energy policy change could take place over the past decade.

\subsection{China's Energy Policy Change - Questions, Explanations and Gaps}

Any study seeking to explain China's energy policy change must answer two fundamental questions: What is the mechanism of national policymaking in today's China? And what are the underlying politico-economic forces that have induced the energy policy shift in the specific way that occurred? In other words, we need to know how China's socio-economic policy priorities are determined in general, and why the energy policy as a key component of economic policy is made with specific priority at a certain periods of time.

The growing global significance of China's energy policy change has been documented by a growing body of literature over the last two decades. Together, existing literature on China's energy policy generally provides two analytical approaches to explain the policy change, each underpinned by different assumptions of national policymaking. The first takes a Rational Model of policymaking and focuses on international pressure and influences on China's energy policy change; the second one follows a Bureaucratic Politics Model and emphasises the bureaucratic bargaining and consensus building between central government's industrial departments and key stakeholders to induce major energy policy change.

\subsubsection{Existing Explanations of Policy Change}

\section{Rational policymaking}

Literature following this line of analysis tends to employ a rationality model of policymaking, explicitly or implicitly, and puts external factors at the centre of its analysis to understand the shift of China's energy policy. It generally regards policy 
shift as a calculated, rational response to an emerging energy-environment 'dilemma' facing the country. It is argued that China takes energy efficiency policy as a means to achieve energy supply security in a new international environment where external supply risks are common and where global climate politics increasingly puts new limits on domestic energy use.

The geopolitical and macro-economic risks of energy dependence have been a central topic in International Relations (IR) and international political economy (IPE) literature following the 1970s and 1980s' oil shocks. In the aftermath of the oil shocks, the industrialised western energy consumers began to develop a series of energy policies aiming to reduce dependence on foreign oil by improving domestic energy efficiency. The most typical were the "Project Independence" in the US (Brown 2002, p.227) and Japan's industrial energy efficiency policy (Sano et al. 2007). To many energy analysts, China also needs a strong energy efficiency policy in addition to its energy supply security policy to safeguard its energy interests as the country becomes increasingly dependent on imported oil (Constantin 2007; Zhao 2013). ${ }^{3}$ Similar to the advanced industrialised economies like the US and Japan, China has always viewed energy as a strategic sector that profoundly affects its national defence and modernisation (Zha 2006). Especially after the Sino-Soviet rift in the 1960s and through witnessing the macro-economic problems that plagued the western economies during the 1970s' oil shocks, China in the first two decades of its transition largely constructed its national energy interest upon a pre-reform doctrine of self-sufficiency and self-reliance (zili gengsheng) (Downs 2006; Taylor 2014). As China became a net oil products importer in 1993 and net crude oil importer in 1996, Chinese policymakers began to face increasing supply security challenges which the country had not worried about for three decades (Downs 2006; Kennedy 2010; Zha 2010) (see Figure 1 on the next page). At that time China was largely isolated by international society following the 1989's political turmoil and the US had successfully led a group of western democracies to invade one of the world's major oil producers. With perceived US dominance in the Middle East, the ongoing political instability in this oil-rich region

\footnotetext{
${ }^{3}$ In 2011 when China published its 12th FYP, China's oil dependence rate had reached 57 percent. See State Council (2012).
} 
and the limited choice of energy transport sea lanes, China's national energy policy from the mid-1990s to the mid-2000s was largely developed to cope with the growing oil supply risks. As a result, in the following decade from 1995, China engaged in a "global hunt for energy" (Zweig and Bi 2005), which has been well examined by a growing body of IR and IPE literature.

Figure 1 China's Energy Intensity and Overall Energy Dependence 1982-2011

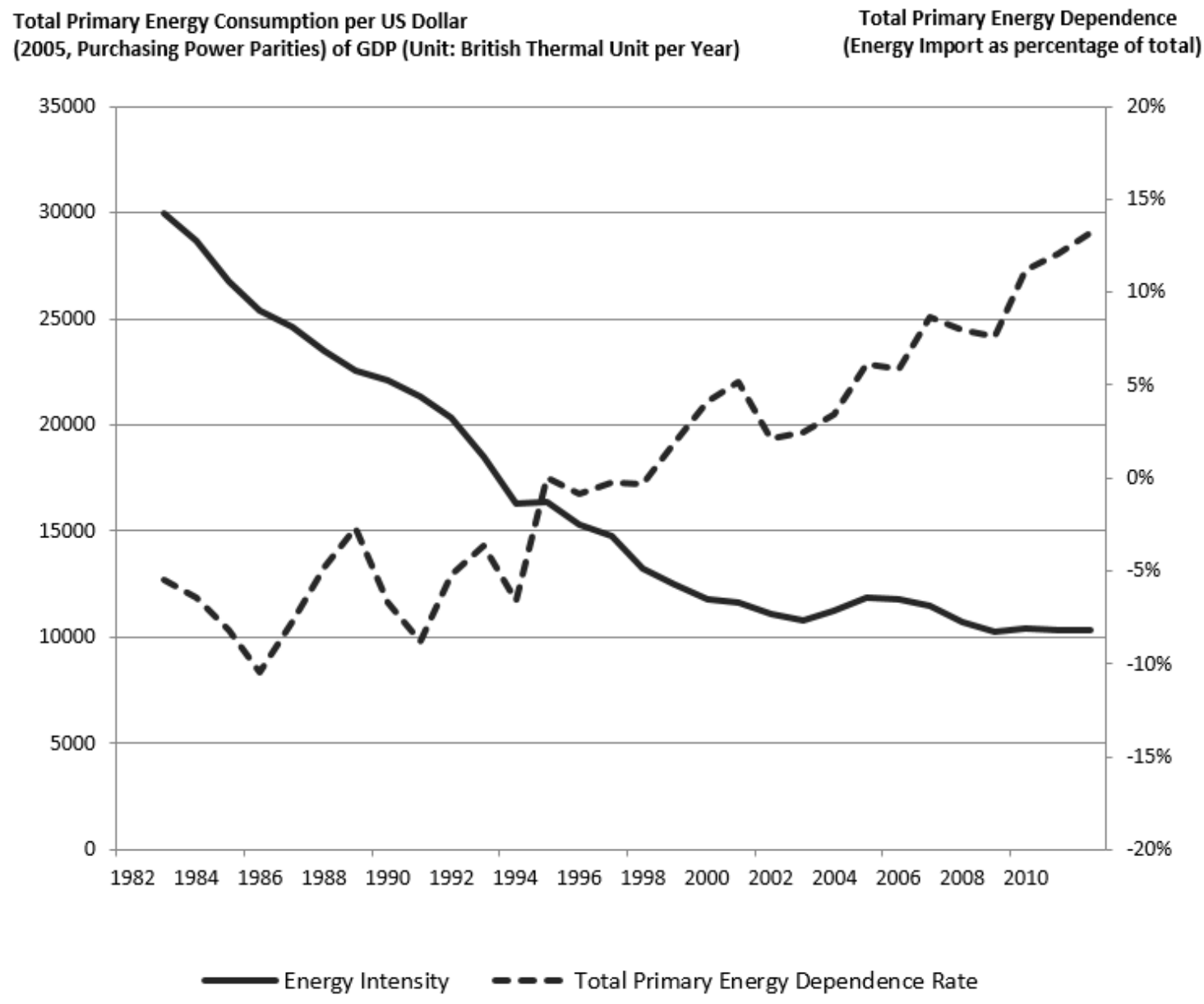

Data source: EIA, 2013

However, in the early 2000s, due to rapid economic growth and surging energy demand, two parallel trends emerged in China's energy situation: the already-massive 
and rapidly-increasing demand for fossil fuel, and the rising energy intensity of the whole economy (see Figure 1). These two trends together make China one of the world's largest energy consumers and greenhouse gas (GHG) emitters. China began to face not only energy supply risks, but also increasing pressures on other energy-related issues, especially environmental problems which effectively created a policy dilemma for the Chinese government (Song and Woo 2008). Under such circumstances, to choose to prioritise energy efficiency becomes a rational choice to achieve the dualtarget of mitigating energy supply risks and protecting the environment (OECD/IEA $2007 \mathrm{~b}$, p.30). It is commonly argued in this line of analysis that rational decisionmaking has been best illustrated by China's drastic change of stance in international climate negotiations, because of the strong positive correlation between energy intensity and carbon emissions (Cohen-Tanugi 2010).

Unlike most western democracies where strong environment civil societies exist, environmental concern is believed to affect China's energy policy mostly because of energy implications and international pressures. Traditionally, China gave a low priority to global environment issues relative to economic growth fuelled by energy consumption, as was reflected in China's opposition to timetables and ceilings for developing countries under the United Nations Framework Convention on Climate Change (UNFCCC). ${ }^{4}$ However, as the country surpassed the United States to become the world's largest GHG emitter (The New York Times, June 20, 2007), China is increasingly facing an energy-environment dilemma that also tests its role as a responsible major power in the world. Under such circumstances, it is argued that China had to react to adopt indirect climate policies through its domestic energy efficiency policy (Heggelund et al. 2010). As Hatch (2003) predicted, domestic policy to address climate issues is largely driven by the necessity of responding to an international agenda pushed initially by transnational actors and international organizations. And in the absence of pressures from abroad, it is unlikely that China would have devoted much attention to climate change mitigation efforts through

\footnotetext{
${ }^{4}$ For most of the time prior to 2009, China's stance in the Conference of Parties (COP) under the Kyoto Protocol was characterized by sticking to the principle of "common but differentiated responsibilities". See Chan (2004).
} 
domestic energy efficiency policy which is very likely to affect the country's economic growth. It has been acknowledged that, marked by the country's voluntary policy to reduce its carbon emission intensity by 40 to 45 percent by 2020 on the Copenhagen Conference (COP15) in 2009, China's position on energy-related environment issues has significantly changed, thanks to the success of its domestic energy efficiency policy in the 2000s (Christoff 2010).

\section{Bureaucratic politics model}

A second approach to explain Chinese energy policy change looks inside the Chinese state and employs a Fragmented Authoritarianism (FA) theory of Chinese politics. This group of literature is built on a core assumption that China's economic policy bureaucracies and key stakeholders play a major role in shaping energy policy preferences and outcomes.

Based on the seminal work of Lieberthal and Oksenberg (1988), the bureaucratic politics model depicts China's economic policymaking in the transition era as a process of bureaucratic bargaining among a constellation of central government commissions, ministries and key interest groups such as major state-owned enterprises (SOEs) with ministerial ranking; ${ }^{5}$ the change of energy policy is heavily influenced by the way that policy decision-making power is distributed among those bureaucratic policy actors. It challenges a rationality assumption of China's policy making by revealing the entrenched departmental interest and intensive bureaucratic bargaining. With specific reference to the literature on China's energy policy, scholars such as Downs (2004; 2008a; 2008b), Lester and Steinfield (2007), Meidan et al. (2009), and Kong (2006) all claim that a fragmented energy governance structure diminished the government's capacity to produce coherent and effective policies before 2005, and the energy policy priority was largely asserted by powerful interest groups such National Oil Companies (NOCs). Downs (2004) argues that Chinese bureaucratic politics generally explains Chinese energy policy decision-making, which is exemplified by the lack of an energy

\footnotetext{
${ }^{5}$ In China's SOE system, enterprises and their management staff retain administrative ranks that are equivalent to that of government departments and staff.
} 
ministry (since 1993) to coordinate energy policies among the relevant bureaucratic agencies. This alleged incapacity of the central government is also clearly suggested by Lester and Steinfield:

The real problem in China today, and the most important driver of the nation's energy and environment footprint, is not geostrategic ambition, but rather a glaring deficit of governmental regulatory and administrative capacity... the real problem, overshadowing all others and least recognized by outsiders, pertains to the Chinese system's inability to govern coherently (Lester and Steinfield 2007, p.35).

Similarly, Kong $(2006 ; 2011)$ goes so far as to identify the primary source of China's major energy risk as "institutional insecurity", in terms of the inability of the country's energy institutions to deal with energy security challenges coherently. With such an approach, energy policy changes are regarded as the result of changes in the central government's bureaucratic structure. In their attempt to explain energy policymaking in China, Meidan et al. (2009) claim:

Policy initiatives are circulated amongst the different stakeholders for approval, allowing them to amend the drafts according to their interests. This procedure means that approval times are often lengthy and that the final policy proposal is a watered down version of the initial drafts. Furthermore ministries intervene at the implementation stage and have the power to stall or promote projects according to their interests (Meidan et al. 2009, p.597).

Following this line of analysis, many have argued that due to the Chinese National Oil Companies' (NOCs) ministry ranking and their central role in governing China's energy industry for several decades since the 1950s, they enjoy significant privilege in influencing China's national energy policy towards energy security focusing on oil supply. $\mathrm{Xu}$ (2008) notes that the Chinese energy policy process was characterised by "weak and fragmented regulators" and "powerful corporations". She 
observes that the top managers of the NOCs enjoy the trust of the party and enjoy extensive personal networks with party and government officials at the top levels of government, including the Central Committee and the Politburo. Downs (2008a) argues that the corporations have the capacity to advance corporate interests at the expense of national ones. She notes that the primary frustration of central government energy officials was that the major energy companies regularly circumvent the authority of relevant government ministries and meet directly with China's senior leadership.

As the latest rounds of central government restructuring took place in 2003 and 2008 , it is believed that a more unified institutional setup began to emerge in the central government energy governance landscape, which induced a more overarching national energy policy that defies the NOCs' interests and prioritises energy efficiency. Downs (2004; 2008a; 2008b) calls it "China's 'new' energy administration", compared to the “old" fragmented energy policy making structure. The government restructuring in 2002 introduced the National Development and Reform Commission (NDRC) as the central economic policy making agency. Then in 2005 and 2008, before the making of the 11th and 12th FYPs, two new agencies were established to specifically oversee China's energy policymaking and implementation - the State Energy Commission (SEC) and the National Energy Administration (NEA). The latter was soon rising as China's most powerful energy policy agency. ${ }^{6}$ The NEA has a broad mandate including managing the country's energy industries, drafting energy plans and policies, negotiating with international energy agencies and approving foreign energy investments (Downs 2008a; Downs 2008b). It is commonly believed that such administrative restructuring has contributed to further overcoming the 'fragmentation' of policymaking power, thereby allowing more coherent policymaking and the introduction of the latest energy policy change towards energy efficiency.

\footnotetext{
6 The SEC is headed by the Premier and the more than a dozen ministers from different central government ministries. The commission only convenes several times a year. The NEA was initially established to oversee the implementation of the SEC's mandates, but has become increasingly powerful as the status-quo surrogate of the SEC. See Downs (2008a) and Taylor (2014).
} 


\subsubsection{Growing Explanatory Deficits}

In terms of answering the two fundamental questions of China's energy policy change, these two groups of literature adopt two approaches based on different assumptions of policy making, which lead to different views on the underlying political-economic forces that have induced the energy policy change.

The first group of literature largely takes a simplified assumption of the policy process, and its analysis focuses on material or international factors that are exogenous to the Chinese political system and policymaking process. The rationality assumption of policymaking assumes that policy outcomes are the result of an evaluation of choices by a coherent group of policymakers with consistent perceptions of values and ideas in response to perceived challenges. The overarching concern of the group is to advance the national interest. Such an assumption tends to perceive China as a strong, coherent and monolithic authoritarian regime that can effectively evaluate and adjust its policies to advance its material interest. Policy decisions are made primarily in response to energy-related risks and pressures as the country becomes more integrated with the world in a reactive and ad hoc manner. However, contrary to such an understanding, China's energy policy priorities have been fairly stable, with energy efficiency as a top priority, despite some significant new developments indicating serious vulnerability and increasing external risks facing the country's energy security.

Among the exogenous factors that significantly affect an energy consumer and major oil importers' vital energy interest, two are regarded as essential: energy dependence rate and energy price in the global energy market. When the US oil dependence reached 50 percent in the mid-1990s, approaching 60 percent in 2005 , the US government adopted a series of measures to successfully bring its oil dependence down to below 40 percent around 2011 (Sieminski 2014). In contrast, China seems to have simply allowed its oil dependence to grow from less than 30 percent in the early 2000 s to nearly 60 percent in the early 2010s, as it became a highly oil-dependent 
economy. ${ }^{7}$ Such an oil import surge caused the country's overall energy dependence to climb quickly (see Figure 2 below).

\section{Figure 2 China's Oil Dependence and Overall Energy Dependence 1982-2011}

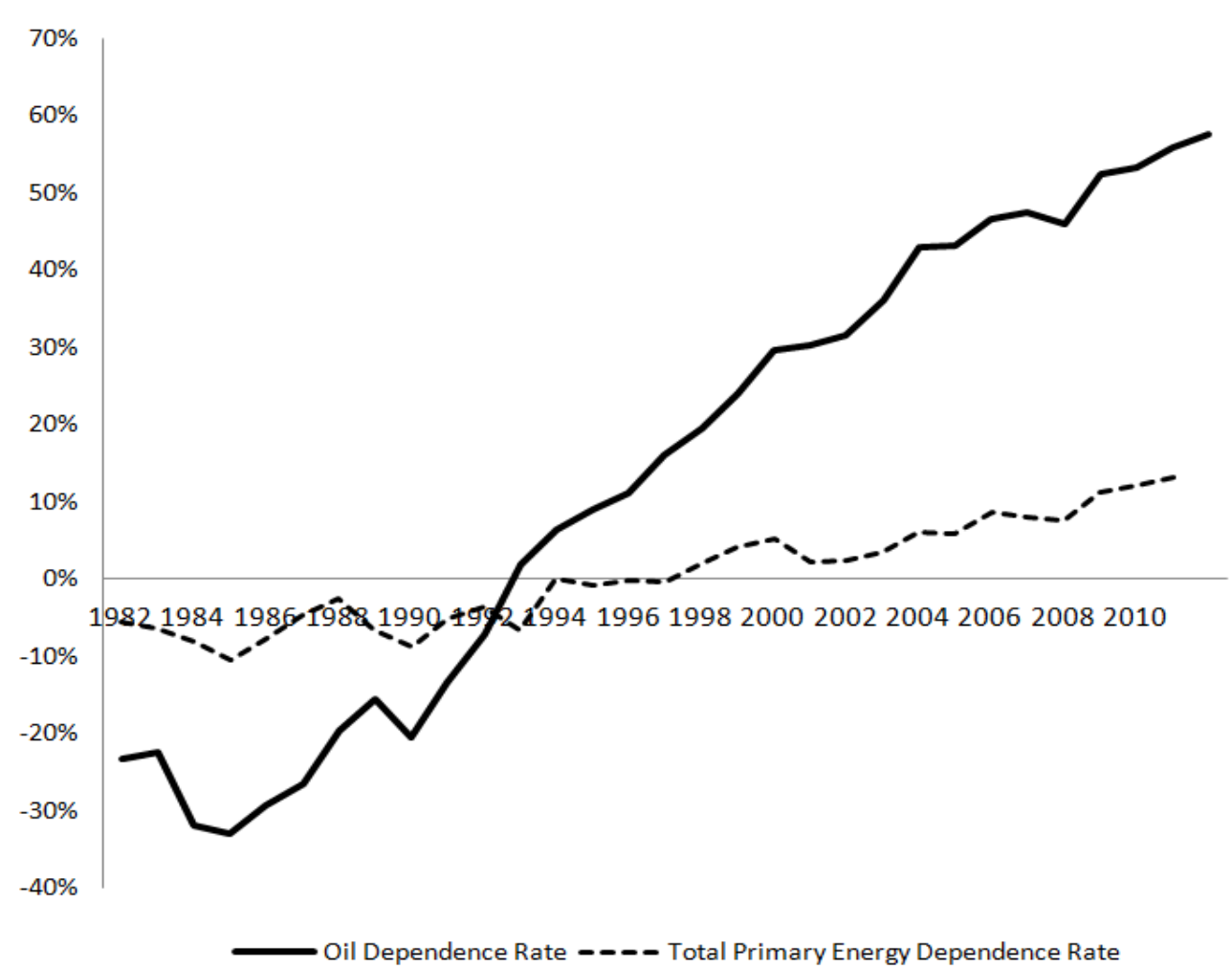

Data Source: IEA, 2013

Also, when international oil prices started to rise, reaching a historical high in 2007 and 2011, the world's major energy consumers responded quickly to resume energy security as the top priority over environmental protection in their respective national energy policies. ${ }^{8}$ In China's case, however, the 12th FYP published in 2011

\footnotetext{
${ }^{7}$ In 2001, China's oil dependence was around 30 percent. In contrast, when the 12th FYP was published, China's oil dependence had reached 58 percent. In contrast, the United States reduced its energy dependence to below 40 percent in 2012. See State Council (2012).

${ }^{8}$ The 113th US Congress introduced the Energy Independence and Security Act in 2007; Japan sought to double its "energy independence ratio" by introducing a new Basic Energy Plan (BEP) in 2010; and in
} 
still firmly prioritised energy efficiency following the 11th FYP. Moreover, contrary to the popular understanding that China adopted energy efficiency policy to mitigate external supply risks, the country's energy efficiency policy in fact did not focus on the oil sector, which is the sector most vulnerable to supply risks. The core projects of China's energy efficiency policy, such as the Top 1,000-Enterprise Project, have all targeted to improve energy efficiency of industrial consumers that mainly rely on domestic coal or coal-based electric power supply. In other words, the policy focal point has been systematically shifted away from oil-centred supply security to industrial energy-consumer-centred energy efficiency over the past decade. Such a cross-sectoral shift has been a hallmark of China's energy policy change. Given that China's oil dependence had already surpassed 50 percent when the 12th FYP was introduced in 2011, and the country had become the second largest oil importer and oil consumer second only to the US - the continued policy priority of energy efficiency stands out as rather unique among the world's major energy consumers.

Thus, a rational model of policymaking that primarily focuses on factors that are exogenous to Chinese political economy faces some inherent difficulties in explaining China's energy policy change. In this respect, a second group of literature with a bureaucratic politics view of Chinese energy policymaking is believed to be helpful.

In their study mapping the institutional structure of Chinese politics in the postreform era, Lieberthal and Oksenberg (1988, p.35) point out that there are several layers of hierarchical institution organising China's energy policymaking and its policy process in general. At the top is a small group of party-state leadership and specialised central party-state bureaucracies that are directly adjacent to the top leadership; at the intermediate level is the State Council's economic commissions and industrial ministries with substantial economic policy responsibilities; and finally, there are local governments and SOEs that are responsible for decentralised policy implementation. According to the bureaucratic politics model, interactions between the policy bureaucracies at the intermediate level could significantly shape China's socio-

the UK, energy security returned to join climate change mitigation at the top of the energy policy agenda from 2005. See Bang (2010), Duffield and Woodall (2011), and Pearson and Watson (2012). 
economic policies (Downs 2004; Kong 2006; Lester and Steinfield 2007). This model has profoundly influenced studies of Chinese politics and policymaking over the past several decades.

Nevertheless, the development of China's political reform and economic transition since the 1990s has clearly demonstrated that the relative role and influence of each layer of policy institutions varies as China's transition advances and deepens. At the early stage of reform in the 1980s, the party-state leadership's control on the intermediate policy actors was relatively weak due to the decentralised reform strategy. It was against this backdrop that the bureaucratic bargaining became widespread in shaping national policies. However, from the mid-1990s, Chinese politics have become increasingly institutionalised and policy decision-making power has been significantly centralised. As noted by the Bureaucratic Politics Model of energy policy change, bureaucratic bargaining and consensus-building between central government policy actors have been significantly reduced through several rounds of central government restructuring in the 1990s and early 2000s. The "fragmentation" of policy authority has been largely counterbalanced through strong policy coordination by newly established economic agencies that directly answer to the top party-state leadership. However, the bureaucratic politics analysis of China's energy policy change still overwhelmingly focuses on the intermediate-level bureaucracies. Some vital developments taking place at the top and bottom levels have been systematically overlooked, which leads to major gaps and blind spots in understanding China's energy policy change.

The first gap overlooked is the role of the top party-state leadership in China's policymaking today. Such a gap means that bureaucratic politics literature has difficulty explaining the fact that China's energy efficiency targets were originally raised by the top party-state leadership as a cornerstone of "Scientific Development Outlook". In a Fragmented Authoritarianism [FA]-based policymaking model, the top-leadership was more of an arbitrator of bureaucratic disputes and policy brokering rather than a policy decision-maker. Naughton (2005) was among the first scholars to note the changing role of the top leadership in recent years, and contends that: 
...top leaders structure the (policy) consultation process and manipulate structure to achieve outcomes they prefer...the authoritarian aspects of the system are stronger today than they were in the 1980s (Naughton 2005).

Naughton (2007, pp. 90-111) further identifies two phases of China's economic transition with distinctive policy regimes. The first phase (1978-1992) was characterised by incremental privatisation; decentralisation of economic policy authority empowered the intermediate-level policy actors. During this time, policymaking was incremental, fragmented and based on consensus-building between relevant central government bureaucracies and key stakeholders. The second phase of reform, from 1993 onwards, is actually characterised by the recentralisation of political authority and resources to the top leadership as more decisive policy decision-makers. Therefore, contrary to the image of the top party-state leadership as passive policy coordinator, it is important to understand why and how it became a pro-active and strategic policy actor moving to introduce energy policy change.

A second major gap was the bureaucratic literature's inability to include key subnational actors such as local government and the private sector. As China's transition advances and deepens with the reforming of SOEs and central-local intergovernmental relations, most intermediate-level policy bureaucracies have been abolished or downgraded, with their power delegated to bottom-level SOEs and the local government. Such decentralisation of policy authority has greatly empowered subnational actors such as local government and the emerging private sector, and made them major pushers of China's energy development in the 2000s. The significant politico-economic forces produced by those subnational actors are also overlooked by the bureaucratic politics analysis.

In sum, existing literature has offered two approaches to answer the two fundamental questions of China's energy policy change. The first approach employs a rationality model of policymaking and emphasises the effect of external and material forces in affecting policymaking. A second approach focuses on the forces of bureaucratic politics among the intermediate-level policy bureaucracies. As analysed, both approaches face some serious difficulties and gaps in understanding the energy 
policy change. For the Rational Policymaking Model, its externally-focused approach makes it difficult to understand the cross-sectoral feature of policy priority change and the relative stability of energy efficiency as a top policy priority. For the Bureaucratic Politics Model, its intermediate-level view makes its analysis static relative to wider institutional development and its impacts on today's Chinese energy policy. As a result, the underlying forces of energy policy change within a dynamic political-economic transformation process are largely overlooked by these two approaches.

In response to these explanatory deficits and in order to better understand China's energy policymaking and the forces that shaped the country's overall socio-economic policy in the 2000s, a new approach is needed to answer the two fundamental questions. Such an approach needs to be built on a robust conceptual framework that allows systematic examination of China's national policymaking mechanism in the first place; it should also be able to move further and deeper to explore the underlying politicaleconomic forces that have induced the cross-sectoral shift of energy policy priority.

\subsection{Understanding Policy Change - A Historical Institutionalism Approach}

\subsubsection{Historical Institutionalism and Policy Studies}

In the wider political science discipline, the study of power and institutions has been the key focus of studies of state policy. Whilst power has always remained of central concern, institutional analysis as a political analysis tradition was challenged by the behaviouralist school in the post-war years. Marked by March and Olsen's (1984) seminal work that called for political scientists to re-examine the organisational nature of human political life, institutional studies have been revived since 1980s. Thus, this so-called "new institutional" analysis began to be seen as a pillar of political science and policy studies. New institutionalism argues that institutions matter, particularly the institutions of the polity and economy, because they shape the behaviour of actors.

In the new institutionalism tradition, political scientists such as Hall and Taylor (1996) define institutions as, “...the formal or informal procedures, routines, norms and conventions embedded in the organised structure of the polity or political economy." The Historical Institutionalism (HI) is perhaps the most inclusive approach among the 
three major branches of the new institutionalism movement. ${ }^{9} \mathrm{HI}$ emphasises that, in addition to material interest emphasised by Rational Choice Institutionalism (RCI) and 'culture' emphasised by the Sociological Institutionalism (SI), political actor's behaviour is also shaped by legacy of the past that affects the persistence or change of the institution. More importantly, in HI-based policy studies, institutions play a fundamental role in understanding policy change. Especially in a unitary state with a strong national or central government, the central government's policymaking mechanism, including the policymaking actors and process, is crucial in determining national policy outcomes. In this sense, major policy change is often a major indicator and consequence of a state's institutional change.

Similar with RCI, HI acknowledges that institutions influence the behaviour of political actors by shaping their perceived interest. But HI differs from both RCI and SI due to its added emphasis on the temporal dimension. The temporal dimension was built upon the fact that when an institution is formed or a policy is initiated by politicians, the choices made at the time have a tendency to persist and influence later institutional development and policymaking (Pierson and Skocpol 2002; Steinmo et al. 1992). Therefore, the HI literature shares a theoretical project that confronts issues of both historical contingency of institutional formation - 'critical junctures' of history and institutional stability - once a certain institution is built and a policy choice is made (Capoccia and Kelemen 2007; Steinmo et al. 1992). Once an institution is built or a policy choice is made, this may produce both intended consequences and unintended consequences over time. Whilst intended consequences serve the original ideas of institutional architects or policymakers, unintended consequences may occur when institutional arrangements interact with a changing environment. Quite often, unintended consequences need to be managed through different types of institutional adaptation to avoid institutional dysfunction (Streeck and Thelen 2005).

Following these basic tenets of HI, political economists such as Katzenstein, Hall, and later Ikenberry shared a central point in their respective analyses - historically formed institutional factors can shape both the objectives of political actors and the distribution of power among them in a given polity (Steinmo et al. 1992, p.6), which

\footnotetext{
${ }^{9}$ For detailed analyses on the three major branches of new institutionalism, namely Rational Choice Institutionalism (RCI) Sociological Institutionalism (SI), and Historical Institutionalism (HI), see Hall and Taylor (1996).
} 
will determine political outcomes often in the form of major policy decisions. On this front, HI has advanced significantly over the past two decades by taking account of new factors such as ideas, and more significantly, the complex interaction between idea, institution and interest, to understand institution and policy change. A major topic of the ongoing theorisation of $\mathrm{HI}$ is to understand how political actors' certain ideas, and their interests shaped by institutions, could interact in a complex way to produce major policy change over time. As Steinmo et al. point out,

...What has been missing (in $\mathrm{HI}$ ) is more explicit theorising on the reciprocal influence of institutional constraints and political strategies and, more broadly, on the interaction of ideas, interests, and institutions (Steinmo et al. 1992, p.14).

Nevertheless, in its two-decade development, HI conceptualisation has been primarily based on the advanced industrial states with mature democratic institutions. Studies such as the varieties of capitalism and welfare state constitute the backbone of the HI project over the past decade. ${ }^{10} \mathrm{HI}$ seems to have few intersections with studies on transitional economies and emerging markets. However, in the last decade, there is a growing group of literature that attempts to employ HI theory to examine the development of the transitional states in China, many of which have not only led to better understandings of China's institutions and policies, but also provided valuable insights to $\mathrm{HI}$ theorisation beyond the traditional area of industrialised western democracies. Tsai's (2006) study on China's adaptive informal institutions as a form of endogenous institutional change, and Young's (2013) study on how local-informal practices leads to national-formal institutional change in China's household registration system, are two notable examples of this emerging literature. Such emerging literature clearly indicates that, with the "deepening" of reform (Dittmer and Liu 2006) and increasing institutionalisation of the Chinese political economy, the latest development of HI theory has become increasingly useful to understand today's China. HI thus offers a basic conceptual framework to examine a more institutionalised Chinese political economy and its profound impacts for policymaking and policy change over the past decade.

\footnotetext{
${ }^{10}$ See, for example, Streeck and Thelen (2005).
} 


\subsubsection{Ideas, Institutions and Interests - A HI-based Framework for Policy Change Analysis}

This study mainly focuses on the fundamental formal political and economic institutions of contemporary China. With a HI view of Chinese political economy, the complex interaction between key political actors in a two-level institutional structure constitutes a basic conceptual framework to explore the mechanism of policymaking and the forces that have induced the energy policy change.

In HI theory, a central tenet is that historically formed institutional factors can shape both the objectives of political actors and the distribution of power among them in a given polity (Steinmo et al. 1992, p.6). Thus, a major way to understand major policy change is to examine asymmetrical power distribution between major policy actors and its long term impact on policymaking (Hall and Taylor, 1996). Asymmetrical power distribution between major political actors is often caused by a multi-level hierarchical structure of state institutions, where political actors are empowered and constrained by different layers or levels of state institution. In a transitional state like China, when political actors at the national level retain national policymaking power and their policy preference is influenced by evolving reform and development ideas, there is a strong probability that major policy change will arise out of the emerging "mismatch" or "friction" (Lieberman 2002) between changing ideational patterns at the national level and certain interest-seeking behaviour of political actors in lower-subnational institutions. Thus, to Historical Institutionalists, to identify and study the idea-interest 'mismatch' is a key approach to understand policy change.

As discussed, scholars have noted that China's party-state regime after 1949 was underpinned by several layers of hierarchical institutions. Since the economic transition began in the late 1970s, especially with major institutional reforms unfolding in the mid-1990s, the dynamics of national policymaking have been increasingly transformed from the horizontal bargaining between bureaucracies within the central government to a new pattern of vertical interaction between major political actors at national level and those at subnational level. Such change is built on several 'deep 
reforms' in China's fundamental political-economic institutions in the 1990s, the StateOwned Enterprise (SOE) reform, and the central-local intergovernmental relations adjustment following the adoption of the Socialist Market Economy objective. It has been a consensus among China studies that this episode constitutes a critical juncture in China's transition course in terms of re-designing the country's fundamental institutions (Naughton 2007; Dittmer and Liu 2006).

Besides this multi-layered institutional analysis, another analytical approach to examine the policy change is cross-sectoral institutional analysis focusing on China's two major energy-based industrial value chains relative to the two major energy policy objectives (see Chapter Two for details). China's industrial development since 1949 has been embodied in the building and reform of the country's fundamental economic institutions, especially the SOE system. During economic reforms, evolving institutional connections between major energy enterprises in different energy-based industrial value chains and the Chinese government at national and subnational levels have organised and adjusted the distribution of energy-related interest. This profoundly shaped their energy-related interests and development behaviour. Therefore, by combining the core concepts of HI theory and the development of the institutions of the Chinese state and industrial economy, the study develops a multi-layered and crosssectoral analytical framework to investigate China's energy policy and its change over the past two decades.

\subsection{Research Design and Methodology}

The study is predominantly qualitative and inductive in an attempt to build theory and a model of policy change in a transitional state, through examining China's energy policy priority shift over the past two decades. It is interested in how evolving institutions, together with the ideas and interests embedded in a transitional state, affect its national energy policy choices over time. At the centre of the research design is a multi-layered and cross-sectoral institutional analysis based on HI theory (see Figure 3 on the following page). 
Figure 3 A Multi-Layered, Cross-Sectoral Analytical Framework

National Level Actors: Top-Leadership and Central Government

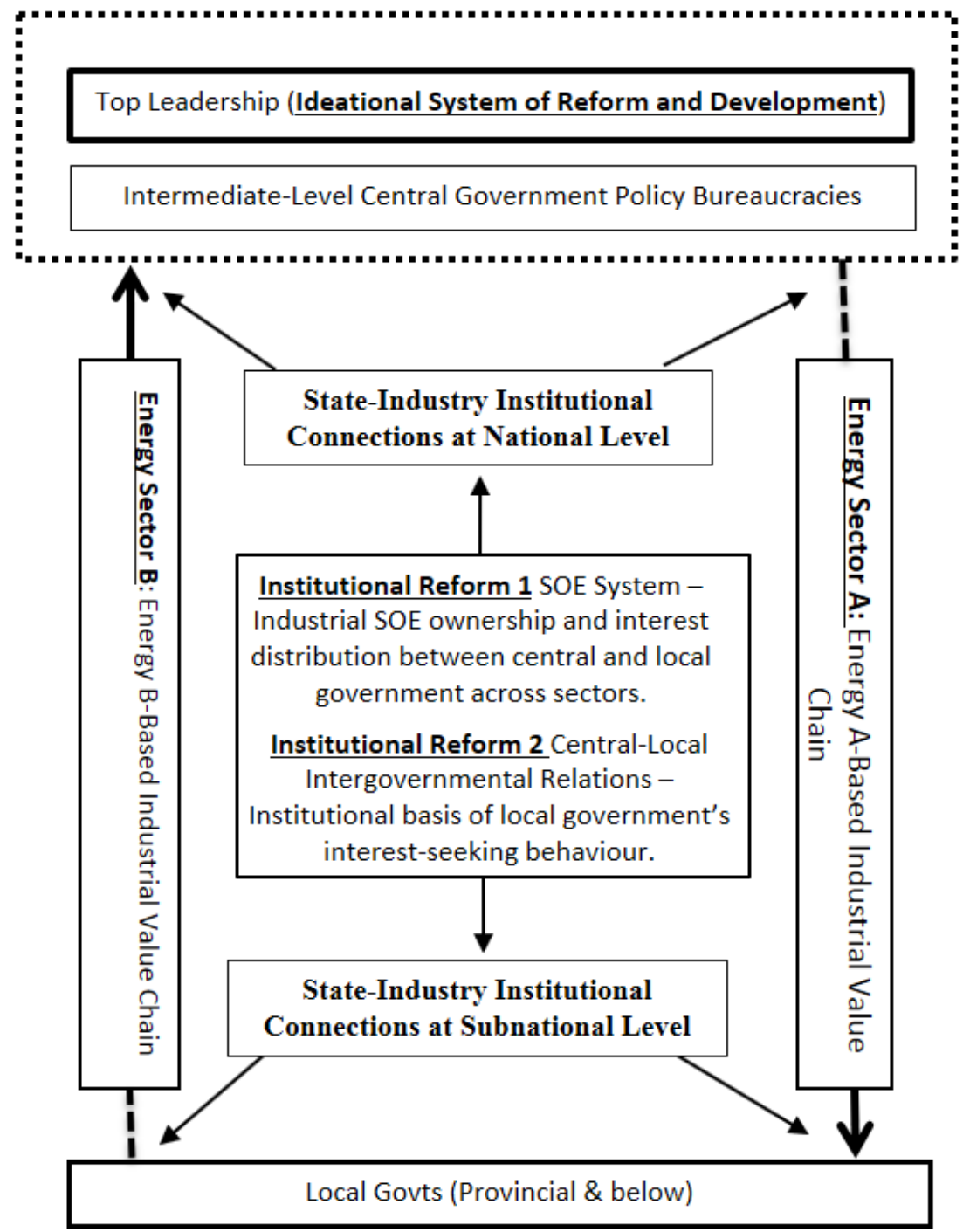

Subnational Level Actors: SOEs and Local Governments

\subsubsection{Multi-Layered and Cross-Sectoral Institutional Analysis}

National level: emerging dynamism of idea-guided policymaking in the 2000 s

Unlike the Bureaucratic Politics model that focuses on the central government bureaucracies, this study examines the latest developments of Chinese politics and finds that the policy bureaucracies' autonomy has been significantly diminished. The top party-state leadership's 'ideational system' has become decisive in shaping the country's socio-economic policies in the 2000s. 
A fundamental feature of contemporary Chinese politics has been the central role of the Communist Party of China (CPC). The CPC and the Chinese state are closely intertwined and their functions are largely combined. The special term "party-state" is created; in the Chinese context, the party-state leadership, the party central organs and central government bureaucracies are often collectively referred to as zhongyang - the centre (Huang 2009, pp. 27-37). This study is interested in particular in the party-state leadership's role in generating systematic and overarching reform and development ideas to define China's strategic interest in the transition era, which has been accompanied by the leadership's growing capability in controlling policymaking actors and process at the central government level to turn their ideas into substantive policies.

The role of ideas in institutions and policy change has been a major topic in both HI and wider new institutionalism theories in recent years. HI scholars have argued that certain ideas, such as political visions, norms and identities, can also shape key political actors' perception of national interest and thus influence their policy preferences (Béland and Cox 2010; Gofas and Hay 2010). So far, studies have identified several types of ideas and their possible sources, such as norms, identifies, cognitive templates, and policy paradigms (Campbell 2002). Following the Tiananmen incident in 1989, the party-state leadership realised the devastating effect of the 'ideology vacuum' following the Cultural Revolution, and of reforms without a clearly-articulated political vision. Thus, from the Jiang Zemin and Zhu Rongji leadership (often referred to as the 'third generation' of top party-state leadership after Mao and Deng), the party-state centre began to develop a more pragmatic reform and development ideas through 'ideational innovation' (li'nian chuang'xin) to conceptualise their political visions of reform and to define the state's strategic interest during the transition era. This ideational innovation trend was carried on and strengthened during the $\mathrm{Hu}$ Jintao and Wen Jiabao leadership in the 2000s (the fourth generation). The comprehensive and overarching ideational systems, such as the Socialist Market Economy Theory and Scientific Development Outlook, were systemically introduced to guide China's institutional reform in the 1990s and socio-economic policymaking in the 2000s.

More importantly, the third and fourth generations' ideational systems have displayed both consistency as well as some major differences. As will be analysed in Chapter Three, different leaderships' perceptions of national interests and major 
challenges evolved significantly over time, making China's policymaking an ideationally-dynamic process. Such an evolving perception of the state's strategic interest, together with the top leadership's tightening control over policy bureaucracies and policymaking process, have infused strong ideational dynamism into China's policymaking mechanism at the national level.

\section{Subnational level: stability of interest-seeking energy development behaviour after the 1990s' institutional reforms}

Since the CPC defeated the Kuomingtang as mainland China's dominant political force and established the People's Republic of China (PRC), several politicoeconomic institutions have been established to jointly organise China's command economy, the most important ones being the SOE institution that organises the state-led industrialisation, and institution of central-local intergovernmental relations (hereafter the central-local relations) structuring power relations between central government and its local agencies. These two institutions constituted the basis of China's planned economy from the early 1950s to the late 1970s. Reforming these two institutions has also been the linchpin of China's economic transition over the past three decades $(\mathrm{Xu}$ 2011).

The years between 1993 and 1998 constitute a critical juncture in China's history of reform, mainly because the Jiang-Zhu leadership at the time was able to systematically reform the two institutions with Deng Xiaoping's urge and support to build a 'Socialist Market Economy'. Political and economic relations between the central government and local governments were drastically adjusted through a fiscal reform in 1994; and the majority of SOEs were restructured or decentralised with the 'grasping the large and letting go the small' (zhuada fangxiao) SOE reform from 1995. After the reform, the two institutions began to display considerable stability in the following decade through shaping the development behaviour of subnational political actors like major SOEs and local governments.

Like other economic sectors, the development of China's energy sectors is also embedded in the building and reforming of these two institutions. During the planned economy era, China had established a centrally-controlled energy industry following the Soviet style industrialisation strategy. Energy supply industries and a cluster of 
energy-consuming heavy industries constituted the backbone of the economy and had contributed considerably to China's economic growth. This central ownership and control over the majority of industries became a major target of the marketization-anddecentralisation urban industrial reforms in the 1980s. However, in the mid-1990s SOE reforms, the Jiang-Zhu leadership adopted a symmetrical reform strategy in different industrial sectors to make the central government maintain and even strengthen control over some "strategic sectors", and delegated most SOEs in other industrial sectors to local government and liberalised relevant markets. Among the country's energy sectors, the oil sector was perceived to have strategic and security implications for economic growth when China turned into a net oil importer in the mid-1990s. As a result, the oil and petrochemical enterprises were systemically centralised and vertically-integrated to be held firmly in the hands of central government. In contrast, other major energy sectors that significantly affect the country's overall energy efficiency performance, especially the coal-based heavy industries, were mostly delegated to local governments and became more market-based.

This historically-formulated and idea-guided reform strategy in the 1990s profoundly impacted China's energy development and energy policy in the 2000s by structuring an imbalanced power-and-interest distribution structure between national government and subnational government in terms of energy development. The central government was able to build strong institutional connections with the country's entire oil-based industrial value chain to make sure its sectoral interest followed the national interest on energy security. The central government protection and support embodied in the institutional connections in turn significantly boosted the Chinese oil sector's profitability and its international competitiveness in the 2000s. In contrast, those coalbased heavy industries became increasingly decentralised and fragmented, and subjected to increasing interest-seeking behaviour of local government shaped by the central-local relations reforms after 1994, under which coal-based heavy industries were regarded as highly valuable to local revenue and local officials' political promotion. As a result, energy-intensive industries such as metallurgy began to expand rapidly from the early 2000s, which changed China's overall economic structure and negatively impacted its energy efficiency performance. 
Energy policy change from the mid-2000s - Ideas vs. Interest

As the fourth generation Hu-Wen leadership was installed in 2002 a Scientific Development ideational system emerged. China's economic policymaking began to reorient to give emphasis to the quality of economic development by adjusting the economic structure. In this sense, heavy-industrialisation development endogenous to Chinese local government's incentive structure has increasingly challenged the new generation of top leadership's 'Scientific Development' strategy. To remedy what Hu Jintao summarises as the "unbalanced, uncoordinated and unsustainable" development became an urgent job for the Hu-Wen leadership in the 2000s (Hu March 12, 2005).

With the failure of several attempts based on the conventional industrial policy system between 2003 and 2005, the top leadership realises that there is considerable idea-interest 'mismatch' between their updated ideational system and the interestseeking behaviour among local governments shaped by the 1990s' institutional reforms. As top-level political actors monopolising national policymaking power, their choice was to adapt existing institutions by designing a central-local energy-efficiency targetresponsibility system to curb the local government's certain interest-seeking behaviour in the two FYPs from 2006. At the same time, although China also faces energy security challenges, the institutional reforms in the 1990s has largely empowered China's entire oil-based industrial sector by institutionalising strong central government control and support. By the early 2000s, the oil sector had become increasingly capable of safeguarding the country's energy security interest at home and abroad. As a result, under the Hu-Wen leadership, energy security has increasingly become a subnationalsectoral policy issue instead of a national energy policy priority.

\subsubsection{Research Methods}

\section{Document analysis}

In any authoritarian regime where national policy is ultimately determined by a small group of senior politicians in the central government, to explore the policymaking mechanism is fundamental to understanding the mechanics of major policy shifts. As China began reform and opening-up in the late 1970s, its policymaking regime experienced several rounds of restructuring. Within the central government at the national level, the power distribution between top party-state leadership and the policy 
bureaucracies has been subject to rounds of central government restructuring from the late 1990s to the early 2000s, resulting in China's policymaking landscape continuing to evolve. Thus, to understand the specific mechanism of policymaking constitutes the first step of this study before moving further to explore the forces that have induced the policy shift. This study primarily employs document analysis to examine China's national energy policy and its priorities, to identify the country's policymaking regime, and to investigate major policies regarding institutional reform from the 1990s.

Document analysis is defined as the "collection, review, interrogation, and analysis of various forms of text as a primary source of research data" (O'Leary 2004, p.177). Document analysis constitutes a basic method first and foremost because the study's focus is on China's formal policies embodied in the party-state's official documents. Therefore, document analysis is employed throughout the study to conduct the empirical analyses on the national policymaking regime in Chapter Three, on historical reforms in Chapter Four and Chapter Five, as well as in the two cases in Chapter Six and Chapter Seven.

The main source of documents used in this thesis includes original official documents such as Party congress and plenum reports; the CPC centre's major policy initiatives; the State Council's mandate (administrative directives) and regulations; laws approved by the National People's Congress; and Chinese local government document archives and local regulations. Other sources include reports from research institutes, statistical year books, academic monographs and edited volumes, peer viewed journal articles, and media coverage from influential news agencies in both English and Chinese. These documents were mostly obtained during the author's field trip to China between November 2012 and February 2013; some of them were obtained through online databases.

\section{Case study}

As analysed in the literature review, a central characteristic of China's energy policy change has been the cross-sectoral shift of policy priority. How to effectively capture and explain it becomes the linchpin to understanding the policy shift and a central criterion to judge any studies on China's energy policy change. This study primarily employs the case study method to investigate and explain this phenomenon. 
The case study method is a widely used approach in social and political science studies. It is a method of studying elements of the society through comprehensive description and analysis of a situation (O'Leary 2004, p.115). In methodological terms, case studies, by the more open-ended nature of the process of data discovery, are suited well to "explanatory" or "theory-building" efforts (Gerring 2004; Roberts 1996). Subnational case studies from a single country allow for increased internal validity. Also, case studies unearth and hold in relief the causal mechanisms that drive broader theoretical arguments and empirical outcomes (Roberts 1996, p.66). In this study, cases mainly serve to investigate the institutional roots of the cross-sectoral policy priority shift. This study selects two subnational and industrial-level cases based on China's major energy-based industrial value chains that significantly shape the country's basic supply-demand situation and lay the energy foundation for the country's industrial economy.

The selection of cases follows two sets of rationale. It firstly follows the definitions of energy security and energy efficiency in the Chinese policy context. As will be analysed in Chapter Two, energy security and energy efficiency each have specific connotations in China's policy discourse and political communication. "Energy (in)security" mainly refers to the strategic, geopolitical and economic risks and vulnerabilities associated with external energy dependence, which had been the most relevant to China's oil supply sector and petrochemical industries. ${ }^{11}$ In contrast, "energy efficiency" in the Chinese context is always associated with those heavy industries depending on coal supply or coal-based electric power supply to operate. Such distinction between energy security and energy efficiency in the context of Chinese policy discourse is a starting point to understand the two priorities of China's energy policy and constitutes a basic rationale for case selection in the study.

Secondly, the 'industrial value chain' concept must be taken into account when studying energy security and energy efficiency. The utilisation of the industrial value chain concept constitutes a key innovation that makes the study distinctive compared to conventional energy policy analysis. Conventional energy policy studies have mostly focused on a single energy supply sector, such as the oil sector, the coalmining sector, or the electric power sector. However, as analysed in the next chapter, energy supply is

${ }^{11}$ For a good analysis on the concept of 'energy security' in the context of Chinese policy discourse, see Constantin (2007). 
important primarily because of the added-value produced by a cluster of downstream industries taking energy supply as vital inputs in their respective production activities. For any major energy consumer, energy supply sectors become much less important if its downstream industries do not require a large quantity of energy as key production inputs. Moreover, study on energy efficiency must take major industrial energy consumers seriously, because it emphasises the way energy is used rather than whether there is enough energy. In the Chinese economy, where industry contributes almost half of the annual GDP and where energy-intensive industries that mainly depend on coal and power supplies account for an exceptionally high share, development of these industries has a profound impact on the country's overall energy efficiency. Therefore, the cases should not only cover the energy supply sector, but also need to be extended to cover major downstream energy consumers that could be collectively identified as an industrial value chain.

Following the two sets of rationale, this study selects two energy-based industrial value chains - the Coal-based Metallurgical Value Chain (CMVC) and the Oil-based Petrochemical Value Chain (OPVC) - as contrasted cases. The CMVC case looks into those industries that significantly affect China's energy efficiency with a focus on how the 1990s' reforms re-shaped the institutional connections between the Chinese state and the CMVC at the central and the local levels. Through examining the institutions that organise China's CMVC and its development in the 2000s, correlations could be made between the growing influence of subnational actors and the diminishing central government control over the country's economic structure change and energy efficiency. The OPVC case presents a contrast with the CMVC case and highlights their different development trajectories following the 1990s institutional reforms. By examining the central government's strong institutional connections with OPVC built during the 1990s SOE reforms, this study is able to identify vital correlations between the strengthening of central government control over OPVC and the relative deprioritisation of the energy security objective in national energy policy.

In sum, the two contrasted cases could provide strong empirical evidence to identify an imbalanced structure of energy development across the two value chains embedded in China's historically-formulated asymmetrical power-and-interest distribution in energy development. Such evidence, together with the discovery of ideational dynamism at the central government level, could effectively capture China's 
emerging idea-interest 'mismatch' in the 2000s as a key force responsible for the policy change.

\section{Participant observation}

Empirical data supporting the cases are collected primarily through two methods: document analysis and participant observation. The latter is particularly important to the study due to difficulties in obtaining first-hand empirical evidence when studying China's energy policy and the country's energy sectors from outside. From Liberthal and Oksenberg's (1988) work on China's energy policy, it has been commonly noted that to access China's energy policymaking process and energy sectors so as to observe and obtain first-hand empirical evidence is very difficult, especially for academics outside of the government and industries. Over the past one and half decades, most influential literature on Chinese energy policy and energy sectors have primarly relied on secondary data sources, which has signifcantly limited the width (energy sectors) and depth (subnational energy development) covered by Chinese energy policy studies in the English language. In this respect, this study makes major contributions to widen and deepen the sectors and levels of Chinese energy policy studies by obtaining first-hand empirical evidence through participating in internships in major Chinese energy SOEs in both oil-based and coal-based industrial value chains. This experience plays a decisive role in shaping the multi-layered and cross-sectoral analysis employed in this study.

In late 2012 and early 2013, the author participated in two internship programmes offered by two of China's largest energy SOEs - China National Offshore Oil Company (CNOOC) and the China Shenhua Group. CNOOC is one of the three vertically-integrated Chinese National Oil Companies, with business spanning from offshore and onshore oil E\&P, to petrochemical manufacturing, to petroleum products distribution and international trade. The two-month internship in the CNOOC headquarters in Beijing from November to December 2012 provided the author a precious opportunity to look inside China's OPVC to understand its strong institutional connections with the Chinese central government following the 1990s' reforms, and how those connections profoundly shape CNOOC's political and commercial interest, at home and abroad. 
Another internship in January and February 2013 with the Shendong Coalmine, located in the Inner Mongolia Autonomous Region, gave an opportunity to observe China's energy development at the subnational level. Shendong Coalmine is a major subsidiary of China Shenhua Group - the largest coal company in the world. The group has contributed around 15 percent of China's total coal production throughout the 2000s. As the only coalmining yangqi group under the State Council, the Shenhua Group is famous for its high quality raw coal production that is suitable for coal-fired electric power generation and metallurgical purposes. This internship gave the author an opportunity to trace the coal-based industrial value chain and observe the Chinese local governments' heavy involvement in coal-based energy and heavy industrial development from the early 2000s. This allowed an investigation of the historical and institutional factors that shaped the interest-seeking development behaviour of local government officials. The extensive personal connections built with Chinese energy experts and local government officials during these two internship programmes were of enormous benefit in terms of developing a multi-layered and cross-sectoral analytical approach to understand China's energy policy change.

\subsection{Thesis Outline}

This study is divided into seven chapters. Chapter Two begins with analysing China's national energy policy in the FYPs. The first section presents an examination on the purposes, functions, and influences of the national energy policy embodied in China's Five-Year Plan/Programme system over the last several decades. It reveals the role of energy policy as a fundamental component of China's industrial development policy and reviews the shifting energy policy priorities from the 9th to the 12th FYPs (1996-2015). By examining the industrial basis of China's energy policy, the second section provides detailed analysis on China's Oil-based Petrochemical Value Chain (OPVC) and the Coal-based Metallurgical Value Chain (CMVC). It then explains why the former is at the heart of the country's energy security, and the latter is more closely associated with the energy efficiency. Overall, Chapter Two provides the basic policy and industrial context for the study, and lays a solid foundation for the cross-sectoral analysis.

Chapter Three explores the mechanism of national policymaking in today's China. The first section examines Chinese top party-state leadership's institutionalised incentives 
and enhanced capability to generate ideational systems to guide China's transition and development. This section will focus on why and how such ideational systems could evolve to display dynamism across the recent two generations of leadership. The distinction between Jiang-Zhu leadership's 'Reform-to-Grow' strategy and the Hu-Wen leadership's 'Scientific Development' strategy will be the focus. The second section looks into how China's socio-economic policymaking structure and process, described in the Fragmented A theory, has been re-modified by stronger top party-state leaderships to let their ideational systems guide the making of FYPs. A central point of this section is to examine how the making of China's institutional reform strategy and socio-economic policy has been influenced by two recent generations of top party-state leadership and through their ideational systems. With such an analysis, this chapter offers an idea-guided energy policymaking mechanism at the national level, which laid a solid foundation for the following examination on the historical-institutional forces of policy change.

Chapter Four provides detailed analysis of the 1990s institutional reforms under the Jiang-Zhu leadership and how it shaped an imbalanced structure of industrial development. The first section will examine the State-Owned Enterprise (SOE) system as a fundamental institution to organise China's industrial economy. This section first provides an overview of China's SOE reform with a focus on the 'grasping the large and letting go the small' strategy in the mid-1990s and the subsequent centralisation of those large SOEs in certain 'strategic sectors' of the economy. As a key objective of the "grasping the large" SOE reform strategy, the central government has significantly tightened its control over a small group of elite SOEs in key areas of the economy through an improved governance mechanism such as the State Council's State Assets and Administration Commission (SASAC). Then the second section will highlight the institution of China's central-local relations as the other fundamental institution to organise China's decentralised economic development. This section will examine how reform on the central-local fiscal system, along with political competition embodied in the reforms on China's central-local relations, shape the incentive and imperative of local government in promoting local economic growth. Then in the third section, the study will look into why and how the effect of the two institutional reforms discussed shaped the asymmetrical power-and-interest distribution over certain industrial sectors between the central and local governments. 
Chapter Five and Chapter Six provide the two contrasted cases of the CMVC and OPVC. Examination of these two cases aims to 1) build causal links between the institutional reforms in the mid-1990s and the imbalanced structure of Chinese energy development of the late 1990s; and 2) investigate how the asymmetrical pattern of institutional connections between the government and industries at the national and sub-national level provided key incentives for idea-guided institutional adaptation in the form of energy policy change. Chapter Five will focus on the development of CMVC as a case of local government's growing influence over China's coal-based and energy-intensive industries. This chapter highlights how the development of China's CMVC has increasingly diverged from a 'Scientific Development' national strategy from the early 2000s, largely due to its intersection with the institution-shaped local government interest from the 1990s' institutional reform. Chapter Six will highlight the fact that China's OPVC has been systematically centralised and vertically-integrated during the "grasping the large" SOE reform strategy in the mid-to-late 1990s, and how such reform enabled the Chinese central government to exert greater control and provide direct support to the NOCs to safeguard the country's energy security from the early 2000s.

The final chapter, Chapter Seven, discusses the major findings made by the study in the proceeding chapters and points out the study's theoretical contributions. The seventh chapter concludes that China's socio-economic policies in the 11th and 12th FYP period were formulated with a leadership-controlled policymaking mechanism at the national level; and that the shift of the energy policy priority between two major energy policy objectives was based on the leadership's idea-guided institutional adaptation. The mechanism and forces of policy change are endogenous to the development of Chinese political economy over the past two decades. In terms of theoretical contribution, these findings are important in three respects. First, the study discovers the central role of ideational innovation and ideational systems in China's policy formulation; second, it develops a multi-layered and cross-sectoral institution analytical framework to examine the mechanisms and forces of state policy change. Finally, the chapter concludes that the whole study establishes an institutional adaptation model of policy change that has greatly enhanced our understanding of China's cross-sectoral shift of energy policy in the 2000s. 


\section{Chapter Two: Priorities of China's Energy Policy and their Industrial Basis}

This chapter presents detailed analysis on the shift of national energy policy priority between energy security and energy efficiency in China's last four FYPs and their relationship with the country's two major energy-based industrial value chains to provide a basic context to analyses in the following chapters. The first section presents an in-depth analysis on the purpose, function, and influence of the national energy policy embodied in the country's Five-Year Plan/Programme policy system over the last two decades. By examining the past several FYPs and the energy policy priorities promulgated in the National FYP Guidelines, the systematic shift of the country's energy policy focal point from energy security to energy efficiency is clearly revealed. The second section focuses on the industrial basis of China's energy policy. This section investigates the major downstream industries of the two largest primary energy sources - raw coal and crude oil - and conceptualises the Oil-based Petrochemical Value Chain (OPVC) and the Coal-based Metallurgical Value Chain (CMVC) as China's two major energy-based industrial sectors based on detailed energy and industrial data. It then explains why the CMVC is the central factor in determining China's energy efficiency; and why the OPVC has been at the heart of the country's energy security. This dichotomy and inter-linkage of China's energy supply sectors and its downstream industries is the key to understanding the underlying forces that have induced China's cross-sectoral energy policy shift.

\subsection{The Two Energy Policy Priorities in China's FYPs 1996- 2015}

\subsubsection{The FYP Policy System and China's National Energy Policy}

In the first three decades of the People's Republic of China's history from early 1950s to early 1980s, economic planning embodied in the country's Five-Year Plans had been a basic way to organise the Communist Party's modernisation project with a focus on the Soviet-style industrialisation that gives top priority to heavy-industries. Since the beginning of China's transformation in the late 1970s, the role of the Five-Year Plan 
has been increasingly transformed from a socialist planning system to a national socioeconomic policy system to guide China's reforms and development. ${ }^{12}$ And there has been growing interest in China's FYP around the world due to its unparalleled role in stipulating the guidelines, objectives and priorities of China's economic development. As the second largest economy, China's industrial development policies and priorities have become particularly influential to the world economy. Since the first FYP (19531957), China has consistently put the development of energy industries as a central component of its industrial development policy. This is firstly because modern energy industries have become a complex economic sector involving a variety of downstream processing and manufacturing industries. Secondly, energy supply is vital in providing essential fuel, power and raw materials to many other industries, such as petrochemicals and metallurgy, which are essential to China's industrialisation in the planned era and the economic growth of today.

As the Chinese economy "grew out of the plan" (Naughton 1995) in the 1980s and early 1990s, the commanding functions of China's FYP diminished in many economic sectors, but its guidance to the macro-economy and some key areas of the Chinese economy has been strengthened. This is particularly true for industrial development and energy development. The National Five-Year Plan/Programme Guideline (wunian jihua/guihua gangyao) that sits at the top of China's hierarchical FYP system depicts a clear picture of China's key industrial and energy development objectives and priorities in every five years. It is a reflection of China's overall energy situation at the time and the top priority of energy development in the following years. ${ }^{13}$

\footnotetext{
12 This is largely the reason that the title of the national policy document was changed from 'Five-Year Plan' (wunian jihua) to 'Five-Year Programme' (wunian guihua) during the making of the 11th FYP 2006.

${ }^{13}$ The State Council stipulated the formal structure and process of FYP making in 2005. In the State Council's mandate No. 2005[33], the FYP is defined as a "3-level-and-3-category" policy system. Vertically, the FYP system includes the National Five-Year Programme Guideline (guojia guihua) that outlines key national objectives and priorities; the Provincial Five-Year Programme (shenji guihua) made by province-level governments (including province and municipalities); and the Prefecture/County-level Five-Year Programme (shixian guihua). Subnational FYPs are made by Chinese local government according to the national FYP guideline and is largely localised implementation of the national FYP. Horizontally, the FYP system includes National FYP Guidelines as the country's overall socio-economic policy (zongti guihua), the Project-Specific Programmes (zhuanxiang guihua), and Region-Specific
} 


\subsubsection{Priorities of China's Energy Policy 1996-2015}

\section{The priority of energy supply security}

In the early years of the People's Republic of China (PRC), the country relied almost entirely on biomass and coal for the needs of its rural population and limited urban industrial sector. China's energy demand during the 1950s substantially exceeded domestic supply, especially in terms of crude oil (Zha 2006). The gap was filled by imports from the Soviet Union. In order to meet the energy demand of rapid industrialisation, China put the development of energy supply industries as a top priority from the first Five Year Plan (1953-57). With energy imports (mainly crude oil) from the Soviet Union and increasing domestic coal production, the first FYP was a success. ${ }^{14}$ However, from the early 1960s, the deteriorating Sino-Soviet relations and the Western embargo forced the young regime to put energy supply security, especially oil supply security, as a constant priority of its energy development policy during the planned economy era. As economic reforms unfolded in the late-1970s the rapidly increasing energy demand quickly surpassed the country's energy production, which added extra weight to the importance of energy supply security.

The 1960s Sino-Soviet split and the Western embargo forced Mao Zedong to adopt a 'self-reliance' (zili gengsheng) doctrine to rely on domestic resources to achieve industrialisation and to prepare for war against the two hostile superpowers. With abundant coal reserves and the discovery of several major oil fields in the early 1960s, China gradually became energy self-sufficient (Kambara and Howe 2007, p.24; Andrews-Speed 2010a, p.20). In the following three decades, domestic coal and crude oil production did not only meet domestic demand, but was also exported as commodities (Owen and Neal 1989; Zha 2006). However, the launch of economic reform in the late 1970s created a rapidly growing energy demand and gradually pushed China away from self-sufficiency. Energy deficit first emerged in the electric power sector and then in the oil sector. In the late 1980s, the central planners realised the lack

Programmes (quуи guihua) derived from key objectives and priorities set in the National FYP Guideline. See State Council (2005[33]).

${ }^{14}$ During the 1950s, China's oil imports from the Soviet Union amounted to 14 million metric tons (mmt), with a peak in 1959 of three mmt, of which $2.4 \mathrm{mmt}$ were petroleum and the balance was crude oil. In total, China imported more than $24 \mathrm{mmt}$ at a cost of over USD 1 billion, which was a heavy fiscal burden to the young regime. See Kambara and Howe (2007, p.12). 
of power capacity investment would most likely create a 'bottleneck' for the rapid economic growth. Thus, with the self-sufficiency of crude oil production, the 7 th and 8th FYPs (1986-1995) put electric power supply capacity-building as the priority of China's energy development. Energy conservation focusing on electricity conservation was stressed in the two FYPs in order to alleviate growing pressure on the country's sluggish power supply capacity-building. Nevertheless, it was the emerging oil deficit in the early 1990s that seriously worried Chinese policymakers by poking the country's sore spot of external energy dependence. China's oil imports began to rise rapidly from 1988. In 1993, the country's oil imports exceeded its oil exports, as China became a net importer of crude oil. By 1996 China became a net energy importer despite its continued oil and coal exports (Zha 2006). This happened at a time when China was largely isolated by international society since 1989 and the perceived US dominance in the Middle East after the Gulf War. With an energy 'self-reliance' mentality lingering and the macro-economic consequences of 1970s' oil shocks in mind, Chinese policymakers began to put oil supply security as the top priority in its energy development policy from the mid-1990s.

In 1993, then-State-Premier Li Peng defined the central objective of the country's energy policy in the following decade as "to secure the long-term and stable supply of oil to China" (Chang 2001, p.233). The increasing oil dependence was perceived by the top Chinese party-state leadership as a major potential threat to China's reform and development in the 1990s and 2000s. As a result, oil supply security was put as top priority in the 9th and 10th FYPs (1996-2005). In the opening section of the 9th FYP that sets the long-term development objectives till 2010, increasing oil deficit is defined as a "major problem to restrict economic development in the long run" (NPC 1996: Section 1, Part II). In the industrial development section, the country's energy development policy guideline stated, "energy industry should develop in accordance with the growth of the national economy, and the energy 'bottleneck' problem must be gradually alleviated", government should "accelerate the exploration of oil and gas reserves..." (NPC 1996: Section 2, Part IV). The overseas energy supply problem was stressed for the first time in FYPs. It was announced that China needed to take advantage of "energy resources both home and aboard" to develop the oil industry (NPC 1996: Section 3, Part IV). The 10th FYP formulated in 2000/2001 added more emphasis on the oil supply security. In the opening section, oil 
was defined as a "strategic resource" which was in shortage and required an urgent policy response (NPC 2011: Introduction). In Chapter Seven that outlined the industrial development policy, it specifically stated that, "[China should] actively take advantage of overseas resources, establish overseas oil and natural gas supply bases, diversify the sources of overseas oil supplies, establish national strategic petroleum reserves, and safeguard the national energy security" (NPC 2001: Section 3, Chapter VII). Energy supply is also mentioned in Chapter 17, which promulgates China's open-up policy. Chinese enterprises were encouraged to "go global" to "explore the resources in severe shortage domestically" (NPC 2001: Section 4, Chapter XVII).

Such emphasis on the energy supply security in the 9th and 10th FYP was unprecedented. It was also the first time the concept of "national energy security" (guojia nengyuan anquan) was formally introduced into the FYP document, marking a major shift in China's energy development policy from focusing on energy selfsufficiency to the security of overseas energy supply. ${ }^{15}$ In the decades following 1995 , China's "global hunt for energy" (Zweig and Bi 2005) to diversify its energy supply sources has been well examined by a growing body of IR and IPE literature.

\section{The shift to energy efficiency from 2006}

As noted by policy analysts and industrial observers around the world, the priority of China's energy policy began to systematically shift from energy supply security to energy efficiency in the 11th FYP around 2006. As a Senior Consultant of the World Bank discovered, China's 11th FYP significantly deviated from previous FYPs by promoting "three corresponding objectives: economic efficiency, the reduction of poverty, and environment preservation" (Zhang 2011). More importantly, with such an energy policy priority shift, the country's overall energy strategy has also been re-oriented from energy supply towards a more balanced strategy emphasising more on the efficiency of energy use through introducing obligatory energy efficiency targets and implementation mechanisms, especially the energy-conservation-target

\footnotetext{
${ }^{15}$ In Chinese policy discourse, 'energy security' (guojia nengyuan anquan) is a concept that specifically refers to oil supply security. As an official report in support of energy policy formulation of the 11th FYP in 2004 produced by the State Council's Development Research Centre (DRC) points out, "to China, energy security largely equals to oil supply security". See Feng et al, (2004, p.83). Professor Zha Daojiong of Peking University also notes that in existing Chinese energy policy studies, the concept of 'energy security' is also largely used as a surrogate of oil supply security. See Zha (2008).
} 
responsibility system (jieneng mubiao zeren kaohe tixi, hereafter the 'target responsibility system') (Andrews-Speed 2009; Betz 2013; Meidan et al. 2009; Price et al. 2011; Yuan and Zuo 2011).

In the opening part of the 11th FYP formulated in 2005-2006, the statement about oil as a strategic resource that was emphasized in the 10th FYP was removed. Overseas energy supply was only briefly mentioned as "expand cooperation on overseas oil and gas resources exploration" in the industrial development policy section (NPC 2006: Section 3, Chapter XII). This seems rather peculiar given that the country's oil dependence rate had almost doubled in merely five years - rising from 28 percent in 2001 to almost 50 percent in 2006 - and China had just surpassed Japan to become the world's second largest oil consumer and importer (NBS 2009; EIA 2013). Moreover, the Second Gulf War that started in 2003 was widely regarded as a major threat to China's energy supply security as almost half of the country's oil imports relied on the Middle East (EIA 2013). Nevertheless, the concept of "national energy security" highlighted in the 10th FYP was systematically removed from the 11th FYP. Conversely, in the opening section of the 11th FYP, the top priority of China's energy development and even the whole industrial development in the following five years is characterised by an energy efficiency target aiming to reduce China's energy input per unit of GDP output by 20 percent based on the 2005 level. Then again, in the 12th FYP formulated from 2010-2011, a similar target of 16 percent energy intensity reduction continued to dominate China's energy policy, making energy efficiency a sustained top priority over the decade 2006-2015. In contrast, when international oil prices reached a historical high in 2007 and 2011 following the Arab Spring, the world's major oil importers responded quickly to put energy security back to the top of their respective national energy policies (Bang 2010; Duffield and Woodall 2011; Pearson and Watson 2012). With China's oil dependence rate reaching 58 percent in 2011, and with an increasing share of oil-import costs in its GDP, the country's efficiency-focused energy policy in the 12th FYP is unique against the background of ongoing geopolitical instability in the Middle East and the oil price volatilities in the global market. ${ }^{16}$

\footnotetext{
${ }^{16}$ In 2012, China spent $3.2 \%$ of its GDP the same year for oil imports, the highest among major energy consumers such as the United States (2.7\%) and the European Union (2.7\%), and equals that of Japan. See EIA (2013).
} 
A central characteristic of China's updated energy policy has been the introduction of obligatory targets and new mechanisms to manage industrial energy intensity. It has been widely noted by the world's energy efficiency experts that the energy efficiency target responsibility system has contributed the most to China's energy efficiency gain so far (Ma et al. 2012). This new mechanism was primarily embodied in the Top-1000 Energy Consuming Enterprise programme (qianjia qiye jieneng xingdong) in the 11th FYP. Launched by the State Council in April 2006, the Top-1000 program covered 997 large-scale enterprises nationwide in 9 major energyconsuming industries that each consumed a minimum of 180,000 tce energy in 2004. They were set the target to reach an aggregate energy saving of 100 million tons of coal equivalent (Mtce) energy by 2010 (Price and Wang 2007). Most of these enterprises depend on coal and electric power supply to operate. ${ }^{17}$ In 2006 , a total of 30 provincial governments signed energy efficiency responsibility agreements with the State Council. The agreement promulgates energy efficiency targets to be achieved in each province; similar agreements were then signed between local governments and local industrial enterprises. Thus, a two-tier target-responsibility system was set up to ensure the program monitoring and decentralised implementation in provinces and individual enterprises (NDRC 2011a). In this way, the Chinese party-state centre added energy efficiency performance of local enterprises as a key criterion of the party-state's cadreofficial evaluation and promotion system, which provides strong political incentives of decentralised policy implementation to improve the energy efficiency of a large number of industrial energy consumers (Ma et al. 2012). According to Price et al. (2011, p.2168), the Top-1000 Enterprise Project together with local-initiated energy efficiency programmes contributed as much as 74 percent of China's energy efficiency gain during the 11th FYP period.

Based on such a success in the 11th FYP, the 12th FYP goes on to adopt a similar policy mechanism to achieve the "16 percent" target. The Top-1000 project is expanded to become a Top-10,000 project aiming to save 250 Mtce between 2011 and 2015 (NDRC 2012). From 2012, a total of 14,119 industrial enterprises were included

\footnotetext{
17 These enterprises are mainly from ferrous metallurgy (iron and steel), petroleum and petrochemicals, chemicals, electric power generation, non-ferrous metals, coalmining, construction materials (cement), textiles, and pulp and paper. The total energy consumption of these enterprises accounted for more than 33 percent of China's total energy use in 2004. See Price and Wang (2007).
} 
in the Top-10,000 project, which accounted for about 60 percent of China's total annual primary energy consumption. By late 2013, they have already saved energy by 249 Mtce through efficiency gains (NDRC 2012; Zhao and $\mathrm{Wu} 2015$ ). China's actual efficiency gain by 2015 is likely to overshoot the original target by a large margin. It is believed that provincial energy efficiency programmes and the Top-10,000 Enterprises project will contribute an even higher share to the energy efficiency gained during the 12th FYP period.

In sum, by reviewing the past several FYPs and the energy policy priorities promulgated in the National FYP Guidelines, we can identify that the country's energy policy focal point has been systematically shifted away from energy security to energy efficiency in the country's formal policy documents since the 11th FYP made in 20052006. This policy priority shift is characterised by the introduction of obligatory energy efficiency targets and implementation mechanisms featuring the target responsibility system which contributed most of China's energy efficiency gain over the past decade. In the following section, thorough analysis will shed light on the industrial basis of the two major policy priorities in China's energy policy. The value chain effect of energy supply will be the focus to highlight the cross-sectoral feature of the energy policy change that most existing studies have failed to capture and explain.

\subsection{Energy Security, Energy Efficiency and China's Two Major Energy-based Industrial Value Chains}

\subsubsection{China's Energy Situation and the Concept of Industrial Value Chain}

An overview of China's overall energy situation is necessary before further discussions on the country's energy-based industrial value chain. There are two striking characteristics of China's basic energy situation over the past two decades: the role of coal production and use in its energy system; and the increasing oil deficit and heavy dependence on foreign oil.

Coal

Up to 2013, Chinese production and consumption of coal increased for the 13th consecutive year. China is by far the world's largest producer and consumer of coal, 
accounting for 46 percent of global coal production and 49 percent of global coal consumption - almost as much as the rest of the world combined (NBS 2013a; NBS 2013b). Coal has constantly accounted for around 70 percent of China's aggregate energy consumption since the late 1970s. In contrast, coal was only 18 percent of US energy use and 28 percent of global energy use in 2012 (EIA 2013). Coal consumption will continue to grow due to economic growth and the relatively low cost. The US Energy Information Administration (EIA) predicts coal consumption in China will peak around 2035 (EIA 2013). Although estimates by different agencies vary, there is little doubt that domestic coal production will continue to account for over half of China's total primary energy demand in the foreseeable future.

Oil

As the second largest primary energy source, crude oil accounted for around $18.7 \%$ of China's primary energy consumption in 2013. The country's total oil and gas production surpassed Iran in 2008 and China has since become the world's fourth largest oil producer behind Saudi Arabia, Russia and United States (EIA 2013). Although its oil and gas production has risen by about 54 percent over the past two decades and serves only its domestic market, it has not kept pace with demand growth. In 2009, China became the second-largest net oil importer behind the US. Average net total oil imports reached 6.2 million bbl/d in 2013, accounting for nearly a third of global oil demand growth (EIA 2013). In 2012 imported oil accounted for 58 percent of China's total crude oil consumption (State Council 2012).

Other

The country's hydropower production has grown rapidly during the past decade, from 1906 billion $\mathrm{kWh}$ in 1995 to 4829 billion $\mathrm{kWh}$ in 2007. In 2007, the share of hydropower in electricity generation was $18.4 \%$, and its share in total energy consumption was approximately 6 percent (Ma et al. 2009). By 2009, there were 11 operational nuclear power units in China, with an installed capacity of 9100 Megawatt (MW). However, the share of nuclear energy is very small in total electricity generation. Its share in both total energy production and consumption is lower than one percent (NBS 2009). 
China has been accelerating investment and development of renewable energy sources such as wind and solar power. In 2009, China overtook the United States as the largest renewable and clean energy investor in the world (Rogers 2010). China has emerged as the world's largest manufacturer of solar panels. Although current renewable energy sources provide only four percent of electricity generation capacity and less than one percent of total primary energy consumption, the Chinese government plans for wind, solar and biomass energy to represent 8 percent of its electricity generation capacity by 2020 (Bradsher 2010).

In sum, fossil fuel in the form of raw coal and crude oil (and gas) together accounted for over 90 percent of China's primary energy production and aggregate energy consumption. China's major energy-based industrial value chains are mainly built upon these two sectors as the major energy suppliers to its downstream energy consumers.

\section{Going beyond energy supply sectors - Industrial Value Chain analysis}

Value Chain Analysis has been widely-used to study how clusters of industries are inter-connected to contribute to economic growth (Hirschman 1958; Porter 1985). The development of most industries can be linked to derived demand, i.e. the provision of input for a given activity. Similarly, all industries are forward linked to output utilisation. Outputs from a given activity will induce attempts to use this output as inputs in new activities (Drejer 2002). Hence, those individual industries that are closely interlinked by such input-output relations can be regarded as industrial value chain (Porter 1985; Tordo et al. 2011). Because of the strong value chain effects between energy supply industries and its downstream energy consumers, priority between energy security and energy efficiency in the FYPs impacts major industrial sectors of the Chinese economy quite differently. Hence, it is necessary to first identify China's major energy-industry value chains as a basic context to explore the underlying forces that have induced China's energy policy change.

As the second largest economy, the Chinese economy is unique compared either with the rest of the world or the OECD due to the large share of industrial value added in its GDP and the dominant role of industrial energy demand in its energy situation. China's industrial sector has contributed about half of its annual GDP from the early 
1990s. Calculated at a 2000 constant price, the proportion of industrial value-added in China's GDP increased from 33.9\% to 49.7\% during 1980-2008 (Wang 2010). In 2012, Chinese industrial value added accounted for 45 percent of its GDP; in contrast, the world average was about 30 percent in 2012 (The World Bank 2013). Along with its economic growth, China's total primary energy consumption increased almost five-fold. Industrial energy consumption accounts for about 70 percent and is triple the OECD average of 22 percent (Ke et al. 2012), and double the world average of 30 percent (IIASA 2012, p.516).

\subsubsection{China's Energy Policy Priorities and Two Energy-Based Industrial Value Chains}

Amongst China's industrial sectors, there are two groups of industries that heavily rely on a large amount of fossil fuel to operate. One heavily relies on crude oil and the other on raw coal. These groups of industries are particularly important to the Chinese economy in terms of industrial value-add and their fundamental role in shaping the country's overall energy situation.

\section{The Coal-Metallurgical Value Chain (CMVC) and China's energy efficiency}

China has been a coal-based economy. Coal is widely used in many industrial sectors to provide heat and feedstock for industrial activities. The country's demand for raw coal has been primarily driven by the power sector's demand for thermal coal and the metallurgical industry's demand for coking coal. From the early 2000s, the metallurgical industry has been the largest end-user of raw coal and coal-based electric power in China. The booming Coal-Metallurgy Value Chain (CMVC) has thus become a major pillar of the Chinese economy. The value chain mainly involves coalmining as the upstream; coking and thermal-power generation as the midstream; and metallurgy as the downstream. Due to the energy-intensive nature of the sub-sectors along the value chain, the rapid expansion of China's CMVC has been widely identified as a central factor contributing to the rising industrial energy intensity, the declining energy efficiency of the whole economy and the surge of the country's GHG emissions (see Figure 4 on the following page). ${ }^{18}$

${ }^{18}$ For example, see Zeng et al., (2014); Zha et al., (2009); and Zhao et al., (2010). 


\section{Figure 4 Average Energy Intensity of China's Major Industrial Subsectors between 2000 and 2008}

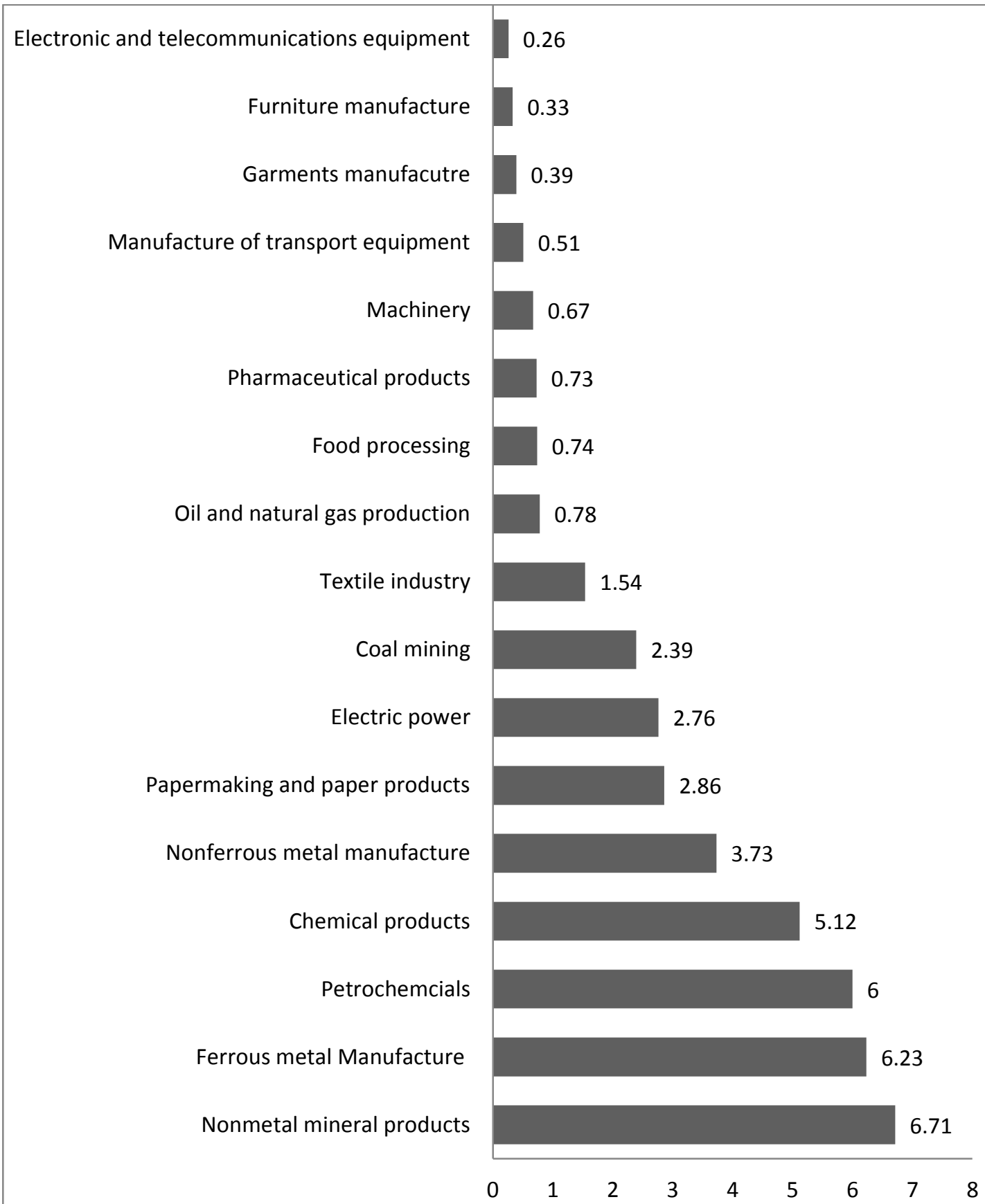

Unit: Tons of standard Coal per RMB 10,000 Yuan GDP

Data Source: Zhou et al. (2012, pp. 67-68). 
CMVC starts at the coalmining sector. Coal supplies are mainly dependent on coalmining that involves exploitation and preliminary processing of raw coal from both surface and underground coalmines. Globally, industrial energy consumption is mainly concentrated in four sub-sectors, namely power and heat generation, metallurgy, chemical production and building materials (OECD/IEA 2007a, pp. 291-296). Similarly, China's annual raw coal production has been primarily consumed in two ways. About 50 percent of coal is thermal coal consumed by the power sector, and another 17 percent is consumed by the metallurgical industry, such as iron and steel, and nonferrous metal manufacturing as coking coal. In terms of indirect coal consumption via coal-based electricity consumption, metallurgy emerges as the single largest industrial coal end-user. The metallurgical sector consumed $18.2 \%$ of China's electric power produced in 2012. If calculated in tons of coal equivalent (tce) energy, the metallurgical industry accounted for as high as 13 percent of China's total energy consumption in 2012, representing the single largest industrial energy consuming sector in the whole Chinese economy. Coal use in other sectors such as the residential sector collectively accounts for the remaining 20 plus percent of raw coal consumption. ${ }^{19}$

Coal-based electric power generation, or conventional thermal power production, is a primary way to convert fossil fuel, mainly raw coal, into electric power. As the largest coal consuming industrial sector in the Chinese economy, the electric power sector accounts for about half of China's total coal consumption throughout the 2000s. Over the past three decades, coal-based power generation has constantly accounted for 70 percent of China's power capacity mix, 28 percent higher than the world's average (CPNN 2014). Although accounting for half of the raw coal use, the coal-based electric power sector is not a major final user of coal, but primarily an energy converter and transmitter. More importantly, under current technological conditions, electricity cannot be stored large scale upon generation. Industrial electricity can only be consumed in real time upon generation. The physical attribute of electricity, and the huge fixed-asset investment requirement for power generationtransmission capacity-building, together determine the development of coal-based power sector needs to be driven by downstream demand for electricity. For this reason,

\footnotetext{
${ }^{19}$ Data of China's energy situation in this chapter are calculated by the author primarily based on statistics from NBS (2013a) and NBS (2013b) unless otherwise indicated.
} 
this study takes the coal-based electric power sector mainly as a midstream energy converter-and-transmitter that serves its downstream power users.

Among the downstream coal and power demand sectors, iron and steel, aluminium, chemicals, pulp and paper, and cement are the biggest industrial energy consumers. These five sectors account for more than half of the global industrial energy use and energy consumption represents a large portion of their production costs throughout the world (EIA 2013, p.128; IIASA 2012, p.516). Iron and steel making and aluminium making are the two major sub-sectors of metallurgy, which are highly energy-intensive manufacturing industries that mainly rely on coking coal and electricity to operate. ${ }^{20}$ Metallurgy can be broadly understood as the production of metal from ore. ${ }^{21}$ It includes both ferrous (iron and steel) and nonferrous (aluminium, copper and zinc) operations. Due to the huge demand for fossil fuel to process iron ore, ferrous operations are also accompanied by emission of large quantities of carbon and sulfur oxides, and particulate pollutants (USEPA 2014). According to the IEA, the iron and steel industry accounts for the largest share - approximately 27 percent - of carbon dioxide emissions from the global manufacturing sector (China Energy Group 2014).

In China, metallurgy constitutes the major downstream sector of the coal-based industrial value chain. Ferrous metallurgy has played a pivotal role in China's industrialisation and has been a major driver of coal and electric power production. Since the 1950s and 1960s, China's industrialisation strategy has focused on metallurgy capacity building, mainly due to iron and steel's fundamental role in supporting the country's rapid industrialisation. This was summarised in China's industrial policy as "gongye fazhan yigang weigang" (Steel as the Central Sector of Industrialisation) (Yuan 2007, p.3). Because of the strong input-output industrial linkages, China's central planners paid serious attention to coordinating the development of the coal sector and metallurgy during the planned economy era. By 1981, metallurgical energy consumption accounted for around 22 percent of China's total industrial energy consumption, including 38.6 million tonnes of metallurgical coal, 15.8 million tonnes

\footnotetext{
${ }^{20}$ Metallurgical coal, also known as coking coal, is the kind of raw coal with chemical composition suitable to produce coke as a major source of heat for ironmaking.

21 The metallurgical industry can be broadly divided into primary and secondary metal production operations. Primary refers to the production of metal from ore. Secondary refers to production of alloys from ingots and to recovery of metal from scrap and salvage. See USEPA (2014).
} 
of thermal coal and 30.2 billion kwh of electricity (Lin 1996, p.140). ${ }^{22}$ As the world's largest iron and steel producer and exporter, around 13 percent of China's raw coal is directly consumed as metallurgical coal used in the iron \& steel manufacturing process, making it one of China's largest industrial energy consumers. In terms of non-ferrous metallurgy, annual energy consumption of non-ferrous metal manufacturing increased rapidly during economic reform. Non-ferrous metals are produced because of desirable properties such as the low weight of aluminium. ${ }^{23}$ Worldwide, more than half of the energy used in non-ferrous metals is for the highly electricity intensive aluminium production process (OECD/IEA 2008). The electricity cost alone comprises 35 percent of aluminium production costs. Both the electricity intensity and the share of electricity cost are the highest among all metallurgical sub-sectors (The Aluminium Dialogue 2012). Hence, in economies where coal-fired power plants generate most of the electricity, the boom of aluminium manufacturing often significantly drives thermal coal demand through power consumption.

Although other industrial sub-sectors such as the chemical and crude oil-based petrochemical industries are also energy-intensive relative to light-manufacturing and service industries, their influence on China's overall energy efficiency is much less compared to the metallurgical sectors due to their smaller scale relative to the whole economy. Therefore, compared with other economic sectors and industrial sub-sectors, the scale of the metallurgical manufacturing industry is a key variable to determine the Chinese economy's overall energy efficiency (see Figure 5 on the next page). The key role of metallurgy in influencing China's energy efficiency has been clearly demonstrated by the structure of industrial energy users included in China's Top-1,000 Enterprises project during the 11th FYP. Among the 997 enterprises selected to participate in the ambitious programme, metallurgical enterprises added up to 334 , accounting for more than one-third (ferrous $26 \%$, and non-ferrous $7 \%$ ), representing the

\footnotetext{
22 Thermal coal was mainly used for heating boilers, sintering and pelletizing, coal gas generation and blast furnace injecting; electricity was used for the rolling and forging of steel, transportation, ferroalloy production, steelmaking in electric arc furnances, and mineral process. See Lin (1996) for more details.

${ }^{23}$ In metallurgy, a non-ferrous metal is any metal, including alloys, that does not contain iron in appreciable amounts.
} 
biggest industrial sub-sector targeted by China's energy efficiency policy (see Figure 4 below). ${ }^{24}$

\section{Figure 5 Mix of Industrial Enterprises in China's Top-1,000 Project}

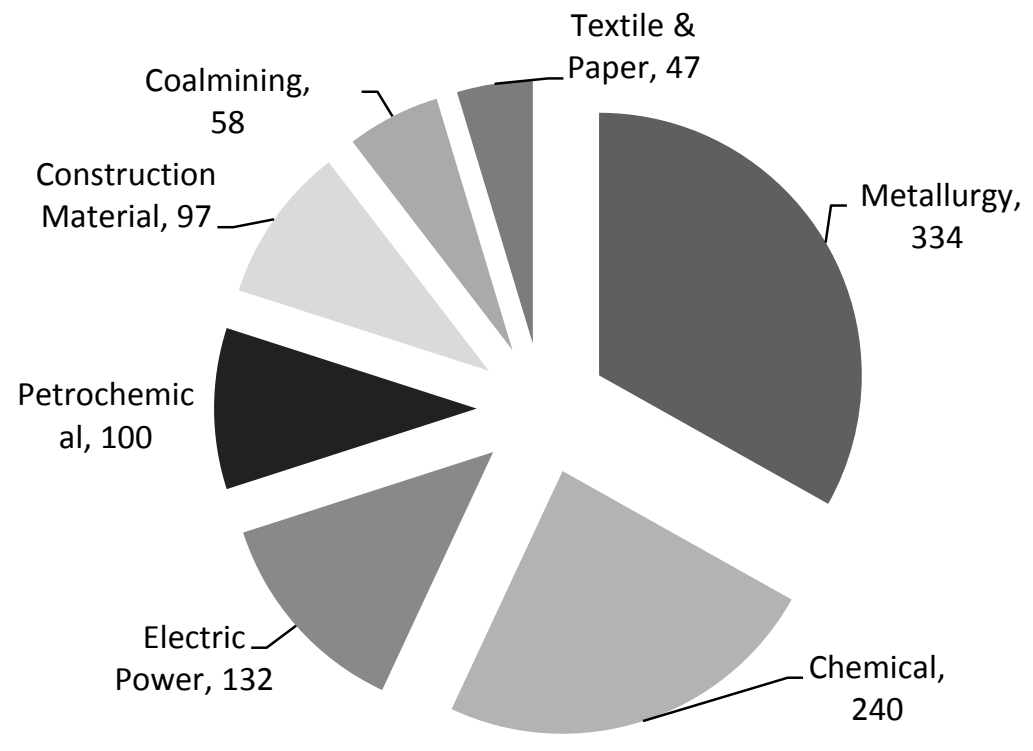

Data Source: NDRC, 2006

In sum, the hyper-growth in the metallurgy sector has significantly driven the demand for coal and electric power, and profoundly influenced China's industrial energy intensity as well as the energy efficiency of the whole economy since the early 2000s. As of 2012, about $49.4 \%$ of the country's raw coal production was thermal coal consumed by the power sector, and another 17 percent was consumed by the steel industry as coking coal. In terms of indirect coal consumption through power consumption, the metallurgy is the largest industrial end-user of power among all manufacturing industries. It used $18.2 \%$ of China's total electric power produced in 2012 (industrial power consumption currently accounts for around 75 percent of China's annual electricity consumption) (NBS 2013a; NBS 2013b; EIA 2013). If calculated in tons of coal equivalent (tce) energy, the metallurgical industry accounted for as high as 13 percent of China's total primary energy consumption (Ma et al. 2012,

${ }^{24}$ Author's calculation based on NDRC (2006). 
p.44), representing the No.1 industrial energy end-user in the economy. ${ }^{25}$ Such an input-output linkage closely connects the coalmining sector with the downstream metallurgy market, making the coalmining, power generation, and metallurgy the largest and the most important coal-based industrial value chain that influences the whole economy's energy efficiency.

\section{The Oil-Petrochemical Value Chain (OPVC) and China's energy security}

As the second largest primary energy source, crude oil production also leads to a series of downstream industries. Compared with the CMVC, the Oil-based Petrochemical Value Chain (OPVC) is more commonly known due to the influence of vertical-integrated International Oil Companies (IOCs) such as BP and Royal Dutch Shell. Contemporary oil-based petrochemical industries across the world are characterised with major IOCs and NOCs whose business portfolios include part or the whole OPVC. The OPVC starts at the upstream of crude oil exploration and production $(\mathrm{E} \& \mathrm{P})$. Crude oil production needs to be processed in petrochemical refineries and manufactured into a variety of products. The refining process is often referred to as the midstream of the value chain. Most products are different kinds of fuel and lubricants used in powering combustion engines for transportation or industrial purposes; certain products are the principal feedstock for chemical industries. Thus, the oil products and petrochemical feedstock are subsequently distributed to retailers or industrial users. The distribution section is often referred to as the downstream of the value chain.

The OPVC starts with the upstream crude oil E\&P. Crude oil E\&P is a key mining sector. It firstly involves identification of suitable geological sites for oil (and gas) reserves. If the reserves were proved to be economically exploitable, engineers will drill for full-scale production, followed by the building of infrastructure to connect the oil wells to refining facilities. Crude oil is not a homogeneous material. Modern oil consumers, such as gas and diesel engines, aviation turbojet engines and ship bunkers need fuels manufactured to precise specifications (Tordo et al. 2011, pp.109-112).

\footnotetext{
${ }^{25}$ Coal-fired power generation accounted for 56 percent of the marginal increase in coal use between 2000 and 2005. Between 1990 and 2007, growth in thermal coal use for power generation was followed by growth in coking coal use for steel making (18 percent), the end-use of coal for production of building materials (mainly cement, 6 percent), delivered heating (residential district heating, 6 percent), and chemical production ( 3 percent) as the largest growth drivers. See Aden et al., (2009, p.7).
} 
Therefore, crude oil almost always needs to be refined and manufactured into petroleum products or feedstock.

Oil refining is the process of converting crude oil into finished petroleum products. It is a major manufacturing sub-sector and the backbone of petrochemical industry. Refineries can consist of a number of different process units that undertake separation, conversion and treatment of oil. The output of these conversion units is then treated or blended for distribution (Tordo et al. 2011, pp.109-112). Refineries are usually categorized by size and configuration. The configuration or sophistication of a refinery refers to the technical capabilities and flexibility to process different kinds of crude feedstock into a large number of different petrochemical products. There are primarily two categories of production out of the refining process - fuel and petrochemicals. The main categories of fuel are fuel oil (residual fuels), gas oil, jet/kerosene, gasoline, naphtha and liquefied petroleum gases (LPG). The three main energy-related uses for these oil products are heating, power generation and transportation (Tordo et al. 2011, pp.109-112). Beside fuel, petrochemicals are a second important output from the refining process. Petrochemicals are chemicals made from crude oil and natural gas and account for approximately 40 percent of the world's chemical market (Devold 2013). The oil industry became involved in petrochemicals from the 1920s, since naphtha (from refineries), natural gas and natural gas liquids constitute the principal feedstock. Chemical products based on these base materials are the basis for a wide range of manufacturing products such as car tires, pipes, and electronic components (Tordo et al. 2011, pp.109-112).

The marketing and distribution of refined products could be in forms of domestic industrial wholesale or retailing, or exported as industrial commodity. For the fuel products that account for the majority of refining products, road transportation fuels are primarily distributed at retail stations, heating oil is usually delivered to residential and industrial customers, kerosene is purchased directly by individual airlines and airports, and residual fuels are also sold directly to shipping companies, utilities and industrial plants (Tordo et al. 2011, pp.109-112). In terms of international trade, both crude oil and major petrochemical products such as gasoline are important 
commodities in the global energy and chemical market. The global petrochemical market is estimated in 2013 to be valued at USD \$3 trillion in terms of trade volume (Platts 2015). International trade of petrochemical products has been a major way to achieve industrial value-add in the midstream petrochemical sector.

China had little crude oil production and petrochemical capacity when the PRC was established in 1949. Crude oil was mainly imported from the Soviet Union. Because crude oil and petrochemical products play an important role in national defence, transportation and chemical industries, the building and development of China's OPVC has been closely linked to national security from the very beginning. In the 1960s, the Sino-Soviet rift made the Chinese top leadership fully realise the strategic role of oil. Mao himself ordered the People's Liberation Army to launch a "Great Oil Campaign” (shiyou da huizhan) in search for oil fields in 1960 (Zhang 2004, pp.71-74). This search subsequently discovered several major oil fields in Eastern China in the early 1960s. Increasing domestic crude oil production and the abundant coal reserve brought China energy self-sufficiency, which became a pre-eminent symbol of Mao's 'self-reliance' doctrine. In 1963, the crude oil production from Daqing oil field along reached $9 \mathrm{mmt}$ (Kambara and Howe 2007, p.24). In the mid1970s, the first oil shock turned China into a major oil exporter (Kambara and Howe 2007, p.24). In 1978, China's crude oil production reached a historical high volume of 100 million tons (Zhang 2004, p.77).

However, in the 1980s the surging energy demand rapidly eroded China's oil surplus. China's crude oil exports peaked in 1985, reaching $30 \mathrm{mmt}$. In 1993, the country became a net oil products importer and by 1996 became a net crude oil importer (Zha 2006). Although the Chinese government and NOCs adopted a series of measures, including investment heavily in both onshore and off-shore E\&P, which has enhanced domestic crude oil production by about 54 percent over the past two decades and put restriction on oil exports, it has not kept pace with demand growth. In the 2000s, China's crude oil imports increased rapidly. In 2007, China overtook Japan to become the world's second largest oil importer behind the United States. In 2009, the country's oil imports dependence surpassed 50 percent. As of 2011 when the 12th FYP was made, China's oil dependence rate reached 58 percent (State Council 2012). 
With successful upstream E\&P, midstream petrochemical capacity also expanded rapidly and becomes a highly-profitable sector of the economy. On the eve of economic reform in 1978, China's petrochemical sector produced 70 million tons of fuel products and 388,000 tons of ethylene (Zhang 2004, p.77). In the post-reform era, petrochemicals expanded quickly to become a major manufacturing industry, creating industrial value-add for the whole economy. Petrochemical demand for crude oil became a key driver of China's energy security policies in the 9th and 10th FYPs' period. At the beginning of the 9th FYP in 1996, China became the world's fourth largest oil refiner and the fifth largest ethylene producer. By the end of the 9th FYP period in 2000, petrochemical sales revenue reached RMB 1430 billion which accounts for about 18 percent of China's total industrial revenue of that year. It contributed RMB 108 billion net profit (25 percent of total industrial profit) and 397 billion industrial value-add (17 percent of total industrial value-add) in the year 2000 (ChinaPetrochemcial 2005). These numbers made the petrochemical manufacturing industry become one of China's most profitable industrial sub-sectors at the turn of the 9th and 10th FYP in 2000-2001.

Due to sluggish domestic oil production, the Chinese petrochemical industry has become increasingly dependent on oil and petrochemical feedstock import to feed its rapidly expanding capacity in the 2000s. This considerably erodes the industry's profitability and exposes the sector to external supply risks and price volatility. Before the making of the 11th FYP in 2004, China became the second largest oil refiner and the third largest ethylene producer with $300 \mathrm{mmt}$ and $5.6 \mathrm{mmt}$ per annual capacity (Cao 2004). In the same year, the domestic upstream E\&P sector only produced $160 \mathrm{mmt}$ of crude oil. Crude oil and feedstock imports accounted for a large share of the industry's production cost and brought a huge trade deficit. In 2004, Chinese petrochemical industry made USD 41 billion export revenue, but it spent USD \$118 billion on crude oil and petrochemical feedstock imports, making the bulk of China's trade deficit. ${ }^{26}$ This trend has continued over the past decade as the Chinese petrochemical industry grows. At the beginning of the 12th FYP in 2012, China became the world's second largest petrochemical manufacturer. Its oil refining capacity reached $710 \mathrm{mmt}$ per

${ }^{26}$ Crude oil imports accounted for 52 percent of the USD \$77 billion trade deficit; the rest was made by processed petrochemical feedstock such as polyethylene. See Feng (2005). 
annum, accounting for $12.4 \%$ of the world's total capacity; ethylene capacity has also reached $17.4 \mathrm{mmt}$ per annual, accounting for 11.2 percent of the world's total (Wang 2014). In contrast, the domestic upstream E\&P sector only produced $204 \mathrm{mmt}$ crude oil in 2012. To feed the petrochemical capacity, China imported $282 \mathrm{mmt}$, making the country's oil dependence reach 58 percent. The USD \$252 billion cost accounted for $3.2 \%$ of its GDP, much higher than other major energy consumers like the US and EU (EIA 2013).

The downstream distribution sector is very important to achieve the industrial value-add in the up-and-midstream of the OPVC in domestic market due to the profitability of fuel products. The OPVC's downstream includes both fuel and other petrochemical product trade internationally as well as wholesale and retail domestically. Due to the high sales revenue net profits and tax attached to the products, the downstream sector of the OPVC has been a focus of industrial interest distribution between the central and local government, and between the state sector and private sector during economic reforms in China.

In sum, by examining the industrial basis of China's energy policy, this section investigates the major downstream industries of the two largest primary energy sources - raw coal and crude oil - and conceptualises the Oil-based Petrochemical Value Chain (OPVC) and the Coal-based Metallurgical Value Chain (CMVC) as China's two major energy-based industrial sectors based on detailed energy and industrial data. It then explains why the CMVC is the central factor in determining China's energy efficiency; and why the OPVC has been at the heart of the country's energy security. The interlinkage of China's energy supply sectors and its downstream industries as well as the major differences between the two major energy-based industrial value chains is the key to understand the fact that the priority of China's energy policy has systematically shifted from the security of overseas oil-supply to the efficiency of domestic industrial energy consumers. As such, it constitutes the basic analytical approach to organise the case studies. See Figure 6 on the following page for an overview of China's two energy-based industrial value chains. 
Figure 6 Overview of China's Two Energy-based Industrial Value Chains

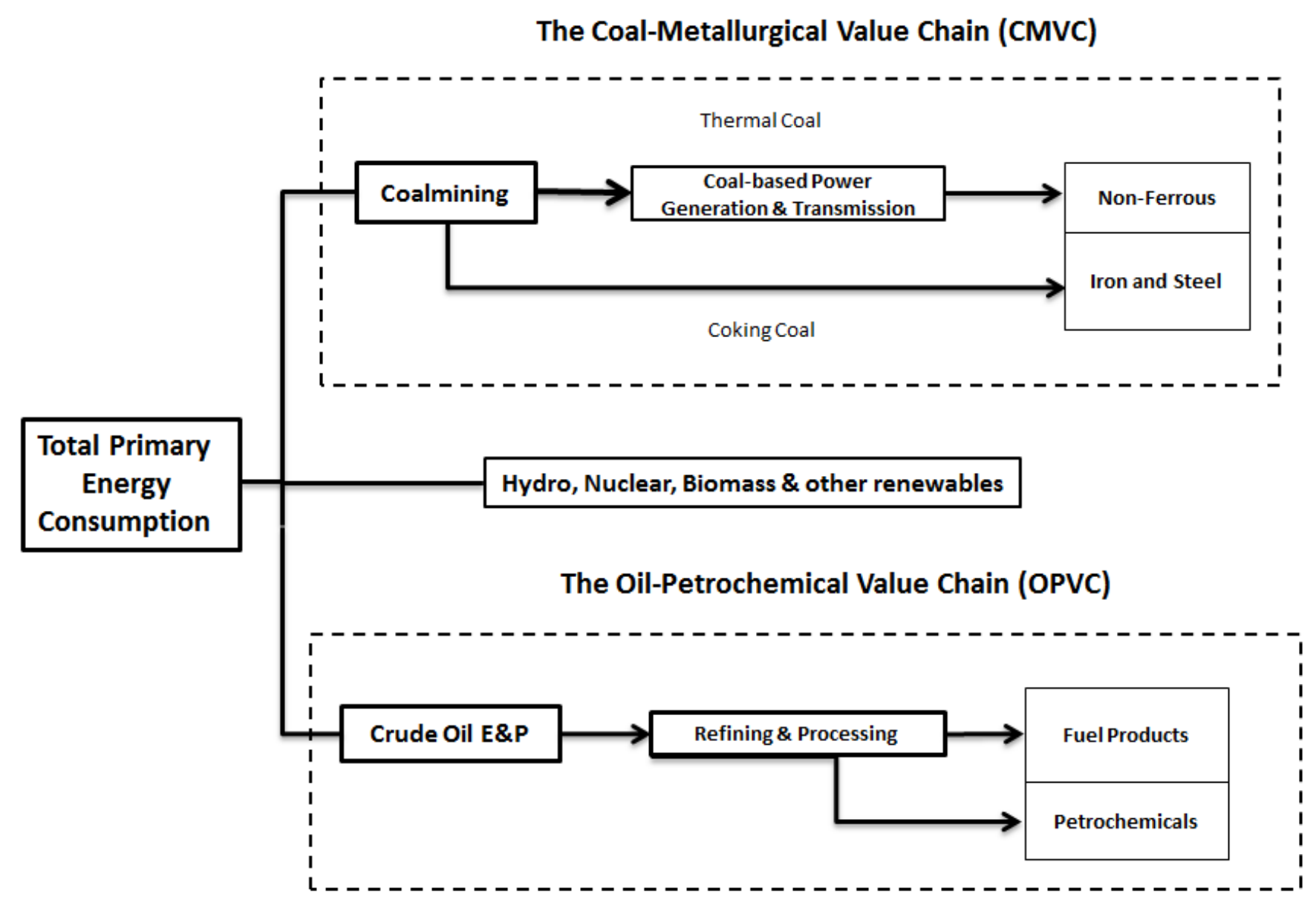




\section{Chapter Summary}

This chapter presents a basic context on the shifting national energy policy priorities in the FYPs and their relationship with the country's two major energy-based industrial value chains. It illustrates the role of energy policy as a fundamental component of China's socio-economic development policy and the traditional policy priority of energy supply security focusing on oil dependence in the 9th and 10th FYPs (19962005). However, from the 11th FYP made in 2005/2006, energy policy priority and focal point have systematically shifted away from the oil-centred supply security to coal-based industrial energy intensity through the introduction of obligatory energy efficiency targets and new policy mechanisms. However, as analysed in Chapter One, the shift in priority from energy security to energy efficiency at a time of increased oil import dependence is not well explained in current studies.

In the second section, detailed analysis of China's basic energy situation and two major energy-based industrial value chains demonstrate that, in the Chinese policy context, energy security as a key policy objective mainly concerns the OPVC; and energy efficiency as a key policy objective mainly targets the rising industrial energy intensity due to the rapid expansion of CMVC. By examining the industrial basis of China's energy policy, this chapter distinguishes the OPVC and CMVC as the two major energy-based industrial value chains that underpin the two major energy policy objectives. This dichotomy highlights the cross-sectoral feature of China's energy policy shift. It also constitutes a basic method to organise the case studies in Chapters Five and Six. In the following chapter, the focus is on investigating the first fundamental question of China's energy policy shift: the mechanism of policymaking in today's China. 


\section{Chapter Three: Ideational Dynamism in China's National Policymaking}

This chapter aims to examine China's policymaking mechanism at the national level. The first section examines the top party-state leadership's growing capacity to generate an 'ideational system' to guide China's reform and development. The first section will investigate why and how the ideational system emerges and how it could evolve to display dynamism over time. The focus of analysis will be on the profound influences of Jiang-Zhu leadership's 'Reform-to-Grow' strategy, and the Hu-Wen leadership's 'Scientific Development' strategy, on China's reform strategy in the 1990s and development strategy in the 2000s. The second section will look into how China's socio-economic policymaking structure and process has been modified by a stronger top party-state leadership over the past two decades. A central point of this section is to identify how China's reforms and the making of its FYPs are influenced by top partystate leadership's ideational systems. By doing so, this chapter provides an important update to the conventional assumptions and models of policymaking at the national level. Such an updated policymaking mechanism would further direct the study to capture and examine the underlying forces that have induced the cross-sectoral policy priority shift that have been overlooked by literature using conventional models of policymaking.

\subsection{Chinese Party-State Leadership and Their Ideational Systems}

After China entered the 'transition era' or 'reform era' in the late 1970s, even though the 'Mao Zedong Thought' stressing the communist ideology continued to be a guiding ideology of the CPC, the party-state's 'ideological purism' has been increasingly replaced by 'ideational pragmatism' (Dittmer 2003) that is based on a series of ideational innovations (linian chuangxin). The ideational innovations started from the rise of Deng Xiaoping Theory on Socialist Market Economy and have been carried on firmly by the third and fourth generation leadership through their development of ideational systems to guide China's development and to legitimise the CPC's reform course. 


\subsubsection{Institutionalisation of the Party-State Leadership in the Post- Reform Era}

Since the beginning of the Deng Xiaoping era in 1978, politics at the top level of China's political-economic institutions have undergone deliberate and incremental institutionalisation. The dynamics and mechanism of leadership transition have changed in favour of a much more predictable rule-based process. Such impetus for institutionalisation of political leadership has derived directly from the revision of the CPC's fundamental task in post-Cultural Revolution China and the beginning of the country's open-up and reform strategy.

Leadership transition in China is not institutionalized as explicitly as in democratic countries. Instead, it has been decided through informal and factional politics, with inevitable conflict and instability as a result, in particular from the 1950s to the late 1980s. Political conflict after the Great Leap Forward in the early 1960s, political chaos during the Cultural Revolution in the early 1970s, and political instability during the 1980 s were all directly or indirectly related to the issue of underinstitutionalised leadership transition. Once back in power in the late 1970s, Deng Xiaoping and his reformist leaders decided to institutionalise the top leadership selection and transition to guard against the concentration of dictatorial authority that Mao had achieved. Deng openly raised the issue of reforming the party-state leadership at a Politburo meeting in August 1980. Deng enforced a limit of two five-year terms for the party and state leaders. He also enforced the retirements of a whole generation of veteran incumbents who were over certain age limits. By the time of the 14th Party Congress in 1992, the Advisory Committee composed of elder party leaders with lifetime tenure had been abolished and a retirement system established. Deng also succeeded in stage-managing the CPC's first orderly pre-mortem succession, with himself ceding all formal power in 1989 although his informal influence was not relinquished until his death (Lee 2010; Vogel 2013).

Deng's agenda of institutionalising party-state leadership was carried on and became increasingly evident over the following three decades with the normalisation of major party-state events. From the 11th National Party Congress in 1977, the Party Congress has been held every five years without exception. At the same time, since 
1978, the National People's Congress (NPC) has been held regularly every year, and reconstituted every five years without exception. Regular convening of major partystate organizations has contributed tremendously to the institutionalisation of leadership. (Miller 2008; Li 2012). Recent leadership changes at the CPC's 16th (2002), 17th (2007) and 18th (2012) Congress have clearly demonstrated this trend in Chinese politics.

As Deng's hand-picked successor and the core of the third generation of partystate leadership, Jiang Zemin continued Deng Xiaoping's efforts to institutionalize leadership tenure. Jiang quite successfully managed leadership transition from the third to the fourth generation in the early 2000s. At the 16th Party Congress in November 2002, all the members of the Standing Committee of the Politburo, except Hu Jintao, were prohibited from running for re-election at the Central Committee. Fourteen of the 24 full members of the Politburo were replaced, and more than half of the Central Committee members were phased out in accordance with age restrictions. With Jiang's efforts, informal and factional politics continue to diminish compared to the increasing formal rules at the top level of Chinese politics (Lee 2010).

As the core of the fourth generation leadership, Hu Jintao has endeavoured further to institutionalise political leadership since he took over the position of General Secretary of the CPC in 2002. At the first Politburo meeting after the 16th Party Congress, $\mathrm{Hu}$ emphasized the importance of preserving the normative rules and procedures of collective leadership in decision-making processes, and demanded a strengthening of the rule of law and the Constitution. At the 18th National Party Congress in 2012, Hu Jintao himself demonstrated such a course by passing both the position of General Party Secretary and the chairmanship in the CPC Central Military Affairs Commission to Xi Jinping, which completed the leadership transition to the fifth generation in one stroke. Such 'full retirement' of China's paramount party-state leader was unprecedented (Xinhua News Agency November 15, 2012).

China is some distance away from having transparent and predictable political processes, but the country has already made great headway in institutionalising political leadership transition. A most important consequence of such institutionalisation of Chinese politics is the changing dynamics and processes in its reform and socio- 
economic development policymaking at the national level. First, stable and predictable rules allow the recent two generations of leadership to concentrate on institutional reforms and economic development; second, stable and predictable power transition allows the top leadership to tighten control over the actors and process of socioeconomic policymaking.

\subsubsection{Deng's Legacy: Socialist Market Economy Theory and Ideational Innovation}

In the late 1970s, when Deng became China's paramount top leader after Mao's death, he and his reformist-minded colleagues found that the CPC's guiding ideologies must be shifted from the Maoist class struggle doctrine. As the de-facto paramount leader of China from the late 1970s to the early 1990s, Deng developed a series of innovative ideas and concepts, which were later systematically theorised as "Deng Xiaoping Theory on Building Socialism with Chinese Characteristics" (commonly known as The Deng Xiaoping Theory).

Deng argued that as a developing country China was at "the preliminary stage of socialism", during which the country's primary goal was to build an economic material base and rapidly achieve a prosperous and strong socialist state as a key step towards the ultimate goal of communism. With the success of the spontaneous localgovernment "household contract responsibility" experiment that greatly improved China's agricultural output in the early 1980s, a consensus emerged among the leadership that administrative and fiscal decentralisation should allow local initiatives of reform experiments to greater political-economic transition. Based on such judgement, Deng further raised a series of innovative concepts that were embodied in famous slogans such as "the white cat and black cat" theory, and "crossing the river by groping the stones", to legitimise and encourage the economic reforms. By adopting the Household Responsibility System and encouraging the development of rural Township and Village Enterprises (TVEs), China's reform first broke through in the ruralagricultural sectors. Later in the urban-industrial sectors, the central government adopted a dual-track pricing system to encourage greater efficiency in urban industrial SOEs. Such an experimentalist and gradualist reform approach was famously summarised by Naughton (1995) as "growing out of the plan". 
Hence, during the entire 1980s till the early 1990s, China's reform and development proceeded, featuring decentralised reform. This empowered policymaking by intermediate level policy bureaucracies in the central government and local government autonomy to experiment with reforms, without an overarching reform idea or a clearly defined transition agenda (Naughton 2007, pp. 90-111). Then, in the early 1990s, following the Tiananmen incident and with the collapse of the Soviet Union in sight, the conservatives within the CPC central were able to halt Deng's reforms by criticising that they led to the decline of the party's role in governing the state. In November 1989, Deng stepped down to pass his power to Jiang Zemin. As Deng's successor, Jiang was also under heavy pressure and compromised with the conservatives. Jiang compromised by claiming that "class struggle would continue for a considerable period of time within certain parts of China", which contrasted markedly with Deng's economic development and reform ideas. As a result, Deng felt that reform by increment or by default was insufficient. It was necessary to clarify China's overall reform objective and agenda (Saich 2004, p.75).

In his 'Southern Tour' in 1992, Deng made a famous speech to define that the central objective of the CPC was to build "socialism with Chinese characteristics" primarily through constructing a "socialist market economy" (Vogel 2013). The focus of the CPC's work was to put economic construction as the absolute priority with two principles. On the one hand, China must continue to open-up to the world and take advantage of all economic forms, including capitalist elements and market institutions, to achieve rapid economic growth. On the other hand, the CPC must maintain effective political leadership and state ownership must be maintained in key sectors of the economy to guarantee the socialist nature of the Chinese state. Such ideational system was systematically summarised at the 14th Party Congress at the end of 1992 as 'Deng Xiaoping Theory' of building socialism with Chinese characteristics. Then, at the 15th National Party Congress in 1997, the Deng Xiaoping Theory was formally written into the CPC's constitution, following Marxism-Leninism and Mao Zedong Thought (Guo 2013).

Deng Xiaoping and his socialist market economy theory profoundly impacted China's overall transformation in the following two decades in two ways. First, to build 
a 'socialist market economy' through systematic institutional reforms became paramount to Deng's successors in the 1990s and marked the beginning of China's “deep reform" (Dittmer and Liu 2006). Some fundamental political-economic institutions that organise the polity and economy, which had barely been touched by the gradualist reforms in the 1980s and early 1990s, could be drastically re-arranged under a strong leadership with a more coherent and overarching reform agenda. Second, the introduction of Deng Xiaoping Theory initiated a convention of 'ideational innovation' for later two generations of party-state leadership, which helped hugely to strengthen the CPC's legitimacy and the authority of the leadership. After Deng, the third and fourth generations of leadership all managed to develop their own ideational systems to assert their updated political visions on China's reform and development, and to guide the country's socio-economic policymaking.

\subsection{Reform-to-Grow: The Jiang-Zhu Leadership's Strategy in the 1990 s}

\subsubsection{Growth-Oriented Institutional Reforms}

Marked by the introduction of Deng Xiaoping Theory, China's overall transformation began to enter a new phase of reforming fundamental economic institutions with overarching objective and coherent agenda in a top-down manner. In order to push forward market economy reform, Deng Xiaoping publicly commented during his southern tour that, "Those who do not continue the reform course must step down (from the leadership)", which was commonly regarded as a warning to Jiang Zemin's conservative turn (Vogel 2013). With acknowledgement that Deng was still the defacto paramount leader of Chinese party-state, Jiang submitted self-criticism in 1992 and marginalised the conservative-minded State Council Premier Li Peng to form a new alliance with the reform-minded Vice-Premier Zhu Rongji. ${ }^{27}$

\footnotetext{
${ }^{27}$ Zhu Rongji became State Council Premier at the 15th Party Congress in 1997. Due to his central role in making the reform policies throughout the 1990s, this study takes the third generation leadership mainly as the Jiang-Zhu leadership between 1993 and 2002.
} 
Jiang-Zhu's agenda: reform, growth and stability

Rising out of the political chaos in the late 1980s that severely damaged the party's legitimacy, the Jiang-Zhu leadership realised that economic growth was the key to maintaining the regime after 1989. At the second Plenum of the Eighth National People's Congress in March 1994, Jiang argued that "Reform, Growth and Stability" should be on top of the CPC's working agenda in the 1990s (Chen 2011). According to Jiang, "economic growth is the central objective", "reform is the powerhouse of economic growth", and "stability is perquisite to both growth and stability" (Chen 2011). Rapid growth must be achieved by 'deep' institutional reforms to build a socialist market economy. The political vision of the relationship between "ReformGrowth-Stability" can be found in Jiang's important speeches and the Party's documents throughout his tenure. It constituted the backbone of Jiang-Zhu leadership's ideational system on the basis of the Socialist Market Economy theory over the first five years of their tenure (1992-1996) (Chen 2011; Party Literature Research Center 2005). With Deng's urging and full support during the last years of his life, the JiangZhu leadership in the early 1990s was able to systematically reform China's fundamental political-economic institutions, especially those at subnational level, and to design institutional infrastructure for the socialist market economy (Saich 2004, p.24).

Indeed, during the Jiang-Zhu leadership, China experienced rapid growth thanks to a series of institutional reforms that unleashed the power of the market from the old command economy. At the centre of these reforms were two policies targeting to adjust China's two fundamental institutions governing the relations between the Chinese central government, its local agencies, and the state-owned industrial sector. One was a "grasping the large and letting go the small" (zhuada fangxiao) themed reform on the SOE institution that decentralised and liberalised the majority of urban industrial sectors from the mid-1990s; the other was reform China's Central-Local intergovernmental institution, marked by the introduction of a new fiscal system in 1994. ${ }^{28}$ Due to the vital role that these two sets of institutions play in China's socioeconomic development, this study sees the introduction of the two institutional reforms as a critical juncture in China's history between the early 1990s and the early 2010s.

\footnotetext{
${ }^{28}$ For a brilliant analysis on the fundamental role of these two sets of institutions in the Chinese history, see Xu (2011).
} 
The State-Owned Enterprise Institution had been at the heart of the Chinese economy from the 1950s to early 1990s. However, SOE's role as production units in a command economy determines its low efficiency compared to market-based economic actors. Consensus emerged among the second generation of reformist leaders headed by Deng that urban industrial institutions must be reformed. Over the past three decades, Chinese urban SOEs since the early 1980s can be divided into two phases based on different strategies adopted (Li and Putterman 2008; Lin et al. 1998; OECD 2009). In the first phase of reform, from the early 1980s to the mid-1990s, SOE reform was characterised by introducing market mechanisms to improve state sector efficiency. After the introduction of Socialist Market Economy, the reform entered a new phase as the Socialist Market Economy theory clarified China's economic reform. In 1995, the Jiang-Zhu leadership decided to push SOE reform forward by introducing a "grasping the large and letting go the small" (zhuada fangxiao) strategy. Such strategy is two-fold: 'grasping the large' meant that a small number of large-SOEs in industries in 'strategic sectors' of the national economy, such as petroleum, electricity, defence, and telecommunications, must be controlled by the state, especially the central government. ${ }^{29}$ 'Letting go of the small' means to 'dispose of' the loss-making SOEs that are not in the vital areas of the national economy through delegation, ownership diversification or complete privatisation (Garnaut et al. 2006). Such an SOE reform strategy profoundly shaped the face of the Chinese industrial economy in the following one and half decades. On the one hand, it reduced the relative weight of the state sector in the whole economy, causing the state to retreat from many sectors the Chinese economy and leaving much development space for the booming non-state economies; on the other hand, it caused the state's assets to concentrate on a number of highly profitable 'strategic sectors' that were important to the whole economy.

Another institution that is fundamental to Chinese political economy has been the institution governing China's central-local intergovernmental relations. Being a unitary and authoritarian state after 1949, Chinese local government at provincial level is the major subnational agency of the central government under the top party-state leadership. Since 1949, a personnel-fiscal two-dimensional intergovernmental

\footnotetext{
${ }^{29}$ In the mid-1990s, the Chinese leadership headed by Jiang Zemin and Zhu Rongji decided to retain ownership of 500 to 1,000 large SOEs and let the rest go. See Garnaut et al., (2006).
} 
institution has been established in China. During the decentralised reforms from the late 1970s, local government mainly at the provincial level was granted much political and fiscal autonomy to initiate reforms and develop the local economy. However, the decentralised reform strategy caused China serious problems in the late 1980s and early 1990s with an over-heated economy and political chaos. As the Jiang-Zhu leadership was installed, to restore political and economic stability by reforming the central-local intergovernmental relation became an urgent task. On the political side, the party-state centre tightened control over local cadre and official evaluation \& promotion system; on the economic side, by introducing a tax-centred fiscal reform from 1994, the central government began to control the majority of state revenue to steer the macro-economy, and significantly remodified the local government's relationship with the industrial sector (Tao and Yang 2009). The state sector of the economy kept declining, which in turn facilitated non-state economies such as the private sector and foreign firms.

Largely as a result of the two reforms that systematically rearranged some of the most fundamental institutions of political-economic development, China was able to achieve hyper-growth with unprecedented political stability in the decade 1992-2002 in spite of external shocks such as the Asian Financial Crisis. The country's GDP growth averaged 8.9\%. Since the re-launch of reform in 1992 till the 1997 Asian Financial Crisis, China's annual GDP growth averaged a staggering 12.1\%. Even during the Asian financial crisis, China's growth dwarfed the world's major economies with the average of $7.6 \%$ between 1997 and 2001 (NBS 2009). In an article published in People's Daily in 2006, Vice-Premier Zeng Peiyan, who was in charge of China's urban economic development, hailed the Jiang-Zhu leadership's major contribution to China to lead the country to realise the dual-target of doubling total GDP and GDP per capita based on the 1980 level (Zeng August 20, 2006).

\subsubsection{Passing-on Ideational Innovation: the 'Three Represents'}

The Jiang-Zhu leadership also carried on ideational innovation to legitimise their reform course in the 1990s and early 2000s. Under the Jiang-Zhu leadership, the institutional reforms and the hyper-growth created a mixed economy that significantly changed China's socio-economic structure. China started to become a more pluralistic 
society, with an emerging middle class made up of a growing group of elite entrepreneurs. The third generation of party-state leadership sensed an increasing tension between such reality and the CPC's communist/socialist nature. Following the 'ideational pragmatism' convention set by Deng Xiaoping, Jiang and his advisors developed a "Three Represents" concept to adapt to the emerging non-state socialeconomic dynamics after two decades of economic reforms. The formal statement, made by Jiang at the 16th CPC Congress in 2002, stipulated that the CPC is representative of advanced social productive forces, advanced culture, and the interests of the overwhelming majority. It aims to update the Communist Party from its old image of a vanguard of the proletariat, to an all-inclusive party with the pragmatic objective of economic development and national rejuvenation (Shambaugh 2008). Consequently, the "Three Represents" was written into the CPC constitution at the 16th Party Congress in 2002 and into the state constitution by amendment at the 10th NPC in 2004.

Although Jiang's 'ideational innovation' has been criticised as a political legacy project with the main purpose being to equate himself with former leaders Mao Zedong and Deng Xiaoping, the official endorsement of "Three Represents" profoundly influenced Chinese politics by reaffirming the legitimacy and effectiveness of the partystate leadership's ideational innovation. With the demise of communist ideology and the passing away of charismatic strong men such Mao and Deng, following generations of the CPC leadership have had to increasingly rely on theorisation and ideational innovation to adapt the $\mathrm{CPC}$ to changing social-economic environments, and to produce a coherent and overarching reform agenda to manage China's transformation, especially in the face of daunting challenges from within and without.

In sum, with Deng's ideational innovation that helped the Chinese party-state to break Mao's ideological constraints and set an overarching reform objective, the JiangZhu leadership further developed an institutional reform agenda and carried on the CPC's ideational innovation course. When Hu Jintao stepped up as the core of the fourth generation leadership in 2002, the CPC had largely been transformed from a 'revolutionary party' with Communist ideology to a ruling party with a pragmatic ideational system of reform and development. 


\subsection{Scientific Development: Hu-Wen Leadership's Updated Strategy in the 2000 s}

With the institutionalisation of the party-state leadership and the ideational innovation convention started from Deng and passed down on by Jiang, the fourth generation leaders were able to develop rather coherent reform ideas at an early stage of their tenure to guide both China's overall transition and specific social-economic policymaking during 2003-2012. The Hu Jintao-Wen Jiabao leadership's ideational system was characterised by the core concept of "Scientific Development" (kexue fazhan).

\subsubsection{Hu-Wen's Scientific Development Outlook in the 2000s}

\section{Reaching 'Harmonious Society' through 'Scientific Development'}

$\mathrm{Hu}$ and his colleagues' ideational innovation targets reorient China's reform path from a largely single-minded 'reform-to-growth' model to a 'Scientific Development' path emphasising "comprehensive, coordinated and sustainable" development (Chen 2011; Shambaugh 2008). In the early 2000s, after a decade of rapid growth under Jiang-Zhu leadership, the single-minded pursuit of economic growth and an achievement-based legitimacy began to be viewed as deficient in their moral and philosophical foundation, being overshadowed by social and economic problems including social injustice, regional disparities, and emerging environmental problems. The fourth generation leadership quickly realised that efficiency without equity was unsustainable. But in theory, instead of emulating a western model of a welfare state, they turned to a traditional Confucian idea of a Datong society with, social harmony as the defining characteristic (Guo 2013, pp.107-108).

Hu-Wen's "Harmonious Society" (hexie shehui) concept marks a shift away from the growth-at-all costs agenda of the Jiang-Zhu era (Shambaugh 2008). Hu's vision of a Socialist Harmonious Society first appeared at the 4th Plenary Session of the 16th Party Congress in September 2004 as one of the five aspects indicating the CPC's overall governing capacity. In 2005, Hu Jintao expounded upon this concept in a speech

delivered to the Central Party College. The 17th Party Congress quickly elevated this new concept and added this new tenet into the CPC's constitution in 2007. Nevertheless, 
some developments in the second half of the Hu-Wen administration 2007-2012 revealed a subtle waning of the concept in the Party and government policy discourse. The formal concept of Socialist Harmonious Society (shehui zhuyi hexie shehui) was systematically removed from the 12th FYP National Guideline and replaced by a rather common term of "social harmony" (shehui hexie), which is in stark contrast with the 2006 11th FYP guideline that dedicated the whole social policy chapter to elaborate the concept (NPC 2006; NPC 2011). Also, although the 17th Party Congress had already adopted the "Socialist Harmonious Society" and incorporated it into the Party constitution, it was only put as one of the CPC's five governing goals (Hu October 15, 2007; CPC News October 21, 2007). In contrast, it is the 'means' to achieve the harmonious society - the "Scientific Development Outlook" (kexue fazhan guan) that was elevated in parallel with Mao Zedong Thought, Deng Xiaoping Theory and Jiang's "Three Represents" in the Party Constitution amendment on the 18th Party Congress in 2012 (Hu November 18, 2012).

Such a change indicates, as an admirable but a relatively distant idea from China's reality, that the Socialist Harmonious Society concept is difficult to be achieved in short-to-medium term that can enshrine the Hu-Wen leadership along with their predecessors in the party and state history. Instead, as a more tangible and substantial economic development strategy, the Scientific Development Outlook eventually prevailed to become the cornerstone of Hu-Wen's ideational system.

\section{The Prevailing of Scientific Development}

The Scientific Development Outlook was raised by $\mathrm{Hu}$ at the very beginning of his tenure in 2003. Hu first stated his view on 'comprehensive development'. Later in the year, Hu further elaborated his theory on differentiating 'development' and 'growth' by putting forward a "comprehensive, coordinated and sustainable" (quanmian xietiao kechixu) development model. Hu stressed that,

We acknowledge that 'development' is the absolute priority of our Party's governance, but here 'development' is by no means limited to economic growth, it means whilst taking the economic construction as our central task, 
we must strive to achieve comprehensive development on the basis of growth (Party Literature Research Center 2005, p. 396).

In October 2003, Hu defined Scientific Development as representing a "comprehensive, coordinated and sustainable" development model (quanmian xietiao kechixu) at the Third Plenary Session of 16th Party Congress (Party Literature Research Center 2006, pp.60-61). With the Politburo's formal endorsement of the "Scientific Development Concept" at the end of 2003, Hu Jintao and Premier Wen Jiabao, along with the party's research institutions such as the Central Party College, systematically elaborated the Scientific Development concept in the following two years. Hu crystalized his perception of China's development problems and the alternative 'scientific development' in the early 2000s by making a series of important speeches (Party Literature Research Center 2006).

$\mathrm{Hu}$ and his colleagues theorise The Scientific Development Outlook as an economic engineering programme to manage the growing structural problem, which is summarised by $\mathrm{Hu}$ and Wen as an "unbalanced, uncoordinated and unsustainable" development path (Hu 2005, p.483). Such a growth model is believed predominately embedded in the conventional path of achieving growth by expanding scale of production, especially in the resource-energy-intensive heavy manufacturing industries, which is argued to be inherently against China's long term development interest during its transformation (Party Literature Research Center 2006, p.310). To transform such 'growth by quantity path' to a more efficient 'growth by quality' one requires an alternative development model. According to $\mathrm{Hu}$ and Wen, a key method to achieve the development model shift is to improve overall economic efficiency through structural adjustment. For instance, at a CPC Central Committee's Conference in 2005, Hu stressed that the economic structure issue is one of the biggest problems facing China's development at this stage. The Chinese state would suffer heavy and unrecoverable losses to allow the economy to continue growing rapidly with a distorted structure where the low-efficient and highly-polluting industries contribute a major share of growth. Hu commented that "the fundamental solution would be profound adjustment 
to the existing economic structure by fully adopting the 'Scientific Development Outlook', and to transfer to a new model of economic development" (Hu March 12, 2005). Later, on various occasions before and during the drafting of the 11th FYP in 2005-06, Hu and Wen put economic structure adjustment as a central idea of the Scientific Development Concept (Party Literature Research Center 2006).

\subsubsection{Scientific Development: Development Model and Economic Structure}

Some core ideas of the Scientific Development Outlook, such as the stress on economic structure and efficiency, had actually appeared since the commencement of China's transformation in the early 1980s. But the difference made by $\mathrm{Hu}$ and Wen was that they structure those ideas into a coherent and clearly-articulated ideational system and actually used the system to guide China's economic policymaking during their tenure.

\section{From growth to development: altering China's development model}

The Party-state leadership's concern about China's development model first emerged in the emphasis on industrial efficiency during the sixth and seventh FYPs (1981-1990). In the 1980s, the Chinese economy was predominately state-owned and was characterised by the large share of heavy industries such as mining, metallurgy, and chemicals. To cope with the rampant resource waste that plagued the SOEs' operation at the time, the sixth FYP was made with a central objective of promoting the efficiency of SOEs by upgrading industrial technology and improving management mechanism, which is also a part of early industrial reform experiment. Premier Zhao Ziyang suggested in 1985 that 'energy consumption for per unit of industrial product' should be adopted as a key economic indicator to assess SOEs' industrial efficiency (Zhao 1982; Zhao 1985). In 1995, Premier Li Peng framed industrial efficiency improvement as the primary means to "transform [China's] economic growth from a mass production-based model (cufang xing) to a conservation-oriented model (jiyue xing)" (Li 1995). In 2000, Zhu Rongji also raised the issue of "improving economic efficiency through strategic adjustment of economic structure". He argued that the 
Party central's vision of 'strategic adjustment of economic structure' was to upgrade the quality of three economic sectors (primary/agricultural sector, secondary/industrial sector, and tertiary/service sector) with a focus on optimising the industrial structure by reducing the share of resource-intensive industries and promoting the share of technology-intensive industries (Zhu 2000).

Nevertheless, the previous conceptualisations were either shattered by political instability in the late 1980s or marginalised by 'reform-to-growth' in the 1990s. The economic structure adjustment ambition was largely only an ideal picture of China's optimal development model, with the daunting task of domestic institutional reforms and the challenge from external shocks such as the Asian Financial Crisis 1997-1998.

Unlike the previous leaderships, the Hu-Wen leadership took the structural challenges seriously from the early 2000 s by theorising and integrating the Scientific Development Outlook into policy making. An assessment of the economic policy guidelines, macro-economic objectives and specific policy priorities set by the Annual Central Economic Working Conference (ACEWC) (zhongyang jingji gongzuo huiyi) clearly demonstrates China's evolving priorities of overall economic policy from 1993 to $2012 .{ }^{30}$ As showed in Table 1 on the next page, Hu-Wen's "Scientific Development Outlook" provided a distinctive revision and departure from Jiang-Zhu's reform-togrowth agenda. Through the intense ideational innovation efforts at the first three years of their tenure, $\mathrm{Hu}$ and Wen successfully reoriented China's economic policy agenda from 'growth' to 'development'. By 2005 when the 11th FYP was drafted, the Scientific Development Outlook had grown to become a fully-fledged ideational system to guide policymaking in the following decade.

\footnotetext{
${ }^{30}$ The ACEWC is China's highest level of annual economic policy working conference. It has been jointly sponsored by the CPC Central Committee and the State Council in December of every year since 1992. According to the People's Daily website, the central objective of this event is to summarize the past year's economic work and to plan the central government's work in the coming year based on the economic policy in the current FYP and the changing domestic and international economic situations. See People's Daily (2012).
} 
Table 1 Overview of China's Macro-Economic Objectives 1993-2011

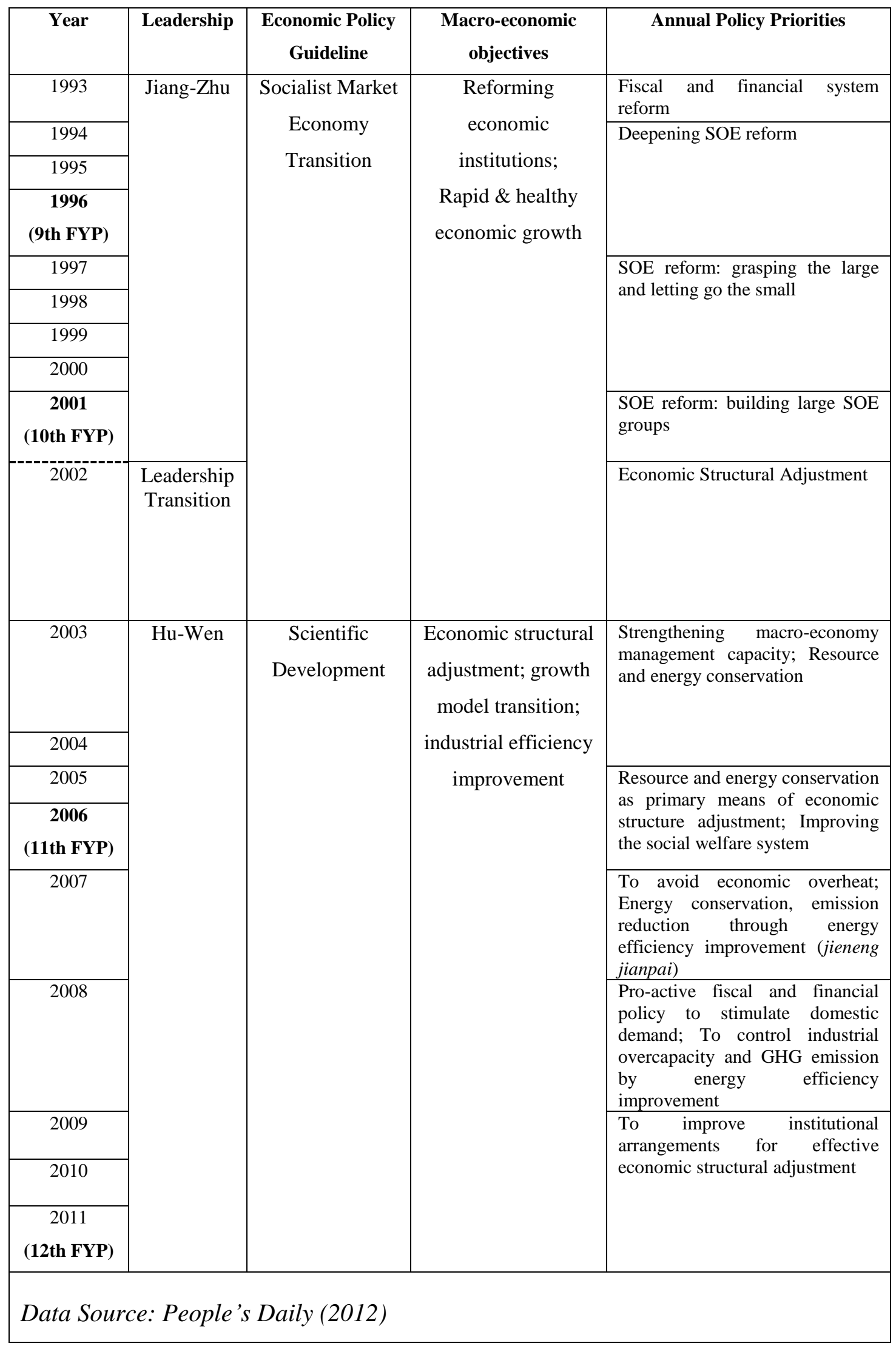


The focus of economic structure and the role of energy efficiency

In the Scientific Development concept that aims to adjust the economic structure, energy efficiency is regarded as a key indicator. As analysed in Chapter Two, one of the most striking characteristics of the Chinese economy in the early 2000s was the weight of energy-intensive heavy industries, which consume large amounts of energy and raw material but contributed only limited added-value compared to other sectors such as the light industries, high-technology-based manufacturing and service industries. Between 2000 and 2004, industrial output accounted for 62 percent of China's annual GDP growth. In contrast, the service sector contributed 30 percent and agriculture only 8 percent (NBS 2005). As many scholars have discovered, although the absolute industrial energy intensity in China has kept declining since the early 1980s, the whole Chinese economy was increasingly shifting away from light industries such as garment manufacturing, towards heavy industries such as metallurgy, making the whole economy less efficient in terms of resource and energy use per unit of GDP created (Andrews-Speed 2009; Price and Wang 2007; Rosen and Houser 2007; Zhao et al. 2010).

Under such circumstances, whether the Hu-Wen administration could transfer the Scientific Development Outlook into substantial policies to effectively govern China's energy efficiency became a major test of their leadership. As Ma Kai, the founding Director of the State Council's NDRC, stressed, "energy efficiency and GHG emission reduction (jieneng jianpai) becomes the breaking point to adjust economic structure and to alter the economic growth model" (Xinhua News Agency December 14, 2006).

\subsection{Turning Ideas into FYPs - Evolving Policymaking Actors and Process at the National Level}

From the beginning of China's 'deep reform' in the 1990s to the present day of 2010s, walking hand in hand with the Party-State leadership's ideational innovations has been their growing capability to integrate ideational systems into China's socio-economic policymaking, especially the Five Year-Plan/Programme. China's economic reform and development policymaking has been increasingly guided and coordinated by the top 
party-state leadership. This has been achieved mainly through adjustments on two aspects of China's policymaking at the national level: streamlining of central government policy bureaucracies, and top leadership's effective control over policy agenda setting.

\subsubsection{Streamlining Central Government Policy Bureaucracies}

As a highly centralised country with vast territory and the world's largest population, the central government has played a crucial role in state building and governance since the imperial dynasties and republic era. As the PRC was founded in 1949, the building of a massive and complicated central government went hand in hand with the establishment of a Soviet style centrally-planned economy. Although in the Maoist era, most central state and party bureaucracies were systematically paralysed and abolished during the Great Leap Forward and the later Cultural Revolution, they were restored quickly when the economy recovered under Deng's leadership. The number of government agencies reached its peak in China by the end of 1981. There were a total of 100 agencies at the central government. These included 52 ministries and 43 ministry or bureau ranked agencies directly attached to the State Council (Burns and Zhou 2010, p.4). During the early reform era of the 1980s and early 1990s, the national policymaking problems caused by incongruence between a complicated bureaucracy structure and an increasingly market-based economy was accurately captured by a group of China scholars to develop the classic "fragmented authoritarianism" [FA] model of Chinese policymaking.

In order to keep pace with the changing socio-economic reality and to improve the effectiveness and efficiency of governance, past generations of Chinese leadership have initiated several rounds of central government restructuring to streamline the massive central government bureaucracies and to reform their functions from businessowner and industry-administrator to market regulator and macro-economic controller. From the early 1980s to the mid-1990s, there were three rounds of central government restructuring, which took place in 1982, 1988 and 1993. However, the restructuring only produced a "trapped cycle" that saw the State Council departments go back to 
their original scale not long after each restructure (Kong 2005). For example, in the five years from 1993 to 1998, the State Council departments (guowuyuan gongzuo bumen, including ministries and sub-ministerial ranked departments that directly report to the State Council) grew quickly from 59 to 72 ; the number of central government employees exceeded that of the pre-1993 reform. This is largely because of the persistence of economic planning and industrial administration functions of the State Council's commissions and ministries. As long as economic commissions and industrial 'line ministries' still directly oversee a large number of SOEs, real streamlining is difficult to be achieved. However, when Zhu Rongji became Premier in 1998, real change began to take place in the central government. Thanks to the socialist market economy objective and the subsequent 'grasping the large and letting go the small' themed SOE reform, hundreds of large SOEs that used to be managed by the State Council's commissions and ministries were either delegated to local government or privatised (see Chapter 4 for details). Such divestiture of industrial administration functions from central government bureaucracies paved the way for a new round of streamlining in 1998.

Zhu Rongji's restructuring programme in 1998 aimed to transition the Chinese central government's function from commanding and administration to macroeconomic governance. Zhu reduced the number of central government ministries from 40 to 29 and total state council departments from 72 to 53 , with staff size trimmed by nearly half. The heaviest axe of the restructuring fell on the industrial line ministries that had been the backbone of the planning system (Yang 2004, p.37). Many industrial ministries, especially those concerned with energy and heavy manufacturing that used to oversee a large number of SOEs and controlled the bulk of the Chinese economy, were abolished, downgraded or corporatized into SOEs. For example, the Ministry of Electric Power surrendered its regulatory powers to the State Development Planning Commission and became the State Power Corporation. The Ministries of Coal Industry, Machine Building, Metallurgical Industry, Internal Trade, and Forestry, as well as the National Councils of Light Industry and Textile Industry, were streamlined and downgraded to become state bureaus (guojia ju, sub-ministerial state council 
department) under the supervision of the State Economic and Trade Commission (SETC) in 1998. By early 2001, eight of these state administrations under the SETC had been completed abolished, with their functions absorbed into SETC (Yang 2004, p.37). Streamlining and downsizing also occurred within the remaining ministries, and the number of internal departments in ministries decreased by more than 200. Much of the streamlining and reintegration was aimed at promoting the unity of administrative authority and curbing the bureaucratic fragmentation that China scholars have long noted (Zhang 2004, p.102).

As many State Council departments lost their independent turfs in the 1998 reforms, the bureaucratic line-up of the Chinese government became much like those found in other East Asian economies. The State Planning Commission, renamed as the State Development Planning Commission (SDPC), retained its functions in heavily regulated areas such as energy and grain but shifted its main duty to that of forecasting the medium and long-term macro-economy situation. Much of the day-to-day macroeconomic steering, including industrial policy implementation and regulation of investments in technical renovation projects, was housed in the powerful State SETC. The SETC and SDPC were joined by the Ministry of Finance and the People's Bank of China as the central institutions of economic governance (Yang 2004, p.40). This bureaucratic line-up was matched by the transformation in economic philosophy marked by the "socialist market economy" idea. As the State Councillor Luo Gan enunciated in his report to the National People's Congress on the 1998 restructure, the main duties of government agencies such as the SETC and SDPC should be focused on maintaining macro-economic balance, curbing inflation, and optimising the economic structure, instead of economic planning and commanding (Yang 2004, p.41).

In spring 2003, with Wen Jiaobao succeeding Zhu Rongji as the State Premier, Wen announced a new round of streamlining. Again the bulk of the changes were about economic policy bureaucracies. Building on the 1998 reform plan and the reforms that had been taken from 1998 to 2002, the 2003 plan was more about rationalising and fine tuning than about downsizing (Yang 2004, p.61). The focus of the 2003 restructure was 
to reduce institutional conflicts of interests, blurred responsibilities, and to improve bureaucratic coherence. The most significant part of the 2003 restructure was the dismemberment of the once powerful SETC, and the subsequently strengthened SDPC (later adapted into the National Development and Reform Commission, NDRC). In the 2003 restructure, the SETC's industrial policy and regulatory functions were handed over to the NDRC, and its domestic trade regulatory function was incorporated into the Ministry of Foreign Trade and Economic Cooperation (MOFTEC) to build a new Ministry of Commerce (MOC). Meanwhile, the remnant of the former State Economic System Reform Commission (SESRC), which had in 1998 been downgraded to a modest office under the State Council, was merged into the NDRC, making China's economic transition an integral part of macroeconomic policymaking and implementation (Yang 2004, p.62). The disappearance of the SETC and the takeover of its economic policymaking functions by the NDRC made the latter a powerful department, much like Japan's MITI (now METI), playing an important role in promoting the coherence of national economic policymaking and implementation.

Besides streamlining and fine tuning, the 2003 restructure also marks the rise of another powerful economic bureaucracy - the State Assets Supervision and Administration Commission (SASAC). While most of the SETC power transferred to NDRC, the state enterprises owned by the SETC were transferred to SASAC. The SASAC is ministerial-ranked and it reports directly to the State Premier. As a massive institutional device to 'own' and govern a group of elite central government-owned enterprises (yangqi), which are the largest and most profitable among China's thousands of SOEs, SASAC became a powerful instrument to strengthen the top leadership's control over state-owned industrial sectors. Also merged into the SASAC were a part of the Ministry of Finance that acted as de facto equity owner and had power to register and approve equity transactions, such as mergers, as well as the former Central Enterprise Work Committee, which oversaw the appointment of top managers and supervisory boards in large central SOEs (Yang 2004; Naughton 2008). Hence, with the SASAC looking after the yangqi fleet, the NDRC became more even- 
handed in its policymaking and regulatory functions and its capacity to formulate policies and strategies with the entire economy in mind.

The 2003 restructure was followed by two smaller scale restructures in 2008 and 2013, seeking to consolidate the result of the 2003 restructure. As a result, the Chinese central government in the 2000s has largely been changed from a 'bureaucratic labyrinth' (Lieberthal and Oksenberg 1988), comprised by a large number of equallyranked economic planning bureaucracies with often overlapping responsibilities and conflict of interests, into a set of increasingly well-coordinated 'hierarchical' policy institutions. As Bell and Feng (2013, p.115) find, "the horizontal bargaining that characterised the fragmented authoritarianism has been declining and a hierarchical policy system emerged in Chinese central government in the 2000s". Behind the rounds of central government restructuring has been the growing power of the top party-state leadership. Unlike the assumption of a passive, re-active leadership in the bureaucratic politics model, the new generation of top leadership plays a vital role in this new hierarchical structure of policymaking by asserting their ideational system to guide and coordinate the state's major socio-economic policymaking in the 2000s.

\subsubsection{Top Party-State Leadership's Increasing Control over Policymaking}

Along with the consolidation of governance authority structure came an improved policymaking process, which enabled the party-state leadership to transfer their ideational innovations into substantive socio-economic policies. According to the classic FA theory of Chinese politics, the top leadership was preoccupied with administrative and policy disputes among central government policy bureaucracies. The role of top leadership was more of passive dispute arbitrator and policy broker than decision-maker (Lieberthal and Oksenberg 1988). Indeed, during the planned economy era and at an early stage of reform in the 1980s, policy decision-making tended to be plagued by delays and inefficiency, while the agenda of top party-state leaders was overloaded with what would have been trivial matters in a market-based economy (Yang 2004, p.29). Streamlining of central policy bureaucracies in the late 1990s and early 2000s significantly changed central government policy structures and processes. 
The top leadership was able to tighten its grip on the national economic policy agenda setting and effectively turn their ideas into systematic and substantial economic policies. As Naughton (2005) notes, the making of the 11th FYP started to feature "a controlled consultation process" under the Hu-Wen leadership, so that "...the authoritarian aspects of the system are stronger today than they were in the 1980s."

\section{Policymaking in the 1980 s and 1990 s}

As the most important socio-economic policy system of contemporary China, the making of the FYP has long been characterised by intense bargaining between a variety of political actors, including formal policymakers such as party Politburo members, ministers, and key stakeholders, such as top managers from major SOEs. As Saich (2004, p.76) notes, "the fixing of FYPs are always times of tense debate in China. Once a document that will dictate policy for the coming five years has to be written down, it becomes more difficult to paper over the cracks within the government." Influential Chinese scholars like Yan Yilong, Wang Shaoguang and $\mathrm{Hu}$ Angang demonstrate how the national policymaking model has experienced several different models between the 1950s and 1990s (Yan et al. 2013). During the 1960s and 1970s, decision making on the development priorities and targets of the second, third and Fourth FYPs, from 1958 to 1975, were largely subject to Mao's personal preferences under a "Dictatorial Decision Making Model". This model was largely responsible for the economic disasters of the Great Leap Forward and later the economic chaos caused by the Cultural Revolution (Yan et al. 2013). When Deng gradually took over the leadership from Mao's hand-picked successor Hua Guofeng in the late 1970s, national economic policymaking was largely restored to an "Intra-Government Collective Consultation Model", similar to the first FYP in 1953. Under such a model, policymaking was heavily influenced by planning agencies and a large number of ministries.

From the 7th FYP made in 1985/1986 - the first Five-Year Plan made in the reform era - to the 9th FYP made in 1995/1996, each FYP was largely made under an Intra-Government Collective Consultation Model similar to the core tenets summarised by the FA theory. According to the State Planning Commission's FYP drafting guideline published in 1991, the drafting of national FYP was primarily coordinated by the State Planning Commission under the State Council. Due to the fragmentation of 
economic governance and regulatory power, the SPC had to rely on other central planning agencies such as SETC, and a large number of central line ministries or state council departments to formulate specific plans and targets within their own areas of economic governance (Li 1991). Prior to the drafting of a National FYP Guideline, the SPC will publish the basic guidelines and macro-economic targets for the next five years to let industrial line ministries and provincial governments to assess and comment. Once receiving feedback, the SPC would process these data and work towards drafting a comprehensive national FYP. During the drafting process, the SPC will repeatedly “consult and negotiate with due departments and local governments" (Li 1991, p.37) to reach consensus between the leadership's ideas, the specific industrial/regional plans and targets proposed by a variety of different departments and provinces, as well as the macro-economic targets set by the SPC itself. Once consensus was reached and a FYP draft completed, the SPC will submit the draft to the State Council for review. Then the State Council Premier will introduce the draft to the CPC Central Committee at its plenary session at the end of the year to formulate the CPC central's "suggestions" and bring the revised draft to the next year's NPC session for approval (Li 1991, p.37). Once approved, the FYP draft becomes national policy to be implemented by ministries, SOEs and local governments in the next five years. ${ }^{31}$

Although in formal policy process the top leadership holds the power to review and revise the draft, such power was rarely used to significantly influence the FYP making process in the 1980s and early 1990s, largely due to the lack of an overarching reform objective and strategy as well as the absence of independent 'in-house' policy research institutes that could directly advise the top leadership without being subject to bureaucratic interests and bias. Under the planned economy, policy research institutes were mostly housed in central government policy bureaucracies, and largely made policy proposals based on the interests of their home bureaucracy. National level macro-economic research institutes existed only in planning agencies such as SPC and SETC, but with only limited research capacity (Zhu 2013). In 1992-1993, the SDPC was comprised of 32 departments; among them were only 8 research institutes, with limited staff specialised in areas such as macro-economy, investment, energy,

\footnotetext{
${ }^{31}$ For detailed analyses on China's FYP making process in the 1980s and 1990s, see Song and Li (1991) and Li (1991).
} 
transportation, and land resources (Xinhua News Agency 1992). In such circumstances, the fragmented authority structure and consensus building policy process made the FYPs little more than the sum of various bureaucratic and departmental interests.

Policymaking in the 2000s

The large central government restructurings in 1998 and 2002, and the improved policy process that characterised the making of the 11th and 12th FYPs in 2005/2006 and 2010/2011, meant that the national economic policymaking process was significantly changed to allow for increasing influence of the top leadership over both the general policy agenda and the setting of specific economic policies. Chapter 48 of the 11th FYP guideline, published in 2006, specifically promulgates the FYP making process, marking the formal establishment of China's hierarchical policymaking structure at the national level (NPC 2006).

According to Chapter 48 of the 11th National FYP Guideline, the new National FYP Guideline process is comprised of six stages, with party-state leadership playing a decisive role in setting the national policy agenda and policy priorities in key areas of reforms and development. The first step is a mid-term review on the implementation of the previous FYP. The NDRC authorises research institutes such as Centre for China Studies of Tsinghua University, the Development Research Centre (DRC) of the State Council and the World Bank Office in Beijing to conduct the review. Following the mid-term review of the previous FYP, the NDRC identified key areas and issues to be researched in-depth before drafting the next FYP. The organizations and experts involved in the research were selected through a bidding process by calling for tenders organised by the NDRC. For example, as many as 56 research institutes won the bidding for key policy research in dozens of areas of the 11th FYP in 2003 (NDRC December 2, 2003). In 2008, the scale of policy research for the making of the 12th FYP doubled to more than a hundred external research institutes (Hu March 6, 2011). Based on reports produced by those institutes, the NDRC then works to create the first draft of a 'basic policy initiatives' (jiben silu), which is submitted directly to the CPC Central Committee and the State Council. The Politburo Standing Committee will then deliberate to determine the policy priorities over the next five years. A FYP Drafting Small Group, headed by the State Council Premier and including members from the 
State Council's Development Research Centre (DRC) and the NDRC, works to create a formal policy 'outline' (ti'gang) based on the leadership's decisions and to formulate a 'draft of policy recommendations' (jianyi gao). During the annual CPC plenum meeting prior to the next General Assembly of the National People's Congress (NPC), the CPC Central Committee will issue a formal document titled "The CPC Centre's Policy Recommendations to the Making of Five Year Programme", presented by the State Council Premier, who is also a key member of the Politburo Standing Committee. During the Party plenum, the draft was discussed further and more opinions for revision were collected from senior Party officials. The feedback is then passed on to the NDRC to produce a final draft of the National FYP Guideline. The State Premier will then introduce the final draft on behalf of the State Council to the 3000-plus representatives at the NPC's General Assembly held every five years. Once the final draft is approved (usually with only minor revisions) by voting in the General Assembly, it is officially titled as The National Five-Year Programme Guideline of Socio-Economic Development and becomes a national policy (Hu March 6, 2011; Moffat July 10, 2014; NPC 2006).

The highlight of this new policymaking process is the greater influence of the party-state leadership on policy agenda setting, with the assistance of in-house research institutes like the DRC, and the bureaucratic champions like the NDRC which emerged out of the central government restructurings. During the making of the 11th and 12th FYPs, the Hu-Wen leadership took advantage of their power to suggest and revise the FYP drafts to systematically integrate the Scientific Development Outlook into the FYPs and China's annual macro-economic policy agenda setting on the ACEWCs (see Table 1 on page 70 and Table 2 on the following page). Meanwhile, with the assistance of both in-house and external independent research institutes, the party-state leadership is able to advance their preferred policy priorities from the beginning of the FYP drafting process and to oversee those targets to be operationalised by research institutes. In other words, the party-state leadership is now capable of controlling both the overall policy agenda setting and the formulation of substantive policies, especially in key areas of economic policy such as energy policy. 


\section{Table 2 Formulation and Implementation of Energy Efficiency Target Responsibility System in the 11th FYP}

\begin{tabular}{|c|c|c|c|}
\hline Time Line & Policy Actor & Policy Document & Objective/Measure \\
\hline \multirow[t]{2}{*}{2005 Oct } & CPC Central Committee & The CPC Centre's Policy & To cut energy intensity \\
\hline & & Recommendations to the 11th FYP & by $20 \%$ by 2010 \\
\hline \multirow[t]{3}{*}{$2005 \mathrm{Dec}$} & State Council; NDRC; & Proposal on Establishing Energy & Operationalization of \\
\hline & DRC; external research & Intensity Evaluation System & national energy \\
\hline & institutes & & intensity target \\
\hline \multirow[t]{3}{*}{2006 Mar } & State Council; NPC & The $11^{\text {th }}$ National FYP Guideline & Formal adoption of the \\
\hline & General Assembly & & $20 \%$ energy intensity \\
\hline & & & target \\
\hline \multirow[t]{4}{*}{2006 July } & NDRC (authorized by & Signing Energy Efficiency Agreement & Decentralized policy \\
\hline & State Council) & with China's 30 provincial & implementation at local \\
\hline & & governments $\& 14$ centrally-owned & government and major \\
\hline & & enterprises & yangqi \\
\hline
\end{tabular}

Adapted from Ma et al. $(2012, p 4)$

\section{Chapter Summary}

Differing from the exogenous view under the Rational Policymaking Model and the static view with a Bureaucratic Politics Model, this chapter finds that China's policymaking in the late 1990s and 2000s has been characterised by the top party-state leadership's tightening control over central government policy bureaucracies to advance their ideational systems of reform and development. On the one hand, ideational systems developed by the top party-state leadership have been increasingly important to define key national policy objectives and priorities. On the other hand, core ideas in the two ideational systems developed by the recent generations of leadership have differed markedly, making China's ideational-based policymaking a dynamic process.

These findings provide an important update to China's policymaking mechanism and offer new insights to factors and forces that have induced the policy change beyond 
the conventional views. With the ideational dynamism of national policymaking, more emphasis on energy efficiency is firstly a consequence of the country's overall development strategy reorientation. However, as analysed in Chapter Two, what makes China's energy policy change special is the move-up of energy efficiency targets over the energy security concern on the national policy agenda. In other words, while an updated ideational system could direct more emphasis on energy efficiency targets, it does not necessarily come at the cost of the de-prioritisation of the energy security objective, especially at a time when the country's energy security seems in trouble. Therefore, it is necessary to further examine both sides of the policy change to capture the underlying political-economic forces that led to the cross-sectoral policy priority shift.

In the Historical Institutionalism approach of policy studies, a major way to account for the dynamics of policy change has been by tracing the asymmetrical power relations between major policy actors and by examining the impact of long term institutional legacies for policymaking. In the case of China, when political actors on the national level monopolize policymaking power and are prone to develop new ideational systems, there is a strong probability that the specific pattern of policy change is driven by a mismatch between evolving ideational systems and the persistence of certain interest-seeking behaviour among political actors embedded in lower level institutions. Thus, in the following chapters, the study will move on to investigate the power relations between China's major energy-based industrial value chains and major subnational political actors mainly on the provincial level, in order to examine whether an idea-interest 'mismatch' exists. 


\section{Chapter Four: Institutional Reforms and an Imbalanced Structure of Industrial Development}

This chapter provides analysis of the 1990s institutional reforms under the Jiang-Zhu leadership and how it crafted an imbalanced structure of industrial development through shaping asymmetrical state-industry power relations at national and subnational levels. Section 4.1 examines the State-Owned Enterprise (SOE) as a fundamental institution to organise China's industrial economy. This section first provides an overview of China's SOE reform with a focus on the "grasping the large and letting go the small" (zhuada fangxiao) strategy in the mid-1990s and the subsequent creation of a fleet of centrally-controlled SOEs (yangqi) in some 'strategic sectors' of the economy. The vital role of oil and petrochemical yangqi in China's "grasping the large" strategy is a focus. Section 4.2 highlights China's central-local relations as the other fundamental institution to organise China's decentralised economic growth during the transition era. This section first examines how the reform of the central-local fiscal system, along with heated political promotion competition, provided incentives and the imperative to local government to create revenue through local economic growth following the introduction of the 1994 fiscal reform. Then in Section 4.3, the study looks into why and how the long term effect of the two reforms in the 1990s produced the unintended consequence of encouraging and empowering a decentralised heavyindustrialisation by building local governments' strong institutional connections to major coal-based and energy-intensive industries. The chapter overall illustrates how the differential SOE reform created an imbalanced structure of industrial development where some national interests were effectively managed by centrally-controlled industries, but the realisation of other national objectives were significantly hindered by local governments' interest-seeking behaviour shaped by the reformed central-local relations. 


\subsection{SOE Reform and Central Government Control over 'Strategic Sectors'}

Studies on China's state sector reform generally agree that reform on the urban industrial SOEs since the early 1980s can be divided into two phases based on different strategies adopted. The first phase of reform from the early 1980s to the mid-1990s. SOE reform in this phase was characterised by expanding individual enterprise's autonomy and the introduction of market mechanisms to improve state sector efficiency. From the mid-1990s, reform entered a new phase of 'grasping the large and letting go the small'. Chinese central government restructured the core assets of its massive SOE fleet and created an elite group of yangqi (centrally-controlled SOEs) in certain areas that are considered as strategic and highly profitable. The central government could effectively control these sectors through powerful agencies such as the State Council's SASAC.

\subsubsection{China's SOE-based Industrial Sector and Early Reforms}

\section{Building industry with SOEs}

Following the establishment of the People's Republic of China (PRC) in 1949, the Chinese government inherited a war-torn agrarian economy in which 89 percent of the population resided in rural areas and the industrial sector contributed only 13 percent to the national income (Lin and Tsai 2004, p.341). With the example of the Soviet industrialisation and the international embargo and isolation since the 1950s, the clear choice for the country to safeguard national security was a Soviet-style industrialisation strategy supported by a highly centralised command economy (or a 'centrally-planned economy'). The new communist leadership headed by Mao was determined to concentrate the country's limited resources on the heavy-industrial sectors producing energy, metallurgy, chemicals and machinery (Naughton 2007, p.55). Between the 1950s and 1970s, China pursued a development strategy giving overwhelming priority to channelling the maximum feasible investment into heavy industries. ${ }^{32}$ Such industrial ambition naturally requires an institution of state-owned industrial enterprises as the

\footnotetext{
${ }^{32}$ For example, Li Fuchun, Vice-Premier and head of the State Planning Commission (SPC), stressed in the report on the first FYP in 1953 that "socialist industrialisation is the primary task of our country in the transitional period. The key component of socialist industrialisation is to give priority to the development of heavy industries." See Lin et al. (2003, p.36).
} 
basic micro-economic actor to support a command economy and state-led industrialisation path (Lin and Tsai 2004).

Therefore, from the early 1950s the CPC began to systematically transfer the country's private industries into state ownership, initiating the construction of a large number of new industrial projects. Collectively-owned rural agricultural production cooperatives and urban handicraft business cooperatives were also established in the 1950s to provide food and capital for the country's rapid industrialisation. With the aid from the Soviet Union, the first FYP (1953-1957) focused on the construction of 156 key industrial projects and another 694 important projects, which would lay the foundation for China's industrialisation in the following decades (Lin et al. 2003, p.36). The Chinese economy started to feature total state-ownership in major industrial sectors. Most SOEs were directly administered by the central government's economic commissions and ministries, especially those large enterprises in heavy-industrial sectors such as defence, energy, metallurgy, heavy-chemical and machinery. ${ }^{33}$ These SOEs represented the bulk of the economy in terms of revenue, output and employment. At the subnational level, the local governments also established and controlled a considerable number of SOEs. However, these local SOEs tended to be medium or small-sized enterprises in sectors and industries that were not vital to the whole economy (Naughton 1995).

The distribution of industrial SOE ownership and administration between the central government and local government is often referred to as the "tiao-kuai" (lineblock) relations, which determine the fundamental institutional connections between the government and the industry at national and subnational level. Tiao (line) represents the central government's vertical control over SOEs through the State Council's economic planning commissions and industrial ministries. Kuai (block) refers to local governments' control over SOEs (Tang 1983). China's industrial institutions during the planning era were characterised by constant adjustments between the tiao-kuai in search of equilibrium between central control and local autonomy over the development

\footnotetext{
${ }^{33}$ These SOEs are often referred to as 'the central state-owned', or 'centrally-controlled enterprises', zhongyang guoqi, or yangqi in short. Those SOEs owned by the local government down from provincial level are referred to as the 'local state-owned' or 'the locally-controlled enterprises', defang guoqi, or diqi in short.
} 
of China's industrial economy. ${ }^{34}$ Between 1950 s and early 1980s, the central government's vertical control of major industrial SOEs prevailed most of the time. This was largely determined by the nature of the centrally-planned economy, in which the central government maintained control over the general direction of local development and imposed blanket controls over the whole economy (Naughton 1995, p.43). The local government had either political incentives or fiscal conditions on the development of their local industries. For example, as will be analysed later, China's central-local intergovernmental fiscal system during the planned economy featured "unified revenue and unified expenditure" (tongshou tongzhi). Under such a fiscal system, SOEs were the main source of state revenue and therefore an integral part of state budgeting. ${ }^{35}$ Most SOE financing needs were covered by the central government, and profits and losses were directly included in the central government budget.

After nearly three decades of development, SOEs were at the heart of stateowned industry institution and the Chinese economy just before China's reform in the late 1970s. In 1978, SOEs represented 77 percent of overall industrial production. SOEs accounted for 76 percent of gross industrial output and 57 percent of industrial employment. SOEs' profit remittance was 57.2 billion RMB, accounting for $50.5 \%$ of total government revenue (OECD 2009; Li and Putterman 2008). From central to provincial level, government imposed strict personnel and operational control over the SOEs they respectively supervised. SOEs were assigned responsibility for meeting specific output targets with an agreed number of employees and payroll, and with assigned allocations of raw materials, energy, capital goods and other intermediate inputs from state planning. Individual enterprises and their manager's performance were not judged by profitability, but by the capability to fulfil their assigned roles (Li and Putterman 2008).

\footnotetext{
${ }^{34}$ There were two rounds of SOE decentralisation and delegation during the Great Leap Forward and Cultural Revolution which saw hundreds of SOEs delegated from central government to local governments. However, decentralisation-delegations were often followed by SOE re-centralisation due to the economic chaos created by an over-decentralised and fragmented industrial economy. See Naughton (1995) and Huang (1996).

${ }^{35}$ Due to the negligible role of non-state business, the SOEs' profit remittance to the government was the major source of state revenue in the planned economy. Before 1984, Chinese SOEs had to remit all the profits to the state with no more that 10 percent returned as reward funds. See Chen (2009).
} 
At the outset of economic reform in the early 1980s, most Chinese SOEs functioned as passive agents of the central planning agencies and the industrial line ministries they subordinated (Jefferson and Rawski 1994). This system was proved to be inefficient and unsustainable in the late 1970s. SOEs' role as production unit in a command economy determine its low long-term efficiency compared to market-based economic actors in the long term. It was a consensus among the second generation of reformist leadership headed by Deng that urban industrial institutions must be reformed following the successful experiments on the rural agricultural sector (Lin et al., 2004).

The SOE reform started from expanding enterprise autonomy (Naughton 1995, p.99). During the famous third Plenum of the 11th Central Committee in 1978, Deng called for relaxation of the state's control over SOEs. Between 1979 and 1984, a series of mandates and regulations were issued by the central government to grant more autonomy to the SOEs. In 1982, an "industrial production responsibility system" (or 'industrial production contracting') that draws on the successful experience of the rural "household responsibility system" were implemented to cover 80 percent of industrial SOEs nation-wide. In 1984, at the third plenum of the 12th CPC Central Committee, the party-state leadership decided to establish a "dual-track pricing" system to further reform the planned economy towards a market-influenced one. Enterprises were encouraged to sell above-plan output and to obtain out-of-plan inputs in market-type transactions at unregulated prices: hence the enterprises' production decisions would be responding to market forces (Naughton 1995). In the following decade, the share of SOEs' activity based on plan targets and input provision kept declining, and the share based on autonomous decision making and market prices kept steadily increasing. Also, in 1983 and 1984, SOEs' profit remittance to the state was changed to Enterprise Income Tax (EIT). All of these reforms in the early 1980s helped to grant SOE managers increasing autonomy to determine the enterprises' operation and development strategy (Li and Putterman 2008).

Two factors which emerged in the mid-1990s required further changes to fundamentally reform the SOE institution rather than introducing limited market incentives as had previously been the case. The first was the CPC's adoption of the Socialist Market Economy objective. The second was the declining profitability and 
growing debts of SOEs. Chinese SOEs were facing increasing financial difficulty from the late 1980s. The proliferation of more competitive non-state firms, ranging from rural collective firms to emerging private business and foreign enterprises, brought intense competition in many industrial sectors. Because of their greater exposure to market forces, greater flexibility and general hard-budget constraints, the non-state economy performed significantly better than the majority of SOEs in terms of profitability and efficiency. In contrast, the majority of SOEs in the early-to-mid 1990s were struggling to survive with state subsidies (Naughton 2007). For instance, Chinese SOEs had after-tax profits of 40.2 billion RMB in 1991, but the loss-makers collectively lost 36.7 billion RMB, making the net profit only 5.3 billion yuan, not accounting for government subsidies (Tao and Yang 2008). Hence, the huge number of soft-budget-constrained SOEs became an increasing heavy fiscal burden to the state (Garnaut et al. 2006).

\subsection{2 "Grasping the large" and the Formation of Centrally-Controlled SOE Fleet}

In 1995, the Jiang-Zhu leadership pushed SOE reform forward by adopting a "grasping the large, let go of the small" (zhuada fangxiao) strategy. ${ }^{36}$ As analysed in Section Two of Chapter Three, 'Grasping the large' meant that a small number of large-SOEs in industries at the commanding heights of the national economy must be restructured and controlled by the state. ${ }^{37}$ 'Let go of the small' meant to encourage governments from the central to local to 'dispose of' the loss-making SOEs that were not in the vital areas of the national economy through downward delegation, ownership diversification or complete privatisation (Garnaut et al. 2006).

As a result of "let go of the small", between 1995 and 2000 some 82 percent of a total of 59,410 SOEs nation-wide, which together accounted for about 33 percent of

\footnotetext{
${ }^{36}$ In 1994, the State Economic and Trade Commission (SETC) sent a report titled, "Guanyu gaohuo xiaoxing guoyou qiye de jianyi" (Suggestions on Revitalizing Small State-owned Enterprises), to VicePremier Wu Bangguo, who was in charge of enterprise reforms. In September 1995 the policy was formally announced by the Central Committee of the Chinese Communist Party in one of its plenaries and went forward as a suggestion for the 9th FYP (1996-2000). See Garnaut et el. (2005).

${ }^{37}$ In the mid-1990s, the Chinese leadership headed by Jiang Zemin and Zhu Rongji decided to retain ownership of 500 to 1,000 large state firms and 'let the rest go'. See ibid.
} 
overall SOE output, underwent systematic restructuring. At the central government level, up to 2004 a total of 725 centrally-controlled SOEs were delegated to the local governments, mainly at provincial level. The central government provided a total of RMB 63 billion Yuan subsidy to relevant local governments to restructure these assets and dismiss their 1.9 million employees (Qi 2006). At the local government level, more than 80 percent of state and collective firms at the level of the county or below had gone through fundamental restructuring, involving direct privatisation in most cases by the end of 1998 ( $\mathrm{Li}$ and Putterman 2008). In 1998, industrial SOEs' output still accounted for almost half of the whole economy; by the end of the 10th FYP period in 2004, this share was estimated to be only about 30 percent (OECD 2009). Nevertheless, the 'let go' of a great number of loss-making SOEs contributed hugely to alleviating the state's fiscal burden, which allows the state, especially the central government, to focus on a group of well-equipped, well-financed large SOEs in sectors that are highly profitable and strategic to the whole economy. The result is summarised as "less ownership, more state control” (Mattlin 2009).

\section{Restructuring centrally-controlled SOEs}

In the late 1980s, as the local non-state economy was booming with a decentralised reform strategy, there were increasing voices within the top party-state leadership calling for a "national team" of large, centrally-controlled enterprises groups (these SOEs are often referred to as "yangqi", the centrally-owned SOEs) to strengthen the influence of the state over the macro-economy. "Grasping the large" strategy was largely derived from such a call (Nolan 2001; Sutherland 2003). When Hu Yaobang and Zhao Ziyang were steering China's reform with Deng's endorsement in the 1980s, much emphasis was put upon administrative and fiscal decentralisation to facilitate the development of medium-and-small sized state or collectively-owned local enterprises. Such strategy was disputed by some party-state leaders headed by Chen Yun and Li Peng, who favoured large industrial SOEs in maintaining the socialist nature and technological advancement of Chinese industry (Eaton 2013). With Hu Yaobang's fall and Zhao Ziyang's purge in the late 1980s, the state sector reform strategy that favours large SOEs began to increasingly appear on the centre's reform agenda. In 1989 when 
Jiang Zemin was appointed, he announced at the Fourth Plenum of the 13th Party Congress that: "We must do everything possible to revitalise large and medium-sized SOEs. They are the backbone and foundation of our socialist economy" (Eaton 2013, p.67). During the short Jiang Zemin-Li Peng leadership from the early to mid-1990s, policy experiments were initiated and broadened to support large SOEs' development.

In 1991, the State Council decided to select a number of 100 SOEs nation-wide as a pilot project. Each of these enterprises would be brought under the discrete planning system and given broadened international trade privileges, rights to access preferential loans and expanded enterprises autonomy. By 1995, a total of 56 SOEs were selected and put into trial. As 'grasping the large' was officially adopted in 1995, 120 enterprises were selected as members of the 'national team' by 1997 (NBS October $8,2002)$. In the late 1990 s, as the Chinese economy was increasing integrated into the global market and with the accession of the GATT (later WTO) in sight, the large enterprise strategy was also increasingly reviewed so as to prepare China in the global market. The Chinese leadership explicitly expressed their admiration of other East Asian economies' success in "picking winners" by developing systematic industrial policy to form large and internationalised enterprise conglomerates (Nolan 2001).

When Zhu Rongji became Premier in 1998, he continued such strategy of grasping the large with new policies. Instead of only focusing on the most prominent elite SOEs, Zhu Rongji also set the target of "getting major SOEs out of trouble in three years" (sannian tuokun) at the 15th CPC National Party Congress, which aimed to bring a number of 6,599 loss-making medium-to-large SOEs out of debt between 1997 and 2000 (NBS October 8, 2002). Restructuring accelerated from 1998. Strategies were implemented such as huge layoffs, debt reduction, debt-equity swap, and technology improvement support (OECD 2009). With the improved central fiscal capability since the 1994 fiscal reform and banking system reform, both the 'national team' strategy and the 'three-year' target achieved success in the early 2000s (Eaton 2013, p.70). By the end of the 10th FYP in 2005, the state-owned part of the economy was producing solid profits, with SOE profits multiplying both in absolute terms and relative to the whole 
economy and government revenue. By 2003, the number of industrial yangqi under the management of the State Council's SASAC was only $196,{ }^{38}$ but their proportion of asset, revenue and total profit represented 52 percent, 51 percent and 64 percent respectively (OECD 2009). ${ }^{39}$ The 'grasp the large' strategy has disproportionally benefited the Chinese central government and strengthened the central government's control over key areas of the national economy.

\section{SASAC and central government control over yangqi}

As a consequence of the "let go of the small" and the central government restructuring between 1998 and 2003, the central government lost many planning and commanding tools to directly intervene in the economy for macroeconomic adjustment. The elite group of yangqi in strategic sectors of the Chinese economy thus became a key instrument to guide the macroeconomy. However, in the late 1990s, ownership and management over those yangqi were dispersed among a constellation of central government departments and a series of the Party's reform leading groups. As dozens of economic commissions and industrial line ministries were disbanded in the two rounds of central government restructuring between 1998 and 2003, how to effectively manage these elite group of SOEs became a salient issue for the Chinese leadership at the time. At the 16th Party Congress in November 2002, the party-state leadership set the goal of reforming the management system for state assets. It was agreed that the management of yangqi should be put under a unified institutional framework within the State Council (Jiang November 8, 2002). As a result, the State Council established SASAC in June 2003 as a key component of the 2003 central government restructuring.

Officially, SASAC is defined as a ministerial rank "special organisation" reporting directly to the State Council (guowuyuan zhishu teshe jigou). Incidentally, SASAC is the only organ in this organisational category, which appears to have been established exclusively for it (Mattlin 2009). According to the State Council's mandate

\footnotetext{
38 The number of central SOEs, including their local and overseas subsidiaries, was reported as about 21,000 .

${ }^{39}$ In 2005, the entire state-owned sector made a net profit of RMB 644.7 billion See NBS (2006).
} 
to establish SASAC, the State Council itself, on behalf of the Chinese central government, has the government ownership over individual yanqi and authorises its SASAC to take specific investor and administrative responsibilities over yangqi (Naughton 2008). In relevant sections of China's new Company Law which took effect in January 2006, SASAC is defined as the organisation that wields ultimate power in matters related to yangqi. In May 2009, the Law on Enterprise State Assets (qiye guoyou zichan $\mathrm{fa}$ ) came into force, confirming SASAC's role as the State Council department designated to handle issues related to state assets (Mattlin 2009).

Upon its establishment in 2003, the State Council SASAC took over the most elite 196 yangqi from a variety of State Council departments. According to $\mathrm{Li}$ Rongrong, the founding director of the SASAC, the 196 centrally-owned enterprises controlled over 90 percent of the state assets in China's 'strategic industries', such as oil-petrochemical, electric power and defence (Xinhua News Agency August 12, 2010). Although the SASAC's responsibilities do not extend to yangqi's day-to-day operation, it holds the majority of shares of central SOEs and has executive control over corporate policy and executive appointment. Its main priority is to ensure efficient company performance through the control of its board of directors and setting of the company's main strategy agenda (Szamosszegi and Kyle 2011). As state asset investor, the SASAC exercises strategic ownership rights over yangqi's assets. SOEs' investment strategies, financial planning, corporate development and asset and equity management are ultimately controlled by the SASAC. This includes all transactions involving assets and liabilities of both parent company and NOC subsidiaries. The SASAC also exercises regulatory powers over the remuneration allocation, disposal of assets and restructuring plans regarding mergers and acquisitions. The SOEs could not mobilise capital, file bankruptcy or issue company bonds without the SASAC's approval. Moreover, the defining and registering of property rights, appraising, verifying and taking stock of state assets and liabilities, together with supervising and managing property rights trading of NOCs, are also under the supervision of the SASAC (Naughton 2008; Mattlin 2009). 
One of the most notable jobs that SASAC does to strengthen the central government guidance over yangqi is to assist the Central Organisational Department of the CPC (zhongzu'bu) to effectively control the appointment and removal of their top management staff. As Naughton (2007, p.316) observes, the party-state holds tightly on its appointment power through SASAC and shapes the career paths and incentives of large state enterprise managers. SASAC has the power to appoint members of boards of directors and establish procedures for appointing managers. In particular, the Party Committee of SASAC (guoziwei dangzu) plays a key role in assisting the Central Organisational Department in managing the promotion and demotion of the Party's cadre corps in yangqi, since most of the executives and managers are also senior party members and retain bureaucratic ranks equivalent to central government officials. Thus their posts are also on the central nomenklatura list managed by the central Party Organisational Department (Brødsgaard 2012). The Organisational Department retained the direct appointment power for the top jobs of 53 of the 196 enterprises managed by SASAC and has delegated significant appointment power for the remaining top jobs to the Communist Party Committee within SASAC (Naughton 2007, p.316; Naughton 2008).

Therefore, this combined ownership and management power effectively makes SASAC the first central government agency that enjoys such a concentrated power of SOE governance since the commencement of SOE reform. Although the yangqi have much more operational autonomy than the SOEs under the command economy, the strategic and administrative control imposed by SASAC significantly limits their capacity to pursue business and commercial interests that may be divergent from national interests. The central government is assured that national interests defined by the party-state leadership are closely followed by the increasingly wealthy and influential yangqi groups.

\subsubsection{Yangqi as means of Controlling Strategic Sectors}

\section{Energy industries as the core of 'strategic sectors'}

From the early 2000s, the Chinese economic policy discourse is full of terms that denote the importance of the state's control over enterprises in certain sectors of the 
economy, such as "economic lifeline" (jingji mingmai), "strategic industry" (zhanlue chanye), "pillar industry" (zhizhu chanye), "key area" (guanjian lingyu) and "backbone enterprises" (gugan qiye). On December 5, 2006, a Guiding Opinion on Promoting the Adjustment of State-Owned Capital and the Reorganization of State-Owned Enterprises, drafted by the SASAC, was approved by the Premier (State Council 2006[97]). This document, together with the comments of SASAC's leading officials, provides good ideas of the top party-state leadership's view on the "strategic sectors".

In the document, the SASAC specifically named four areas considered strategically important to the Chinese economy, in which the state has to maintain absolute control through either sole ownership or an absolute controlling share. The four areas include industries that concern national security, key infrastructure and mineral resources, industries that provide important public service and public goods, and 'backbone' large SOEs in the pillar industries and some high-technology industries (State Council 2006[97]). In an interview with Xinhua News Agency, Li Rongrong specified that seven sectors are considered strategically important by SASAC, including oil and petrochemicals, defence, power generation and distribution, coal mining and processing, aviation and shipping, and telecommunications. The state, especially the central government, would maintain sole ownership or absolute control over those strategic industries. Some other industries, such as high-end equipment manufacturing, auto, information technology, construction, iron and steel, non-ferrous metals, chemicals, and surveying and design, were seen by SASAC as "pillar industries". Central government and local government at provincial and municipal level should together hold a relatively strong control position over the pillar industries (Xinhua News Agency December 18, 2006).

With such a view of the state sector, SASAC has been doing an impressive job in improving its yangqi fleet's profitability and directing their business portfolio to concentrate on those strategic sectors and lifeline industries of the Chinese economy (Naughton 2007, p.367). The number of firms in SASAC's fleet dropped from 169 in 2003 to 116 by the end of 2013 through a series of mergers. Although the State Council SASAC's yangqi comprise only a tiny number out of a total of nearly 120,000 SOEs owned by governments in various levels and regions nation-wide (including 
subsidiaries of SOEs where government has controlling share), their size and importance to the national economy in many respects surpasses that of all the other SOEs combined. Many of the yangqi monopolise key areas of the Chinese economy or enjoy oligopolistic status along with several other yangqi with overlapping business portfolio. The most typical are the oil-based energy industries along the OPVC.

The State Council's document and Li Rongrong's explanation clearly reveals the vital role of the energy sector in China's centrally-controlled strategic sectors. Among the three major energy sectors, namely oil and petrochemical, coalmining and processing, and power generation, the oil and petrochemical are undoubtedly the most 'centralised' energy-based industrial sector, with the whole Oil-Petrochemical Value Chain under central government control. In contrast, although the SASAC also wished to control the coalmining and power sectors by the early 2000s, these two sectors had been much more decentralized and fragmented and were subject to strong local influence (see analyses in Section 4.3 and Chapter Six). Through a series of restructures between 1998 and 2001, the upstream, midstream and downstream of China's OPVC, which used to be dispersed and controlled by a variety of national and subnational actors such as local governments and local private business, have been systematically vertical-integrated and centralised under a few yangqi, which immediately became the largest and wealthiest 'industrial champions' in SASAC's yangqi fleet. Indeed, as an intended consequence of the "grasping the large", a centrally-controlled oligopolistic structure began to feature in China's OPVC development from the late 1990s.

\section{The vital role of OPVC in centrally-controlled strategic sectors}

China's OPVC development can be traced back to the 'Great Oil Campaign' to search for domestic onshore oil fields in the 1960s and the establishment of The Ministry of Petroleum Industry (MPI). The MPI represented the whole upstream crude oil E\&P and a considerable share of midstream petrochemical capacity in the planned economy. As economic reform spread to the urban industrial sector in the early 1980s, in 1983 the State Council decided to put over 90 percent China's crude oil refining capacity under a centrally-controlled petrochemical SOE - Sinopec. A year earlier, the China National Offshore Oil Company (CNOOC) was already established under the MPI to advance international cooperation in offshore E\&P. In 1988, the MPI was 
restructured into the China National Petroleum Corporation (CNPC), which inherited most of MPI's upstream crude oil assets. Thus, China's three major National Oil Companies (NOCs), designed to separate commercial functions from a number of industrial line ministries, came into shape. At the same time, the fuel and petrochemical products marketing and sales function was assigned to more than 30 provincial oil companies owned by the local governments. Thus, by the late 1980s, China's OPVC became vertically-separated between several SOEs, and between the central and the local governments. In the early 1990s, as the Socialist Market Economy was adopted as the paramount objective, deepened marketization and liberalisation reform was extended to the oil and petrochemical sector. China's OPVC began to become progressively decentralised and fragmented, like the coalmining and electric power sectors. Between 1992 and 1997, a series of sectoral reform policies were introduced to encourage non-central actors, including local government, private firms, and foreign enterprises, to invest along the whole OPVC from upstream offshore E\&P to downstream products marketing and retailing. However, this OPVC marketization and liberalisation trend was drastically reversed as China became a net crude oil importer in 1996 and the introduction of "grasping the large, and let go the small" SOE reform strategy occurred in the same year.

As China's economic growth accelerated in the 1990s, Chinese policymakers from State Council's departments to the top party-state leadership all sensed that the oil-based industries would be strategic to China's development based on western countries' experience of the post-war development and during the 1970s' oil shocks. As the country's oil imports climbed rapidly in the late-1990s, it was commonly perceived by the government officials and policy analysts that China was at a serious disadvantage in accessing a stable and affordable foreign oil supply mainly because of the lack of internationally-competitive large oil companies to advance the national interest in an unfamiliar global energy market. With a historical contingency that "grasping the large" SOE reform started to be introduced by the Jiang-Zhu leadership from 1995, the OPVC was regarded as a strategic sector that must be controlled firmly by the central government. Therefore, with the State Council's direct mandate, China's OPVC underwent major restructuring in 1998 and has since become verticallyintegrated and highly-centralised. 
In 1998, the State Council initiated a large-scale assets swap between CNPC and Sinopec. Some core upstream crude oil E\&P assets owned by CNPC were handed to Sinopec in exchange for the latter's midstream petrochemical assets. Meanwhile, another crude oil E\&P yangqi - China National Offshore Oil Company (CNOOC) was allowed to develop its own petrochemical capacity and distribution networks. Moreover, international oil trade permits that used to be monopolised by SinoChem during the planned economy, and had been gradually liberalised to allow local and private petrochemical enterprises to import foreign oil from 1992, were also revoked by the State Council. Only the three vertically-integrated OPVC yangqi and a handful of other centrally-owned trade firms were allowed to take part in international oil trade. Moreover, the central government also issued a series of mandates and regulations that practically banned the development of non-central OPVC firms between 1998 and 2003, causing the booming oil business owned local governments, private firms and foreign enterprises to be systematically 'squeezed out' from China's OPVC from the late 1990s. With the central government's support, the three NOCs, namely CNPC, Sinopec and CNOOC, rose to dominate China's domestic OPVC and became a rising power in the international energy market. By the time that the State Council SASAC was established in 2003 and took over the three NOCs, they had already become national champions and an icon of the central government's control of strategic sectors.

When SASAC was established in 2003, the 196 yangqi under its governance earned an estimated 300 billion RMB of profits, which equals to $2.2 \%$ of China's GDP that year. In just four years in 2007, yangqi earned RMB One Trillion Yuan in profits, over four percent of Chinese GDP that year (Naughton 2008). Moreover, within the central enterprise fleet, the bulk of the profits are disproportionally generated by a handful of enterprises headed by the three NOCs. In 2005, the top-40 most profitable yangqi accounted for 95 percent of all profits made by the yangqi fleet, while the twelve most profitable firms made 79 percent of all central enterprise profits (Mattlin 2009). The three NOCs reside at the very top. According to a latest survey conducted by China's Ministry of Finance (MOF), the total revenue of CNPC, Sinopec and CNOOC accounted for almost half of all SASAC's yangqi fleet and the three's net profits together accounted for 70 percent of all yangqi's profits combined (Fu September 6, 2014). 
With their huge oligopolistic profits made at home and with central government's support, they also actively expanded their business overseas to become the spearhead of China's "going-global" (zouchuqu) strategy. By the end of the 10th FYP period in 2004 the three NOCs had concluded 61 oil projects in more than 25 countries around the world (Jiang and Sinton 2011). By the end of the 11th FYP in 2009, they had invested USD \$18.2 billion on merger and acquisition deals, accounted for 13 percent of total global oil and gas acquisitions (USD \$144 billion), and for 61 percent of all acquisitions by national oil companies around the world (USD $\$ 30$ billion) (Jiang and Sinton 2011). At the beginning of the 12th FYP in 2011, the profit of PetroChina, CNPC's major subsidiary, reached USD \$21.1 billion, compared with USD \$29.8 billion for Royal Dutch Shell and USD \$24.8 billion for BP (Nolan 2014). International analysts such as Naughton (2008) and Nolan (2014), by tracking the profits made by some of the most internationalised Chinese yangqi in comparison with their western counterparts, have all argued that China's "grasping the large" strategy and the central government's control over strategic sectors of the economy has largely succeeded over the last one and half decades.

In sum, the Jiang-Zhu leadership's "grasping the large and let go the small" SOE reform strategy initiated in the mid-1990s has turned out to be successful on the central government's side. By building a group of elite yangqi in key areas of the Chinese economy and guiding their development through the State Council SASAC, the Chinese central government has significantly strengthened its control over certain strategic sectors of the economy, such as the oil and petrochemical industries along the OPVC, in the 2000s.

\subsection{Central-Local Institution Reform and Local Government's 'Growth Imperative'}

Besides the reform of China's SOE institution, the other set of institutions that has played a fundamental role in shaping Chinese political economy has been the institution of Central-Local intergovernmental relations. Being a unitary state, Chinese local government is a subnational agency of the national government under the top party- 
state leadership. ${ }^{40}$ As a vast country with almost 30 provincial level local governments whose size and population are comparable with those of an average sovereign state, to search for the equilibrium between the central and the local has been a constant theme of Chinese politics. In the reform era, a good intergovernmental institution arrangement should, on the one hand, provide the localities with political incentives and economic interests to promote decentralised development; on the other hand, the central government must preserve political control over the localities to keep them in line with the central government's reform and development guideline as embodied in the top party-state leadership's ideational systems. Since 1949, a two-dimensional intergovernmental institution has been established in China as the political-economic basis of the country's command economy between the 1950s and late 1970s, and to promote the decentralised economic growth in the reform era.

\subsubsection{The Political \& Economic Dimensions of Central-Local Relation}

\section{Political dimension: growth-oriented local official evaluation \& promotion}

China's central-local intergovernmental institution first features the political dimension of the party-state's local official evaluation \& promotion system. Such cadre system has been regarded as a Chinese variant of the Soviet nomenklatura system (Burns 1989). The relative success and stability of the Communist Party's rule in China has evoked much debate on the unusual robustness of the CPC in contrast to the collapsed Soviet. Many have argued that the party-state centre's tight control and effective management over the local cadre with leading positions (lingdao ganbu) in local government is a central factor contributing to the CPC's relatively stable rule and China's rapid economic growth (Landry 2008; Shambaugh 2008; Brødsgaard 2012)

\footnotetext{
${ }^{40}$ China is a unitary state and its political system is composed of four layers of state administration at subnational level: provincial level, including 23 provinces (sheng), 4 municipalities (zhixia'shi), 5 autonomous region (zizhi'qu), and 2 special administration regions; prefecture level, including prefecture/city (shi) and region (di'qu); county level, including county (xian) and some city's suburbs (qu); and finally, townships (xiang). The 31 (excluding 2 SARs) provincial level units play a pivotal role in China's political system. Thus, when analysing Chinese local government, this study mainly focuses on the governments on the provincial level.
} 
In all Communist-Leninist states, the ruling communist party and the state are closely intertwined and their functions are largely combined into one body, featuring the tight control of the party through its organisational apparatus, for which the term "party-state" is created (Huang 2009, pp.27-37; Guo 2013, p.135). At the apex of the party-state is the national Party organization headed by the Standing Committee of the Politburo, the Politburo, and the Central Committee. At provincial, municipal, and county levels there are similar leadership bodies (CPC committees) and staff offices. Every agency of the national, provincial, and county governments has within it a Party Committee (dang wei), usually made up of the Party Secretary, key members of the Party apparatus, head of local government and head of key departments of the local government (Lieberthal and Lampton 1992). In this sense, the CPC's cadre management system lies at the heart of the Chinese polity. The Chinese leaders have attached considerable importance to the organisational capacity of the ruling party, especially its monopoly over the appointment of officials at all levels of the country's vast bureaucracy. The CPC controls the selection and promotion of 10.5 million officials posted in 307,000 work-units, among whom 508,000 are high ranking cadres “above the county level” (Landry 2008, p.16).

Especially after 1989, the party-state leadership fully realised the consequences brought by the over-decentralised administrative system, especially the party's relaxed control on the leadership selection at local government level. A key lesson learnt from the collapse of the USSR was that the Soviet Communist Party had allowed its organisational capacity to atrophy. Subsequent surveys by the CPC during the 1990s on its own organisational status and cadre management were showing alarming signs of deterioration (Shambaugh 2008). During Jiang Zemin's tenure, the CPC undertook a series of systematic and comprehensive programmes intended to improve the party's governing capacity with the focus on strengthening local cadre management (jiaqiang ganbu duiwu jianshe), including the introduction of a civil servant system and the party's 'one-level down' cadre appointment mechanism. The introduction of these two personnel management mechanisms in the 1990s significantly strengthened the political dimension of China's central-local intergovernmental institution. Under the Jiang-Zhu leadership's Reform-to-Grow strategy, one of the most important functions of such 
institutions is to provide sufficient political incentives for decentralised economic growth.

Chinese scholars observe that in the 1990s and early 2000s, decisions on promotions of leading local government officials in most regions have been primarily based on an evaluation of local economic performance. Thus, a defining feature of China's central-local political relations has been a "tournament competition" of local government official promotion (Li and Zhou 2005; Chen et al. 2005). Such 'tournament competition' of local cadre promotion is built on three characteristics of the Chinese political system. First, personnel control is centralised in the hands of the party-state centre and the economic performance of provincial leaders is a crucial indicator in personnel evaluations. Second, a "M-form" structure of the Chinese economy makes each provincial leader's performance individually distinguishable and comparable and thereby allows for a sensible link between performance and turnover. ${ }^{41}$ Third, government officials move up in an internal political labour market and there is virtually no outside opportunity (Qian and Xu 1993; Maskin et al. 2000).

The tournament competition of political promotion has made local government officials operate within a well-defined career structure inside the CPC's 'one-level down' cadre management system. Promotion (or demotion) decisions for provincial officials are made by the party-state centre, and opportunities that lie ahead include membership of the State Council, the vice-premiership, the premiership and membership of the Politburo. Maskin et al. (2000) find that the political status of a Chinese province (measured by the number of Central Committee members) is correlated with the provincial economic ranking. It is also well-documented that lower levels of local government also control 'one level-down' county and township officials by linking their performance to promotion (Whiting 2000; Tsui and Wang 2004; Burns and Zhou 2010; Heberer and Trappel 2013). It is common that local party secretaries sign performance contracts with lower-level party and government officials. In these contracts, lower level officials pledge to achieve targets established by the superior officials, and are held personally responsible for attaining those targets. Performance targets are ranked as 'soft' targets (or anticipated targets) and 'hard' targets (or

\footnotetext{
${ }^{41}$ The "M-form" of the Chinese command economy was different from a "U-form" of command economy in the Soviet Union, where subnational regions were assigned with different priorities of economic development by the central planners. See Maskin et al. (2000).
} 
obligatory targets) (Heberer and Trappel 2013). Fulfilling hard targets, which are usually economic ones, is fundamental for political promotion and bonuses (Edin 1998; Edin 2003; Xu 2011). It has been well-documented that regional Gross Domestic Product (GDP) record and government revenue have been increasingly adopted as hard indicators of performance evaluation across Chinese local governments since the mid1990s (Burns and Zhou 2010; Heberer and Trappel 2013). ${ }^{42}$ Apart from promotions, terminations, including early retirement and demotions, can also serve as a strong incentive mechanism (Li and Zhou 2005). In this way, local government officials' concerns about their prospect of promotion and termination become a major political incentive to promote local growth.

\section{Economic dimension: central-local fiscal system}

Besides the growth-oriented local official management, a second dimension is the fiscal system that determines the local government revenue. Between the 1950s and early 1980s, China adopted a highly centralised intergovernmental fiscal system, usually known as a system of "unified revenue and unified expenditure" (tongshou tongzhi) as the fiscal basis of the planned economy. According to Lin et al. (2003), a highly centralised intergovernmental fiscal system was necessary to achieve rapid industrialisation in a capital-scarce and underdeveloped economy like China. Such a system was characterised by tight central government control on local revenues and expenditures. The accounting system of provincial government was directly incorporated into the central government budget. Local governments did not have independent budgets and fiscal interest. Thus, Chinese local government in general had little autonomy and few incentives to promote local economic development during most of the planned economy. Such a fiscal system had operated, with minor modifications, from the 1950s to the late 1970 s and is considered as a major institutional factor in causing the low-efficiency of the planned economy.

\footnotetext{
${ }^{42}$ Such obsession with economic growth has also been increasingly criticised by Chinese academics and media from the early-2000s as local government officials" "GDP worship", namely promoting local economic growth at the expense of other values such as social harmony and environmental protection. See Jiang (2004).
} 
Given the fundamental role of the intergovernmental fiscal system in shaping the economy, fiscal reform was regarded as a "the breakthrough point" to push China's economic transition (Shirk 1993, p.149). Throughout the 1980s, several revenue sharing schemes that divide government revenues into central-fixed revenues, localfixed revenues, and shared revenues were introduced and experimented to provide fiscal incentives of local development. The most influential was the 'fiscal contracting system' between 1988 and 1993. Based on the experience of previous fiscal reforms in the early 1980s, the State Council introduced a fiscal contracting system in 1988. The State Council negotiates fiscal contracts with each province on revenue remittances to the centre, permitting most provincial governments to retain the bulk of newlygenerated revenues. Six variants of revenue-sharing contracting were experimented with over the period 1988-1993. This system also required each provincial government to contract similarly with its subordinate level of governments to meet certain revenue and expenditure targets on an annual basis (Shen et al. 2012).

Fiscal reforms in the 1980s, especially the 1988 fiscal contracting system, successfully mobilised local enthusiasm to develop the economy. Many China political economy scholars attribute the country's economic 'miracle' in the 1980s to the decentralised fiscal system and argue that a 'market-preserving federalism' was practised in China in the 1980 s to the early $1990 \mathrm{~s} .{ }^{43}$ Nevertheless, many associated problems also followed with such fiscal decentralisation, especially the overheating of the whole economy due to local governments' uncoordinated and unrestricted investment decision-making (Huang 1996). Many local governments rushed to an investment fever because they could keep most revenues at their disposal under the fiscal contracting system. Local governments expanded their investment in the thenhighly lucrative sectors that produce the household applications which were in constant shortage during the command economy (Tao and Yang 2008). Such excessive investment caused nation-wide inflation and shortages in energy and raw material supply. Also, as provincial investment concentrated on the most profitable industries, duplication of industrial structure and convergence of production pattern among

${ }^{43}$ For example, see Montinola et al. (1995); Jin et al. (2005); and Lin and Liu (2000). 
different provinces became increasingly serious from the early-1990s, which caused vicious inter-provincial competition and rampant local protectionism over resources and markets, described by scholars as "dukedom economics" (zhuhou jingji) (Shen and Dai 1990; Montinola et al. 1995). When Zhu Rongji was appointed as Vice-Premier, he realised that the central government had lost control over China's macro-economy. With the introduction of the Socialist Market Economy objective in 1992, the central party-state leadership began to consider a redesign of China's national fiscal system.

\subsubsection{Fiscal Reform and 'Growth Imperative' at Subnational Level}

\section{The 1994 fiscal reform}

In 1994, Zhu Rongji pushed a major fiscal reform to strengthen the central government's fiscal control over the localities. The centrepiece of the re-designed system was the introduction of a Tax-Sharing System (fenshui'zhi). Such Tax Sharing System clarifies the centre and the localities' respective revenue-collecting powers and expenditure responsibilities. The central government regained the majority of national fiscal revenue, while the local governments' fiscal position was significantly weakened.

For decades prior to 2011, Chinese government revenue had come from two major sources: Extra-Budgetary Fund (EBF) and Tax Revenue. For EBFs, SOEs' profit remittance contributes the bulk due to the dominant role of SOEs in China's command economy. ${ }^{44}$ For instance, SOEs contributed 80 percent of the 1990's total EBFs collected by all levels of government (Saich 2004, p.168). However, as the "Remittance-to-Tax" reform was implemented in SOEs from 1983-1984, taxes became increasingly important to government revenue. By the mid-1990s, as the state sector's efficiency and profitability kept declining, and with the non-state economy continuing

\footnotetext{
${ }^{44}$ Between 1994 and 2011, Chinese government revenue by law was comprised of two major components: the unitary budget and the extra-budgetary funds (EBFs) for all levels of governments. The unitary budget is subject to formal annual budgeting by the central government. It comprises taxes, fees and other revenues. The Ministry of Finance provides the central supervisory role together with the local authorities. The EBFs covered officially sanctioned charges such as profit remittance from SOEs run by various levels of governments, surcharges from taxes and public utilities, as a variety of administrative service fees. In 2011 EBFs were abolished by China's Ministry of Finance (MOF). See Wedeman (2000), and People's Daily (Feburary 10, 2012).
} 
to grow, tax replaced the EBF to become the most important government revenue source. In 1994, the State Council initiated a major overhaul of the tax system. The reform attempted to re-modify China's central-local fiscal relations by arresting the central government's revenue decline, and to modify revenue and expenditure assignments to different levels of government (Wong 2000; Dabla-Norris 2005). Government expenditure responsibilities were defined by the State Council's Mandate on the Tax-Sharing System that came into effect on 15 December 1993 (State Council December 15, 1993). The Budgetary Law which came into force in January 1995 defines the items and sources of government revenue. On the basis of these two documents the central government established a new fiscal system, often referred to as the '1994 fiscal system', which has governed China's central-local fiscal relations over the past two decades.

Under the 1994 fiscal system, the most significant change is that the central and local taxes under the fiscal contracting system are merged into three major forms: Value-Added Tax (VAT), Enterprise Income Tax (EIT) and Personal Income Tax (PIT). VAT is especially important and accounts for over 60 percent of total taxes collected by all levels of government in the 1990s. The new tax system requires local governments to hand over 75 percent of their VATs to the central government, which significantly altered the central-local fiscal situation (Lin 2001, p.95). Together with the fiscal rules defined by the law and regulation, the 1994 fiscal system is also institutionalised by the reform of tax administration systems. Separated central and local tax administrations were established. The State Administration of Taxation (SAT, guo'shui) is responsible to collect central taxes and shared taxes, mainly VAT and consumption tax. The Local Administration of Taxation (LAT, di'shui) is responsible to collect local taxes. The new system instantly raised central government revenues. The ratio of the central government budget to GDP and the ratio of centrally collected revenue to total budget revenue have risen steadily since 1994. The centre's share of budgetary revenue was doubled from $2.8 \%$ of GDP in 1993 to $6.2 \%$ in 1998 . From 2001, centrally collected government revenue began to exceed that of locally collected $-52.4 \%$ as opposed to $47.6 \%$, and has continued to increase over the past decade (Saich 2004, p.169-170). 


\section{Fiscal reform, political competition and emerging 'local growth imperative'}

For Chinese local governments, the situation got worse as local expenditure increased sharply under the 1994 fiscal system. The delegation of public service responsibilities to local government is another major consequence of the 1994 fiscal reform (Qian and Weingast 1997). According to the State Council's mandate in 1993, the central government expenditure includes national defence and armed police, the central government departments' administrative and operational expenses, investments on national socio-economic projects, and the expenditure to adjust the macro-economy, such as through inter-regional and inter-sectoral development coordination (including the centre's fiscal transfer to the local governments). The expenditure of the local governments includes mainly the local government departments' administrative and operational expenses, the expenditure for local economic projects, infrastructure construction and local SOE's technological innovation; local expenditure also includes a wide range of social service expenditure, such as rural and urban public utility maintenance, price subsidies for consuming products, medical and education, etc (State Council December 15, 1993). The relatively coherent definition on central expenditure and 'murky' definition on the local expenditure effectively makes the subnational governments bear an expanding range of public spending that is increasingly disproportional to their fiscal revenue growth. In the early 2000s, local governments accounted for over 90 percent of total spending in culture, education and health, and for virtually all the social relief and welfare expenditure, including pension payments which are decentralized all the way down to the county level (Dabla-Norris 2005).

From the mid-1990s, an increasing number of influential studies have noticed a mismatch between subnational governments' expanding responsibilities and their shrinking revenues (Saich 2004, p.171) (see Figure 7 on the following page). Many have noted that under the 1994 fiscal system Chinese local governments tend to stress revenue mobilisation at the expense of other distributional and growth objectives. As Park et al. (1996, pp.751-752) argue: 
"Heightened pressures on revenue starved local governments may lead to over-investment in revenue generating industrial enterprises, [encourage] bureaucratic predation of enterprise resources and regional protectionism, and [divert] attention away from long-term development strategies."

Figure 7 Chinese Local Government Revenue \& Expenditure as Percentage of National Total 1978-2012

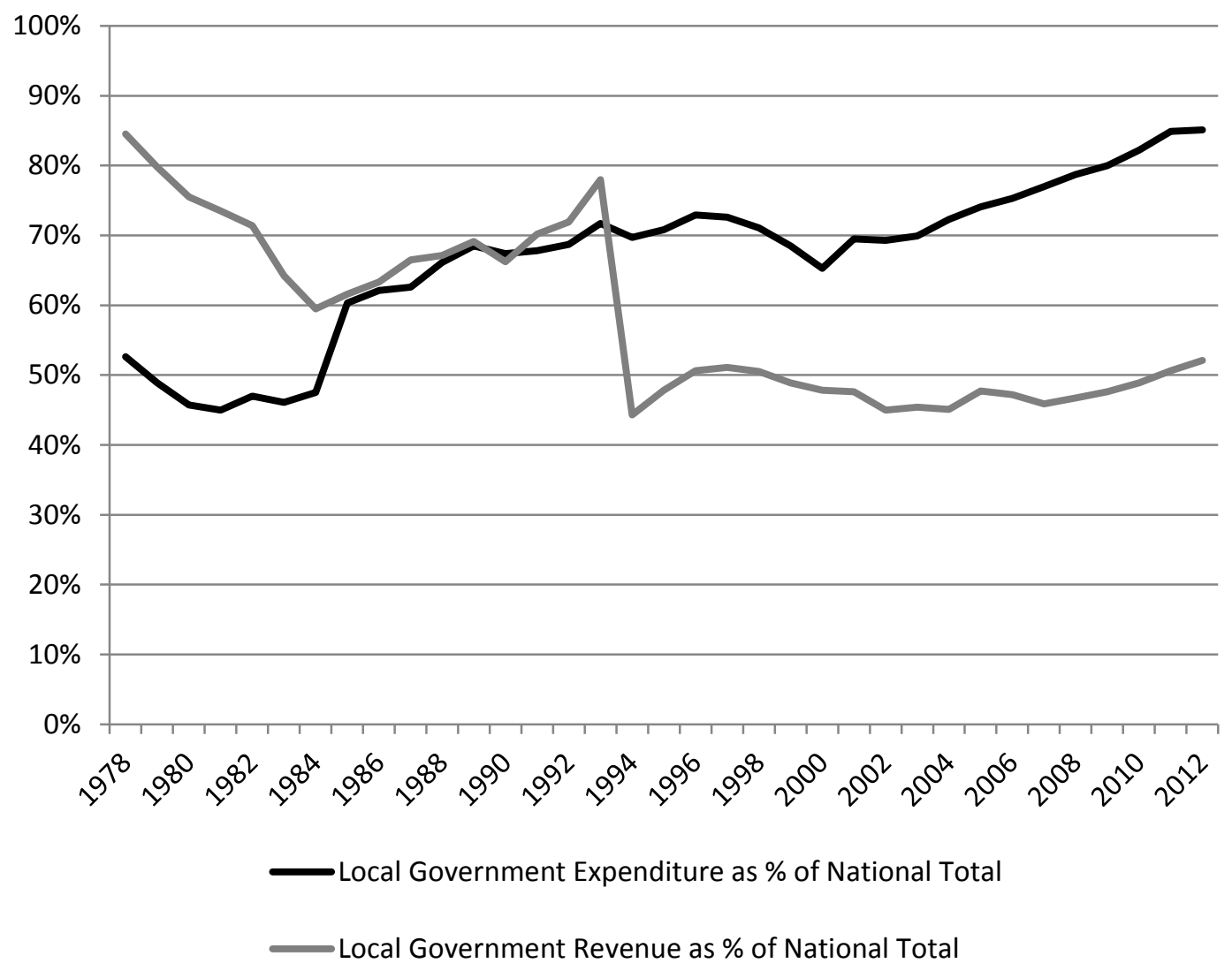

Data Source: CSFM (2013a, 2013b)

Tsai (2004) asserts that the re-design of China's central-local fiscal institution has led to a series of unintended consequences to the whole Chinese political-economy in the following decades through examining the local governments' development 
behaviours shaped by the 1994 fiscal system. The most widely noticed and analysed was the proliferation of local government's illicit EBFs other than traditional sources such as SOE profit remittance, which ultimately caused the central government abolishing EBFs in 2011 (People's Daily Feburary 10, 2012). According to Huang (2002), some landlocked western provinces derived as high as 80 percent of their educational funding from EBF in the late 1990s. Wong (2000) estimates the EBFs to amount to 12 percent of national GDP as compared to an official budget of 14 percent in the year 2000. Saich (2004, p.173) also notices that the financial pressures led to the preference for a development plan that maximizes short-term revenue over longer-term needs. It had largely resulted in a desire to expand TVEs in the mid-1990s as a first priority, as TVEs are seen as the most stable sources for local income. It has later led many inland provinces to set up similar manufacturing industries as in the more developed coastal provinces, irrespective of whether there is the necessary production factors and market for the product itself.

As analysed in the last section, local economic performance has increasingly become government officials' major concerns about their prospects for political promotion and termination. Thus, the growing fiscal revenue-expenditure mismatch under the 1994 fiscal system, together with the heated competition for political promotion focusing on local economic performance, have effectively forced most Chinese local governments striving to boost local economy growth to expand local revenue sources. Such updated 'local growth imperative', ${ }^{45}$ shaped by the reformed central-local intergovernmental institution from the mid-1990s, has profoundly influenced the development behaviour of Chinese local government in the following two decades.

\footnotetext{
${ }^{45}$ The author thanks Professor Dali Yang for making this point during a discussion on the China 2014 Update Symposium at the Australia National University. Prof. Yang contends that the 1994 fiscal reform, together with the declining performance of local SOEs and the financial tightening in the mid-1990s, shaped Chinese local governments' 'revenue imperative' to encourage them to broaden the local tax base and to nurture new EBF sources. See Tao and Yang (2009).
} 


\subsection{Emerging Post-Reform Heavy-Industrialisation at Subnational Level}

At the subnational level, the combination of SOE reform and central-local relations reform changed the linkage between local government and the local industrial economy. The two institutional reforms profoundly shaped the local government's development behaviour by structuring incentives and opportunities to develop heavy industries as a means to promote local economic growth. As a result, the Chinese economy started to become increasingly energy-intensive from the early 2000s.

\subsubsection{SOE reform and Local Proliferation of Energy-Intensive Industries}

\section{Delegation of heavy-industrial SOEs}

During the "grasping the large, let go of the small" SOE reform from 1995 and the 1998 central government restructuring that aimed to separate government administration and SOEs' operation, many of the State Council's industrial line ministries that used to administrate a large number of heavy-industrial SOEs were either dismissed or downgraded. According to the State Council SASAC, a total of 725 SOEs that used to be administered by State Council's industrial line ministries in areas such as coalmining, metallurgy, and heavy chemicals were delegated to the local governments, mainly at provincial and municipal level. By 2004, the central government had provided a total of RMB 63 billion subsidy to the local governments to restructure these state assets and their 1.9 million employees (Qi 2006).

As the Ministry of Coal Industry (MCI) was downgraded and merged into the SETC in 1998, the administration for all of China's 94 centrally-owned large coalmines were transferred to 23 provincial and municipal governments along with all their mining assets, employees and affiliated service units. ${ }^{46}$ The fiscal auditors to these coal enterprises were also assigned from the local governments and taxes generated by these

\footnotetext{
${ }^{46}$ The only exception was the centrally-owned Shenhua Group, which owns several large coalmines in Inner Mongolia and Shaan'xi province. See Chapter Five for details.
} 
coal enterprises going to local governments (Thomson 2003, p.165). These coalmines together produced 40 percent of China's raw coal with relatively advanced technology, equipment and coal-processing capacity. As a result, compared to the local small coalmines typically as Township-and-Village Coalmines (TVCs), a much higher share of raw coal produced from these large mines can be utilised by industrial consumers as thermal coal for power generation and coke for metallurgical manufacturing. Thus, the Chinese coal sector, which has been the "No.1 Commodity" (Wong 1985, p.262) for China's heavy-industrial value chains, has been almost completely decentralized. The central government now focused more on regulation regarding environment protection and safety (Peng 2009).

A similar situation also happened in the downstream energy-intensive manufacturing industries such as metallurgy. During the 1998 central government restructuring, the Ministry of Metallurgy Industries (MMI) was also downgraded and merged by the SETC between 1998 and 2002, and was later abolished in 2003. As a result, operational control of all but four of China's largest iron \& steel SOEs (Baosteel, Anstell, Wusteel, and Pansteel) were handed over to dozens of provincial governments (Zheng and Abrami 2011, p.391-393). ${ }^{47}$ For the nonferrous sectors administered by MMI, three nonferrous yangqi were established. However, they were disbanded only one year later, and most nonferrous plants were handed over to local governments following the iron and steel sector's example.

\section{Delegation of Industrial Investment Review authority}

Together with this decentralisation of industrial SOEs was industrial regulatory authority delegation, which had significantly reduced the central government's control over local industrial development in the early 2000s. Before the SOEs reform in the 1990s, the central government exerted relatively strong control over national industrial investment through planning agencies such as SPC, SETC and a variety of industrial line ministries. With economic reform rapidly spread from the rural agricultural sector to the urban industrial sector in the 1980s and 1990s, Chinese local government has

\footnotetext{
${ }^{47}$ When the SETC was replaced by the NDRC in 2003, the State Bureau of Metallurgy was disbanded and part of its regulatory function was taken over by two industrial associations - China Iron \& Steel Industry Association, and China Nonferrous Metals Industry Association.
} 
increasingly replaced the central government as the predominant investors in industrial sectors such light and textile industries, construction, and urban public utilities (Huang 1996). Nevertheless, the central government maintained strong control over the fixedasset investment regarding large-sale heavy industrial projects. A comprehensive Fixed Asset Investment Review \& Approval System (guding zichan touzi shenpi zhidu) was built upon a series of administrative regulations issued and enforced by the State Council's and provincial government's departments. Such an investment approval system inherited an old investment planning system. The investment approval system was particularly important to manage the development of heavy industrial projects involving land use, commodity and energy supply, and large-scale construction work. Non-central government investors, including local government, local SOEs, and private and foreign firms, must get approval from relevant central government departments before initiating new projects. For instance, according to the Beijing Municipal Government, before 2002 any industrial fixed-asset investment made by private firms needed to obtain approvals from more than 30 local government departments (Xinhua News Agency May 9 2002).

However, this system had been significantly weakened in the mid-1990s, with most investment approval authority delegated to lower levels of government, in particular provincial government. For the investment approval authority that remains at the hands of central government, the approval process was not as strict as before due to lack of regulation-enforcement and supervision agencies following the central government restructuring between 1998 and 2003. Such regulatory authority delegation largely facilitated the booming local private business to access the development of heavy-industrial sectors. Due to non-state investments' growing influence in building revenue-generating industries, and the fact that key heavy-industrial production factors, especially land, transportation, and energy supply, were mostly at the local government's discretion, private industrial interests began to 'marry' the local government's growth imperative from the late 1990s. As a result, massive investmentapproval evading at a local level emerged across the country from the early 2000s. A considerable number are illegal projects, often referred to as "weipi xianjian" (project constructing without lawful approval), which has been repeatedly criticised and sanctioned by the State Council throughout the 2000s (State Council 2009[38]). These 
new industrial projects construction and expansion of existing projects have been explicitly or implicitly facilitated by local government without finishing the lawful review and approval process, causing the central government increasingly to lose control over local heavy-industrial projects. As a result, China's total investment in fixed assets jumped from 36 percent to 47 percent of GDP over the three years 2002 to 2005 (Rosen and Houser 2007). By the end of the 10th FYP in 2005, China became firmly established as the world's largest producer of steel (35 percent of world output), aluminium (28 percent of world output), cement (48 percent of world output), and flat glass (49 percent of world output) (Rosen and Houser 2007).

\subsubsection{SOE Reform, Central-Local Institution Reform and Changing Dynamics of Local industrialisation 1980s-2010s}

\section{Local Light-Industrialisation 1980s-mid 1990s}

A fundamental factor causing the Chinese economy's poor performance under the planned economy was a Soviet style heavy-industrialisation strategy that ignored China's comparative advantages (Lin and Tsai 2004). Rather than choosing a development strategy in line with its natural endowments (rich in labour, poor in capital and technology) as other Asian economies had done, the Communist leaders dragged China in pursuit of rapid heavy-industrialization. As economic reforms spread to the industrial sector in the early 1980s, the previously suppressed light industries in the planned economy, such as consumer goods manufacturing ranging from bicycles and household appliances like television, and the burgeoning service sector were boosted by the development of the non-state-owned economies, especially with firm support from local governments (Su et al. forthcoming; Tao and Yang 2009). International energy experts like Smil (1990) and Kambara (1992) note that the Chinese economy was structurally shifting away from energy-intensive industrial subsectors to more energyefficient ones throughout the 1980s and early 1990s, which was a major factor to cause China's energy intensity to decline over this period. ${ }^{48}$ According to influential studies on the Chinese political economy over the past two decades, the fiscal contracting

\footnotetext{
${ }^{48}$ With regard to the breakdown of the contributions, 50 percent of energy savings during the period 1981-88 were attributed to structural adjustments, while strengthening energy management and technologies transformation were responsible for $40 \%$, with the remainder covered by imports of energyintensive products. See Smil (1992).
} 
system in the 1980s and early 1990s played a key role in bringing about such lightindustrialisation.

It has been well documented that China's economic success in the 1980s and 1990s was largely based on the utilisation of China's comparative advantage to develop labour-intensive light-industries through the rapid expansion of rural collective economies (Oi 1992; Wong 1992; Qian and Weingast 1997). It is argued that the structure of fiscal incentives was coupled with a set of transitional economic characteristics. These characteristics include the high pent-up demand arising from the traditional shortage of consumer goods typical of planned economies, and relatively high prices for consumer products as well as dual-track pricing. They encouraged Chinese local governments to make business investments, especially in supporting collective economies featuring light manufacture industries, with their growing revenue under the fiscal contracting system. ${ }^{49}$ The 1980s fiscal contracting system served to provide strong fiscal incentives for local governments to benefit from the local growth they promoted. Local collectively-owned industries in the form of Township-andVillage Enterprises (TVEs) became the engine of economic growth and pushed the economy to shift away from energy-intensive industry.

As a non-state economy, TVEs must purchase inputs according to market prices under the dual-track pricing system; they cannot obtain low-interest loans from the state-owned banks and face harder budget constraints than the SOEs. Therefore, their gross increase of tax was largely equivalent to the net increase of tax revenue to the state, whereas the net increase of tax revenue from SOEs was calculated after deducting government subsidies and discounted loan interest (Lin et al. 2003, p.199). Between 1990 and 1994, Chinese national tax revenue increased by RMB 204.2 billion, of which RMB 80.4 billion was from TVEs, accounting for $39.3 \%$ of the total. Also, TVEs constituted one of the major sources of local government EBFs in China. According to Lin et al. (2003), at least one-third of Chinese local government EBFs had come from TVEs in the mid-1990s. From 1985 to 1990, the increase of the Gross National Product in manufacturing and tertiary industries was RMB 709.1 billion, of which RMB 213.4 billion was contributed by TVEs, accounting for 30.1\% of the total. From 1990 to 1994, these two figures were RMB 2,205 billion and RMB 1,186 billion, with the TVEs'

${ }^{49}$ Scholars like Jean Oi coined the term "local state corporatism" to describe this phenomenon. See Oi (1992). 
share standing at 53.8\%. By the mid-1990s, the rapidly-growing TVEs had become the major force in the growth of rural areas as well as of overall national economic growth (Lin et al. 2003, p.199).

The booming non-state sector led by the TVEs pushed the Chinese economy away from a heavy-industry-oriented structure to a more balanced structure that features consumer-goods manufacturing and a growing service sector. The declining energy intensity between the late 1970s and early 2000s serves as a good indicator to such trends (see Figure 1). In the planned economy featuring Soviet-style heavyindustrialisation from the 1950s and the early 1980s, the majority of resources available at the time were directed out of the rural agriculture sector and into heavy industries like metallurgy, heavy chemicals and machinery. Between 1949 and 1978, industry's share of economic output grew from 18 to 44 percent, and the amount of energy required to produce each unit of economic output tripled (Lin 1996, p.23). Within the industrial sector, heavy industry, whose energy intensity is many times that of light industry, contributed to over half of gross industrial output (Lin 1996, p.25). Only a few economies were in the same range of intensity of energy use as China in the early 1980s (Sinton and Levine 1994; Lin 1996). ${ }^{50}$ However, as the booming of local collective economies in the 1980s and 1990s, by 2000 Chinese economic activity required two thirds less energy per unit of output than in 1978, a huge economic efficiency improvement. Energy intensity reducing on this scale was unprecedented for a large developing country, and meant that China in the year 2001 accounted for only 10 percent of global energy consumption, rather than 25 percent based on a businessas-usual scenario (Rosen and Houser 2007).

\section{Local growth imperative and local heavy-industrialisation in the $2000 \mathrm{~s}$}

The mid-1990s saw the acceleration of privatisation as part of the 'letting go of the small' SOE reform strategy. Local government-owned SOEs and most collective firms were divested and privatised on a massive scale, and the importance of the private sector has steadily grown (Garnaut et al. 2006; Xu 2011). More importantly, the 1994

\footnotetext{
${ }^{50}$ In the early 1980s, the Chinese economy's energy intensity was one of the highest in the world. According to the World Bank, energy consumption per dollar of GDP was 2.13 kilograms standard coal equivalent (kgsce) in China, compared with $0.51 \mathrm{kgsce}$ in Japan, $0.57 \mathrm{kgsce}$ in the United Kingdom, 0.61 kgsce in Brazil, and $1.05 \mathrm{kgsce}$ in the US and India. See Lin (1996, p.23).
} 
fiscal reform significantly diluted the connections between local government and local collective economies. Under the fiscal contracting systems before 1994, TVEs were taxed primarily by local government at variable rates depending on the product type and their connections with local authorities. The product tax rates ranged from 3 percent to 60 percent (Bird and Wong 2005). Since 1994, the highly variable and complicated tax rate systems were replaced by a VAT for all manufacturing activities at the rate of 17 percent. The VAT was shared between central and local governments at the ratio of 75-25. This package of tax and fiscal reforms significantly altered the incentives for government involvement in industries. As they could no longer rely on profits and taxes from local collective firms to fill the gap between local revenue and local expenditure, most Chinese local governments have become more interested in developing those 'revenue-generating industries', especially heavy manufacturing sectors that depend on coal and power supplies. ${ }^{51}$

Beside industrial VAT, the 'spill-over effect' based on the forward and backward linkages of manufacturing value chain provided strong incentive for local government to promote those heavy industries passed down from central government and encouraged private and foreign firms to invest in related industries ( $\mathrm{Su}$ et al. forthcoming). Once heavy-industrial factories are built and start to operate, their backward linkages could also drive demand for industrial commodities such as coal, iron ore and construction material, which have been decentralised and delegated to the local government. A large amount of fixed assets investment to build urban manufacturing value chains could also boost local infrastructure buildings, such as energy supply, transportation, and telecommunications. What also appeals to local governments is the fact that the agglomeration of urban manufacturers will spill over and foster downstream industries and the service sector in the long run. Therefore, from a revenue perspective, urban industries do not only generate VAT and income taxes, but also contribute to a growing stream of Enterprise Income Tax (EIT) and Personal Income Tax (PIT) assigned solely to local governments between 1994 and 2011.

\footnotetext{
${ }^{51}$ Investments in manufacturing generate two kinds of tax revenue: the VAT and EIT. Under the 1994 fiscal system, local governments receive $25 \%$ of VAT, and all of the EIT, as well as the personal income tax paid by employees. Under the 1994 fiscal system, VAT and EIT together constitute the bulk of local budgetary revenue and have been the most stable revenue sources. The local retention rates for the enterprise and personal income taxes were adjusted in 2002-2003. Since 2003, local governments are allowed to retain the 2001 base amount plus $40 \%$ above the base amount while the central government receives $60 \%$ percent of the income taxes above the 2001 base amount. See Liu (2010).
} 
Additionally, local governments are eager to tap into new sources of EBFs, such as land lease fees and various administrative levies. ${ }^{52}$

Such enthusiasm to develop heavy industries is particularly evident in China's majority of landlocked central and western provinces. Those less-developed provinces have fewer choices of revenue-generating industries than their more developed coastal counterparts, who can benefit from matured private business and increasing FDI from the mid-1990s. However, many of them, such as Inner Mongolia, Shanxi, Shann'xi, Hebei and Henan, are blessed with abundant coal reserves, which are essential inputs for a wide range of heavy industries such as metallurgy, heavy chemicals and construction material. With the industrial decentralisation and deregulation in the late 1990s, heavy-industrial sectors featuring mining and energy-intensive manufacturing have become increasingly accessible and profitable to local government.

Besides the growing revenue imperative, the political dimension of central-local intergovernmental relations added extra weight for local government officials' enthusiasm to promote rapid industrialisation. With heated competition for political promotion focusing on local economic performance, Chinese local government reports or provincial yearbooks often contain detailed information on the relative rankings of the provincial performance, ranging from GDP growth, to steel production, and to miles of road constructed ( $\mathrm{Li}$ and Zhou 2005). For example, in an evaluation scheme for provincial leading officials, 60 percent of these leaders were assigned to targets related to economic growth (Tsui and Wang 2004). According to a handbook issued by the CPC party centre, 'work achievement' focusing on economic achievement accounts for 60 to 70 percent of the evaluation of regional officials, while other aspects, such as political integrity, competence and diligence together account for the remaining 30 to 40 percent (Edin 2003; Xu 2011, pp.1092-1094). At a time when the 1994 fiscal reform has significantly diluted fiscal interest linkage between local officials and local business, political promotion becomes increasingly important in local government officials' incentive structure.

\footnotetext{
${ }^{52}$ In fact, Chinese local government has been using local land lease as an important financing measure since the 1994 fiscal reform. See Lu and Sun (2013).
} 
At last, around 2000/2001 a new round of commodity boom began with the passing of the Asian Financial Crisis and China's accession to the WTO. Heavyindustrial business such as coalmining and metallurgy became increasingly lucrative. The decentralisation of heavy industrial SOEs and growing profits provided both strong fiscal-political incentives and opportunities for local government's deep involvement (Tao and Yang 2009). As a result, It has been well-documented by international experts that the last three years of the 10th FYP from 2002 to 2005 were marked by an impressive boom in economic growth and a surge in the output of heavy industry in China (Naughton 2007, p.140-175). The national energy efficiency gains made during the 1980s and 1990s were reversed from 2002. As energy intensity rose, the production and consumption of all forms of energy accelerated and levels of emissions of both carbon and other pollutants also surged (Andrews-Speed and Dannreuther 2011, p.15).

\section{Chapter Summary}

This chapter provides analysis on the 1990s institutional reforms under the Jiang-Zhu leadership and find they have created an imbalanced structure of industrial development at the subnational level from the early 2000s, which proudly impact the development of the country's energy sectors and their downstream industries in the following decade. The 'imbalance' of this structure mainly refers to the asymmetrical pattern of stateindustry institutional connections at the national and sub-national level.

At the national level, through "grasping large" SOE reform, the central government has successfully strengthened its close institutional connections with industries in the strategic sectors of the economy. Such connections are established and consolidated by the formation of the centrally-controlled yangqi fleet and by the State Council SASAC's effective yangqi management mechanism to assure that vital national interests defined by the party-state leadership are being closely followed by the major SOEs. A typical case has been the restructured NOCs that monopolise China's OPVC on behalf of the central government. At the subnational level, however, the central-local relations adjustment drastically remodified institutional connections between the government and industry, first by shaping local government political-fiscal interest to promote local economic growth. More importantly, the SOE reform has put the previously centrally-controlled heavy industries and investment regulatory power in 
the localities' hands, which caused uncontrolled heavy-industrialisation in many provinces. Such an imbalanced structure emerging out of the historical reforms in the 1990s has served as an institutional foundation for China's energy-based industrial development in the following one and half decades.

In the following two chapters, the two cases of CMVC and OPVC will be investigated to see how this imbalanced structure affected China's energy-based industrial development asymmetrically, benefiting China's national energy security but at the same time causing severe energy efficiency problems that challenged the national strategy of Scientific Development from the early 2000s. 


\section{Chapter Five: Case Study I - CMVC Restructure in the 1990s and China's Energy Efficiency in the 2000s}

Chapter Five and Chapter Six provide two contrasting cases of CMVC and OPVC. These two cases aim to examine how this imbalanced structure affects China's energybased industrial development asymmetrically by benefiting China's national energy security but causing energy efficiency problems that challenge the national strategy of Scientific Development from the early 2000s.

Chapter Five analyses the development of China's CMVC over the past several decades as a case of local government's growing influence, and the central governments' losing control, over China's coal-based heavy industries after the 1990s' institutional reforms. The focus of the analysis is how the reforms reshaped institutional connections between Chinese state and the CMVC, which profoundly impacted the country's overall energy efficiency situation in the 2000s. Section 5.1 briefly reviews the building and reform of CMVC and examines how the central government and the CMVC were closely inter-linked by mechanisms of economic planning and administrative control. Section 5.2 explores how the 1990s' SOE reforms re-shaped the connections between the state and the CMVC by 'diluting' the central government's control over the CMVC at the national level, and at the same time allowing local government to build institutional connections with the value chain at the subnational level. How industrial decentralisation and sectoral deregulation in the 1990s enabled local governments and private sector to access and influence the CMVC since is the focus of this section. Section 5.3 sheds light on Chinese provinces' role in the hypergrowth and expansion of CMVC in the 2000s with a focus on the energy-intensive metallurgy sector. And finally, Section 5.4 will point out the economic structure and efficiency problem caused by the hyper-expansion of decentralised CMVC heavyindustries as a major unintended consequence of the 1990s' institutional reforms, and why the central government under a new generation of leadership had to react by introducing energy efficiency targets to tackle the problem in the 11th and 12th FYPs. 


\subsection{Formation of China's CMVC and Industrial Energy Efficiency in the 1980s}

\subsubsection{Formation and Development of China's Centralised CMVC 1950s- $1980 \mathrm{~s}$}

Since a centrally-planned economy was established in China in the mid-1950s, the development of coal mining, electric power production and metallurgy have been a constant priority of China's industrial development policy in FYPs. These sectors were fundamental to the CPC's industrialisation ambition not only because of the vital role they play in defence industry, but also because of the inter-industrial linkages that connect them with a wide range of industries in the Chinese economy. As a result, in the planned economy era and the early reform years in the 1980s, the China's CMVC was highly centralised, featuring the central government commissions and ministries' operational control.

\section{Coalmining sector}

Due to coal's fundamental role as a major primary energy source for industrialisation, the newly established PRC quickly nationalised most foreign coalmines and the Nationalist government coalmines and put them under the central government's supervision after 1949. Coalmining and coal distribution were put as a central component of the commodity planning system. In 1949, state-owned coalmines accounted for 68 percent of China's total coal production. By 1954 when the first FYP began to be implemented, state-owned coalmines already accounted for 93 percent of national total coal production (Peng 2009). In the following three decades, the central government-owned major state coalmines met the bulk of China's coal consumption.

In 1955, the Chinese leadership felt it was necessary to set up an independent ministry in charge of the coal sector. ${ }^{53}$ Thus, the Ministry of Coal Industry (MCI) was established by separating the coal sector planning and administrative functions from the Ministry of Fuel Industry, to grant the coal sector greater autonomy and a more coherent planning structure. Similar with the Ministry of Petroleum Industry (MPI), the

\footnotetext{
53 There were 24 coalmining projects within the 156 key projects designed with aid from the former Soviet Union in the first FYP from 1953-1957.
} 
Ministry of Coal Industry (MCI) was given proposed output targets which were communicated to all the various sub-units, mainly its regional coal-administrative bureaus that were built to manage major state owned coalmines across the country. The coal sector planning also involves a series of complicated balance tables to command the annual production and consumption of coal across regions and sectors of the economy, and to schedule the mode and route of transportation for raw coal production. Under the supervision of the State Council's general economic planning agencies, such as the SPC and SEC, the MCI oversaw the development of coalmining, coal processing and related coal capacity building, such as special railway lines for coal transportation (Thomson 2003).

China's coalmines under the planning economy were divided into three main categories according to types of ownership: Major State Coalmines (guoyou zhongdian meikuang), the Local State Coalmines (guoyou difang meikuang), and Township and Village Coalmines (TVCs) (xiangzheng meikuang). Major State Coalmines were directly administered by the MCI and were under the supervision of other central planning agencies such as SPC. The Local State Coalmines were operated either by provincial, prefectural, or county governments, while TVCs were operated by townships, communes, or collectives. Although the Local State Coalmines were usually administrated by Provincial Coal Industry Bureau, their output was also generally under unified distribution planned by the MCI and other central planning agencies, which means their raw coal production must be sold to certain industrial users designated by the centre at state planning prices. The provincial Industry Bureau usually functioned as regional planning agency to manage raw coal production from TVCs (Thomson 2003; Peng 2009). Over the three decades from the early 1950s to the early 1980s, raw coal production from the unified distribution coalmines met most of China's coal demand. In 1978, over 80 percent of raw coal production was contributed by the unified distribution coalmines (Peng 2009). Chinese central planners fully recognised the coal sector's importance to its downstream industries, especially electric power and metallurgy. During most of the time from the 1950s to the early 1980s, coal was seen as a 'category one' commodity, over which the state exercised particularly strong control (Wong 1985). Even during the 1980s' price reforms that applied market-based pricing 
applied to most commodities, the price for unified coal distribution was tightly regulated by SPC and set very low to boost downstream power generation and metallurgical production, as well as to prevent inflation.

\section{Coal-based power sector}

As the midstream of CMVC, the Chinese power sector was a vertically integrated state utility sector with complete central government control until 1985. Power generation, transmission, distribution and retail were all planned, managed, and owned by the central government. The Ministry of Electric Power (MEP) was the primary controller of the whole power sector and was supported by the regional, provincial, municipal, and county power bureaus at the local levels (Yeoh and Rajaraman 2004). It ran both the country's generating plants and the major power grids that connected power plants with industrial power consumers. Nationwide, the large and modernised coal-based thermal power plants were virtually all owned and under the direct management of MEP. For local government, only some provincial governments had very limited power capacity (Lieberthal and Oksenberg 1988, pp.94102).

The MOE and its subordinate units had close liaison with the upstream coalmining sector and downstream industrial consumers such as metallurgy. This is demonstrated by the low thermal coal price and the low power price for industrial users during the planned economy and the early stage of reform in the 1980s. Before the price reform was introduced in the 1980s, thermal coal used for power generation (dian $m e i)$ was seen as vital to the operation and expansion of China's power capacity. Thus its price was kept very low to boost power generation. ${ }^{54}$ The central planners also kept electricity for industrial use very low to facilitate the downstream industrial SOEs' development. As summarised by Lin and Tsai (2004), this systematic distortion of price was perceived to be necessary to achieve industrialisation in a command economy.

\footnotetext{
${ }^{54}$ In fact, the state's price control over dianmei was not totally eliminated until 2002 when China started a new round of power sector reform. See Xu (2011).
} 
In the downstream metallurgy sector, iron and steel making and aluminium making are the two most important sectors in terms of energy consumption and metal output. Iron and steel making was pivotal to a modern state's national defence and development. However, in 1949, China's national total production of pig iron was only 250,000 tonnes, and the steel production was 158,000 tonnes, accounting for a mere $0.2 \%$ of the world's total steel production and ranking No.26 in the world (Song and Liu 2012, p.2). One of the central objectives of the CPC's heavy-industrialisation ambition was to boost China's metallurgical output to catch up with major industrialised economies. The early Chinese top leadership, in particular Mao himself, had strong sense for developing metallurgical industries in China. "gongye fazhan yigang weigang" (steel is the principle of industrialisation) became China's industrial development policy guideline between the 1950s and 1970s (Yuan 2007). One of the central objectives of the Great Leap Froward in 1958 was to boost Chinese iron and steel production to catch up with that of the UK and US within a decade. ${ }^{55}$ Thus, from the beginning of its industrialisation, China's industrial and financial resources were disproportionally poured into heavy industries such as metallurgy (Lin 1996; Rosen and Houser 2007).

Due to the strong inter-industrial linkages between the CMVC sectors, development of metallurgy heavily depends on energy and raw material inputs. Thus, a Ministry of Heavy Industries (MHI) was established in 1949 and expanded in 1954 to administer and coordinate the development of coalmining, metallurgy and other heavychemical industries. Thus, the MHI became one of the earliest industrial line ministries under the State Council and was the predecessor of most heavy-industrial line ministries merged in the following decades. During the first FYP 1953-58, eight major metallurgical projects were constructed. China's metallurgical output, especially the

\footnotetext{
${ }^{55}$ A "Great Iron \& Steel Campaign" (dalian gangtie) was initiated as the central component of the Great Leap Forward (1958-1961). It targeted to boost China's iron \& steel production by building millions of 'backyard steel furnaces' to catch up with Western countries' steel production within a decade. Although the campaign hardly produced any qualitative metal and brought huge damage to the ecological system, it nonetheless proved the Chinese leadership's resolution to build a strong metallurgical industry in a short time. See He (1999).
} 
iron \& steel output, began to grow rapidly. When the MHI was abolished in 1956, the Ministry of Metallurgical Industries (MMI) was established. ${ }^{56}$ The core function of the MMI was to plan, administer and regulate the state-owned metallurgical sector. Its Ferrous Metal Bureau and Non-Ferrous Bureau were the two core departments of the ministry. Under the planning and administration of the MHI/MMI, the central government built and upgraded several iron \& steel projects during the first FYP 19531957 and laid the foundation of China's metallurgical industries. Between 1958 and 1970, three very large centrally-owned steel enterprises (Anshan Steel, Wuhan Steel and Baotou Steel), five large centrally-owned steel enterprises (Taiyuan Steel, Shijingshan Steel, Chongqing Steel, Hunan Steel and Ma'Anshan Steel), and 18 province-owned medium-to-small steel manufacturers were established. These 26 iron and steel manufacturers represent virtually all of Chinese iron and steel productivity during the planned economy (He 1999). Besides the steel manufacturing, due to the irreplaceable role of non-ferrous metals in providing raw material to key sectors such as defence industry and telecommunication, non-ferrous metal manufacturing also developed quickly under the planning of MHI and MMI. There were 31 non-ferrous projects constructed during the first FYP 1953-58, with 16 non-ferrous ore-mining enterprises and 15 non-ferrous metal manufacturers. These state-owned mines and plants made the backbone of China's non-ferrous industry during the planned economy. Among the non-ferrous metal productivity, aluminium manufacturing has consistently accounted for more than half of the output (He 1999).

After three decades of rapid industrialisation, the industry sector's share in the output of the Chinese economy reached 44 percent and the amount of energy required to produce each unit of economic output tripled in the early 1980s. Within the industrial sector, heavy industries contributed to over half of gross industrial output (Lin 1996, p.25). By 1981, metallurgical energy consumption accounted for around 22 percent of China's total industrial energy consumption. This mainly included around 38.6 million tonnes of coking coal, 15.8 million tonnes of thermal coal, and 30.2 billion kwh of

\footnotetext{
${ }^{56}$ Several industrial line ministries, such as the Ministry of Metallurgical Industries (MMI) and the Ministry of Chemical Industry (MCI), were established in 1956 to take over its industrial planning functions. See ibid.
} 
electricity (Lin 1996, p.140). ${ }^{57}$ China's limited industrial and financial resources were disproportionally allocated to heavy industries, making its industrial energy intensity one of highest in the world and the whole economy's energy efficiency very low (Rosen and Houser 2007). ${ }^{58}$

\subsubsection{Central Government Control over Industrial Energy Intensity in the $1980 s^{59}$}

\section{Institutional basis of central government's industrial energy control}

Besides the structural shift of the Chinese economy due to the growth of light-industryfocused rural collective economies, another factor contributing to China's industrial energy intensity decline in the 1980s and 1990s was the Chinese central government's energy intensity management system (Liu et al. 1994; Sinton and Levine 1994). Such a system was built on a command economy to monitor and improve the production efficiency of state-owned heavy industries. Over the sixth and seventh FYPs' period (1981-1990), the central government had established a nation-wide system thanks to the majority of centrally-owned SOEs in the urban industrial sector in the 1980s and early 1990s. Nevertheless, when China's economic transition deepened from the early 1990s with large-scale SOE reform and intergovernmental relations adjustment, such system of energy efficiency governance lost the institutional basis it was built upon and most mechanisms ceased to work from the early 1990s.

China's industrial energy intensity control system in the 1980s was constituted by a series of agencies and industrial actors from the central to the local government, and extended to directly cover individual major energy-consuming SOEs. The highest government body of the system and the paramount energy efficiency regulator was the State Council Energy Conservation Office (SCECO, guowuyuan jieneng'ban). The SCECO played a vital role in making overall energy efficiency policy guidelines

\footnotetext{
${ }^{57}$ In metallurgy, coking coal was used to produce coke, which was then fed into blast furnaces for ironmaking. For the use of thermal coal and electricity in metallurgy, see footnote no. 22 on page 46.

${ }^{58}$ Also see footnote no. 50 on page 114.

${ }^{59}$ The historical data on China's industrial energy intensity governance in this section were all collected during the author's internship in China Shenhua Group over January-February 2013 unless otherwise indicated.
} 
directly supervised by the State Council Premier. With the office's sponsor, the State Council used to hold an annual Energy Conservation Working Conference in every December between 1985 and 1993. Hosted by the Vice-Premier in charge of urban industrial development, the country's most important industrial planners and regulators were gathered to coordinate energy efficiency polices and projects in the following year. In 1986, the SCECO summarised the successful energy efficiency governance experiences during the Sixth FYP (1981-1985) and issued two regulations that laid the foundation for systematic energy efficiency governance in the Seventh FYP (19861990). ${ }^{60}$

With the two regulations, the SCECO established a centralised top-down national energy efficiency governance system. All industrial line ministries and provincial governments must establish energy intensity standards for major industrial products under the guidance of the SCECO. Major energy-consuming SOEs' energy efficiency performance in relation to these standards will affect their energy supply quotas and the award of financial bonuses to SOE managers. Under the guideline set by the SCECO, the SPC and industrial line ministries were responsible for working out more specific policies and industrial regulations. The SPC Bureau of Energy Conservation was established at the beginning of the Sixth FYP to carry out national energy conservation policymaking and planning. Industrial line ministries were responsible to issue energy conservation regulations applied to subordinate SOEs. The Ministry of Machinery and Electronic Equipment, for example, developed and manufactured more than 2,000 items of energy conservation equipment, published 11 official lists of energy-intensive products that should be phased out, and promoted adoption of 13 electricity-saving technologies across the country (Liu et al. 1994). Provincial governments also worked pro-actively to issue their own energy efficiency regulations that applied to local government-owned SOEs. Between 1983 and 1988, the SPC Bureau of Energy Conservation sponsored the annual Working Conference of National Energy Conservation that aimed to push local governments' energy

\footnotetext{
${ }^{60}$ In 1986, with the advocate of SCECO, the State Council passed two key regulations - Temporary Regulations for Energy Conservation Management, and Decision Regarding Strengthening Industrial Enterprises Management. The regulations summarise the successful energy efficiency governance experiences during the Sixth FYP (1981-1985) and laid the foundation for systematic energy efficiency governance at local government and major SOEs in the Seventh FYP (1986-1990). See Liu et al. (1994).
} 
conservation. For example, at 1984's conference, a total of 110 local officials from 28 provincial governments who were in charge of local energy conservation work attended the conference to study the State Council's guidelines on energy conservation and discuss their localised implementation. As a result, almost all the provincial governments passed their own energy efficiency regulations by the mid-1980s. Besides institutional arrangements, the central government during the Sixth Five-Year Plan poured funds equal to about 11 percent of energy supply budget into energy conservation projects.

Such state commitment and fiscal investment in industrial energy efficiency was very remarkable especially given the central government's deteriorating fiscal situation under the 1980s fiscal contracting system. As a result, in the 1980s China had systematically incorporated industrial energy intensity management in the country's industrial development in a way that few countries could parallel (Sinton et al. 1998).

\section{The central role of metallurgy sector}

The effect of government energy intensity management was particularly evident in heavy industrial sectors. In the 1980s, the country's three most energy-intensive industrial sectors were metallurgy, chemicals, and building materials (mainly cementmaking). They respectively accounted for about 20 percent, 17 percent and 15 percent of China's energy end-uses consumption in 1990 (Liu et al. 1994, p.18). The net energy conserved in the industrial sector over the seventh FYP period alone totalled 608 Mtce. Half of the total savings were contributed by energy efficiency improvements in the three sectors (Liu et al. 1994, p.18). Especially in the downstream sector of CMVC, strict national and local industrial efficiency regulations and standards were promulgated, and administrative mandates were given by energy conservation agencies to eliminate inefficient equipment and processes, and the adoption of efficient ones were supported by government funding.

In ferrous metals manufacturing, the iron and steel industry accounted for roughly $16 \%$ of China's total energy end use in industry by 1990 . Energy conservation projects significantly reduced the energy intensity of ferrous metals manufacturing: nearly one-third of the increase in steel production resulted from conservation investment that increased its energy and raw-material utilisation efficiency (Liu et al. 
1994, p.v.). Government regulations and investments helped reduce steel and iron production energy intensity by $1.6 \%$ annually during the seventh FYP period (19861990). Some government-funded technological renovations, including more efficient coal injection in blast furnaces, continuous casting and rolling processes, and renovated boilers and furnaces, have brought some of China's major iron and steel manufacturing SOEs to levels comparable to those of the developed world for the first time (Liu et al. 1994, p.v.).

Energy conservation gains in the non-ferrous sector mainly came from electricity conservation at aluminium manufacturing during the seventh FYP. In 1987, the SPC and SEC jointly promulgated levels of annual electricity allocation quota to those power-intensive SOEs. Electricity consumed in excess of the quota was to be priced at 5 to 10 times the normal price. For electricity saved within the annual quota there were awards for SOEs and its managers. SOEs, on the other hand, could sell the quota of electricity they conserved to raised energy conservation funds. This document further required key power-intensive industrial sectors, especially aluminium making, to set electricity-consumption standards for their main products and equipment, which covers $70 \%$ of total industrial electricity use in China in 1987 (Liu et al. 1994). With such mechanism, state-owned aluminium manufacturers reduced their electricity intensity significantly. It is documented that many aluminium SOEs reduced electricity consumption by as much as 300-500 kWh/ton. The Zhengzhou Aluminium Company (Henan Province) under the administration of MMI successfully reduced its electricity consumption by $700 \mathrm{kWh} /$ ton of aluminium (typical electricity intensity was nearly 15 MWh/ton) by 1990 (Liu et al. 1994). Similar energy efficiency improvements also took place in chemical and building material manufacturing from the Sixth to the seventh FYPs' period (Sinton et al. 1998).

However, such a system began to dismantle in the eighth FYP period (1991-95) firstly due to the "grasping the large, and let go of the small" SOEs reforms. Lossmaking energy-intensive SOEs, in particular downstream energy consuming sectors of CMVC, were systematically liberalised, with major SOEs delegated to local government, making local governments and private capital progressively access to the traditionally centrally-controlled CMVC. While the central government was focusing on building a 'national team' of elite yangqi and monopolising strategic sectors such as 
OPVC, industrial energy intensity control was largely ignored in the 1990s' institutional reforms. In other words, at a critical juncture of China's transition, energy efficiency governance failed to be integrated into the institutional reforms to maintain the institutional connections between the central government and the coal-based heavyindustrial value chains.

\subsection{0s Institutional Reforms and Decentralisation of CMVC}

China's energy efficiency improvement in the 1980s and 1990s depended on two key factors - economic structural change that shifted away from heavy industries, and the

central government's effective industrial energy intensity control. However, by the late 1990s and early 2000s, neither of the two factors existed due to the Jiang-Zhu leadership's reforms that profoundly changed the institutional connections between the state and the industries at the national and sub-national levels. First, as "grasping the large, let go of the small" was adopted as the guideline to reform the SOE institution, the majority of China's energy-intensive heavy industries were decentralised and deregulated. The central government lost most of its command and regulatory leverage to control industrial energy intensity. Second, to many of the revenue-starved and growth-oriented Chinese local governments, the decentralisation and deregulation of heavy-industrial sectors presented a good opportunity to boost local development. As a result, by the early 2000s, locally-initiated heavy industrialisation emerged and reversed the two-decade decline of China's industrial energy intensity. For the Chinese central government under the newly-installed Hu-Wen leadership, such a situation posed a direct challenge to their Scientific Development ideational system.

\subsubsection{The Coalmining Sector Reform}

In the 1990s' SOE reform, the Chinese coalmining sector that produces the "No.1 commodity" for heavy-industrial value chains became almost completely decentralized and market-based. Thus, the localisation of the upstream coal sector provides the fundamental energy basis to the local proliferation of its downstream heavy industries, especially coal-based electric power and metallurgy in the 2000s. 
In 1985, the enterprise production contracting system was introduced to the unified distribution coalmines to provide market incentives to the sector. Such reform was greatly facilitated by wider economic reforms in the 1980s, such as revenuesharing between the central and local governments, SOE reforms, and the boom of Township and Village Enterprises (TVEs). The coalmining sector thus began to become increasingly market-based.

All these developments in the Chinese coal sector were firmly supported by Chinese local governments down from the provincial level. The fiscal contracting system from early 1980s to early 1990s brought local government officials much enthusiasm for promoting local business. For those regions with abundant coal reserves but located remotely from the more developed coastal area, to encourage coalmining and industrial coal consumption became a viable choice to boost local revenue. With these reforms, Chinese coal production began to pick up quickly from the mid-1980s. Total coal production rose from 635.5 million tons in 1979 to 1.1 billion tons in 1992 . Most of the production increase was contributed by provincial government-owned coal mines and TVCs, which raised their output more than two-fold from 277.8 million tons in 1979 to 632.0 million tons in 1992; in contrast, the centrally-owned major coalmines' output grew more slowly, only increasing from 357.8 million tons in 1979 to 482.5 million tons in 1992 (Peng 2009, p.15).

During the first half of the 1990s, as the coal sector was quickly "growing out of plan" under the dual-track pricing, the timing to reform the coal pricing system from command-based to market-based was ripe. In 1994, the MCI decontrolled the coal price nation-wide, and thermal coal and metallurgical coal from all mines began to be sold at market price. Average coal price jumped by almost two-fold from RMB 58 Yuan per ton in 1990 to 109 Yuan in 1994, making coalmining a highly lucrative business. Although the SPC re-controlled the price for power-generation thermal coal between 1996 and 2002 to ensure a stable electric power supply, the coal sector basically became market-based from 1994 (Xu 2011). 
As the "grasping the large and letting go the small" principle on SOE reform was introduced in 1997, the Chinese coalmining sector began a large scale decentralisation which saw most centrally-owned major state coalmines being handed to the local government. In 1998, the Ministry of Coal Industry was abolished and its coalmining regulatory functions were transferred to SETC. Following this, the ownership and administration for all of China's 94 centrally-owned large coalmines were transferred to a total of 23 provincial and municipal governments along with all their mining assets, employees and affiliated service units like hospitals and schools. ${ }^{61}$ The fiscal auditors to these coal enterprises were also assigned from the local governments, with taxes generated by these coal enterprises going to local governments. These coalmines together produced 40 percent of China's raw coal with relatively advanced technology, equipment and coal-processing capacity (Thomson 2003, p.165). As a result, compared to the local coalmines, especially the small TVCs, a much higher share of raw coal produced from these large mines can be utilised by industrial consumers as thermal coal for power generation and coking coal for metallurgy. ${ }^{62}$

\subsubsection{The Power Sector Reform}

The Chinese power industry faced serious challenges to expand power-generation capacity to meet surging demand for electricity in the 1980s. The highly-centralised electricity industry impeded the rapid expansion needed by the power sector to sustain high-speed economic growth. As the central government started to allow local governments, SOEs and foreign companies to invest in the Chinese power sector, in the

\footnotetext{
${ }^{61}$ The only exception was China Shenhua Group. The Shenhua Group was established under the MCI in 1995 and has since stayed as a centrally-owned SOE under the State Council SASAC up to now. The first reason that Shenhua Group was not decentralized is that Shenhua Group is a vertically integrated firm requiring approval and coordination from more than four ministries and six provincial governments, each responsible for either the coalfield, or local land, or infrastructure. It would be very difficult for a local firm to coordinate these complex interests. The second reason is that Shenhua Group faces little competition from local coalmines. There are far fewer local coalmines in Shenfu Dongshen coal fields because the public infrastructure is poor.

${ }^{62}$ The coal production from TVCs, although accounting for an increasing share of China's total raw coal production throughout the 1980s and 1990s, were mostly utilised as fuel to produce heating in the residential sector rather than industry due to their low quality.
} 
1990s and early 2000s, local government started to become a major player in the power sector (Zhang and Heller 2007, p.76).

From the mid-1980s, the central government began to deregulate the power investment system by relaxing sectoral investment approval. Much of the decisionmaking authority for power generation investment with 50MW generating capacity or less was delegated to provincial governments (Xu 2011). To encourage investments, central government promised power investors that they would enjoy preferential use of electricity and guaranteed profits. Also, higher power prices and long-term buying contracts for electricity were permitted, which would guarantee a 15 percent rate of return to investors (OECD/IEA 2006). Due to local governments' strong incentives to improve local infrastructure to attract investments in the 1990s, these reforms yielded a rapid expansion of the Chinese electricity industry. A constellation of local government actors started to extend deep into the power generation sector, including provincial government investment funds and local government SOEs. By 1995 over 40 non-state power investment companies had begun operation and helped to established a growing group of power plants that are characterized by some scholars as 'independent power producers (IPPs)' (Woo 2005). By the end of the 1990s, the proportion of generating capacity controlled by central government was reduced to less than 50 percent (Cunningham 2009, p.109).

The diversification of power project investors and delegation of power capacity building had brought much complexity into the Chinese power sector, which significantly weakened the central government's control over the whole power sector. Because the coal-fired power plants controlled by provincial governments mainly relied on local coalmines for coal supply, local manipulation over the local power sector began to emerge and plague the Chinese power market. ${ }^{63}$ Therefore, in 1996, the State

\footnotetext{
${ }^{63}$ Power dispatch (i.e., turning generators on and off to adjust the power dispatched to the grid as demand for power changes over time) decisions made by the provincial local governments' power bureaus were widely observed as in favour of local government-owned power plants, rather than in order of economic efficiency. Those central government-owned power plants complained that they were discriminated against by the local government power bureau. Such local influence over power sector was regarded as a key factor causing the low-efficiency of the Chinese power sector in the 1990s and has harmed the profitability of power plants owned by central government. See Cunningham (2009).
} 
Council decided to put all centrally-controlled power assets - about 49 percent of China's total installed power capacity and China's national power grid - under the roof of a newly established State Power Corporation of China (SPCC) to consolidate central government's guidance over the power market, also a means to restructure state-owned power assets to "grasp the large" (State Council 1996[48]). Thus, the SPCC immediately became one of the largest centrally-owned energy enterprises.

It was supposed to resolve local manipulation of power generation and dispatch by integrating the central government's power generation assets located in different provinces to coordinate the power grid management nationally. However, the troubles experienced by the SPCC soon demonstrated the steadily-growing local government influences and interests in the power sector. Local manipulation of power management was not mitigated with establishment of the SPCC. In some provinces, regional subsidiaries of the SPCC were dispatching plants owned by the firm. In other provinces, provincial government manipulated local dispatch centres to dispatch locally owned plants. Many employees in these SPCC dispatch centres, originally employees of the provincial power bureau and only recently (and technically) employees of the SPCC, had invested their personal funds into vast swathes of the provincial or local government owned electric generation capacity, thus dispatching to local firms for their own financial interest. Such local manipulation of the SPCC's daily operation was largely responsible for the SPCC's poor efficiency. In 1998, despite controlling over 49 percent of national electric power generating capacity, the SPCC had earned a mere RMB7.01 billion in net profits, based on sales revenue of RMB260.64 billion. Such poor performance led to the breakup of the SPCC into more than ten smaller electric power enterprises that were taken over by the State Council SASAC in 2002 (State Council 2002[5]). ${ }^{64}$

This episode of power sector reform between the mid-1990s and early-2000s clearly indicates the growing influence of local government in the Chinese power sector. In 2007 , the power generation capacity owned by local government, mainly provincial

\footnotetext{
${ }^{64}$ These power yangqi include five generation companies (termed the "Big Five"), two grid companies and several service and ancillary companies. See OECD/IEA (2006).
} 
governments, surpassed that owned by the central SOEs and accounted for 51 percent of China's total installed capacity (Cunningham 2009, pp.95-110).

\subsubsection{The Metallurgy Sector Reform}

As pointed out in Chapter Two, when a country's primary energy mix is stable, it is largely the way that energy supplies are used by downstream industrial energy consumers that profoundly impacts the industrial energy intensity and the country's overall energy efficiency. The large-scale decentralisation of Chinese metallurgy following the "grasping the large and letting go the small" and the subsequent central government restructuring in 1998 plays a decisive role in building strong institutional connections between CMVC and local government at the subnational level, and diluting the institutional connections between CMVC and central government at the national level.

From the early 1980s, Chinese metallurgical industries were changed from a rigid system of state-fixed prices and centrally-planned purchase and sales to one allowing enterprises to purchase raw material and energy input, and to sell an increasing share of products in market under the dual-tracking pricing system and emerging domestic commodity market. In 1983, China Nonferrous Metal Industry Company (CNMIC) was established as a centrally-owned SOE under the MMI. The CNMIC was assigned to manage the state's non-ferrous mines and plants under the supervision of the MMI. The central government gradually reduced the production planning and pricing control on non-ferrous products. In 1985, state control and pricing for all but 14 non-ferrous products were abolished. For the ferrous sector, the central government gradually lowered the ratio of mandatory planned steel to only 20 percent in 1992 (Song and Liu 2012, p.3). Mandatory plans for production and sales of major iron and steel products were abolished and the dual-track steel price was replaced by a market-based price by $1994 .^{65}$

\footnotetext{
${ }^{65}$ At the same time, the central government continued to set guidance prices for several main steel products, partly to restrain inflationary pressures. See Nolan (2001).
} 
Along with the marketization process, a decisive step to reform the Chinese metallurgy market was the large scale SOEs decentralisation and delegation toward the end of the 1990s. During the 1998 central government restructuring, the MMI was downgraded to a state bureau affiliated with the State Economic and Trade Commission (SETC) between 1998 and 2002. With the downgrade of the MMI, the administration of the ferrous sector was firstly decentralised. Operational control of all but four centrally-owned major steel SOEs (Baosteel, Anstell, Wusteel, and Pansteel), were handed over to local governments (Zheng and Abrami 2011). ${ }^{66}$ For the non-ferrous sector, three centrally-owned non-ferrous metal groups, including China Aluminium Group, China Rare Earth Group, and China Group for Copper-Lead-and-Zinc, were established to replace the CNMIC in 1998. However, these three groups were disbanded only one year later, and most non-ferrous production units were handed over to the local government following the steel industry's example. Thus, the whole downstream metallurgy sector of the CMVC became market-based and highly decentralised by the early 2000 s.

In sum, the SOE reform in the 1990s has produced a highly decentralised and market-based CMVC in China. The decentralisation of the downstream metallurgy sector of CMVC is particularly important to determine China's overall energy efficiency. The scale and development of the metallurgy sector relative to the whole economy plays a key role in influencing China's overall energy efficiency. In this sense, by allowing the revenue-starved local government and private business to play a predominant role in the downstream metallurgical development, the Chinese central government practically lost control of the country's energy efficiency in the following decade. Energy efficiency governance mechanism therefore failed to be integrated into the new institutional design to maintain the connections between the central government and the energy-intensive industries.

\footnotetext{
${ }^{66}$ When the SETC was replaced by the NDRC in 2003, the State Bureau of Metallurgy was disbanded and part of its regulatory function was taken over by two industrial associations - China Iron \& Steel Industry Association, and China Nonferrous Metals Industry Association.
} 


\subsection{Local Government Interests and CMVC Growth in the 2000s}

As the SOE reform advanced in the late 1990s, the central government was focusing on restructuring highly-profitable strategic sectors such as OPVC. The decentralised CMVC industries gradually became a major source of local revenue and growth in the 2000s with the success of Zhu Rongji's "three-year target" to improve SOEs' financial situation and economic recovery after the Asian Financial Crisis, as well as China's accession to the WTO. As a result, Chinese local government, especially dozens of provincial governments that respectively control a significant share of the decentralised coalmines and electric power assets, are now capable of utilising them to actively promote the development of downstream metallurgy to boost local economic growth, and to benefit from the growth politically and fiscally.

After the 1990s' institutional reform, Chinese local government, especially at dozens of provincial governments, became owners or major shareholders of significant energy supply assets such coalmines and power generators. For these local governments, an ideal way to benefit from these decentralised assets and to promote local economic growth is to boost the local industrial demand, especially the energyintensive metallurgy manufacturers' demand. The role that Chinese local government plays in promoting metallurgy development since the early 2000s has been two-fold. On the one hand, many provincial governments directly own and manage a considerable share of metallurgical capacity in iron-and-steel making. On the other hand, many local governments proactively encourage and facilitate private investments in metallurgy by offering favourable energy supply deals that go against central government's policies and mandates, especially low electric power prices to local aluminium manufacturers.

\subsubsection{Iron \& Steel Capacity Expansion}

\section{Decentralised iron and steel capacity surge}

Throughout the 2000s, China's ferrous metallurgy sector featured two striking characteristics, the heavy involvement of local government and the fragmentation of the domestic market. China's iron and steel industry has experienced hyper-growth since the early 2000s. Between 1996 and 2004, China's iron and steel production surged from 
100 million tonnes to 272 million tonnes, making China the largest steel producer and first country to surpass 200 million tonnes in the world (Chinanews February 4, 2005; Yuan 2007). At the same time, the profitability of heavy-industrial sectors along the CMVC had kept rising. In 2002, China's iron and steel sector achieved a RMB 91 billion Yuan net profit, representing a 66 percent net profit increase compared to that of 2001. Such a profitability jump made the iron and steel industry China's second most profitable industrial subsector, next only to crude oil and gas E\&P during the 10th FYP period (Zhu Janurary 4, 2005). By the end of the 10th FYP in 2005, China produced 356 million tons of crude steel, accounting for a little more than one-third of the world's total crude steel production (Worldsteel December 2006). By the end of the eleventh FYP in 2010, China's crude steel production had jumped nearly two-fold and reached a staggering 627 million tons, accounting for almost half (44 percent) of the world's total crude steel production that year (Worldsteel December 2010). At the same time, the Chinese iron and steel market is highly fragmented, featuring provincial governments' heavy involvement (see Figure 8 below, and Figure 9 and Table 3 on the following two pages).

\section{Figure 8 Structure of Top-10 World Steel Producers (as of 2010)}

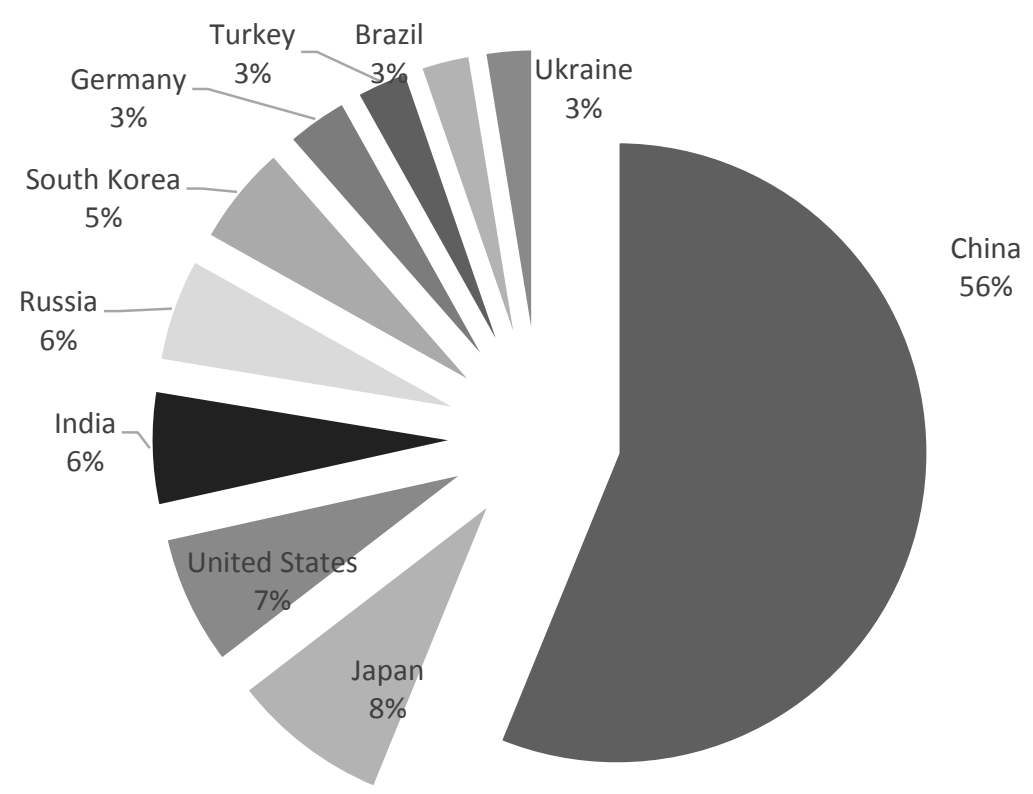

Data Source: Worldsteel (December 2010) 
Figure 9 China's Steel Production by Provinces as Percentage of National Total (as of 2005)

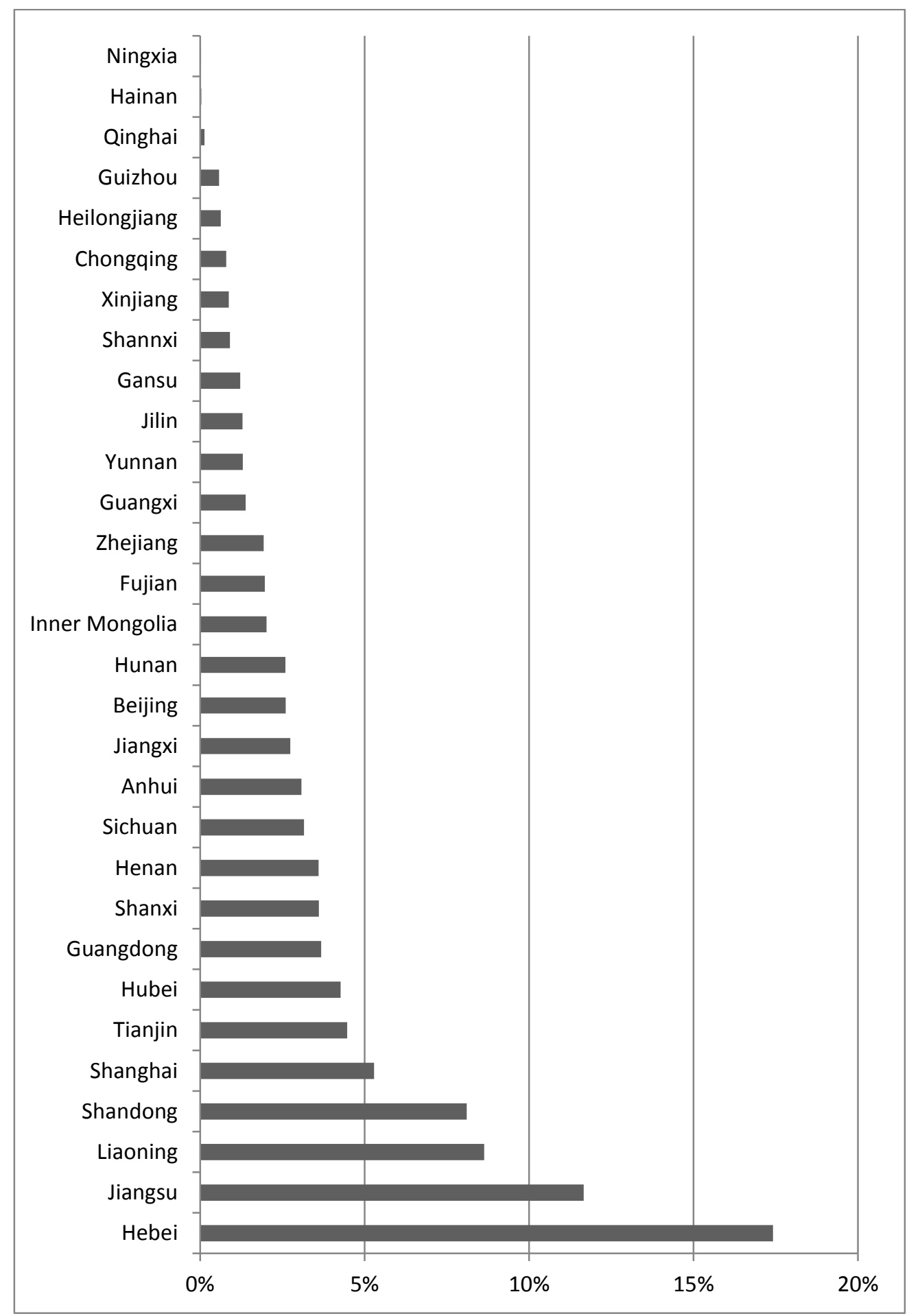

Data Source: China Steel Association (2013) 
Table 3 Ownership of China's Top-20 Steelmakers (as of 2010)

\begin{tabular}{|c|c|c|c|}
\hline Rank & Enterprise & $\begin{array}{l}\text { Capacity (Million Tons, as } \\
\text { of 2009) }\end{array}$ & Owner/Majority Shareholder \\
\hline 1 & Hebei Iron \& Steel Group & 40.24 & Heibei Provincial Govt \\
\hline 2 & Baosteel Group & 38.87 & State Council SASAC \\
\hline 3 & $\begin{array}{l}\text { Wuhan Iron \& Steel } \\
\text { Group }\end{array}$ & 30.35 & State Council SASAC \\
\hline 4 & $\begin{array}{l}\text { Anben Iron \& Steel } \\
\text { Group }\end{array}$ & 29.18 & $\begin{array}{l}\text { Liaoning Provincial Government } \& \text { State } \\
\text { Council SASAC }\end{array}$ \\
\hline 5 & Shagang Group & 26.38 & $\begin{array}{l}\text { Private Entrepreneurs (64\%), Labour } \\
\text { Union (18\%) and Runyuan Trading Co. }\end{array}$ \\
\hline 6 & $\begin{array}{c}\text { Shandong Iron \& Steel } \\
\text { Group }\end{array}$ & 21.31 & Shandong Provincial Govt \\
\hline 7 & Shougang Group & 17.29 & State Council SASAC \\
\hline 8 & Xinwu'an Group & 16.71 & $\begin{array}{l}\text { Private Entrepreneurs }(84 \%) \text { and Wu'an } \\
\text { City Govt }(16 \%)\end{array}$ \\
\hline 9 & Magang Group & 14.83 & Anhui Provincial Govt \\
\hline 10 & Valin Iron \& Steel Group & 11.81 & Hunan Provincial Govt \\
\hline 11 & $\begin{array}{l}\text { Baotou Iron \& Steel } \\
\text { Group }\end{array}$ & 10.07 & Inner Mongolia Govt \\
\hline 12 & $\begin{array}{l}\text { Rizhao Iron \& Steel } \\
\text { Holding Group }\end{array}$ & 9.91 & Shandong Provincial Govt \\
\hline 13 & $\begin{array}{c}\text { Taiyuan Iron \& Steel } \\
\text { Group }\end{array}$ & 9.46 & Shanxi Provincial Govt \\
\hline 14 & $\begin{array}{l}\text { Anyang Iron \& Steel } \\
\text { Group }\end{array}$ & 8.50 & Henan Provincial Govt \\
\hline 15 & $\begin{array}{l}\text { Beijing Jianlong Heavy } \\
\text { Industry Group }\end{array}$ & 8.38 & Private Entrepreneurs \\
\hline 16 & Panzhihua Iron \& Steel & 8.18 & State Council SASAC \\
\hline 17 & $\begin{array}{c}\text { Jiuquan Iron and Steel } \\
\text { Group }\end{array}$ & 7.59 & Gansu Provincial Govt \\
\hline 18 & $\begin{array}{l}\text { Tangshan Guofeng Iron \& } \\
\text { Steel Group }\end{array}$ & 7.58 & $\begin{array}{l}\text { State Council SASAC (51\%), Tangshan } \\
\text { City Govt (49\%) }\end{array}$ \\
\hline 19 & Beitai Iron \& Steel Group & 6.88 & Liaoning Provincial Govt \\
\hline 20 & Jinxi Iron \& Steel & 6.83 & Private Entrepreneurs \\
\hline
\end{tabular}

Source: Adapted from Price et al (October 2010, pp.6-9). 
The SOEs decentralisation in the late 1990s significantly weakened central government's control on industrial investment. This led to increasing involvement of private investments in the CMVC, creating a 'growth alliance' between local governments' interest and private business interest. This constitutes a major factor contributing to the hyper-growth of China's metallurgic capacity.

Before the industrial decentralisation of the late 1990s, the central government exerted relatively strong control over non-state industrial investment by the State Council's departments such SPC, SETC and a variety of industrial ministries at the central government (Huang 1996). Such an investment approval system significantly constrained the building of heavy industrial projects regarding energy supply and energy-intensive industries, which usually require a huge amount of fixed assets construction and investment. Non-state investors, including private companies and foreign firms, must submit detailed project plans to relevant central and local government departments to review and approve before conducting actual project construction. However, as analysed in Chapter Four, this system was significantly weakened during the 1990s' institutional reforms and the central government restructuring between 1998 and 2003. With the burden of investment review of large new projects nation-wide concentrating in a handful of State Council departments such as the NDRC and the MIIT, many local governments chose to approve major local projects without completing the investment review process. Such local practice, often referred to as "weigui chan neng" (unlawful industrial productivity) by industrial observers and central government documents, has spread all over the country from the early 2000s (State Council 2009[38]). The Ministry of Industry and Information Technology (MIIT) estimates that during the 11th FYP China's unlawful iron-and-steel capacity added up to around 400 million tons per year; at least 56 percent of the 627 million tons crude steel produced in 2010 was contributed by these unlawful projects (Xing 2011). The NDRC estimated that at least 58 million tons per year capacity were built without government review and approval over the same period (Zhang October 23, 2009). 


\section{Fragmented Iron \& Steel Market}

Due to the heavy involvement of dozens of provinces, the degree of fragmentation in the Chinese iron and steel industry is the highest among the world's major steel producers. By the end of the 10th FYP in 2005, steel was produced in 30 of China's provincial level regions. This means that among PRC's 31 provincial regions, only Tibet does not have an iron and steel industry of economic scale (Price et al. October 2010). While steel production is concentrated in the northeast, no province accounts for more than 18 percent of China's annual production. Moreover, several provinces have annual production of less than 5 million metric tons per year (see Table 9). In terms of steel producers, by the end of the 10th FYP period in 2004, only Baosteel in Shanghai Municipality ranked among the world's ten largest producers. Only two Chinese producers, Baosteel and Anshan Steel (now Anben) in Liaoning Province, produced more than 10 million tons of crude steel in that year, while eight reached that level in 2005 (Price et al. October 2010). During the 10th FYP period 2001-2005, the concentration of the Chinese steel industry had rapidly decreased. The share of crude steel produced by the Top-4 enterprises dropped from 28 percent in 2001 to 17 percent in 2006; and the share of Top-10 enterprises dropped from 45 percent in 2001 to 33 percent in 2006. In comparison, the Top-4 steel makers' market share was 58 percent in the US, 71 percent in EU and 77 percent in Japan (Wu November 2010).

The central government has recognized the negative impacts such industrial over-capacity and fragmentation would bring to upstream energy supplies and industrial energy efficiency since the early 2000s. Thus a central focus of China's iron and steel industrial policy has been market consolidation by mergers in the past decade. However, implementing the consolidation policy proved difficult, with provincial governments standing in the way. For instance, the Shanghai-based Baosteel, which was then China's largest steelmaker and the largest iron and steel yangqi, aggressively sought out inter-regional mergers under the State Council SASAC's policy guideline during the 10th FYP period. By 2004, merger negotiations were under way with the Magang Group in Anhui Province, with Handan Steel in Heibei Province (now a 
subsidiary of Heibei Iron \& Steel Group), and with Baotou Steel in Inner Mongolia. In each case, local-provincial government proactively blocked the deal. Anhui government officials stated that the provincial government has no interest in seeing its largest steelmaker merged with Baosteel (Zheng and Abrami 2011). In contrast, since 2005, mergers have mainly occurred within provincial borders. The formation of China's fourth largest steel producer, Anben Iron \& Steel Group in 2005, was achieved by a merger of two Liaoning-based steelmakers - Anshan Steel and Benxi Steel - thanks to the brokering and coordination from the Liaoning provincial government (Wang August 17, 2005). Similarly, pushed by the Hebei provincial government, Handan Steel was merged with its primary local rival Tangshan Steel in 2008. The two constitute core subsidiaries of a new Hebei Iron \& Steel Group, which instantly surpassed the Baosteel Group to become China's largest steel producer (Zheng and Abrami 2011). This degree of geographic and market fragmentation clearly demonstrates the desire of Chinese local governments to have the iron and steel industry promote local growth, whether or not such an industry was economically viable.

\subsubsection{Decentralised Aluminium Industry and Local Manipulation of Energy Supply}

\section{Decentralised aluminium capacity surge}

Besides the hyper-growth and fragmentation of ferrous metallurgy, non-ferrous metallurgy, especially the most energy intensive aluminium manufacturing, also experienced similar local-led capacity expansion in many regions of China from the early 2000s. Aluminium manufacturing was also put as a key area of industrial development in more than ten central and northern provincial regions, such as Henan, Shandong, Shaanxi, and Inner Mongolia. Hundreds of private aluminium enterprises entered the market and brought drastic aluminium productivity during the 9th and 10th FYP periods (1996-2005). As a result, China's aluminium production tripled from 2.19 million metric tonnes to 6.98 million tonnes. At the beginning of the 10th FYP period in 2001, China already surpassed the US and became the largest primary aluminum producer, with its annual production capacity at one-fifth (22.4 percent) of the world's 
total (Chen 2005; Lan 2009, p.37). In 2005, Chinese non-ferrous industry consumed 43.2 million tons of coal equivalent energy, accounting for $3.7 \%$ of national industrial final consumption, but only contributed to $1.5 \%$ of GDP. The aluminium industry alone consumed over 6 percent of national electric power generated that year, but only contributed to around 0.3 percent of national GDP (Yang 2005; Wang and Chandler 2010). By 2010, Chinese aluminium output alone accounted for almost half of the worls's total (see Figure 11 below).

Figure 10 Output of the World's Top-10 Aluminum Producers (as of 2010)

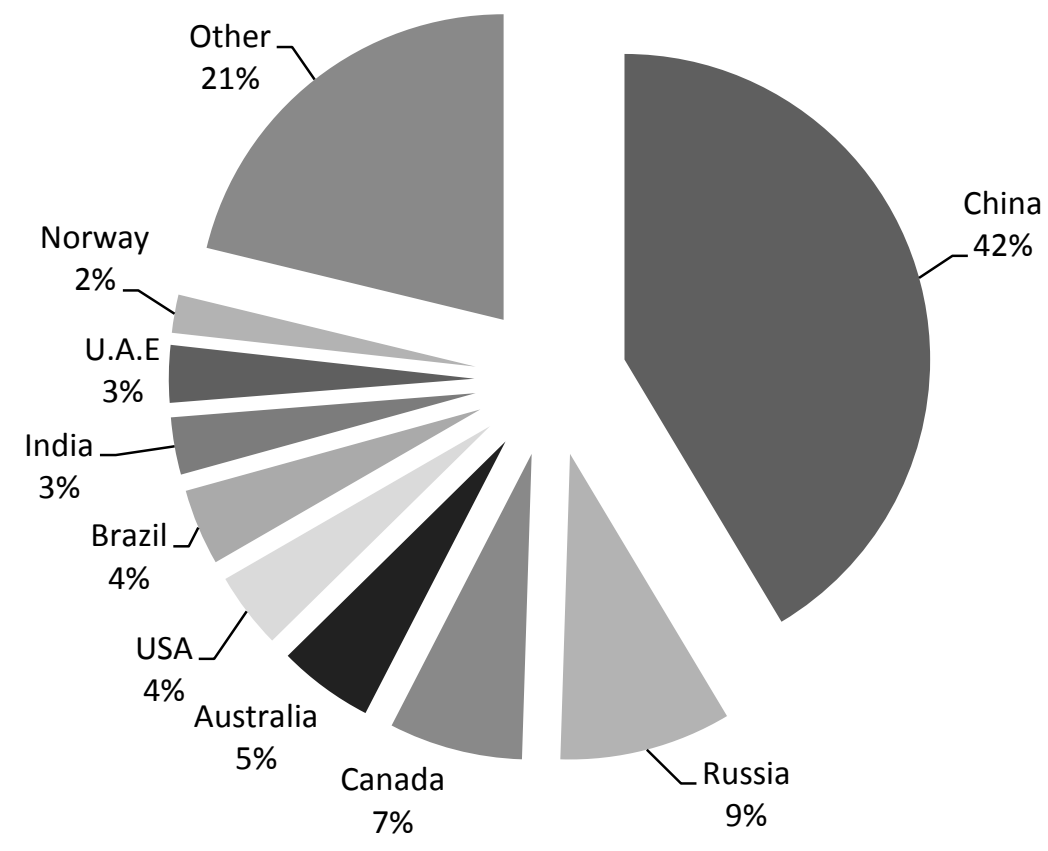

Data Source: The Aluminium Dialogue (2012)

The SOE reforms in the Chinese non-ferrous sector in the 1990s saw the ups and downs of several centrally-owned non-ferrous metallurgy SOEs. By the beginning of the 10th FYP period in 2002, the previous centrally-owned non-ferrous enterprises were all handed over to the local governments, except for China Aluminium 
Corporation (CHALCO), which inherited the core assets of China Aluminium Group and became one of the yangqi under the State Council SASAC since 2003. ${ }^{67}$ As a result, the Chinese aluminium industry started to feature the predominant role of local private investment in production capacity expansion throughout the 2000s. By the end of the 10th FYP period in 2004, there were a total of 152 electrolytic aluminium enterprises located in 25 provinces of China, more than all the aluminium manufacturers in the rest of the world combined ( $\mathrm{Li}$ 2008). The majority of aluminium manufacturers were concentrated in those central and western provinces with abundant coal reserves and power generating capacity, such as Henan, Shandong, Shanxi and Inner Mongolia. These four provinces together had 53 electrolytic aluminium enterprises, with almost half (49 percent) of the national total aluminium capacity (Li 2008). As analysed in Chapter Two, electricity is an essential input which accounts for over one-third of the aluminium production cost world-wide. In China's case, the rapid development of the aluminium industry has heavily depended on local governments' distortion of China's national electricity pricing system in favour of local producers.

\section{Local manipulation of electric power pricing}

Before 1986, China's electricity price was strictly set by the central government agencies like the SPC and MEP based on central government's monopoly on national power capacity-building. From the mid-to-late 1980s, the central government began to reform the centrally planned power investment and pricing system to encourage local government and foreign firms to invest in power supply, and to balance the affordability and social equity (OECD/IEA 2006). A feature of such a reformed electricity pricing system was the implementation of "Catalogue Prices" depending on the types of electricity end-user. Chinese power prices in the 1990s and early 2000s were divided into categories such as urban household price, non-household illuminating power price, agricultural irrigation power price, commercial power price, 'common industry' power price, 'big industry' price, and wholesale power price for certain large

${ }^{67}$ In 2003, the share of CHALCO in China's electrolytic aluminium market was around 23\% and it has kept declining since due to local private aluminium capacity expansion in the 2000s. See Li (2008). 
SOEs (Zhang 2010, pp.55-56). In June 2004, the State Council issued a mandate to enforce a new Differential Electricity Pricing (chabie dianjia) policy designed by the NDRC (NDRC 2004). This new differential electricity pricing policy primarily targets six electricity-intensive industries, headed by aluminium and iron-and-steel. Under the new differential pricing policy, the enterprises in these six industries were charged with a premium on top of the basic industrial power rate. The central government hoped that such discriminative power pricing would immediately affect the rapid expansion of these industries. ${ }^{68}$ However, this new national power pricing policy met constant resistance from many regions primarily due to local government's strong and interlinked interest in the midstream power sector and the downstream aluminium manufacturing of the CMVC.

According to the NDRC, the new differential power pricing was only implemented in less than half of the 31 provinces by early 2007 , three years after the State Council's mandate to introduce the policy and almost a year since the State Council's second mandate to amend the policy and to stress the importance of local implementation (State Council 2006[77]). In December 2006, the NDRC had already pointed out that, in those provinces and autonomous regions where non-ferrous metallurgy accounted for a considerable share in the local economy, differential electricity pricing was not well implemented. As a result, the NDRC sent working groups to eight provincial governments, including Henan, Shanxi and Inner Mongolia, to investigate the local implementation of differential pricing (Chinanews December 14, 2006). In April 2007, the NDRC announced that it had discovered serious problems in local implementation of the new power pricing policy. According to the NDRC, in China's 30 provincial regions, only 15 local governments had implemented the differential power pricing by listing local electricity-intensive industrial enterprises and charging the premium accordingly; an extra 7 local governments had promulgated local

\footnotetext{
${ }^{68}$ These six industries include electrolytic aluminium, iron-and-steel, ferroalloy, calcium carbide, caustic soda, and cement In 2006, this policy was revised by the NDRC to cover two more industries - yellow phosphorus and zinc smelting - and the power price premium for all the eight industries was further increased by as much as 50 percent. See State Council. (2006[77]) and Hu et al., (2012).
} 
adoption of the State Council's mandate but had not started to list the local enterprises and charge the premium; the remaining 8 local governments had completely ignored the State Council's mandates and did not initiate any forms of implementation of the differential power pricing.

Besides the local resistance to the differential power pricing policy, what was worse than local non-implementation was local distortion of power pricing, especially in China's middle and western regions where non-ferrous metallurgy had been one of the major revenue-generating industries (see Figure 11 on the next page). Between 2004 and 2007, a total of 14 provincial governments had promulgated a variety of illegal local policies to offer major industrial power consumers, especially to local aluminium and other non-ferrous manufacturers, with a discounted wholesale electricity price, running directly counter to the national power pricing policy (NDRC 2007[3550]; Xinhua News Agency April 17, 2007). According to Jia Yinsong, deputy head of the NDRC's Macro-Economic Bureau, a large number of local aluminium projects built in the early-to-mid 2000s and local governments' heavy involvement in local power generation capacity-building made many local governments reluctant to adopt the differential power pricing and even proactively encourage excessive industrial power consuming (Xinhua News Agency April 27, 2007). To many provincial governments in the middle and western regions, local implementation of differential power pricing imposed a heavy financial burden to local electricityintensive enterprises and drastically reduced the local industrial output; shrinking power demand due to higher prices would affect the utility rate of local governmentowned power generators, making local generators turn-down more often to reduce ongrid power; and last but not least, shrinking power demand would also mean less revenue for local government-owned coalmines. Thus, higher industrial power prices in practice meant giving up a considerable amount of tax and EBF revenues. 
Figure 11 China's Electrolytic Aluminum Production by Provinces as Percentage of National Total (as of 2010)

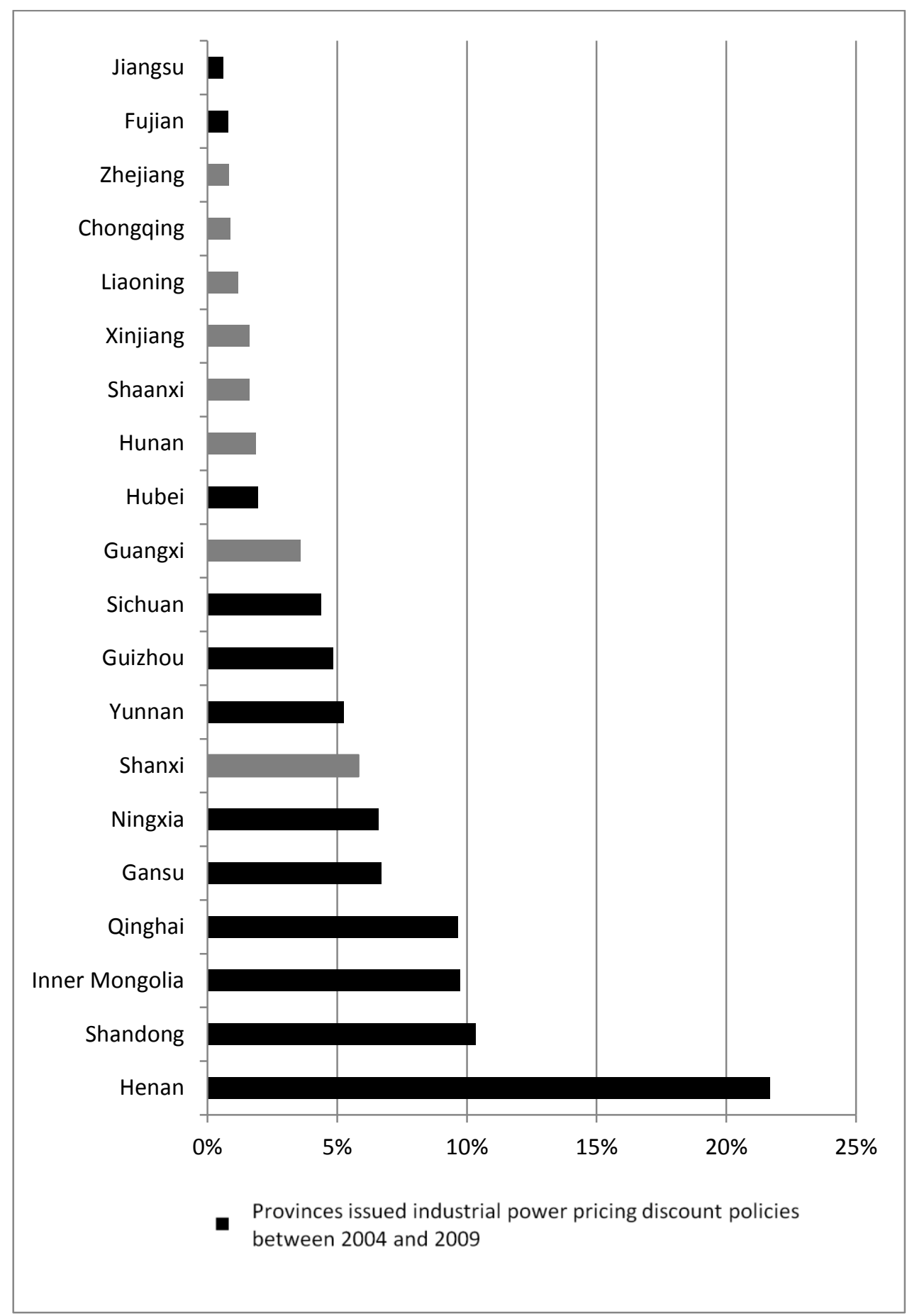

Data Source: China NonFerrous Industry Association (2012), and Xinhua News Agency (April 17, 2007; February 24, 2009). 
Such a chain effect therefore brought widespread local resistance and a distortion of national industrial policy that had been rare since the early 1990s. In response, in April 2007, the NDRC initiated a national census of power pricing by sending working groups to all provincial governments (Xinhua News Agency April 17, 2007). Based on the national census result, in December 2007 the NDRC issued a special mandate, titled as Mandate on Cancelling Power Price Discounts on Electrolytic Aluminium and Other Energy-Intensive Industries, ordering provinces and municipalities like Sichuan, Chongqing, Gansu and Guangxi to phase out regional power discounts in favour of local aluminium manufacturers (NDRC 2007[3550]). Moreover, in October 2007, the NDRC further amended the differential power pricing policy by assigning the premium power price revenue to local government (NDRC 2007[2655]; People's Daily October 12, 2007).

Despite the central government's resolution in seeing the differential power pricing implemented, local distortion of national power pricing continued to exist throughout the rest of the 11th FYP period along with local aluminium productivity expansion. In November 2008, the Inner Mongolia Regional Government introduced the Multilateral Electric Power Transaction Bill to offer RMB 0.08 Yuan per Kwh discounts to local energy-intensive enterprises (Li Febuary 24 2009). Such blatant challenge to national power pricing was soon followed by other provinces and regions, including Qinghai, Gansu, Ningxia, Sichuan and Yunnan. According to Yunnan local government officials, the largest local non-ferrous metal manufacturer, Yuannan Aluminium Ltd., alone consumed about one-fifth of Yunnan's total on-grid power. Yunnan's local power discount policy could effectively save Yuannan Aluminium Ltd. RMB 800 Yuan per ton of aluminium production (Li Febuary 24 2009). In response, the NDRC initiated a new round of national power pricing inspections in 2010 and issued a series of mandates to order immediate abolition of illegal local power pricing policies (NDRC 2010[978]; NDRC 2010[1023]). 


\subsection{FYPs' Energy Efficiency Policy as Institutional Adaptation toward Scientific Development}

Decentralised and fragmented CMVC development is at the centre of China's heavyindustrialisation trend and has had a profound impact on China's overall energy efficiency situation from the early 2000s. With the installation of the fourth generation party-state leadership and the Scientific Development Outlook as updated national socio-economic policy guideline from 2003, such decentralised and CMVC-centred heavy-industrialisation posed the first serious challenge to the structural adjustment objective. In the early years of the Hu-Wen leadership between 2003 and 2005, the central government reacted by issuing a series of industrial policies following the conventional model of the State Council mandate jointly-drafted by relevant ministries and departments. However, these conventional measures failed due to the breakdown of central control measures over the heavy industries. As a result, a mandatory Energy Efficiency Target Responsibility System was introduced in the 11th and 12th FYPs to re-build institutional connections of energy efficiency in the coal-based heavyindustrial value chains such as the CMVC.

\subsubsection{The Failure of Conventional Industrial Policy 2003-2005}

By 2003, the central government already came to realise the hyper-growth of metallurgy and several other energy-intensive industries would be very likely to impact China industrial energy efficiency negatively, and more importantly, to hinder the country's economic structure adjustment. At the Central Conference on Economic Work in December 2003, the newly-installed Hu-Wen leadership expressed much concern over the rapid expansion of Chinese heavy industries led by the CMVC. According to Zen Peiyan, former head of SPC and then-vice Premier of the State Council, Hu Jintao and Wen Jiabao made it very clear at the conference that further reckless investment in energy intensive-industries like steel, aluminium and cement must be prevented to make sure they would not overheat the macro-economy and not hinder the country's economic structure adjustment. Immediately after the conference, the State Council issued a key document ordering local governments and SOEs to strictly control local steel, aluminium, and cement project investment. The document, titled The State Council Mandate on Preventing Reckless Investment in Steel, Aluminium and Cement Manufacturing (State Council 2003[103]), was jointly 
sponsored by as many as 10 State Council's commissions and ministries, including the NDRC, Ministry of Land and Resources, Ministry of Commerce, Ministry of Finance, Ministry of Construction, the State Bureau of Environment Protection, and the People's Bank of China. These State Council departments almost covered the entire economic policy bureaucracies that emerged from the central government restructuring earlier in 2003, indicating the special role of this document in China's industrial policy system. At the beginning of the mandate, the State Council stresses,

In recent years, some regions and enterprises has been motivated by economic interests to invest heavily in industries like steel, aluminum, and cement. Such large-scale project building and productivity expansion disregarded the market, resource constraint and macro-economic situation; most of the investments are made in defiance of central government regulations and against the law... such reckless development is bound to bring serious consequences such as industrial over-capacity, waste of energy and natural resources, and environment pollution. It is also very likely to cause much more profound macro-economic problems... (State Council 2003[103]).

Thus, the control of energy-intensive industries' development was brought to the level of macro-economy following the Hu-Wen leadership's "Scientific Development Outlook" in the same year. To prevent the imminent heavyindustrialisation, the State Council ordered a nation-wide survey of local metallurgy productivity. Those newly-built projects and recent-expansion of existing projects that were against the State Council's industrial policies and regulations, mainly those being built without due investment approval documents, must be shut down and reported to the State Council at a deadline by the end of February 2004 (State Council 2003[103]). The State Council hoped the mandate would curb the hyper-growth of metallurgy by the end of the 10th FYP and set an example for dealing with other energy-intensive industries. However, as analysed in the last section, it failed to curb the hyper-growth of local heavy-industrial productivity, led by the CMVC expansion in the following years. As a result, China's industrial energy intensity, which had been declining due to the combined effect of economic structure shift and the effective energy efficiency governance in the 1980s and 1990s, began to increase from 2002/2003 (see Figure 1 in Chapter One). 


\subsubsection{Introduction of Energy Efficiency Target Responsibility System in the 11th and 12th FYPs}

By the time that the drafting of the 11th FYP started in early 2005, the Hu-Wen leadership was already very conscious that the ongoing decentralized heavyindustrialization was a problem embedded in China's existing political-economic institutions shaped by the 1990s reforms. Efficiency consequences could not be managed unless a more overarching policy was made and implemented consistently in the following decade to adapt the existing institutions according to their Scientific Development ideational system. At the Annual Central Economic Working Conference on December 3rd 2004, Hu Jintao made a keynote speech titled Strengthening and Improving Macroeconomic Adjustment Capacity (jiaqiang'he gaishan hongguan tiaokong). In the speech, Hu emphasizes the fundamental role of institutions.

The flaws and loopholes within existing institutions and half-way reforms are the very source of many problems that emerged during our socioeconomic development. If we do not accelerate institutional adaptation and innovation cannot be accelerated, we would lose the very institutional basis of socio-economic development. This is exactly the reason that reckless investment keeps increasing and economic fluctuation repeatedly occurs, and it is the biggest obstacle in our way to comprehensive, coordinated and sustainable development, there is little time left for us to tackle the [institutional] problem. ... We must be persistent to design and implement solutions in the long run (Hu 2006, p. 456).

Based on this judgement, and with the failure of conventional industrial policy between 2003 and 2005, the energy policy of the 11th Five-Year Programme became the last resort to achieve such institutional adaptation in order to curb the ongoing decentralized and unregulated heavy-industrialization. In October 2005, Wen Jiabao announced the party center's policy recommendations to the 11th FYP and raised the target of reducing China's energy intensity by 20 percent (CPC Central Committe October 11 2005) (see Section 2.1 in Chapter Two and Table 3 in Chapter Three). As the target was officially adopted by the 11th FYP National Guideline in March 2006, the State Council issued a series of mandates to establish a decentralized policy 
implementation and monitor mechanism during the 11th FYP period, and improved and expanded the capacity of the mechanism over the following 12th FYP.

The core component of this mechanism is a Central-Local Intergovermental Energy Efficiency Target Responsibility System (nengxiao mubiao zerenzhi) that integrates the energy efficiency targets into the party-state's local government official evaluation and promotion system (Ma et al. 2012). Between 2006 and 2007, the State Council issued three key mandates (2006[28]; 2007[15]; 2007[36]) to promulgate the basic rules of the Intergovernmental Target Responsibility System. According to the documents, local government officials' energy efficiency work is evaluated by a series of criteria based on centrally-assigned energy efficiency targets and localised energy efficiency actions. Local government officials' energy efficiency achievements are evaluated by the scores assigned to each specific criteria (see Table 4 below).

\section{Table 4 Energy Efficiency Work Evaluation System for Chinese Provincial Government}

\begin{tabular}{|c|c|c|}
\hline Category & Items & Points \\
\hline $\begin{array}{l}\text { National Target } \\
\text { Achievement }\end{array}$ & $\begin{array}{l}\text { Energy efficiency Improvement (GDP per RMB Ten-Thousand } \\
\text { Yuan) }\end{array}$ & 40 \\
\hline \multirow[t]{8}{*}{ Provincial Actions } & Economic Structural Adjustment & 20 \\
\hline & Energy Conservation Investment and Projects & 10 \\
\hline & Energy Conservation Technology R\&D & 9 \\
\hline & Local Enterprise Energy Efficiency Management & 8 \\
\hline & Infrastructure Energy Conservation Work & 5 \\
\hline & $\begin{array}{l}\text { Sub-provincial Energy Efficiency Target Breakdown and } \\
\text { Implementation }\end{array}$ & 3 \\
\hline & Provincial Implementation of Energy Laws and Regulations & 3 \\
\hline & Energy-related Work Organisation and Leadership & 2 \\
\hline
\end{tabular}

Data Source: Adapted from State Council (2007[36]) 
The State Council dispatches special energy working teams to China's provincial level local governments to evaluate local leading officials according to the categories in the evaluation scheme on an annual basis. The results are recorded by the working teams and feedback to the CPC's Central Organisational Department (COD) as a key determinant of the promotion or demotion of corresponding local leading officials. According to the COD, from 2008 those local officials with energy efficiency work scores lower than 60 points are immediately removed from their current position (Chinanews November 25 2007). For the first time in the post-reform era, working achievements other than political loyalty and economic growth became one of the key criteria for Chinese local government officials.

Moreover, the central government also established energy efficiency linkage with decentralized energy-intensive industrial enterprises by incorporating the Top1000/Top-10,000 programmes into the Evaluation System. The item with the heaviest weight in the system - the 40 points national energy efficiency target improvement mainly depends on local implementation of the Top-1000 programme. For the local government-owned energy-intensive enterprises, the State Council also designed a similar system to evaluate their energy efficiency work, so local governments could decide the promotion or demotion of local enterprise managers according to the system (State Council 2007[36]).

In the following four years between 2008 and 2011, this system played a crucial role in the decentralized implementation of national energy efficiency over the 11th FYP. According to Price et al. (2011, p.2168) the Top-1000 Enterprise Project together with local-initiated energy efficiency programmes together contributed as much as 74 percent of China's total primary energy savings during the 11th FYP period, making Energy Efficiency Target Responsibility System the most effective policy mechanism to achieve China's national energy efficiency target. Based on such success, the 12th FYP went on to adopt a similar policy mechanism to achieve the "16 percent" target. The Top-1000 project was expanded to become a Top-10,000 project aiming to save 250 Mtce between 2011 and 2015 (NDRC 2012). From 2012, a total of 14,119 industrial enterprises were included in the Top-10,000 project, which accounted for about 60 percent of China's total annual primary energy consumption. By late 2013, 
they had already saved energy by 249 Mtce through efficiency gains (NDRC 2012; Zhao and Wu 2015). The project's actual efficiency gain by 2015 is likely to overshoot the original target by a large margin.

Moreover, energy efficiency policy based on the target responsibility system over the 11th and 12th FYPs period plays a pivotal role in Hu-Wen's economic structural adjustment ambition (see Figure 12 below). The increasingly stringent energy efficiency regulations erode the profit margin of energy-intensive industrial products such as iron and steel, aluminium and cement. The overall contribution of industry to China's GDP growth from 2006 started to be significantly lower than of the tertiary sector, except for the years 2010-2011 after the Chinese central government introduced a massive RMB 4-trillion programme to stimulate the market in reaction to the world economic recession. According to a report published by the Research Centre of the State Council SASAC, energy efficiency policy over the 11th and 12th FYPs' period has significantly facilitated China's economic structural adjustment in several aspects, especially in terms of curbing the growth of heavy industries, and promoting a huge market of renewable energy equipment and services (SASAC September 25 2014).

\section{Figure 12 The Three Sectors' Contribution to China's Annual GDP Growth 1995-2013 (in percentage)}

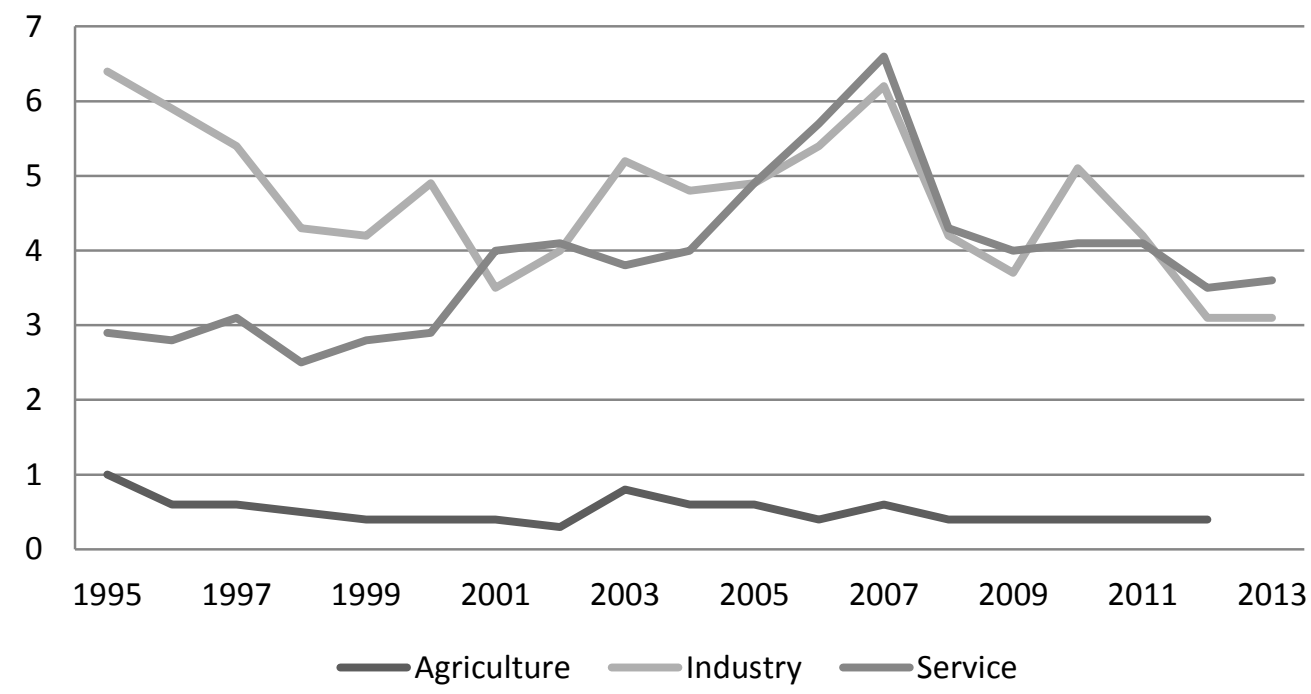

Data Source: NBS (2014) 


\section{Chapter Summary}

This chapter has analysed the development of China's CMVC over the past two decades as a case of local government's growing influence and the central government's losing control over China's coal-based heavy industries after the 1990s institutional reforms. The focus of the analysis is how the reforms re-shaped institutional connections between Chinese state and the CMVC, which has profound impacts on the country's overall energy efficiency situation.

During the planned economy and early reform era, the central government and the CMVC were closely linked by mechanisms embedded in the planned economy. Therefore, the central government's control over China industrial energy intensity was possible based on a well-preserved planned economy and its SOE system. However, the 1990s' SOE reform re-shaped the connections between the Chinese state and the CMVC sectors at the national and the subnational levels. At the national level, due to the large scale SOE delegation and sectoral marketization, the central government disconnected itself from the majority of the CMVC enterprises and focused on building capacity in strategic sectors. At the subnational level, the effect of industrial decentralisation enabled the subnational government and private sector to develop the whole value chain as an important means to achieve local governments' fiscal-political interests shaped by the 1990s' central-local relations reform. As a result, the provincial governments began to play a vital role in the hyper-growth and expansion in the downstream metallurgy sector of CMVC in the 2000s. From the early 2000s local government had strong incentives to promote local metallurgy capacity despite the central government's efforts to curb and rationalise hyper-growth in the sector. Finally, the failure of the central government's conventional industrial policy between 2003 and 2005 made the $\mathrm{Hu}$-Wen leadership realise the institutional problems that challenged their Scientific Development strategy. In response, a mandatory energy efficiency target responsibility system was introduced in the 11th and 12th FYPs to re-build the institutional connection between the central government, the local government, and decentralised heavy-industrial enterprises to provide key political (dis)incentives toward the structure-and-efficiency oriented Scientific Development. 


\section{Chapter Six: Case Study II - OPVC Restructure in the 1990s and China's Energy Security in the 2000s}

Chapter Six provides a contrasting case relative to the CMVC to highlight how the central government managed to establish strong institutional connections with the OPVC following the 1990s' SOE reform, and how such institutional connections enable the central government to exert greater control and provide direct support to China's three major oil and petrochemical yangqi, also known as the National Oil Companies (NOCs), to safeguard the country's energy security from the early 2000s.

Section 6.1 reviews the building and early reform of OPVC during the planned economy and concludes that during most of the planned era the institutional arrangements of China's OPVC were quite similar to that of CMVC, featuring direct central government administrative control over the majority of SOEs across the entire value chain. ${ }^{69}$ Then this section examines how the decentralisation and marketization reforms of the 1980s and early 1990s started to introduce non-central actors such as local government and private firms to participate in the OPVC development, especially in the midstream petrochemical and downstream products marketing sectors. In this period, local governments and private business were increasingly allowed to invest in the OPVC. This was similar to what happened in the CMVC at the time. Section 6.2 then demonstrates how this trend was drastically reversed by a major industrial overhaul in 1998 as part of the SOE reform. On the one hand, the central government restructured the NOCs to make them vertically-integrated to cover the entire value chain and put them as core assets under the SASAC. On the other hand, non-central interests established in the previous reforms were systematically 'squeezed out' from the OPVC to shield the NOCs from domestic competition. Thus, by the early 2000s, the OPVC had become one of the strategic sectors controlled by the central party-state and

\footnotetext{
${ }^{69}$ The data on China's OPVC were all collected from published corporate statistics during the author's internship in CNOOC during November - December 2012, unless otherwise indicated.
} 
started to expand their overseas projects and business aggressively with state support. This is in stark contrast to the CMVC, where centrally-controlled assets were systematically decentralised and featured increasing local government and private sector interests after the 1990s SOE Reform.

\subsection{Formation and Early Reform of China's OPVC}

\subsubsection{Formation and Development of OPVC in the Planned Economy}

In 1949, in the wake of the Civil War, China relied almost entirely on biomass and coal for the needs of its huge rural population and very limited urban industries. Domestic energy demand, especially demand for crude oil and fuel, substantially exceeded domestic production in the 1950s. The gap was mostly filled by imports from the Soviet Union. At the same time, China also began to establish its own energy industry during the first FYP with aid from the Soviet Union. In the early 1960s, the discovery of major oil fields in Eastern China and the increasing domestic coal production brought China energy self-sufficiency. China began to establish a complete OPVC, from upstream crude production to midstream petrochemical and downstream distribution. The whole value chain was under overall central government control through the State Council's economic planning commissions, together with the petroleum and chemical industrial line ministries.

At the top level, the State Planning Commission (SPC) and State Economic Commission (SEC) were in theory the dominant State Council bodies to command the whole OPVC. The SPC formulated long-term and medium term investment plans, production plans, approved large projects, set the prices for both crude and products, and designed the allocation plans for commodities needed by the petroleum sector and the products produced by refineries. Most of the oil-petrochemical planning within SPC was conducted by a Fuel and Power Bureau established in the early 1950s, whereas most investment related work was carried out by Investment Bureau (Lieberthal and Oksenberg 1988, p.70). The SEC was mainly responsible for the formulation and adjustment of annual planning and to organise the implementation of the production 
plans made by the SPC. It also played a role in regulating SOEs (Lieberthal and Oksenberg 1988, p.72).

In the upstream crude oil sector, The Ministry of Petroleum Industry (MPI) ${ }^{70}$ was the specific line ministry in charge of the operational activities, investment and production plans drafted by the planning agencies. Between the early 1960s and late 1980s, the MPI practically controlled China's entire upstream crude oil production assets by establishing Petroleum Administrative Bureaus (PABs) to manage the country's major oil fields (Zhang 2004, p.77). Till the mid-1990s, the overall development strategy for China's onshore oil industry was still proposed by the MPI's major successor - China National Petroleum Corporation (CNPC). The production functions of the ministry were discharged mainly by its PABs, which were one level lower than the Ministry. MPI exerts direct operational control over PABs' production, marketing, and financing activities (Zhang 2004, pp. 78-90). Therefore, during most of the planned economy era, China's upstream crude sector was practically synonymous with the MPI.

The mid-stream petrochemical sector was more diversified, largely because the petrochemical sector provides fuel and feedstock for multiple manufacturing subindustries administered by different line ministries. From the 1960s to the early 1980s, a number of refineries were constructed under MPI management to process its PABs' crude production. Meanwhile, other industrial line ministries such as Ministry of Chemical Industry (MCI), Ministry of Textile Industry (MTI), Ministry of Electric Power (MEP), and many provincial and even county level governments also owned refineries and petrochemical enterprises. Such proliferation of medium-to-small scale refineries was greatly encouraged by the early Chinese leadership, especially Mao himself, from the Great Leap Forward to boost crude processing capacity. Hundreds of "tea pot" refineries were constructed by local governments in Heilong Jiang, Jilin, Shanxi and Guangxi, many of which later became the backbone of locally-owned

\footnotetext{
${ }^{70}$ During the planned economy, the ministry that governs China's crude oil E\&P had experienced several rounds of restructures with different names, such as the Ministry of Fuel Industries in the early 1950s, and the Ministry of Fuel and Chemical Industries in the 1970s. But over most of the time, it was named as MPI.
} 
petrochemical industry (People's Daily November 29, 1959). Thus, the petrochemical sector had been more fragmented compared to the upstream crude sector during the planned era. For instance, in 1983 seven petrochemical enterprises were located in the municipality of Shanghai. They were under the administration of five different line ministries and four municipal government departments at the same time. The largest two included Shanghai Oil Refinery managed by the MPI, and Gaoqiao Chemical Factory administered by the MCI. Their crude feedstock and product distribution were planned and coordinated across a constellation of planning agencies and ministries at national level, as well as between industrial departments under the dual leadership of central ministries and local government level, which often causes intense bureaucratic bargaining, often resulting in low production efficiency and less-than-ideal crude oil utilisation rate (Shanghai PetroChemical Industry Editorial Committee, 1997).

The downstream petrochemical product distribution features government planned pricing and allocation. During this stage, the allocation and distribution of commodities in the country were based on a rigid annual plan, which contained many interlocking balance tables for commodities. Petrochemical refineries had no right to sell their products and had to submit all their products to be allocated under the government allocation system, at prices set by the government (Wang 1999). The prices for crudes and petroleum products were used by the government as a tool to support economic, fiscal and energy policies, and to control inflation or re-allocate income, rather than being a price signal that reflects the value of goods. The petroleum pricing system experienced the no price stage (1959-1955), the high price stage (1955-1971) and the low price stage (1972-1978). Especially during the last stage, a large share of petroleum was exported. The crude oil export increased from $0.3 \mathrm{mmt}$ to $12.8 \mathrm{mmt}$ from 1965 to 1978. In terms of trade, the import and export of crude oil and petrochemical products was tightly controlled by the government through the China Import Company, an SOE established in the 1950s under the administration of MCI. The name of the company was later changed into the China Chemical Import and Export Company (“Sinochem”) from 1965 (Ma 2008, pp.111-234). 


\subsubsection{Decentralisation and Marketisation 1981-1997}

This section examines how the marketization reforms in the 1980s and early 1990s start to decentralise and vertically-separate the centrally-controlled OPVC by establishing new SOEs and introducing non-central elements such as local government and private business to develop the value chain.

\section{Crude Oil Sector Reform}

In 1978, China's crude production reached a historical high volume of 100 million tons, and became the fourth largest oil producer in the world. Meanwhile, the petrochemical sector produced 70 million tons refined products and 388,000 tons of ethylene. However, existing oil fields under the MPI's management began to deplete and central government's investment in both upstream E\&P and midstream petrochemical capacity was shrinking. In 1981, the country's total oil output was 101 million tons, a drop from 105 million tons in 1979. And the investment allocated to MPI for exploration and development was only half of that in 1980 (Zhang 2004, p.77). How to raise sufficient funds and provide oil enterprises market incentives to stabilise output and build new crudes and refinery capacity became an urgent problem. Against this background, the central government began to reform the industry from 1981 as an important part of the unfolding reforms in the urban industrial sectors.

In 1982, the State Council introduced the production responsibility system in the upstream crude sector, also known as the "big contract" model (Zhang 2004; Ma 2008). Under the big contract, the MPI began to gain more autonomy in crude production and distribution. The MPI applied similar contracts with its subordinate PABs. Thus, the contracting system provided strong economic incentives for crude production. ${ }^{71}$ From 1981 to 1985 , MPI raised a total RMB 12.6 billion for oil exploration and development (Zhang 2004, p.78). Dual-track pricing also applied to the crude sector in 1984. The central planners set the price for the contracted oil. The price

\footnotetext{
${ }^{71}$ The MPI needs to hand over $94.5 \%$ of annual crude output, and could then export the rest and retain the revenue to re-invest. See Jin Zhang, Catch-up and Competitiveness in China, ed. Nolan and Dong, (2004, p.48).
} 
for oil produced in excess of the contracted quality followed the international and domestic market price. For example, in 1981 the contracted price for crude was about RMB 100 Yuan per ton, crude for domestic market was RMB 545 Yuan per ton, and crude for export was RMB 600 Yuan per ton (Zhang 2004, p.78).

In 1983, the State Council initiated vertical unbundling to separate the refining and petrochemical assets under the MPI. The MPI's refining and petrochemical assets were grouped together with the chemical and synthetic fibre manufacturing enterprises previously under the MCI and the MTI, to create a new SOE - China National Petrochemical Corporation (Sinopec), which was responsible for the administration and development of China's petrochemical industry. Sinopec was ranked as ministry-level and reported directly to the State Council. Hence, the MPI was left with only the upstream crude development and regulation responsibility.

In September 1988, the Chinese central government drastically reformed the country's energy administration system, marked by the abolition of several energyrelated line ministries, including the Ministry of Coal Industry (MCI), Ministry of Water Resources and Electric Power (MWREP), and the MPI. They were all restructured and corporatized to become SOEs. The MPI was restructured into China National Petroleum Corporation (CNPC). CNPC thus inherited most of MPI's crude and petrochemical assets, mainly MPI's 87 production units such as PABs and refineries, to become a ministry-ranked SOE. CNPC was designated to conduct onshore E\&P in China and offshore shallow water. Deep water E\&P was designated to another SOE established 1982 - China National Offshore Oil Corporation (CNOOC). ${ }^{72}$ In 1997, CNPC produced 143.2 million tonnes of crude oil and 17.2 billion cubic meters of natural gas, accounting for 90 percent of China's total oil output and 77

\footnotetext{
${ }^{72}$ Established under the MPI in 1982, CNOOC is a vice-ministry ranked SOE. It was charged with offshore deep water E\&P and offshore cooperation with foreign oil companies. Due to the technological difficulties in offshore oil E\&P, CNOOC had to mainly conduct its upstream activities in co-operation with large international oil companies and thus became the spearhead of international cooperation at the early stage of China's open-up. As CNOOC gained increasing technological know-how and management experience, its oil and gas production would grow steadily and the company became increasingly important in the industry.
} 
percent of the country's total natural gas output. In addition, CNPC also developed its midstream capacity. By 1997, it had twenty-four petrochemical units under the supervision of its PABs with a total of only 37 million tonnes of crude-processing capacity.

Moreover, the Ministry of Geology and Mineral Resources (MGMR) was also authorised by the State Council to conduct limited exploration activities onshore. At the end of 1996, its exploration functions were spun off from the ministry and turned into China's third upstream oil company - China Star Petroleum Cooperation (CNSPC). Although CNSPC was a relatively small and new player in China's oil industry in the 1990s, it was designated with business functions that covered almost the whole OPVC, making CNSPC China's first comprehensive National Oil Company (NOC).

\section{Petrochemical Sector Reform}

Before the 1980s' reform, China's petrochemical assets were dispersed in the hands of a number of line ministries and dozens of local governments. In 1983, the central government initiated a large scale petrochemical sector restructure marked by the creation of Sinopec to complement CNPC's upstream production. In 1992, Sinopec had a total of 38 production enterprises. These firms produced 90 percent of China's petroleum products, 70 percent of intermediate petrochemicals, 57 percent of resins and plastics, and 26 percent of synthetic fibres (Nolan 1996).

Due to the deepening marketisation and liberalisation of the Chinese petrochemical sector from the early 1990s, players other than centrally-owned SOEs, including local government, foreign firms and private business, started to be allowed to invest in the petrochemical sector. By the time of establishment in 1983, Sinopec's petrochemical throughput accounted for over 90 percent of the national total. The earlyto-mid 1990s saw a rapid decline of Sinopec's share in the domestic petrochemical market. By 1996, Sinopec's refining and petrochemical capacity had dropped to below 80 percent of the national total and kept declining (Zhang 2004, p.90). The increasing involvement of non-central players in the mid-stream was firstly reflected in the 
participation of local governments and foreign firms in petrochemical capacity building. From the mid-1980s, in order to raise funds to expand crude processing capacity, Sinopec began to offer provincial governments as co-investor and shareholder in the construction of major refinery projects. By 1988, more than 20 major petrochemical projects under construction or planning were co-invested by Sinopec, provincial governments and foreign firms. In an interview with the head of Sinopec at the time, Chen Jinhua, he revealed that those petrochemical projects were in cooperation with 18 provincial governments, almost two-thirds of China's total provincial governments, with a total co-investment of more than RMB 30 billion Yuan (Lin and Ling 1988, p.18). Since 1993, further liberalisation of China's petrochemical market greatly encouraged local government, private and foreign investments. By 1997, there were at least 10 major petrochemical projects featuring mixed investment and shareholding under planning and construction. Once completed, these projects would further diversify the participants in the midstream of OPVC, especially in strengthening the involvement of local governments and foreign firms (see Table 5 on the next page).

The early 1990s witnessed surging local investments in the midstream petrochemical sector. In 1993, there were more than 40 medium-to-large local government-owned or private crude oil refineries located in 11 provinces across the country, with refining throughput of 10 million tonnes, accounting for about 10 percent of Sinopec's throughput that year (Yang and Shi 1994). Their refining capacity grew quickly to 17.8 million tonnes by 1996 (Wang 1999, p.119). These private oil companies provided local governments with significant tax revenue. Just before the 1994 tax reform, the eight major private refineries located in Shandong province created RMB 2.4 billion revenue and contributed 370 million yuan tax revenue to the Shandong provincial government (Yang and Shi 1994). 
Table 5 Major Joint-Venture Petrochemical Projects Under Planned in the Late 1990s

\begin{tabular}{|c|c|c|c|c|c|c|c|}
\hline Project & Project Type & Location (Province) & $\begin{array}{l}\text { Proposed Processing } \\
\text { Capacity (thousands } \\
\text { of barrels per day) }\end{array}$ & $\begin{array}{l}\text { Estimated } \\
\text { Investment } \\
(\text { RMB })\end{array}$ & $\begin{array}{l}\text { Tentative Domestic } \\
\text { Investors }\end{array}$ & $\begin{array}{l}\text { Tentative Foreign } \\
\text { Investors }\end{array}$ & Status, as of early 1997 \\
\hline Beihai & New & Guangxi & 120 & $\$ 2.6$ billion & $\begin{array}{l}\text { Three provincial } \\
\text { governments }\end{array}$ & $\begin{array}{l}\text { Kuok Kerry Group } \\
\text { (Malaysia) }\end{array}$ & $\begin{array}{l}\text { Feasibility study completed; JV } \\
\text { negotiation under way; waiting for } \\
\text { SPC approval }\end{array}$ \\
\hline $\begin{array}{l}\text { Huangdao } \\
\text { (Qingdao) }\end{array}$ & New & Shandong & 200 & $\$ 2$ billion & $\begin{array}{l}\text { Sinochem }(18 \%) \text {, local } \\
\text { government }(14 \%)\end{array}$ & Aramco $(48 \%)$ & $\begin{array}{l}\text { JV Ssanhyong (20\%) negotiation } \\
\text { under way; waiting for SPC approval }\end{array}$ \\
\hline Huizhou & Expansion & Guangdong & 160 & $\$ 4-5$ billion & $\begin{array}{l}\text { CNOOC (20\%), } \\
\text { Sinopec (10\%), Local } \\
\text { government }(10 \%)\end{array}$ & $\begin{array}{l}\text { Shell (50\%) } \\
\text { Hongkong MSN Co. } \\
(10 \%)\end{array}$ & $\begin{array}{l}\text { JV negotiation completed; Feasibility } \\
\text { study in progress; waiting for SPC } \\
\text { approval }\end{array}$ \\
\hline Linggao & New & Hainan & 120 & $\$ 1.67$ billion & & $\begin{array}{l}\text { Hainan Hobond } \\
\text { International Petrochem. } \\
\text { Co. }(100 \%)\end{array}$ & $\begin{array}{l}\text { Feasibility study completed; } \\
\text { construction will start }\end{array}$ \\
\hline Ningbo (Beilum) & New & Zhejiang & 150 & & & $\begin{array}{l}\text { Conor Oil, Hongkong } \\
(100 \%)\end{array}$ & $\begin{array}{l}\text { Project approved by the SPC, under } \\
\text { construction }\end{array}$ \\
\hline Maoming & Expansion & Guangdong & 30 & 30 million & Sinopec & Vitol & $\begin{array}{l}\text { Feasibility study is in progress; } \\
\text { negotiation under way }\end{array}$ \\
\hline Shanghai & New & Shanghai & 120 & $\$ 1.4$ billion & $\begin{array}{l}\text { Sinopec and local } \\
\text { government }\end{array}$ & & $\begin{array}{l}\text { JV negotiation under way; feasibility } \\
\text { study in progress }\end{array}$ \\
\hline Shenzhen & New & Shenzhen, ESZ & 100 & $\$ 1.5$ billion & $\begin{array}{l}\text { CNPC and local } \\
\text { government }(60 \%)\end{array}$ & Yukong (40\%) & $\begin{array}{l}\text { Feasibility study is completed; waiting } \\
\text { for SPC approval }\end{array}$ \\
\hline Zhenghai & New & Zhejiang & $120-140$ & & Sinopec & Amoco & $\begin{array}{l}\text { JV negotiation under way; feasibility } \\
\text { study in progress }\end{array}$ \\
\hline
\end{tabular}

Data Source: Wang (1999) and author's research at CNOOC. 


\section{Distribution and international trade sector reform}

In terms of domestic products marketing, from the 1950s to 1970s China's fuel and petrochemical products were distributed by command in a province-countytownship three-level distribution system. The national products distribution was planned by the SPC and implemented by the Ministry of Domestic Trade and the MPI. The pricing of oil products was under strict central government control (Pan 2005, p.33-35). From 1983, the products distribution system was reformed to a Sinopec-local structure with increasing local and private players' participation. Compared with the up-stream and mid-stream sectors, the products distribution sector was the most liberalised and diversified OPVC sector till the end of the 1990s.

In a State Council mandate in 1984, all Chinese provincial and municipal governments were asked to establish their own oil distribution companies to market for Sinopec's products in their respective regions (People's Daily October 19 1984). As a result, 29 provincial oil companies and hundreds of local branches emerged as the major players in China's downstream distribution sector from the 1980s. These provincial oil companies worked with Sinopec in terms of products quota allocation, but they were fully local government-owned enterprises with the majority of revenue going to local government and personnel appointments administrated by local government for China's local petrochemical products distribution in the 1980s and early 1990s (see Figure 13 on the next page). With the dual-track oil products pricing introduced from 1983 to Sinopec, the share of market-price oil products had steadily increased. Oil products distribution became an important revenue source for various levels of local government throughout the 1990s. ${ }^{73}$

With the share of market-price products steadily increasing, the State Council finally cancelled planned products pricing in 1994 and allowed all petroleum products to be sold at market price. Meanwhile, private firms were also allowed to invest in the distribution sector to participate in products wholesale and retailing business. Such distribution sector reform resulted in the establishment of three petroleum exchanges in Shanghai, Nanjing and Beijing, and private petroleum retailers mushroomed throughout the 1990s. In 1998, the number of private oil products companies grew to a staggering

\footnotetext{
${ }^{73}$ For example, see Sinopec's interview with former Zhejiang Provincial Oil Company manager, Sinopec (June 5, 2013).
} 
59,640 nation-wide, including 3,340 wholesale companies and 56,300 retailers. Most of the private oil business was strongly supported by local governments in the form of favourable tax and land use policies in exchange of stable fiscal revenue, especially after the 1994 fiscal reform. It is estimated that over the six years from 1992 to 1998 , private oil companies contributed over RMB 100 billion value-added tax (VAT) and enterprises income tax (EIT) to local and central governments (Li 2012).

\section{Figure 13 China's Petroleum Products Distribution System - the example of diesel distribution 1980s-1990s}

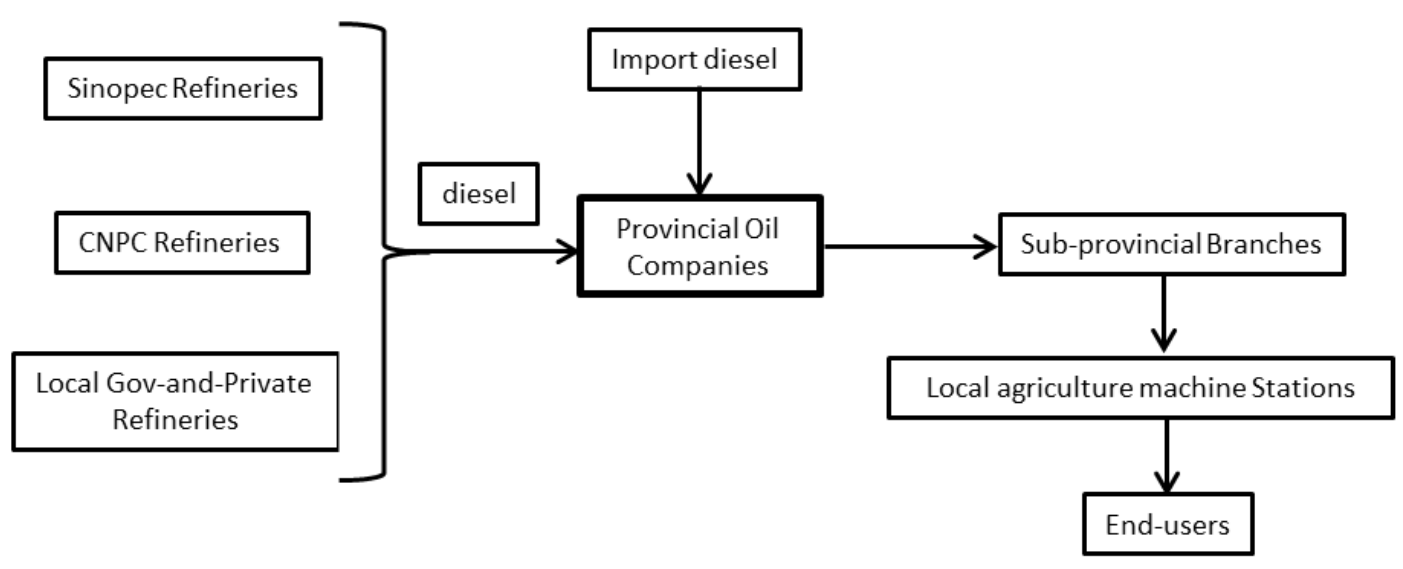

Data Source: Sun (1997) and author's research at CNOOC.

The oil and products trade also saw significant signs of liberalisation and player diversification in the early 1990s. There are two regulatory instruments to control the international crude and petroleum product trade in China: international trade licenses and import quotas. Domestic oil buyers have to apply for import quotas and work through licensed trading companies to get foreign crude oil or products. China's crude and petroleum product trade license used to be exclusively issued to Sinochem before the State Council. ${ }^{74}$ Early in 1993, Sinochem was stripped of its monopoly on the

\footnotetext{
74 There are two regulatory instruments to control crude and petroleum product trade in China: international trade licenses and import quotas. Domestic oil buyers have to apply for import quotas and work through licensed trading companies to obtain crude oil or oil products.
} 
import and export of crude and petrochemical products, and it established two jointventure trading companies with other two SOEs: ChinaOil joined with CNPC, and Unipec joined with Sinopec (Wang 1999, p.54-55). In the same year, the State Council also liberalised principal products imports (i.e. gasoline, diesel oil, kerosene and fuel oil). Product import licenses were not issued exclusively to any company. Up to 1994, provinces could apply for oil import quotas to the State Council SPC on an annual basis. After getting quotas assigned by the SPC, provincial governments could subdivide the quotas and allocate them to various government-owned or private refineries and petrochemical plants (Wang 1999, p.66-67).

With import quotas, many provincial oil companies and private firms rushed into the import business to profit from the price differentials between the domestic and the international markets. In early 1994, there were clear signs that the central government was going to abolish the crude oil import license and quota system. China's four special economic zones (SEZs) were given the right to import crude oil and refined products without being constrained by licenses and quotas. And Sinopec, provincial refiners and private traders were directly assigned import licenses, which allowed them to act independently from Sinochem and its two joint ventures (Wang 1999, p.49-50).

In sum, in the 1980s and early 1990s, the Chinese central government significantly relaxed its grip on the country's OPVC. A host of non-central actors, including local government, private sector and foreign firms, began to participate and invest in the sectors along the OPVC, particularly in the midstream and downstream. As a result, during most of the time in the 1990s, the structure of China's OPVC was characterised by vertical division and player diversification. In the upstream crude oil sector, CNPC and CNOOC are major players, with the emerging CNSPC engaged in domestic onshore E\&P and expanding into the downstream. In the refining and petrochemical sectors, Sinopec was the principal player, but its market share kept declining throughout the 1990s due to increasing participation of local government and foreign firms. In the downstream, Sinochem, with its two joint ventures and occasionally SEZs and local refineries, was responsible for the international crude and product trade, with a growing presence of private and local oil trade business. In terms of domestic products distribution, provincial sales companies along with growing private traders and retailers were the major players. 
Under such institutional arrangements, the NOCs, local government-owned petrochemical enterprises and private oil business in each sector were all competing for investment, crude resources and trying to influence the government's price regulations in their own favour. More importantly, towards the end of the 1990s when the Chinese economy had developed increasing dependence on imported oil, the Chinese central government found itself in urgent need of oil companies with sufficient financial, management and technological capacity to compete with the established international oil companies (IOCs) in the global energy market and to invest in overseas to obtain equity crude from foreign oil producers. As Kong (2006; 2011) argues, such a fragmented oil-petrochemical industry constituted the major institutional factor causing the perceived energy insecurity during the 9th and 10th FYPs period 1996-2005.

\section{2 'Grasping the Large' - Institutional Connections between the State and the OPVC}

As the "grasping the large and letting go of the small" SOE reform unfolding from 1995, the Chinese central government began to restructure major industrial SOEs with the objective of creating internationally competitive firms in strategic sectors of the Chinese economy. At the same time, increasing concerns about China's oil deficits and its national energy security implications provided a strong incentive to the central government to vertically-integrate China's three NOCs. As a result, non-central government elements, such as local governments, foreign firms and private business, have been systematically 'squeezed out' of the OPVC from the late 1990s. China's OPVC start to feature an oligopolistic structure predominated by the NOCs, which constitute the core assets of China's emerging yangqi fleet from the early 2000s.

The State Council's several mandates in 1998 decisively reversed the OPVC's decentralisation trend by restructuring the three NOCs, pro-actively shielding them from domestic competition. In the three years between 1998 and 2000, CNPC and Sinopec each undertook fundamental restructuring with full central government support. A large scale oil-petrochemical assets swap took place between CNPC and Sinopec, and local governments were ordered to hand over their provincial oil companies to the two NOCs. As a result, the new CNPC and new Sinopec have turned into two vertically integrated NOCs with core business covering the whole OPVC; the CNOOC was also encouraged to develop mid-and-downstream business, later to become the third 
vertically-integrated NOC. Such restructure has greatly empowered the three NOCs in terms of efficiency and profitability. At the same time, other elements that used to be encouraged to participate in the OPVC development, such as local government and private business, have been systematically banned by the central government or 'squeezed out' by the NOCs. Chinese OPVC began to feature a central governmentcontrolled oligopolistic structure, which allowed the NOCs to make huge profits at home, which in turn directly contributed to their rapid internationalisation to safeguard China's energy security. This indicates a high level of convergence between China's national energy security interest and the NOCs' commercial interest. Thus, the restructure of China's OPVC has become a symbol of the success of "grasping the large" strategy. More importantly, they are also the symbol of the Chinese state's control over strategic sectors in a 'socialist market economy' environment.

\subsubsection{Restructuring the OPVC}

\section{Making vertically-integrated NOCs}

In contrast to the vertical division between the upstream crude oil and the midstream petrochemical sector in the 1980s and early 1990s, the assets of CNPC and Sinopec were reorganised along geographical lines in 1998. All the crude and refining assets located in eastern and southern China were assigned to the new Sinopec, known as the Sinopec Group; all those in northern and western China were taken over by the new CNPC.

With such a reorganisation scheme, Sinopec transferred 19 mid-anddownstream petrochemical enterprises to CNPC, of which fourteen were engaged in upstream E\&P and five in downstream distribution. CNPC transferred to Sinopec twelve enterprises, including seven upstream E\&P units and one petrochemical plant, the Zhongyuan Petrochemical. Petrochemical plants formerly under the Ministry of Chemical Industry were transferred to either Sinopec or CNPC depending on the locations (see Appendix).

The new CNPC manages large oil and gas production complexes such as Daqing, Liaohe, Xinjiang, Tarim and Sichuan. It controlled 74 percent of the total recoverable oil reserves in China by the end of 1990s, and 67 percent of onshore crude production capacity. Moreover, with more than a dozen major refining enterprises 
transferred from Sinopec, it also managed petrochemical facilities in more than 15 provinces, regions and municipalities, with its refining capacity increased to account for more than 40 percent of China's total refining capacity at the time (Zhang 2004, p.106).

On the other hand, the new Sinopec gained about 30 percent of China's onshore crude oil E\&P capacity, with seven major upstream production units from CNPC. The newly established China Star Petroleum Cooperation (CNSPC) was also merged into the new Sinopec. The new Sinopec began to play a major role in the upstream crude oil E\&P. After the reorganisation, it controlled oil fields and petrochemical companies in 19 provinces. The Sinopec Group also kept the old Sinopec's strong petrochemical capacity. Among its 89 subsidiaries, 25 were China's major petrochemical producers, including large petrochemical complexes such as Shanghai Petrochemical, Beijing Yanshan Petrochemical, Yangzi Petrochemical, Tianjin Petrochemical and Qilu Petrochemical. The Sinopec Group represented about 60 percent of China's total refining capacity and became one of the world's biggest petrochemical producers (Zhang 2004).

Besides the vertical integration by assets swap and mergers between CNPC and Sinopec, CNOOC has also been encouraged to rapidly expand its petrochemical capacity and distribution network. In 2002, CNOOC began to construct its first large petrochemical plant, in a joint venture with Royal Dutch Shell in Guangdong Province. The project was designed with 800,000 tonnes per annual ethylene production capacity and was one of the largest petrochemical plants in Asia. In 2005, CNOOC began to build a second petrochemical plant with 1.2 million tonnes/per annual crude processing capacity. Such rapid business expansion made CNOOC's petrochemical business revenue surpass that of upstream crude revenue for the first time in 2007, making it the 12th largest state enterprise in terms of total revenue among the 157 central enterprises (People's Daily August 1, 2007). At the same time, CNOOC also proactively expanded its sales network with stable products supply. By 2010, CNOOC achieved 50 million tonnes offshore oil and gas production, which roughly equalled Sinopec's onshore production and accounted for 25 percent of China's total domestic oil and gas production of that year (Chinanews Janurary 5, 2011). With rapidly increasing oil and gas production as well as fast business expansion to cover the whole industrial value chain, CNOOC became the third vertically integrated and centrally owned oilpetrochemical enterprise from the early 2000s. 


\section{Taking downstream assets away from local government}

Compared with the assets swap in the up-and-midstream sectors, a decisive measure to enable CNPC and Sinopec to become fully vertical integrated oilpetrochemical giants was to transfer local government's oil companies to the two along geographical lines. Most downstream oil companies in China's oil industry were fully local government-owned enterprises that used to provide stable fiscal revenue in the form of profit remittance and taxation to local governments. Although with complaints from local governments nationwide, the State Council nevertheless issued a mandate in 1998 ordering all local governments to transfer their sales companies, together with thousands of retailing stations, to CNPC or Sinopec (State Council 1998[14]) (see Appendix). The State Council ordered the downstream oil sales companies and their subsidiaries owned by 12 provincial-level governments in the north and west of China to be transferred to CNPC; and sales companies and retailing stations in the rest of the 19 provincial-level governments in the east and south of China were ordered transferred to Sinopec (State Council 1998[14]).

Following the State Council's mandate, the State Administration of Taxation (SAT) also issued an administrative directory that clarified taxation issues of the transferred sales companies. According to the new Tax system under the 1994 fiscal system, the transferred sales companies are treated as subsidiaries of the NOCs, with its Enterprise Income Tax (EIT) re-directed to the central (rather than local) government (SAT 1998 [147]). Although it meant that the local fiscal revenue would further decline, most local governments did not have a choice other than to comply with the central government because most of the crude oil production, imports and refined products were already tightly controlled by CNPC and Sinopec's refineries after the assets swap. Most local government refineries were either transferred to the two NOCs or shut down due to insufficient crude oil input towards the end of the 1990s. According to CNPC, which had few downstream assets prior to 1998, in the five months since the issue of State Council's 1998[14] mandate it had received 15 provincial oil companies that represented RMB 17.5 billion local government assets. Those 15 companies further owned more than 900 subsidiaries, around 4,000 retailing stations, and around 118,000 employees. Almost overnight, the CNPC gained 5.6 million cubic metres product storage facilities, and oil product sales capacity of 120 million tonnes per annum in 
northern and western China. A similar situation happened to the provincial oil companies that were owned by the local governments in eastern and southern China. By receiving several thousands of retailing stations, Sinopec also greatly expanded its product sales capacity (Wang 1999, p.39).

In terms of oil and product imports, the international oil trade license and import quotas that used to be assigned to provincial governments and SEZs were also cancelled by the State Council. Instead, oil import licenses and quotas were exclusively issued to the NOCs and affiliated companies. Only Sinochem, ChinaOil, Unipec and CNOOC are allowed to import crude oil and four principal products (gasoline, diesel, kerosene and fuel oil). Thus, with domestic crude oil monopolised by the NOCs and lack of access to imported oil or products, the booming local petrochemical and distribution companies died out quickly in the years after 1998.

\subsection{2 'Squeezing Out' the Non-Central Players}

A second aspect of the 1998 OPVC restructure was the systematic 'squeezing out' of non-central elements. Neither the local government nor the private sector could influence China's OPVC as they did in the early-to-mid 1990s. Provincial governments and private business which used to have a considerable stake in the form of local petrochemical plants or product distribution companies had to hand over their assets to NOCs, and were denied the opportunity to enter the OPVC in the 2000s.

As part of the industrial restructure programme, the State Council ordered rationalisation of the local oil refineries' productivity in 1999 (State Council 1998[38]). Only 82 plants were allowed to continue to operate among the 193 local refineries with capacity below 1 million tons/per year. Among them, 63 refineries were local government-owned, and 12 of them were later merged by either CNPC or Sinopec and became subsidiaries. The remaining refineries were all shut down and phased out in the 2000s. In 2001, when the State Council discovered that some of the local governments refused to fully implement the 1999[38] mandate and still offered favourable policies to local refiners, the State Council issued another administrative order to mandate local governments to implement the State's policy (State Council 2001[72]). Moreover, by the end of the 10th FYP period in 2005, the State Council NDRC required that newly- 
constructed refineries must reach or exceed the minimum capacity of 8 million tons per annum, and those refineries with capacity less than 1 million tons per year must be phased out (NDRC 2005). At the beginning of the 12th FYP in 2011, the NDRC raised this capacity threshold further to 10 million tons per year, and that those refineries with capacity less than 2 million tons per year must be phased out (NDRC 2011b). Such stringent industrial regulations made it next to impossible for local refineries to survive.

With the oligopolistic OPVC structure and tightened market entry regulation, the remaining local government-owned refineries were dying out quickly in the 2000s. Many of them were either shut down or bought by CNPC or Sinopec. At the beginning of the 11th FYP in 2006, there were only 30 million tons per year non-central refining capacity left, most of which was located in Shandong province in the east, Liaoning province in the north-east, and Guangdong province in the south (Li 2012). According to Wang Yong, the former General Secretary of China Chamber of Commerce for Petroleum Industry (CCCPI) ${ }^{75}$ the private petrochemical enterprises and their products distributing branches contributed about RMB 15.3 billion tax to the Shandong provincial government, accounting for almost 11 percent of the total Shandong provincial government revenue of that year (Qiu 2006). Nevertheless, facing the highly oligopolistic market structure after the 1998 industrial restructure, these private petrochemical companies faced increasing difficulties to survive and develop, even with Shandong provincial government's support and the central government's promise to liberalise domestic oil-petrochemical market with the accession of WTO in $2001 .^{76}$

Similar developments were taking place in the downstream distribution sector. Thousands of private oil products distributors used to be spread across the country in the 1990s and became an important source of local revenue and economic growth.

\footnotetext{
${ }^{75}$ The CCCPI is an industrial association of China's private petrochemical companies.

${ }^{76}$ Although China promised to liberalise its domestic petrochemical market by the end of 2006 according to WTO rules, the Chinese government still inserts some harsh market-entry clauses in the two regulations regarding market liberalisation to maintain the oligarchic structure of OPVC. Such a stringent market-entry threshold practically denies the opportunities for the local government-owned, private and foreign business to influence Chinese oil-petrochemical value chain with significant market share. At the 5th session of the 11th Chinese People's Political Consultative Conference (CPPCC) in February 2013, owners of Chinese private oil companies collectively issued a policy proposal to call for genuine liberalisation of the petrochemical market. See Li (2012) and CAIC (Feburary 28, 2013).
} 
However, from the late 1990s, the two major NOCs began to expand aggressively in the downstream distribution sector. Meanwhile, the central government also supported the integration of the downstream distribution sector into NOCs' business by raising the market entrance threshold. The State Council's 2001[72] mandate promulgates that from September 2001, the building of new gas stations can only be conducted by either CNPC or Sinopec; and those existing non-central oil sales enterprises must meet strict capacity and safety standards. Those which cannot meet those standards should be shut down (State Council 2001[72]). As a result, the number of private oil products distributors declined drastically from the early 2000s. Private distributors were either forced to quit the market, or were bought by CNPC or Sinopec and became their local subsidiaries.

In 1998, the number of private oil products distributors were 59,640, including 3,340 wholesale companies and 56,300 retailers, accounting for over 80 percent of oil products retailers in China at the time ( $\mathrm{Li} \mathrm{2012).} \mathrm{However,} \mathrm{in} \mathrm{a} \mathrm{decade} \mathrm{following} \mathrm{the}$ 1998 OPVC restructure, more than 60 percent of private oil products distributors were shut down or went bankrupt. In terms of products wholesale companies, only 572 out of the 3,340 companies survived by 2011; and only about 100 of the remaining companies were operating with reasonable profits. In contrast, CNPC and Sinopec together owned about 1,600 of oil products wholesale companies by 2011, representing 64 percent of the national market. A similar situation also happened to the retailing business. By 2011, the fuel sales made by the CNPC and Sinopec retailing stations together accounted for as high as 85 percent of China's total fuel sales; the 45,000 private stations accounted for less than 10 percent ( $\mathrm{Li} 2012)$.

In sum, China's OPVC is almost completely centralised and features an oligopolistic market structure consisting of several vertically-integrated NOCs (see Figure 14 on the next page). Before 1998, a host of local government and private players existed in the OPVC, particularly in the mid-stream petrochemical and downstream distribution sectors. However, restructuring has endowed monopoly rights to several vertically-integrated NOCs since 1998, which reversed the decentralisation reform in the 1980s and 1990s and in contrast with the massive decentralisation taking place in other industrial sectors such as CMVC. Moreover, the central government 
utilised systematic regulatory and administrative measures to entrench the oligopoly industrial structure by banning and phasing out non-central players in the oilpetrochemical value chain during the 2000s. Such a trend exists not only in the OPVC, but has also been witnessed in many other industries that are identified as 'strategic sectors' by central government agencies like SASAC and is captured by domestic and international observers as "guojin mintui" ("the state advances and the private sector retreats") that to some extent reverses the trend of growing non-state elements in all sectors of the Chinese economy since the early 1980s (Rabinovitch November 112012 ).

Figure 14 China's OPVC Structure Before and After 1998

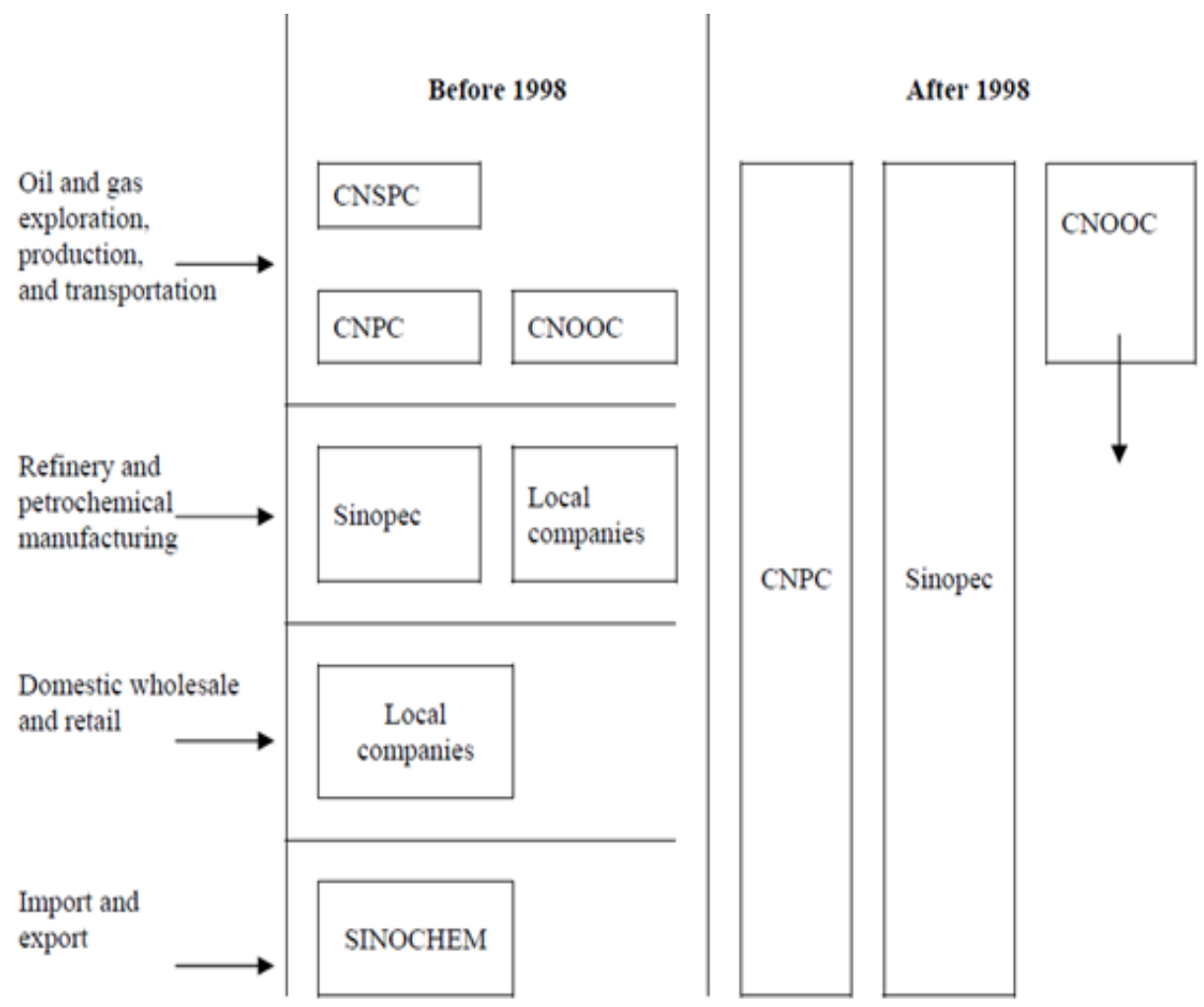




\subsubsection{Putting China's OPVC under the State Council SASAC}

\section{Political control over NOC top executives}

When the State Council SASAC was established in 2003, the three restructured NOCs along with several other centrally-owned oil companies were immediately taken over as the core members of its yangqi fleet. As the biggest and most profitable ones among the 100-plus central enterprises, the CNPC, Sinopec and CNOOC received particularly close attention from the top party-state leadership in the 2000s. With SASAC's management, the central government could confidently make sure the three NOCs' corporate interests converge with the state objective of energy security in the 2000s. Such confidence has been built on the party-state's personnel control over the three NOCs' top management through SASAC and COD.

Along with other yangqi, the nominations and appointments of the three most senior positions - the general manager, party secretary and chairman of the three NOCs - are under the management of SASAC and COD. All executives chosen to hold these positions must be senior members of the CPC and the chairman of the company is usually the party secretary of the corporate party branch. This duality of ranks characterizes the Chinese SOE administrative model, where the board chairman is viewed as the de facto leader whose authority supersedes that of the Chief Executive Officer (CEO) (Li 2015). When it comes to top management appointments, technical knowledge, stable business growth and development are undoubtedly key criteria. However, with their career advancement under party-state control, NOC executives are required, alongside stable corporate results and profitability, to ensure that their firms advance the party-state centre's guidelines and key national interests (Downs and Meidan 2011).

The stringent central government control over NOCs was first put to the test when Sinopec's top management tried to prioritise corporate interest before the state's energy security. As the three NOCs importing a large amount of crude oil from the international market, the issue of price gap between the low domestic state-guided oil price and the rising international oil price between 2003 and 2008 brought losses for the NOCs' midstream petrochemical business. Sinopec, who owns over 40 percent of 
China's oil refining capacity, was hit particularly hard. As a result, the Chairman of Sinopec, Chen Tonghai, made the decision in the summer of 2005 to reduce Sinopec's refining output in order to mitigate the group's huge losses in refining business. Sinopec's action immediately caused fuel shortages in the domestic market, especially for diesel and gasoline, which accounts for more than 90 percent of China's annual oil products consumption. In many provinces in south China, social instability spread in the rural area as the harvest season was approaching and millions of agricultural machines were hungry for fuel. The decision made by Chen was regarded by the partystate leadership as a serious divergence of corporate interest from national energy security interest.

When the international oil price rose again and domestic demand for diesel was high in the summer of 2007, Chen Tonghai was immediately removed from the management of Sinopec by SASAC. With COD's approval, SASAC appointed Su Shulin as the Chairman and Party Secretary of Sinopec. Unlike the disgraced Chen Tonghai, who had been a petrochemical technician and expert most of his life, Su Shulin has a strong party background. Su was just promoted as the party secretary for Liaoning province before being moved to Sinopec to replace Chen (SASAC June 25, 2007). Soon after his inauguration in September 2007, Su ordered Sinopec to import 60,000 tons of gasoline from the international market to supply the domestic market. At that time, the international gasoline price was about RMB 68,000 Yuan per metric ton. In contrast, China's state-guided domestic gasoline price was RMB 65,000 Yuan per ton. The Sinopec lost practically RMB 30 million Yuan on this single transaction (Xinhua News Agency October 31, 2007). In October 2007, the head of SASAC, Li Rongrong, announced that Chen was under corruption investigation by the party-state centre. ${ }^{77}$ According to the staff and management in China's NOCs, there is little doubt that Chen's insubordination regarding refining output was the primary cause of his downfall. And Su was essentially sent by the SASAC to prevent industrial interest divergent from the state interest as it was under Chen's management. ${ }^{78}$ By such

\footnotetext{
${ }^{77}$ Chen was subsequently expelled from the CPC, handed over to the court, and received a suspended death sentence for multiple corruption charges in 2009. See SASAC (October 17, 2007).

${ }^{78}$ Opinion collected from author's personal communications in the management of Chinese NOCs.
} 
personnel arrangements, the SASAC effectively demonstrated that it governs the central enterprise fleet with real teeth.

Integrating NOCs with the central party-state

Besides sanctions on insubordination, in what Downs and Meidan (2011) characterise as the "revolving door" between the party-state senior positions and the central enterprises' top executives, the SASAC and other party-state organs such as COD exert effective political constraints as well as provide sufficient political incentives to make sure oil-petrochemical industrial interest converges with the national interest of energy security (see Figure 15 below). The reshufflings of NOCs' executives in 2011 and 2013 were two further major demonstrations.

\section{Figure 15 The Central Party-State's Control over China's NOCs}

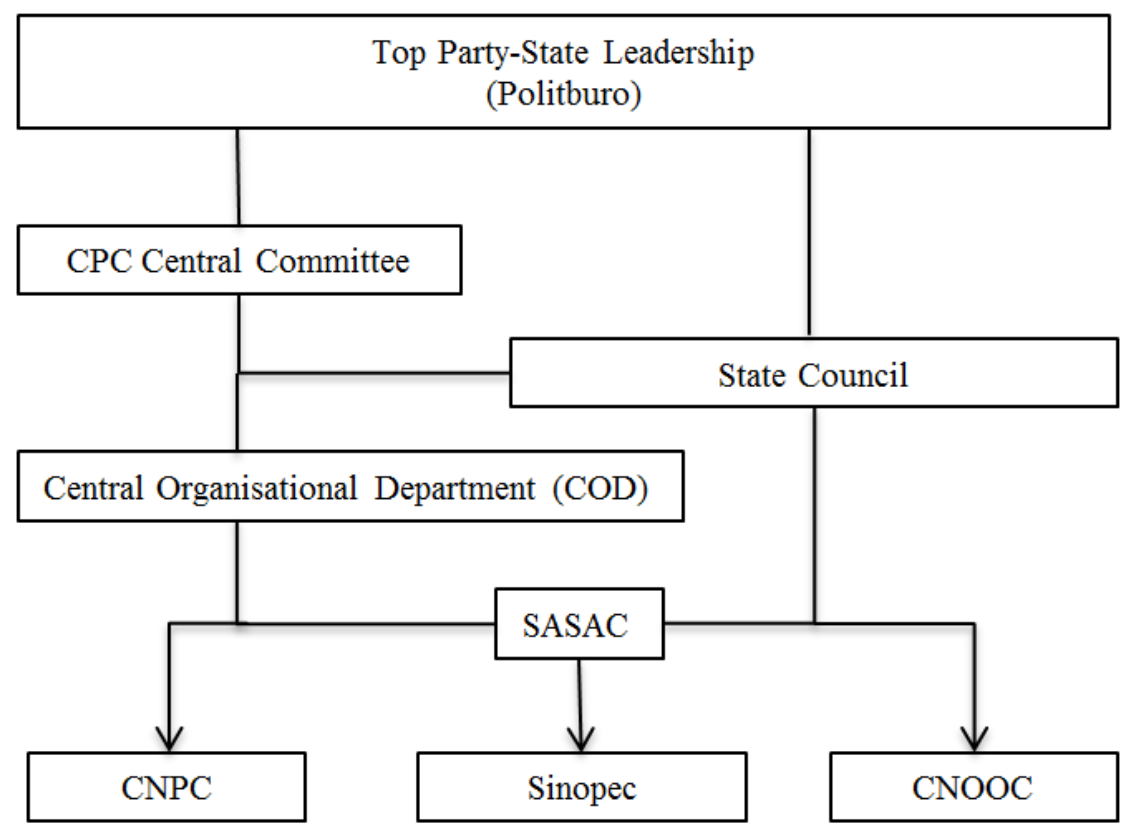

In April 2011, Su Shulin was appointed governor and deputy party secretary of Fujian Province. Such an appointment was rather impressive, because Xi Jinping, then already widely-acknowledged as China's top-leader for the following decade, had worked in Fujian for a long time between 1985 and 2002, and was governing the 
province before he was promoted to the central government. Fu Chengyu, the general manager, party secretary and chairman of CNOOC, was transferred to Sinopec as Su's successor. Wang Yilin, the deputy general manager party committee member of CNPC, became the chairman, party secretary and chairman of the Board of Directors of CNOOC. The vacancy of the CNPC top executive and party secretary was taken over by Jiang Jiemin, who had been promoted from the CEO of PetroChina, the major subsidiary of CNPC. In just two years, Jiang Jiemin was appointed by the COD as the new Director of the SASAC to govern China's yangqi fleet. He was also elected as a member of the 18th Central Committee. This was an unprecedented high government position for a former yangqi executive. The promotion of Su to govern Fujian Province and the appointment of Jiang Jiemin as the SASAC director clearly shows that promotions to executive positions are used by the central government as a control mechanism and an approach to give incentives to individuals who simultaneously promote corporate and state-directed interests.

At the 18th National Party Congress in 2012, only six yangqi executives were elected as full members of the CPC Central Committee, including Jiang Jiemin and Wang Yilin. With SASAC's personnel management, central enterprises' executives become primary candidates for leadership positions in the government. The senior managers of all central SOEs are almost all senior members of the CPC Central Committee. SASAC's mechanism of personnel management clearly indicates that, for China's yangqi in strategic sectors of the economy, corporate success must also be aligned to national interest.

In sum, through the OPVC restructure in 1998 and putting the three oligopolistic NOCs under the management of the State Council SASAC from 2003, the Chinese central government has built strong institutional connections with the whole OPVC. A most important aspect of such institutional connections has been the central government's management over NOCs' top executives through SASAC and COD. By providing political incentives and disincentives through promotion and demotion of NOCs' top executives, the party-state centre effectively limits the NOCs' capacity to pursue business and commercial interests that may diverge from the state's energy security interest. 


\subsection{Restructured OPVC and China's Energy Security in the $2000 \mathrm{~s}$}

After the industrial restructure in 1998, China's OPVC have increasingly become synonymous with the NOCs. The restructure of NOCs has also become a symbol of the country's SOE reform success. Internationally, China's three NOCs have also become Beijing's powerful instrument to safeguard national energy security in the face of increasing oil dependence and oil price volatility. The remarkable progress that Chinese NOCs have made in overseas upstream investment over the decade 2003-2013 was made possible due to huge domestic oligopoly profits and favourable policies received as major yangqi in the strategic sectors of the economy. To most international energy policy analysts, it is clear that there has been a high degree of convergence between the interests of the Chinese government and those of its NOCs since the early 2000s (Andrews-Speed and Dannreuther 2011; Taylor 2014).

Revealed in the 9th and 10th FYPs between 1996 and 2005, increasing oil dependence and the potential supply risks was the Chinese government's top energy policy concern. At that time, the central government was advised by Chinese academics and energy policy analysts that security of supply could be enhanced by raising the level of imports of oil from China-owned or shareholding overseas oil fields, and to diversify the sources of oil imports, which are the two main approaches for most energy importing countries to achieve energy security (Andrews-Speed and Dannreuther 2011, p.67). In addition to these objectives relating to energy security, there are also other important national objectives, such as promoting internationalisation of China's large enterprises, and supporting Chinese foreign policies with business cooperation in the resource and energy exporting regions.

For the three vertically-integrated NOCs, to pro-actively expand overseas business is also necessary for corporate development. The necessities of internationalisation first come from China's depleting oil fields. Over the several decades between 1960s and 1990s, China's major onshore oil fields and, to a lesser extent, offshore seas have been well explored. From the early 1990s the CNPC has struggled to increase oil production within China. By the time that upstream crude oil 
assets were re-structured between CNPC and Sinopec in 1998, the potential to increase domestic crude oil production was very limited and with growing marginal costs. Since the possession of oil and gas reserves for future production is a fundamental requirement for the long-term success of a vertically-integrated oil company, both CNPC and Sinopec, together with rapidly-growing CNOOC, are strongly motivated to go overseas to secure upstream assets globally.

Before the 1998 OPVC restructure, the old CNPC was largely the only Chinese enterprise that was capable of conducting overseas upstream E\&P, thanks to the upstream crude oil assets and technicians it inherited from the MPI. From 1992, CNPC began to make small investments in existing oilfields in Canada, Thailand and Peru, as well as in exploration acreage in Papua New Guinea. Before the industrial restructure in 1998, CNPC made several major commitments in Kazakhstan, Venezuela and Sudan. The largest was in Kazakhstan, where the company bought a share of two oil fields. In Venezuela and Sudan CNPC bought in to proven oilfields as well as the opportunity to explore for new reserves. However, these were virtually all the overseas activities of Chinese oil companies. Compared with major international oil companies (IOC) at the time, CNPC's were all small projects with investment commitments of a few million or tens of millions of dollars, and were mostly directed at fields with proven reserves. Affected by the industrial restructure at home and the Asian Financial Crisis, few initiatives to access reserves in new countries were taken by Chinese oil companies between 1998 and 2002. Such limited international oil activities, in contrast to the country's surging oil imports between the mid-1990s and early 2000s, significantly shaped Chinese energy policymakers' perception of energy priorities when the 9th and 10th FYPs were drafted.

The 1998 OPVC restructure and the international flotation of China's yangqi around 2000 as a part of the "going global" strategy paved the way for China's "global hunt for energy" (Zweig and Bi 2005). With direct mandate from the State Council, CNPC grouped together its core businesses and created PetroChina as its limited liability subsidiary to deal with overseas business in 1999. In February 2000, China Petroleum and Chemical Corporation, known as the new Sinopec, was established on 
the basis of the core business from the old Sinopec Group. In April 2000, PetroChina was listed on the New York and Hong Kong Stock exchanges. Its IPO raised USD $\$ 2.89$ billion. Among the shares issued, 32 percent were bought by major IOCs such as BP Amoco, and strategic and corporate investors around the world. After this global listing, CNPC controlled a 90 percent interest in PetroChina. Only six months later, Sinopec was listed on the stock exchanges in New York, Hong Kong and London. The IPO raised USD \$3.73 billion. 56.06 percent of the interests of Sinopec were controlled by its parent company Sinopec Group, 22.73 percent by the China Development Bank and three Chinese state asset management companies; another 21 percent was held by overseas investors including the three largest IOCs - Exxon Mobil, Shell and BP (Zhang 2004). Similarly, CNOOC Ltd., the limited liability subsidiary of CNOOC, was also listed on Hongkong and New York since February 2001. The international flotation of China's three major oil-petrochemical yangqi has significantly strengthened their financial positions. More importantly, major IOCs and global investors' status as their major shareholders encouraged Chinese NOCs to increasingly follow internationally accepted practices to conduct overseas business, which has not only changed Beijing's perception of a hostile international energy market, but also weakened critics of China's "strategic" or "neomercantilist" energy security policy from the west (Lieberthal and Herberg 2006).

When the State Council SASAC was installed to govern China's central enterprise fleet in 2003, one of its central objectives was to push yangqi "go global" with a focus on overseas resource and energy projects. Since 2003, SASAC officials have made a series of speeches to urge yangqi to proactively search for overseas investment and cooperation opportunities. The SASAC also brokered a series of favourable policies, such as long-term, low-interest loans, as well as to channel financing from other yangqi for the three NOCs to support their overseas investments. As a result, at the turn of the 10th FYP and eleventh FYP periods between 2003 and 2006, a restructured and central-government-supported Chinese oil industry impressed the world with rapidly growing outward investment. An estimated USD \$20 billion was committed to many tens of projects in more than 30 countries, and 75 percent of this was contracted in the two years 2005 and 2006. According to Andrews-Speed and 
Dannreuther (2011, p.88), such a level of outward FDI by a single country's NOCs was quite unprecedented. The destination countries included major oil and gas producers in the Commonwealth of Independent States, in the Middle East and in Africa. Other target countries were spread across Africa and South America, as well as South and East Asia and Australia.

With its advantage in upstream E\&P, CNPC led China's outward FDI surge. In 2005, it invested more than USD $\$ 8$ billion in Sudan's crude oil sector. In the same year, CNPC finalised the USD $\$ 4.18$ billion purchase of Canadian-listed PetroKazakhstan, whose assets include 11 oil fields and licenses to seven exploration blocks. In December 2005, this purchase was complemented by the completion of the 600-mile Sino-Kazakh oil pipeline that will deliver 200,000 barrels per day of crude oil to China by the end of 2006, which was widely regarded as a key step forward for China to diversify its energy supply sources and means of transportation. In the same year, some of CNPC's other overseas investments included a partnership with Sinopec to purchase Canadian firm EnCana's oil and gas assets in Ecuador for USD \$1.42 billion and, together with India's ONGC, buying PetroCanada's 37 percent stake in Syrian oil and gas fields for USD \$573 million. During 2007 and 2008, CNPC continued to build on existing positions in countries such as Canada, Sudan, Niger, Uzbekistan and Venezuela. CNPC also won its first exploitation and development licence in Russia through its joint venture, Vostok Energy. In 2009, with the brokering of the State Council SASAC, CNPC and one of China's three 'policy banks' - the China Development Bank - signed a Strategic Cooperation Agreement to grant the former a USD \$30 billion five-year, low-interest loan for its overseas investment, which significantly improved CNPC's position in many acquisition bids later. By 2013, CNPC's overseas oil and gas production reached 1230 million tonnes, including 592 million tonnes of overseas equity assets (CNPC 2014). In the first year of the 12th FYP period in 2013, CNPC was already ranked No. 4 in the world's top 50 oil companies, with its total crude oil reserve ranked No.8, total oil production No.3, refining capacity No.3, and total product sales ranked No. 12, respectively (PIW January 7, 2013). 
The decade 2003-2013 was distinguished from the previous ten years not just in terms of the scale of investment and geographical spread of CNPC's overseas activities, but also by the internationalisation of two other vertically-integrated oil-petrochemical yangqi, Sinopec and CNOOC, whose overseas merger, acquisitions, and cooperation projects have greatly diversified sources of China's oil imports. In 2003 Sinopec and CNOOC together made a bid of USD $\$ 1.2$ billion to buy British BG group's $16.7 \%$ share of the giant Kashagan field in Kazakhstan. Although this offer was blocked by BG's partners, who invoked their pre-emption rights, it nevertheless announced the rise of the other two Chinese NOCs in the international energy market, which has since greatly accelerated and diversified China's overseas energy projects.

Fu Chengyu, who was firstly appointed as the general manager of CNOOC in 2003 and was then transferred to Sinopec in 2011, played a key role to push both companies to 'go global' and was regarded as China's most 'internationally-minded' yangqi manager (Zhang April 18, 2011). Under his management, CNOOC's USD \$18.5 billion offer to buy the US oil company Unocal surprised the world in 2005. Although this deal was obstructed by the US Congress, citing national security concerns, CNOOC has been particularly successful in building a strong position in gas production in Australia and has significantly pushed China's LNG import and use in recent years (Andrews-Speed and Dannreuther 2011, pp.72-79). In terms of onshore oil E\&P, in 2009 CNOOC was granted the rights to develop Iraq's 2.5 billion barrel Missan oilfield in partnership with the Turkish Petroleum Corporation (TPAO) (People's Daily May 18, 2010). More recently, the company has achieved a series of successes to establish itself in the North America market after the Unocal setback. In 2011, CNOOC obtained a 50 percent stake in Canadian energy company Bridas, and later succeeded in purchasing Canadian oil company Nexen with USD $\$ 15.1$ billion in early 2013 - by far the largest overseas acquisition made by any Chinese enterprise (Rocha Feburary 5, 2013).

Since 2004, Sinopec has also entered into significant upstream commitments in major oil producers such as Angola, Russia, Iran, Algeria and Kazakhstan. In the case of Angola, it was the first Chinese oil company to engage in overseas deep-water offshore E\&P. Sinopec was also one of the few companies to win exploration rights for 
gas in Saudi Arabia in 2004. In 2007, Sinopec was awarded a contract to develop Iran's Tadavaran gas field. When Fu Chengyu took over Sinopec, the company accelerated its overseas expansion. In 2011, Sinopec bought 100 percent of Canadian oil and gas explorer Daylight Energy, which has core assets in 69 oil and gas fields in northwest Alberta and northeast British Columbia. According to IEA, between 2011 and 2013 Sinopec further achieved at least 16 overseas deals around the world, making the company a highly 'internationalised NOC' (Jiang and Ding 2014).

Such speed and vigour of Chinese NOCs' internationalisation global hunt for energy has been assisted by their strong financial positions at home. The high level of crude oil prices since 2003, both internationally and in China, has resulted in all three of China's vertically-integrated companies having sufficient retained earnings to pay for all but the largest projects This strong financial position has been further enhanced by the absence, until 2008 , of a requirement to pay profit remittance to the central government, as well as by favourable tax treatment in comparison with other sectors during the years after the 1998 reform. ${ }^{79}$ All of China's NOCs are able to take advantage of low-interest loans from state-owned policy banks. In addition to cash and loans, China's oil companies draw on a much wider armoury of instruments to gain access to reserves and to bring greater benefits to themselves. The contracts to explore and develop oil and gas fields may be explicitly or implicitly linked to the construction of oil refineries or export pipelines within the host country and to long-term agreements to export oil to China. In addition, the Chinese oil companies bring their own service and construction companies.

China's three oil-petrochemical yangqi have made enormous achievements to bring China more security of energy supply during the 11th and 12th FYP period from 2006 to 2015. In 2013, China's oil dependence rate has reached 58\%. However, the combined overseas hydrocarbon (oil and gas) production has also reached 250 million

\footnotetext{
${ }^{79}$ From 2008, yangqi were asked by the MOF and SASAC to remit only 5 percent of their after-tax profits to the central government MOF. From 2011, the unified profit remittance rate was changed into three levels based on the core business of yangqi. A total of 15 yangqi with highly-profitable core businesses, such as crude oil, petrochemical and tobacco, were asked to remit 15 percent of their after-tax profits. See MOF (December 31, 2010).
} 
tons, in which equity oil production accounted for nearly 40 percent. It means almost half of China's total oil imports in 2013 were produced by overseas oil fields owned by the three Chinese NOCs.

\section{Chapter Summary}

Chapter Six provides a strong contrasting case to the CMVC, illustrating how institutional connections between the central government and the OPVC built during the 1990s' reforms have greatly improved China's energy security situation from the early 2000s. In contrast to the decentralisation-themed CMVC restructuring throughout the 1990s, historical contingency made China become a net oil importer in the mid1990s. As a result, the unfolding "grasping the large and letting go the small" SOE reform was significantly affected by a perception of energy insecurity focusing on increasing oil imports and the lack of competitive NOCs among the central government. The top leadership decided that the oil and petrochemical industries should be monopolised by the central government as a strategic sector and as a central component of the 'grasping the large' SOE reform. As a result, the three National Oil Companies were restructured to become centrally-controlled and vertically-integrated yangqi, and were later put in the powerful hands of the State Council SASASC in the early 2000s. The decentralisation and marketization reforms in the OPVC were thus disrupted and reversed. The local government and private sector, which had built considerable interest in the OPVC in the 1980s and early 1990s, was systematically squeezed out of the OPVC with the central government's regulations and mandates after 1998, which helped to create an oligopoly domestic market for the three NOCs.

The strategic and administrative control imposed by central government, on the one hand, significantly limits the NOCs' capacity to pursue business and commercial interests that may be divergent from the national interests; on the other hand, the NOC's oligopoly market position at home together with the central government's full support greatly facilitated and accelerated the country's overseas energy project development, which significantly contributed to China's energy security over the 11th and 12th FYPs period. 


\section{Chapter Seven: Discussion and Conclusion}

This chapter summarises major findings of the study and assesses how the Historical Institutionalism approach has led to a better understanding of China's energy policy change and to what extent the study has contributed to political theories. It begins with a brief review on the puzzle the study set to explain and the research design the study employs. Then the chapter highlights the two major findings this study has made: China's socio-economic policies in the 11th and 12th FYP period are in general formulated with a leadership-controlled and idea-guided policymaking mechanism at the national level; and the shift of the energy policy priority between two major energy policy objectives is based on idea-guided institutional adaptation. These mechanisms and forces of policy change are endogenous to the development of Chinese political economy. In term of theoretical contributions, these findings are important in three aspects. First, the study discovers the central role of ideational innovation and ideational systems in China's policy formulation; second, it develops a multi-layered and cross-sectoral institution analytical framework to examine the mechanisms and forces behind China's energy policy change. Finally, the chapter concludes that the whole study establishes an institutional adaptation model of policy change that has greatly enhanced our understanding of China's shifting energy policy priority over the past two decades.

\subsection{Research Questions and Research Design Revisit}

As the world's second largest economy, second largest energy producer, and the largest energy consumer and carbon emitter, the making and changing of China's energy policy has almost unparalleled impact on the global energy market and environmental governance. In the past decade, an increasing body of literature in the wider political science field has been seeking to understand two interlinked questions regarding the mechanism of policymaking in today's China, and the underlying forces pushing energy efficiency targets over the country's constant energy security concerns. Studies have advanced two models of policymaking in China to identify the factors causing the 
policy change. The Rational Model of policymaking leads to an exogenous view focusing on international pressures and influences as the main factors inducing China's energy policy change; and a Bureaucratic Politics Model of policymaking stresses the importance of intermediate level policy bureaucracies. However, both groups of literature suffer from serious difficulties capturing and explaining some fundamental aspects of the policy change, including the central role of top party-state leadership and the cross-sectoral characteristic of the priority shift. Therefore, it is necessary to look at new theories and to build a new analytical framework to explore the missing elements and the underlying forces that induced the policy change.

Over the past two decades, the Historical Institutionalism's (HI) theorisation of the stability and change in institutions and its interest-behaviour shaping effect has become quite influential in political studies. In terms of HI-based policy studies, a major way to understand major policy change has been by examining the asymmetrical power distribution between major policy actors and examining its long term impact on policymaking (Hall and Taylor, 1996). Specifically, in a state with a set of hierarchical institutions, policy change could arise out of a 'mismatch' between evolving ideational patterns and institution-shaped interest-seeking behaviour. In terms of investigating Chinese energy policy change, this study develops a HI theory-based, multi-layered and cross-sectoral analytical framework to examine the mechanism of policymaking and the mechanics of energy policy change. This framework focuses on the ideas and interests of key political actors embedded in a two-level institutional structure. At the national level, the top leadership and their ideational system is the focus of analysis; at the subnational level, the study mainly looks into local government's energy-related interest-seeking behaviour based on their institutional connections with China's two major energy-based industrial value chains - CMVC and OPVC - based on fact that the former is a key determinant of China's energy efficiency situation and the latter is at the centre of China's energy security strategy. With this analytical framework, the three empirical chapters and two cases organised by the study led to rich findings that have significantly expanded and deepened our understanding on the mechanism of policymaking and forces of energy policy change in China. 


\subsection{Major Findings}

\subsubsection{Emerging Ideational Dynamism on the National Level}

With a multi-layered analytical framework, the study firstly examines the latest developments of Chinese politics and finds that the top party-state leadership's ideational innovation and subsequent ideational systems have become a key dynamic in shaping the country's reform policies and socio-economic policies.

First, differing from the exogenous view under the Rational Policymaking Model and the Bureaucratic Policymaking Model based on the Fragmented Authoritarianism theory, this study finds that China's national policymaking in the late 1990s and 2000s has been guided by the past two generations of leadership's increasingly systematic and theorised ideas of reform and development. Empowered by institutionalisation of Chinese leadership transition and in need of an overarching reform and development strategy, Jiang and Zhu took on Deng's ideational innovation in the 1990s and pushed China's transition by initiating a series of growth-oriented institutional reforms with a formula of 'Reform-Growth-Stability' in mind. These reforms constitute a critical juncture of China's transition course through integrating a growth-oriented incentive structure to major political actors nationwide, which profoundly impacted the country's development in the following one and half decades.

Second, the core ideas embodied in the two recent generations of leaderships' ideational systems differed markedly, making China's ideational-based policymaking a dynamic process. With the success of the Jiang-Zhu leadership's ideational innovation and relative smooth leadership transition, the fourth generation $\mathrm{Hu}-\mathrm{Wen}$ leadership was able to develop rather coherent reform and development ideas at an early stage of their tenure. The Hu-Wen leadership's ideational system was characterised by the core concept of "Scientific Development" (kexue fazhan), attempting to alter China's development model with a focus on economic structure adjustment. With a "comprehensive, coordinated and sustainable" development model in mind, the $\mathrm{Hu}-$ Wen leadership appeared to be concerned about China's emerging heavy industrialisation trend in the early 2000s. Energy efficiency change that is sensitive to the share of energy-intensive heavy-industries in the economy thus becomes a key indicator of the country's economic structure change. 
Moreover, what actually integrates the ideational dynamism into China's national policymaking process has been the leadership's tightening control on the central government bureaucracies. Between 1998 and 2003, several rounds of central government restructuring and streamlining have effectively restructured the country's national-level policymaking from a horizontal bargaining process to a hierarchical topdown process featuring the top-party leadership's role in determining the agenda and objectives in key areas of socio-economic policies embodied in the national FYP guidelines. Therefore, with an ideationally-innovative political leadership at the top and streamlined policy bureaucracies at the intermediate level, the Chinese central government in the early 2000s became much more coordinated and efficient in making policies to re-orient the country's development model when the $\mathrm{Hu}$-Wen leadership was appointed. More emphasis on energy efficiency is first and foremost a consequence of the country's overall development strategy reorientation with the Scientific Development Outlook.

Nevertheless, what makes China's energy policy change special is the prioritisation of energy efficiency targets over energy security concerns on the country's national policy agenda. While an updated ideational system could direct more emphasis to energy efficiency, it does not necessarily come at the cost of the deprioritisation of the vital energy security issues, especially at a time when the country's energy security seemed in serious trouble. Therefore, besides an updated ideational system favouring energy efficiency objectives at the national level, further examination on the historical-formulated and institution-shaped asymmetrical power relations in a multi-layered and cross-sectoral framework is necessary to understand this specific pattern of China's energy policy change.

\subsubsection{Imbalanced Structure of Energy Development and Institution- Shaped Interest-seeking Behaviour on the Subnational Level}

Through detailed analyses on the institutional reforms in the 1990s designed by the Jiang-Zhu leadership, the study finds the SOE reform and the central-local relations reform together created an imbalanced structure of industrial development. By asymmetrically connecting different industrial sectors with political actors on national and subnational levels, this structure profoundly impacted the country's industrial development in the 2000s. The 'imbalance' mainly refers to a pattern of institutional 
connections that embody asymmetrical energy-related power-and-interest distribution between government and industry at the national level and the sub-national level (see Figure 16 below).

\section{Figure 16 An Imbalanced Structure of Energy Development}

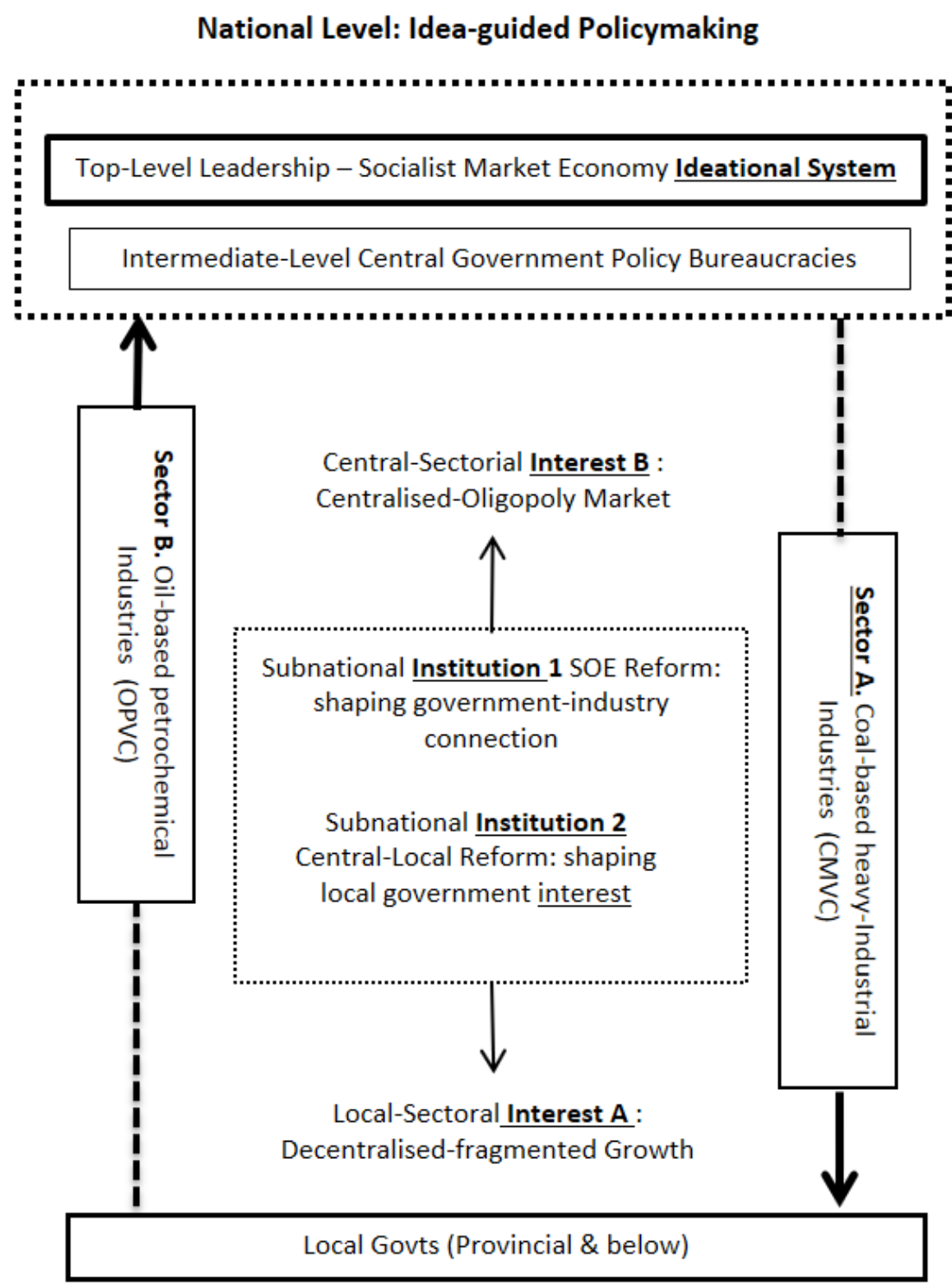

Subnational Level : Institution-shaped Imbalanced structure 
As Figure 16 illustrates, at the national level, through "grasping the large" SOE restructuring, the central government has successfully built strong institutional connections with industries in a number of so-called 'strategic sectors'. The institutional connections are established and strengthened by the formation of a centrally-controlled yangqi fleet, as well as the State Council SASAC's management over individual yangqi's behaviour through political control over their strategic business decision-making and personnel control through appointing or removing the top executives. The institutional connections are also two-fold. They are first and foremost a controlling mechanism to make sure that vital national interests in those strategic sectors are closely followed by yangqi in strategic sectors. Second, they also mean institutionalised state support and protection that enable most of these yangqi to monopolise or oligopolise a highly lucrative domestic market of strategic sectors, making many of them become increasingly internationally competitive.

At the subnational level, the 'letting go the small' SOE reform, together with the widening local revenue-expenditure gap as well as the growth-centred political promotion system, practically forced the local government to develop strong interest and imperative in boosting revenue and rapid economic growth. Such institution-shaped interest-seeking behaviour is one of the most important historical legacies of the two 'socialist market economy' theory-guided institutional reforms under the Jiang-Zhu leadership. With these institutional arrangements established in the 1990s' reforms, many provincial governments were able to build strong institutional connections with coal-based energy sectors and its downstream industries featuring an energy-intensive production process. For local government, the institutional connections are either in the form of direct government ownership over heavy-industrial local SOEs delegated down from the central government, or in the form of decentralised industrial regulatory power over those marketised heavy industries. Through the two forms of institutional connection, a considerable number of local governments have been proactively promoting local industrial development to meet the local growth imperative from the early 2000 s.

Therefore, a key reason that 1990s' institutional reforms constitute a critical juncture is that they disrupted the decentralisation-and-marketisation reforms across most sectors of China's state-owned industries from the early 1980s. Instead, the reforms created an imbalanced structure of industrial development, re-centralising some 
industrial sectors and making others completely decentralised. Embodied in the structure were asymmetrical institutional connections between government and industry at the national level and the subnational level, which shapes a unique convergencedivergence pattern of government-industry interest alignment in the 2000s (see Table 6 below). More importantly, the new institutional arrangements crafted by the 1990s' reforms began to provide incentives and constraints to shape relevant subnational actors' interest-seeking behaviour. Given the ideational dynamism at the national level, it is necessary to further look into the two industrial-level cases to examine if there is a mismatch between ideational patterns at the national level, and institution-shaped energy development behaviours at the subnational level.

\section{Table 6 Matrix of Government-Industry Institutional Connections and Interest Alignment}

\begin{tabular}{|c|c|c|}
\hline $\begin{array}{c}\text { Institutional } \\
\text { Connections and } \\
\text { Interest Alignment }\end{array}$ & $\begin{array}{c}\text { Centralised-Strategic } \\
\text { Industrial Sectors }\end{array}$ & $\begin{array}{c}\text { Decentralised-Marketised } \\
\text { Industrial Sectors }\end{array}$ \\
\hline $\begin{array}{c}\text { National- } \\
\text { Central } \\
\text { Government }\end{array}$ & $\begin{array}{c}\text { Connected- } \\
\text { Converge }\end{array}$ & $\begin{array}{c}\text { Disconnected- } \\
\text { Diverge }\end{array}$ \\
\hline $\begin{array}{c}\text { Subnational- } \\
\text { Local } \\
\text { Government }\end{array}$ & $\begin{array}{c}\text { Disconnected- } \\
\text { Diverge }\end{array}$ & $\begin{array}{c}\text { Connected- } \\
\text { Converge }\end{array}$ \\
\hline
\end{tabular}

\subsubsection{Idea-Interest Mismatch and Idea-Guided Structural Rebalance}

As Hall and Taylor (1996) assert, Historical Institutionalism places asymmetrical power relations and the impact of long-term institutional legacies on policymaking at the centre of analysis. In this sense, the two contrasting cases of CMVC and OPVC provide a clear picture of how China's energy policy change was initiated by the Hu-Wen leadership to rebalance an imbalanced structure of energy-based industrial development, 
in order to push forward the economic structural adjustment agenda under the Scientific Development Outlook (see Figure 17 below).

Figure 17 Energy Policy Change: Balancing the Imbalanced Structure of Energy-based Industrial Development

National Level: Idea-guided Policymaking

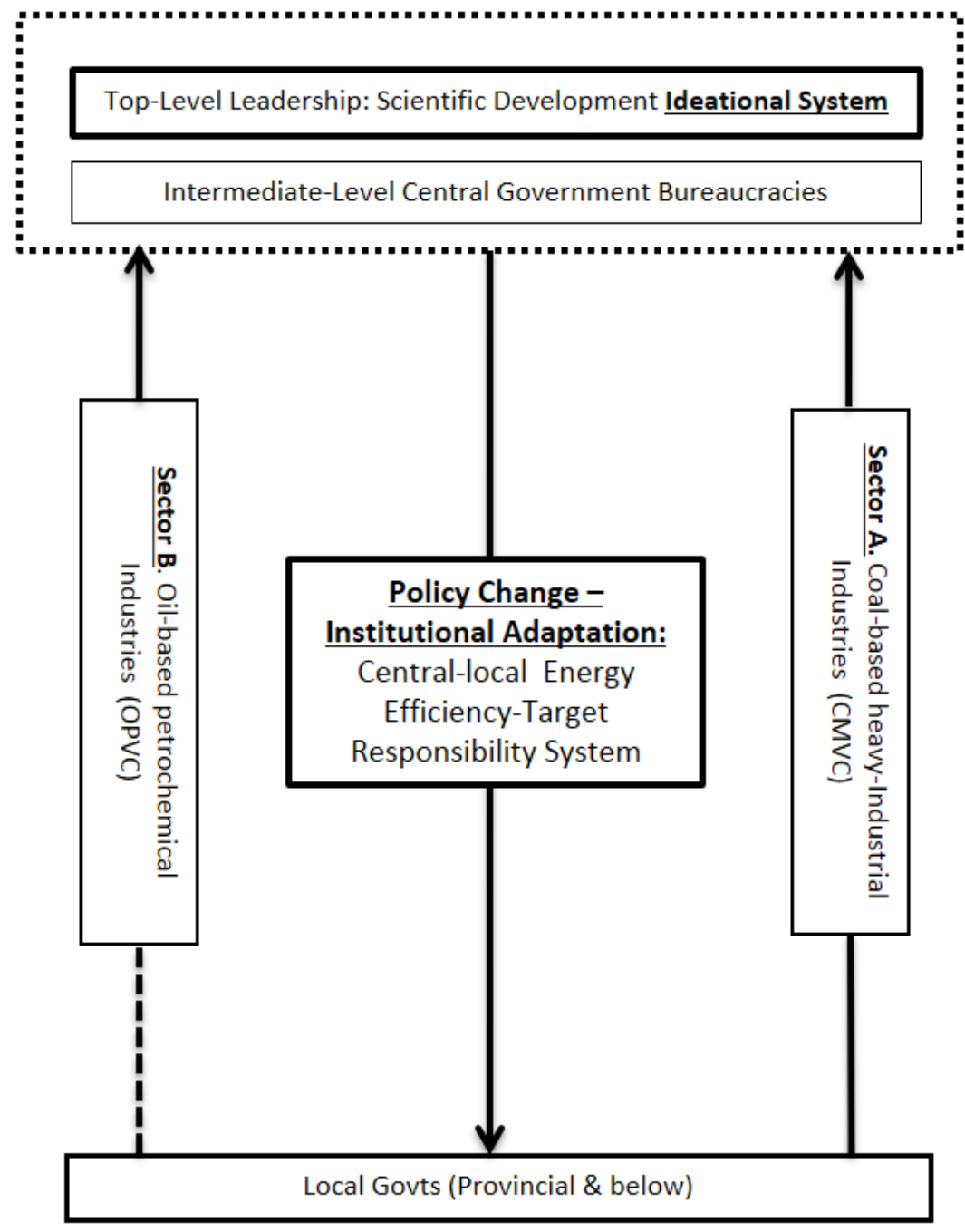

Subnational Level : Structrual Balance

The first case focuses on the CMVC, whose development profoundly influences China's industrial energy intensity and thus the country's overall energy efficiency (see Chapter Two). During the planned economy, the central government and the CMVC 
were closely linked by central government ownership and national energy conservation mechanisms embedded in the planned economy. However, the 1990s' SOE reforms significantly re-shaped the connections between the state and the CMVC sectors at the national and the subnational levels. At the national level, due to large scale SOE delegation and sectoral marketisation, the central government systematically disconnected itself from the majority of the CMVC SOEs to focus on building strong state capacity in strategic sectors. At the subnational level, the effect of industrial decentralisation enabled the subnational government and private sector to develop the whole value chain as an important means to meet local governments' growth imperative. Chinese provincial governments have been playing a pivotal role in the hyper-growth and rapid-expansion of CMVC in the 2000s. Especially many provincial governments from the early 2000s had strong incentives in promoting local metallurgy capacity despite the central government's efforts to curb and rationalise the expansion of the sector.

As a result, the failure of the State Council's conventional industrial policy between 2003 and 2005 made the Hu-Wen leadership realise that the historicallyformulated institutional problems began to challenge their Scientific Development strategy. In response, a mandatory energy efficiency target responsibility system was systematically and constantly introduced in the 11th and 12th FYPs to re-build institutional connections between the central government, the local government, and the decentralised heavy-industrial enterprises to provide key political (dis)incentives to achieve the economic structural adjustment objective. The political dimension of China's central-local intergovernmental relations, namely the local cadre evaluation and promotion system, plays a crucial role in the institutional adaptation and serves as a powerful instrument of policy implementation wielded by the Chinese party-state centre.

To further test the rebalance effect of prioritising energy efficiency over the traditional energy security objective, with which China also seems to have serious problems given its surging oil dependence in an unstable global energy market over the 11th and 12th FYP period, a study of the development of Chinese OPVC, which is responsible for the country's energy security, becomes necessary (see Chapter Two). In contrast to the decentralisation-themed CMVC restructure in the 1990s, a major historical contingency is that China became a net oil importer in the mid-1990s. As a 
result, the unfolding "grasping the large" SOE reform at the time was strongly affected by a shared perception of energy insecurity among the central government policymakers, who concluded that the oil and petrochemical industries should be monopolised by the central government as a strategic sector. As a result, in 1998 Chinese oil and petrochemical industries were restructured to become highly centralised and vertically-integrated, and were later put in the hands of the State Council SASASC as the core assets in the yangqi fleet. On the other hand, local government and the private sector, who had built considerable interest in the OPVC in the previous reforms, were systematically squeezed out of the OPVC with central government's regulations and mandates after 1998, which helped to create a centrallycontrolled, oligopolistic domestic market. The strategic and administrative control imposed by central government, on the one hand, significantly limited the giant and wealthy OPVC yangqi's capacity to pursue business and commercial interests that may diverge from the national interests; on the other hand, the central government's support and protection greatly facilitated and accelerated the country's overseas oil projects over the 11th and 12th FYPs. The case study on the OPVC provides a strong contrasting case to the CMVC, revealing how institutional connections forged between the central government and the industry during the 1990s' reforms significantly contributed to China's energy security.

Therefore, China's energy policy change has been caused by an idea-guided institutional adaptation force that is endogenous to the development of Chinese political economy. At a critical juncture in China's transition in the mid-1990s, institutional reforms created strong power-and-interest connections between the central government and the OPVC, which later produced an intended consequence of enhancing the state capacity in energy security. However, the same historical reforms also produced an unintended consequence of economic structural change and deteriorating energy efficiency performance through shaping provincial governments' strong connections with coal-based heavy-industrial sectors such as CMVC. As a result, a new generation of top leadership placing a high value on Scientific Development reacted by prioritising the energy efficiency objective over the energy security objective in China's national energy policy to rebuild the lost institutional connections between the central government and the decentralised heavy-industrial sectors. 


\subsection{Theoretical Significance}

\subsubsection{The Role of Ideational Innovation in Policy Formulation}

The role of ideas in institutional development and policymaking has been a major topic in new institutionalism theories over the past decade. Historical Institutionalist scholars argue that certain ideational factors can influence institutional development by shaping key political actors' policy preferences (Béland and Cox 2010; Gofas and Hay 2010). A fundamental task in this area of theorisation has been exploring types of ideational factors, tracing the source of ideas, and mapping the causal mechanism of how ideas actually impact institutional development through influencing policy decision-makers. So far, studies have identified several types of ideas and their possible sources, such as norms, identity, cognitive templates, and policy paradigms (Campbell 2002). However, as Béland (2009) finds, existing literature predominantly emphasises the role of transnational actors and processes in diffusing international ideas to induce national policy change. An increasingly large group of HI scholars have argued that national political structure and institutions remain central to the politics of policy change and that more studies are needed to identify the domestic sources of such ideational factors in advanced industrial states and beyond (Béland 2009; Lieberman 2002).

In this respect, the study's analysis of the Chinese leadership's ideational innovation contributes to HI theory and identifies a new form of ideational factor, tracing its source and policy influences in the context of a transitional state. Through the analysis we can see that the Chinese top party-state leadership in the past two decades have purposively built, improved and utilised ideational systems like the Socialist Market Economy and Scientific Development Outlook that have played a vital role in two aspects: pushing forward China's reform and guiding the country's socioeconomic policymaking.

First, the ideational innovation helped to legitimise the reform agenda at a critical juncture of the early-to-mid-1990s when the reform course was confronted by the conservatives and the country was facing international isolation. In this respect, the introduction of Deng Xiaoping Theory on Socialist Market Economy practically saved China's reform course and pushed it forward. Second, the ideational innovation process helped to shape specific reform strategies and produce policy focal points. This has 
been demonstrated in both Jiang-Zhu Leadership's Reform-to-Grow strategy and the Hu-Wen leadership's Scientific Development strategy. In the former's case, Jiang's 'Growth-Reform-Stability' formula effectively directed China's reform from scratching the surface of planned economy institutions in the 1980s to systematically restructuring SOEs and adjust central-local relations to promote rapid economic growth. In the latter's case, Hu-Wen's Scientific Development political vision served to theorise and legitimise his policy agenda, focusing more on a healthy development model and economic structure instead of the speed of growth. Thus, the formulation and policy impact of these ideational systems can all be clearly traced within the Chinese political system since the late 1970s. The casual mechanism of their impact on substantial polices is also clearly mapped out in the study's analysis of the introduction of the energy efficiency target responsibility system. Therefore, ideational innovation in China can be regarded as a new form of ideational factor that could profoundly impact institutional development and policymaking.

Moreover, the role of ideational innovation and ideational systems in policymaking also greatly improved our understanding of the Chinese political economy by updating the models of policymaking in China. As discussed, the findings of the study strongly suggest an Idea-Guided Policymaking Model that is different from both the exogenous view under the Rational Policymaking Model and the Bureaucratic Politics Model. The fact that Chinese policymaking has been guided by the past two generations of leadership's ideational systems indicates that any studies of Chinese policymaking must take those seemingly inane political slogans such as "Scientific Development Outlook" very seriously.

\subsubsection{Multi-layered and Cross-Sectoral Institutional Analysis}

By investigating the key policy actors and processes of China's Five-Year Plan/Programme system, this study also makes significant contributions to institutional studies of a transitional state by introducing a multi-layered and cross-sectoral institutional analysis.

In HI-based policy studies, a major way to understand major policy change has been by examining the asymmetrical power distribution between major policy actors and examining its long term impact on policymaking (Hall and Taylor, 1996). In a 
given polity, an asymmetrical power distribution between major political actors is often caused by a multi-level hierarchical structure of state institutions, where major political actors are empowered and constrained by state institutions on different levels of institution.

Sinologists have observed that China's party-state after 1978 has been organised as a set of hierarchical political-economic institutions. At the top sits a small group of party-state leadership; at the intermediate level is a host of central government's functional bureaucracies; and at the bottom level are institutions connecting the national government with its subnational agencies, such as the provinces and the SOEs. By investigating Chinese energy policymaking in the early-to-mid 1980s, Lieberthal and Oksenberg (1988) argue that Chinese policymaking is characterised by a Fragmented Authoritarianism theory featuring horizontal bargaining between bureaucratic actors at the intermediate level. However, with major institutional reforms and central government restructuring unfolding in the 1990s, the dynamics of national policymaking have increasingly been transformed into a new pattern of vertical interaction between a more authoritarian leadership at the national level and local governments and emerging non-state sectors at the subnational level. By investigating China's energy policy change, this study also tests the assumption that emerging vertical interaction is the main source of Chinese policymaking and change, using ample and rigid empirical evidence. It reveals the fact that the bureaucratic view of Chinese policymaking has become static against the latest development of the Chinese political economy, needing to be revised and even replaced by a vertical interaction model capable of taking emerging multi-layered variables into account.

Moreover, as analysed in the introduction chapter, a central characteristic of China's energy policy change has been the cross-sectoral shift of policy priority. How to effectively capture and explain it becomes the linchpin to understand the policy shift and a central criterion to judge any studies on China's energy policy change. From the late 1990s, the Chinese central government's emphasis on energy supply security has evoked a growing group of political scientists' interest in studying the Chinese energy sector and its international implications. Later, studies have grown quickly to focus more on other energy sectors, like coalmining and electric power, and the renewable energy sectors. However, most of these studies present single-sector analysis. Such analysis is quite insufficient in capturing and examining the forces that led to a policy 
priority shift, from energy security, with the oil-petrochemical sector as its major industrial basis, to energy efficiency, with the coal-based energy-intensive industries as its industrial basis. In this respect, this study has also developed a cross-sectoral approach on top of the multi-layered analysis, based on the dichotomy of energy-based industrial value chains and their evolving institutional connections with government at central and local levels. In sum, the multi-layered and cross-sectoral analytical approach constitutes an important research method innovation, making the study's research design distinctive compared to conventional studies. This method enables the study to compare industrial organisations across different energy sectors, and to examine their changing institutional connections with a multi-layered hierarchy of political actors that effectively explains the cross-sectoral characteristic of China's energy policy priority shift.

\subsubsection{An Idea-Guided Institutional Adaptation Model of China's Energy Policy Change}

Last but not least, the study contributes to a better understanding of China's energy policy change by building a HI theory-based multi-layered and cross-sectoral analytical framework focusing on the complex interaction between ideas, institutions and interests over the past two decades. In new institutionalism policy studies, there has been a call for synthesis of institutional, interest and ideational factors to better understand policy change. Political scientists and policy analysts like Campbell (2002), Lieberman (2002) and Béland (2009) all call for a more systematic integration of different branches of new institutionalism to understand how ideas and interests interact in certain institutional contexts to produce policy change. Many others have also strongly suggested that students of HI should advance the theory by studying and explaining policy change, asking how ideas and interests interact in certain institutional contexts (Béland 2005; Béland and Cox 2010; Gofas and Hay 2010; Hall 1993; Jacobsen 1995).

By examining the endogenous and dynamic factors that have induced China's policy change, this study establishes a model of policy change as a means of institutional adaptation to manage a mismatch between evolving ideational patterns at the national level and interest-seeking behaviour shaping subnational institutions (see Figure 18). 
Figure 18 An Idea-Guided Institutional Adaptation Model of China's Energy Policy Change

1980s-mid 1990s: Balanced Structure

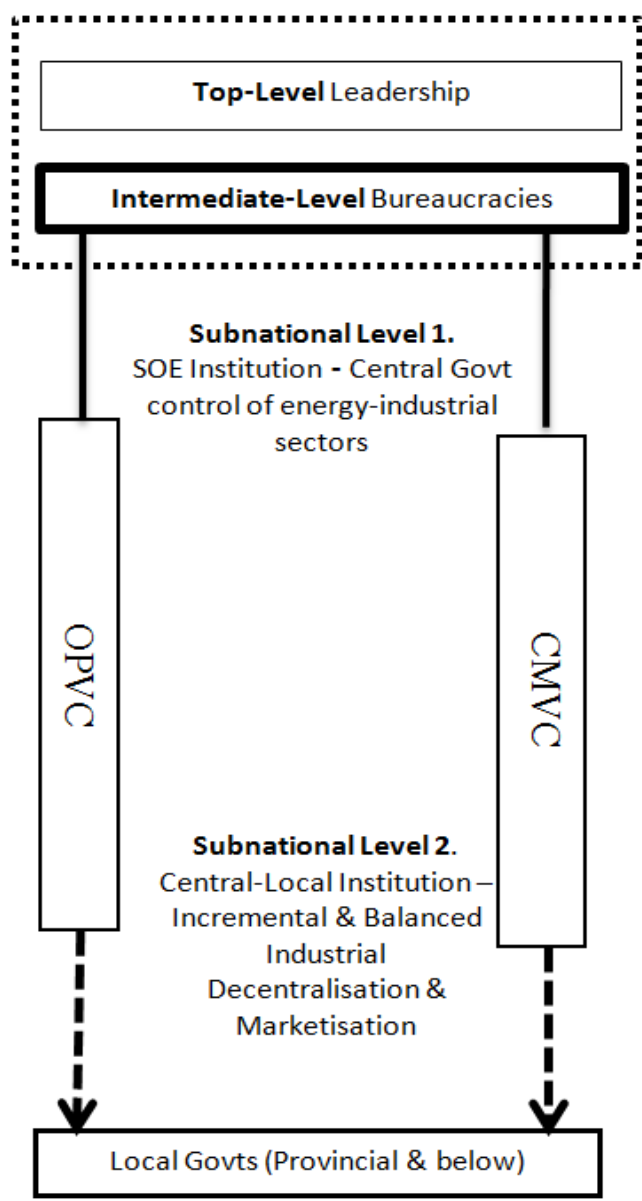

Mid 1990s-early 2000s: Imbalanced structure
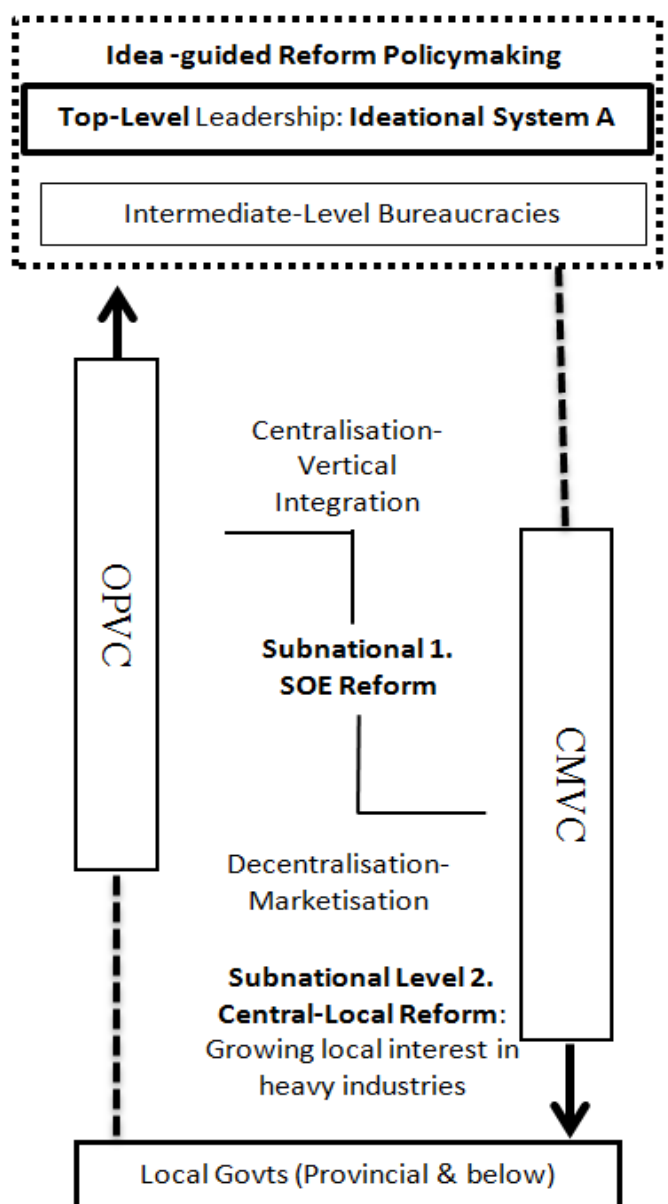

2000s: Idea-Guided Institutional Adaptation

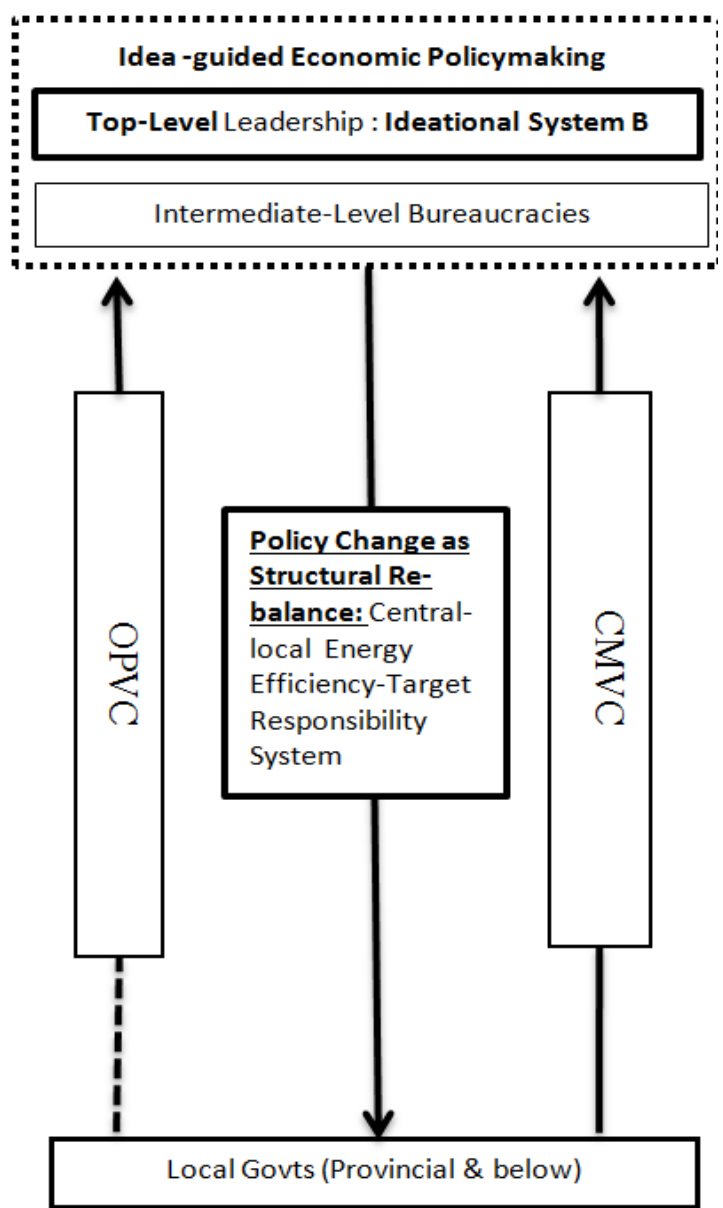


The model has profound implications for the study of a transitional state's political economy beyond China. In the context of a transitional state with an authoritarian leadership, institutional reforms aim to break constraints of a command economy and affiliated institutions. This constitutes a main theme of a transitional state's institutional development. At certain critical junctures of such transitions, when a window for systematic institutional reform emerges, authoritarian leadership could redesign the institutional infrastructure of the state in a punctuated equilibrium manner. Once such institutional redesign is done, the reformed institutions provide stable opportunities and constraints to political actors to shape their behaviour.

However, national leadership acts with bounded rationality, and the reformed institutions that serve their ideas and purposes at the time may produce unintended and unwanted consequences over time, especially when an institutionalised power transition happens and a generation of new leadership with updated reform and development ideas takes over policymaking power. When new reform and development ideas are confronted by those unintended consequences resulted from historical policy choices, and a systematic institutional overhaul is unlikely, major policy change utilising certain mechanisms of existing institutions could serve to integrate new values of the current leadership into historically-formulated institutional arrangements. This institutional adaptation model provides a major option to remedy the unintended consequences of historical institutional reforms. In terms of China's energy policy change, when the SOE reform and central-local relations reform brought unintended and unwanted consequences of economic structural change and energy intensity rise, the party-state's cadre evaluation and promotion mechanism provided a solution to the problem.

\subsection{Conclusion and Future Research}

Overall, this study builds a multi-layered and cross-sectoral analytical framework based on Historical Institutionalism theory to decipher the shift of China's energy policy priority in the country's last four Five-Year Plans/Programmes. This analytical framework focuses on the long term and complex interaction between the evolving 
ideas of national policymakers and the diverging interest-seeking behaviour of subnational policy-actors in a hierarchical institutional structure.

At the broadest level, this research strongly suggests that some core assumptions of Historical Institutionalism are increasingly supported by empirical evidence from transitional states, where an authoritarian political regime and an increasingly market-based economy co-exist in a multi-layered institutional environment. Asymmetrical power relations built in such a multi-layered institutional environment could produce strong forces of institutional adaptation over time in the form of major policy change. This conclusion mainly derives from the Idea-Guided Institutional Adaptation Model of China's energy policy change identified by this study. The model has clearly illustrated how a mismatch between policymaker's ideational systems and other key political actors' institution-shaped interest-seeking behaviour could gradually develop over a period of two decades, and how authoritarian policymakers' perception of the mismatch could induce a major policy change to adapt the historically-formulated institutions that provide incentives and constraints to the country's key political actors to achieve behaviour changing effect.

Also, the study shows that Chinese political economy has evolved significantly over the past two decades, and that some of the most influential theories of Chinese politics and models of Chinese policymaking need serious updating to comprehend China's changing socio-economic policies. Differing from both the exogenous view under the Rational Policymaking Model and the Bureaucratic Politics Model based on the Fragmented Authoritarianism theory, this study finds that China's national policymaking in the past two decades has been increasingly guided by the leadership's systematic ideas of reform and development. This idea-guided policymaking model is a result of incremental institutionalisation of Chinese leadership transition and the need for an overarching strategy of development as China's transition advances and deepens. Those idea-guided institutional reform policies could profoundly redesign the country's fundamental political-economic institutions, which might produce benefits and also create problems for later reforms and development. 
Regarding energy policy and energy development, the dichotomy of CMVC and OPVC is crucial in understanding the cross-sectoral shift of China's energy policy priority. As analysed in the introduction chapter and Chapter Two, a central characteristic of China's energy policy change has been the cross-sectoral shift of policy priority which most existing literature overlooks. By contrast, this study develops a cross-sectoral analysis approach based on the dichotomy of energy-based industrial value chains of OPVC and CMVC. Such a cross-sectoral analysis approach constitutes an important study method innovation that makes the study distinctive compared to conventional energy analysis. It enables the study to compare industrial structures across different energy sectors, and to examine their changing institutional connections with the Chinese government at the national and the subnational levels to discover the imbalanced structure of Chinese energy development. It shows that in transitional states where an authoritarian political regime and an increasingly marketbased economy co-exist in a multi-layered institutional environment, the asymmetrical distribution of energy-based industrial interests between major political actors can significantly influence the development of the country's different energy sectors and profoundly shape its overall energy situation.

By exploring China's energy policy change, the study sheds light on some fundamental problems facing China's reform and development. More future studies are needed to explore these important and challenging topics of Chinese political economy and energy policy. For instance, it would be very interesting to observe how the new $\mathrm{Xi}$-Li leadership would pass on the CPC's ideational innovation tradition in the rest of their tenure to influence China's reform and development. Xi's "FourComprehensiveness" (sige quan'mian) introduced in early 2015 was his first serious attempt to build a new ideational system. Whether this "Four-Comprehensiveness" is going to parallel Hu's "Scientific Development" as an overarching ideational system and how it might affect China's reform and development over the 13th and 14th FYPs' period is a significant topic worthy of detailed examination. 
Another challenging question is how to reconcile an increasing authoritarian political leadership with a progressively market-based economy in terms of energy efficiency governance. On the one hand, this study reveals the value of a strong partystate leadership in terms of utilising top-down personnel control and administrative measures to achieve institutional adaptation and energy development actors' behaviour change. As some core concepts of historical institutionalism such as Path Dependency suggest, institutional change will be more difficult as the critical juncture of systematic institutional reforms passes. Political actors, including the top leadership, will be increasingly constrained by historically formulated institutional arrangements. Transitional states like China are more likely to build a halfway house in face of growing reform costs and stronger resistance from vested-interest groups shaped by the unintended consequences of institutional reforms. In such circumstances, the rise of stronger leadership can be crucial in pushing the marketisation reforms forward. This seemed to be the case following the power transition between the $\mathrm{Hu}-\mathrm{Wen}$ leadership and the Xi-Li Leadership. However, on the other hand, as the whole Chinese economy becomes increasingly marketised and internationalised, how to manage the unintended consequences of previous institutional reforms with regulatory and market-based mechanisms becomes increasingly challenging. This is especially true in terms of energy efficiency policy, when the 'low-hanging fruits' of energy efficiency gains were picked by the target-responsibility system in the 11th and 12th FYPs, and the number of non-state enterprises steadily grows in China's coal-based industrial value chains. Market-oriented actors are more likely to respond to economic incentives and regulatory constraints instead of the party-state's personnel control mechanisms and the State's administrative orders. How to design and introduce more regulatory and market mechanisms that are compatible with strong party-state institutions is vital to China's energy efficiency governance and the country's economic structure adjustment course in the coming decades. 


\section{Appendix:}

\section{Formation of Vertically-Integrated NOCs - Assets Swap Between CNPC and Sinopec and the Transfer of Local Government Oil Companies in 1998}

\begin{tabular}{|c|c|c|}
\hline \multicolumn{2}{|l|}{ New CNPC } & New Sinopec \\
\hline \multicolumn{3}{|c|}{ Oil \& Gas Reserves \& Production } \\
\hline Oil reserves & 4.1 billion tonnes & 1.2 billion tonnes \\
\hline Gas reserves & $\begin{array}{l}76 \text { billion cubic } \\
\text { meters }\end{array}$ & 4.3 billion cubic meters \\
\hline Oil production & 107 million tonnes & 36.3 million tonnes \\
\hline Gas production & $\begin{array}{l}14.8 \text { billion cubic } \\
\text { meters }\end{array}$ & 2.4 billion cubic meters \\
\hline \multicolumn{3}{|c|}{ Upstream: Crude Oil and Gas Production Units } \\
\hline \multicolumn{2}{|c|}{ Daqing Petroleum Administration Bureau } & $\begin{array}{l}\text { Shengli Petroleum Administration Bureau } \\
\text { (Previously CNPC) }\end{array}$ \\
\hline $\begin{array}{l}\text { Jilin Petroleum C } \\
\text { (Previously Prov }\end{array}$ & y Ltd & $\begin{array}{l}\text { Zhongyuan Petroleum Administration Bureau } \\
\text { (Previously CNPC) }\end{array}$ \\
\hline \multicolumn{2}{|c|}{ Liaohe Petroleum Exploration Bureau } & $\begin{array}{l}\text { Henan Petroleum Administration Bureau } \\
\text { (Previously CNPC) }\end{array}$ \\
\hline \multicolumn{2}{|c|}{ Dagang Oil Field Group Company Ltd } & $\begin{array}{l}\text { Jianghan Petroleum Administration Bureau } \\
\text { (Previously CNPC) }\end{array}$ \\
\hline \multicolumn{2}{|c|}{ Huabei Petroleum Administration Bureau } & $\begin{array}{l}\text { Jiangsu Petroleum Administration Bureau } \\
\text { (Previously CNPC) }\end{array}$ \\
\hline \multicolumn{2}{|c|}{ Xinjiang Petroleum Administration Bureau } & $\begin{array}{l}\text { Dianqiangui Petroleum Administration Bureau } \\
\text { (Previously CNPC) }\end{array}$ \\
\hline \multicolumn{3}{|c|}{ Sichuan Petroleum Administration Bureau } \\
\hline \multicolumn{3}{|c|}{ Changqing Petroleum Administration Bureau } \\
\hline \multicolumn{3}{|c|}{ Yumen Petroleum Administration Bureau } \\
\hline \multicolumn{3}{|c|}{ Tuha Petroleum E\&D Headquarter } \\
\hline \multicolumn{3}{|c|}{ Tarim Petroleum E\&D Headquarter } \\
\hline Jidong Petroleur & & \\
\hline
\end{tabular}




\begin{tabular}{|c|c|c|c|}
\hline $\begin{array}{l}\text { Midstream: Major Refining Units and Ca } \\
\text { (above 1,000 tonnes/day) }\end{array}$ & & & \\
\hline Total 87,800 tonnes/day & & Total 125,240 tonnes/day & \\
\hline Fushun Petrochemical Corporation & & Yanshan Petrochemical Corp. & 9,500 \\
\hline (Previously Sinopec) & 9,200 & Maoming Petrochemcal Corp. & 8,500 \\
\hline Dalian Petrochemical Corporation & & Zhenghai Refining and Chemical Co. Ltd & 8,000 \\
\hline (Previously Sinopec) & 7,100 & Qilu Petrochemical Corp. & 8,000 \\
\hline Dushanzi Refinery & 6,000 & Gaoqiao Petrochemical Corp. & 7,500 \\
\hline Daqing Petrochemical Corporation & & Jinling Petrochemical Corp. & \\
\hline (Previously Sinopec) & 6,000 & (Previously Donglian) & 7,000 \\
\hline Jinzhou Petrochemical Corporation & 5,500 & Tianjin Petrochemical Corp. & 6,000 \\
\hline Lanzhou Refining and Chemical & & Yangzi Petrochemical Corp. & \\
\hline Corporation (Previously Sinopec) & 5,500 & (Previously Donglian) & 6,000 \\
\hline Jinxi Petrochemical Corporation & & Shanghai Petrochemical Co. Ltd & 5,300 \\
\hline (Previously Sinopec) & 5,000 & Guangzhou Petrochemical Corp. & 5,200 \\
\hline Jilin Chemical Industry Group & 4,500 & Luoyang Petrochemical Plant & 5,000 \\
\hline Yumen Refinery & 4,000 & Jingmen Petrochemical Plant & 5,000 \\
\hline Liaoyang Chemical Fibre Corporation & & Baling Petrochemical Corp. & 5,000 \\
\hline (Previously Sinopec) & 4,000 & Fujian Refinery & 4,000 \\
\hline Daqing Chemical Synergist Plant & 3,500 & Jinan Refinery & 4,000 \\
\hline Karamay Refinery & 3,300 & Dagang Refinery & 3,000 \\
\hline Liaohe Oil Field Asphalt Plant & 2,500 & Anqing Petrochemical Plant & 2,800 \\
\hline Xianyang Refinery & 2,500 & Shijiazhuang Refinery & 2,500 \\
\hline Linyuan Refinery (Previously Sinopec) & 2,500 & Jiujiang Refinery & 2,500 \\
\hline Anshan Refinery & 2,500 & Wuhan Petrochemical Plant & 2,500 \\
\hline Urumqi Petrochemical Plant & & Shengli Heavyoil plant & 2,500 \\
\hline (Previously Sinopec) & 2,500 & Qingdao Petrochemical Works & 2,500 \\
\hline Harbin Refinery (Previously Sinopec) & 1,500 & Cangzhou Refinery & 1,500 \\
\hline Qianguo Refinery (Previously Sinopec) & 1,500 & Yan'an Refinery & 1,500 \\
\hline Qinghai Refinery & 1,350 & Zhanjiang Refinery & 1,500 \\
\hline Huhhot Refinery & 1,000 & Zhongyuan Refinery & 1,300 \\
\hline Golmud Refinery & 1,000 & The rest 28 units & 6,990 \\
\hline The rest 15 refining units & 3,350 & & \\
\hline
\end{tabular}




\begin{tabular}{|c|c|}
\hline $\begin{array}{l}\text { Downstream: Sales Companies } \\
\text { (all companies were previously owned by local governme }\end{array}$ & unless otherwise specified) \\
\hline Jilin Provincial Petroleum Company (Previously Sinopec) & Beijing Municipal Petroleum Company \\
\hline Liaoning Provincial Petroleum Company & Tianjin Municipal Petroleum Company \\
\hline Dalian Petroleum Company & Shanghai Municipal Petroleum Company \\
\hline Shenyang Petroleum Company (Previously Sinopec) & Hebei Provincial Petroleum Company \\
\hline Innner Mongolia Regional Petroleum Company & Henan Provincial Petroleum Company \\
\hline Shanxi Provincial Petroleum Company & Shaanxi Municipal Petroleum Company \\
\hline Xi'an Petroleum Company & Shandong Provincial Petroleum Company \\
\hline Gansu Provincial Petroleum Company & Anhui Provincial Petroleum Company \\
\hline Ningxia Regional Petroleum Company & Jiangxi Provincial Petroleum Company \\
\hline Xingjiang Regional Petroleum Company & Hubei Provincial Petroleum Company \\
\hline Qinghai Provincial Petroleum Company & Hunan Provincial Petroleum Company \\
\hline Sichuan Provincial Petroleum Company & Jiangsu Provincial Petroleum Company \\
\hline Chongqing Municipal Petroleum Company & Zhejiang Provincial Petroleum Company \\
\hline Tibet Regional Petroleum Company & Fujian Provincial Petroleum Company \\
\hline Heilongjiang Provincial Petroleum Companies & Guangdong Provincial Petroleum Company \\
\hline Harbin Petroleum Company (Previously Sinopec) & Guangxi Regional Petroleum Company \\
\hline Northwest Petroleum Company (Previously Sinopec) & Yunnan Provincial Petroleum Company \\
\hline & Guizhou Provincial Petroleum Company \\
\hline & Hainan Provincial Petroleum Company \\
\hline & Ningbo Petroleum Company \\
\hline & Qingdao Petroleum Company \\
\hline & Xiamen Petroleum Company \\
\hline & Shenzhen Petroleum Company \\
\hline
\end{tabular}

Data source: SAT (1998[147]) and author's research at CNOOC. 


\section{References}

Aden, Nathaniel, David Fridley, and Nina Zheng. 2009. China's Coal: Demand, Constraints, and Externalities. Ernest Orlando Lawrence Berkeley National Laboratory.

http://minotaur.lbl.gov/china.lbl.gov/sites/china.lbl.gov/files/LBNL-2334E.pdf. Accessed in Aril 2012.

Andrews-Speed, Philip. 2009. "China's Ongoing Energy Efficiency Drive: Origins, Progress and Prospects." Energy Policy 37, no. 4: 1331-1344.

Andrews-Speed, Philip. 2004. Energy Policy and Regulation in the People's Republic of China, International Energy and Resources Law and Policy Series. Hague, London, New York: Kluwer Law International, 2004.

Andrews-Speed, Philip. 2010a. The Institutions of Energy Governance in China. The Institut français des relations internationales (Ifri). Paris, www.ifri.org/downloads/noteandrewsspeedenergychina_1.pdf. Accessed in March 2014.

Andrews-Speed, Philip, and Roland Dannreuther. 2011. China, Oil and Global Politics. Vol. 68, Routledge Contemporary China Series. Abingdon, New York: Routledge, 2011.

Bang, Guri. 2010. "Energy Security and Climate Change Concerns: Triggers for Energy Policy Change in the United States?" Energy Policy 2010, no. 38: 1645-1653.

Béland, Daniel. 2005. "Ideas and Social Policy: An Institutionalist Perspective." Social Policy \& Administration 39, no. 1: 1-18.

Béland, Daniel. 2009. "Ideas, Institutions, and Policy Change." Journal of European Public Policy 16, no. 5: 701-718.

Béland, Daniel, and Robert Henry Cox. 2010. eds. Ideas and Politics in Social Science Research. Oxford: Oxford Univeristy Press, 2010. 
Bell, Stephen, and Hui Feng. 2013. The Rise of the People's Bank of China: The Politics of Institutional Change. Cambridge, MA: Harvard University Press, 2013.

Betz, Joachim. 2013. The Reform of China's Energy Policies. German Institute of Global and Area Studies (GIGA).

Bhattacharyya, Subhes C. 2011. Energy Economics: Concepts, Issues, Markets and Governance. London: Springer, 2011.

Bird, Richard M., and Christine Wong. 2005. China's Fiscal System: A Work in Progress. Rotman School of Management Working Paper No. 07-11. University of Toronto, http://papers.ssrn.com/sol3/papers.cfm?abstract_id=875416. Accessed in March 2012.

Bradsher, Keith. 2010. "China Leading Global Race to Make Clean Energy". The New York Times, http://www.nytimes.com/2010/01/31/business/energyenvironment/31renew.html?_r=1. Accessed in June 2012.

Brødsgaard, Kjeld Erik. 2012. "Politics and Business Group Formation in China: The Party in Control?" The China Quarterly 211, no. September 2012: 624-648.

Brown, Charles E. 2002. World Energy Resources. New York: Springer, 2002.

Burns, John P. 1989. eds. The Chinese Communist Party's Nomenklatura System. Armonk, New York: M. E. Sharpe, Inc, 1989.

Burns, John P., and Zhiren Zhou. 2010. "Performance Management in the Government of the People's Republic of China: Accountability and Control in the Implementation of Public Policy." OECD Journal on Budgeting 10/2.

CAIC 全国工商联. Feburary 28, 2013, "quanguo gongshanglian guanyu qingli feizhi xiangguan wenjian guiding gaishan shiyou hangye minjian ziben touzi huanjing de ti'an" 全国工商联关于清理废止相关文件规定改善石油行业民间资本投 资环境的提案 [Chinese Association of Industry \& Commerce's Policy Proposal on Abolishing Discriminative State Polcies against Private Oil Companies], Chinese People's Political Consultative Conference Website, Feburary 28, 2013, 
http://www.cppcc.gov.cn/zXww/2013/02/28/ARTI1362043778296183.shtml.

Accessed in March 2014.

Campbell, John L. 2002. "Ideas, Politics, and Public Policy." Annual Review of Sociology 28, no. ArticleType: research-article / Full publication date: 2002 / Copyright @ 2002 Annual Reviews: 21-38.

Cao, Xianghong 曹湘洪. 2004. "Zhongguo shihua gongye xianzhuang he weilai fazhan zhanwang" 中国石化工业现状和未来发展展望 [The Current Status and Futture Projection of China's Petrochemical Industries], Dangdai shiyou shihua 当代石油石化 [Petroleum \& Petrochemical Today], 12, no. 6.

Capoccia, Giovanni, and R. Daniel Kelemen. 2007. "The Study of Critical Junctures: Theory, Narrative, and Counterfactuals in Historical Institutionalism." World Politics 59, no. April 2007.

Chan, Gerald. 2004. "China's Compliance in Global Environment Affairs." Asia Pacific Viewpoint 45, no. 1: 69-86.

Chang, Felix K. 2001. "Chinese Energy and Asian Security." Orbis 45, no. 2: 211-240.

Chen, Dajun. 2005. "Chinese Aluminum Industry Current Status and Future Outlook 2005 China Aluminum Forum Conference Review." Light Metal Age 64, no. 1.

Chen, Junhong 陈俊宏. 2011. Zhongguo tese shehui zhuyi lilun tixi hexin guandian $j i e d u$ 中国特色社会主义理论体系核心观点解读 [An Interpretation of the Core Ideas in the Theory of Socialism with Chinese Characteristics]. Zhonggong zhongyang dangxiao chubanshe 中共中央党校出版社 The CPC Central Party College Press: Beijing, 2011.

Chen, Shaoqiang 陈少强. 2009. "Guoyou qiye lirun fenpei zhidu bianqian yu wanshan" 国有企业利润分配制度变迁与完善 [Soe Profit Allocation System and Its Reform], Zhongguo caizheng 中国财政 [China State Finance], 2009, no. 8: 2931.

Chen, Ye, Hongbin Li, and Li-An Zhou. 2005. "Relative Performance Evaluation and the Turnover of Provincial Leaders in China." Economics Letters 2005, no. 88: 421-425. 
Cheng, Zhen 程真. April 18, 2011. "Fu Chengyu de guoji shiye" 傅成玉的国际视野 [Fu Chengyu's Global View], China Energy News, April 18, 2011.

China Energy Group. 2014. "Iron and Steel Industry Overview". Lawrence Berkeley National Laboratory, http://china.lbl.gov/research-areas/iron-and-steel-industry. Accessed in October 8, 2014.

China NonFerrous Industry Association 中国有色工业协会. 2012. Fen shengshi zizhiqu shizhong youse jinshu chanliang 分省市自治区十种有色金属产量 [Top-10 Ferrous Metals Production by Provinces]. Zhongguo youse jinshu gongye nianjian 2012 中国有色金属工业年鉴 2012 [China Nonferrous Industry Yearbook 2012]. Zhongguo youse gongye xiehui 中国有色工业协会 China NonFerrous Industry Association: Beijing, 2012.

China Steel Association 中国钢铁协会. 2013. 2.quanguo gangtie gongye zhuyao chanpin chanliang 2. 全国钢铁工业主要产品产量 [Chapter 2: Nation-Wide Steel Production]. Zhongguo gangtie gongye nianjian 2013 中国钢铁工业年鉴 2013 [China Steel Year Book 2013]. Zhongguo gangtie gongye xiehui chubanshe 中国钢铁工业协会出版社 China Steel Association Press: Beijing, 2013.

Chinanews 中国新闻网. February 4, 2005, "2004 nian gangtie chanliang 2.7 yi tun tiaokong quede xianzhu chengxiao" 2004 年钢铁产量 2.7 亿吨 调控取得显著 成效 [China Produced 270 Million Tons of Steel in 2004], China.org.cn, February 4, 2005, http://www.china.com.cn/chinese/jingji/778069.htm. Accessed in July 2013.

Chinanews 中国新闻网. Janurary 5, 2011, "Zhonghaiyou chanliang bijin zhongshihua 2020 nian qian zai jian 'haishang daqing'"中海油产量逼近中石化 2020 年前再 建"海上大庆" [CNOOC's Oil\&Gas Production Approaching That of Sinopec], China News Website, Janurary 5, 2011, http://www.chinanews.com/ny/2011/0105/2766622.shtml. Accessed in August 2014.

Chinanews 中国新闻网. December 14, 2006. "Fagaiwei、guojia dianjianhui lianshou fu 8 sheng qu ducha chabie dianjia" 发改委、国家电监会联手赴 8 省区督查 差别电价 [The Ndrc Sends Working Groups to 8 Provinces and Regions to 
Oversee the Implementation of Differential Power Pricing], China.org.cn, December 14, 2006, http://www.china.com.cn/policy/txt/2006-

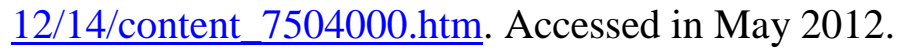

Chinanews 中国新闻网. November 25, 2007. "Guowuyuan xiafa jieneng kaoping fang'an guanyuan jieneng buli jiang yipiao foujue" 国务院下发节能考评方案 官员节能不力将一票否决 [The State Council Promulgate Energy Evaluation System, Officials Will Be 'Veto' on Failing to Achieve Energy Conservation Targets], China.org.cn, $\quad$ November 25 2007, http://www.china.com.cn/news/txt/2007-11/25/content_9286661.htm. Accessed in April 2013.

China Petrochemcial 中国石化工业协会. 2005. Zhongguo shiyou shihua chanye jingji yanjiu niandu baogao 2005 中国石油石化产业经济研究年度报告 2005 [China Petrochemical Industry Annual Report 2005]. Zhongguo tushu xinxiwang 中国图书信息网 China Year Book Information Network:Beijing, 2005.

Christoff, Peter. 2010. "Cold Climate in Copenhagen: China and the United States at Cop15." Environment Politics 19, no. 4: 637-656.

CNPC 中国石油天然气集团公司. 2014. Zhongguo shiyou tianranqi jituan gongsi 2014 qiye shehui zeren baogao 中国石油天然气集团公司 2014 企业社会责任 报告 [Cnpc Annual Report on Corporate Social Responsibility]. Zhangguo shiyou tianranqi zonggongsi 中国石油天然气总公司 China National Petroleum Corporation:Beijing, 2014.

Cohen-Tanugi, David. 2010. Putting It into Perspective: China's Carbon Intensity Target. Natural Resources Defense Council (NDRC). New York, http://www.nrdc.cn/english/E_info_library_info.php?id=586\&down=1\&cid=21 ‥ Accessed in May 2012.

Constantin, Christian. 2007. "Understanding China's Energy Security." World Political Science Review 3, no. 3.

CPC Central Committe 中国共产党中央委员会. October 11, 2005. "Zhonggong zhongyang guanyu zhiding guomin jingji he shehui fazhan di shi yi ge wu nian 
guihua de jianyi" 中共中央关于制定国民经济和社会发展第十一个五年规划 的建议 [Policy Suggestions of the Cpc Central Committe to the Making of the 11th Fyp], October 11, 2005, http://cpc.people.com.cn/GB/64162/64168/64569/65414/4429220.html. Accessed in May 2012.

CPC News 中国共产党新闻. October 21，2007. "Zhongguo gongchandang zhangcheng"中国共产党章程 [The Constitution of the Communist Party of China]. News of the Communist Party of China, October 21, 2007, http://cpc.people.com.cn/GB/64156/65682/4475081.html. Accessed in July 2012.

CPNN 国家电力新闻网. August 4, 2014." Wu Xinxiong zai quanguo 'shisan wu' nengyuan guihua gongzuo huiyi shang de jianghua"吴新雄在全国“十三五”能 源规划工作会议上的讲话 [Speech by the Head of National Energy Administration Wu Xinxiong on the Making of Energy Policy in the 13th Fyp], China Power National News, August 4, 2014, http://www.cpnn.com.cn/zdzgtt/201408/t20140804_704012.html. Accessed in August 2014.

CSFM 中国财政杂志社. 2013. Zhongyang ji difang zhengfu caizheng zhichu ji bizhong 1953-2013 中央及地方政府财政支出及比重 1953-2013 [Central and Local Budgetary Expenditure and Proportions]. Zhongguo caizheng nianjian 2013 中 国财政年鉴 2013 [In China Fiscal Year Book 2013]. Zhongguo caizheng zazhishe 中国财政杂志社 China State Finance Magazine Press: Beijing, 2013.

CSFM 中国财政杂志社. 2013. Zhongyang ji difang zhengfu caizheng shouru ji bizhong 1953-2013 中央及地方政府财政收入及比重 1953-2013 [Central and Local Budgetary Revenue and Proportions]. Zhongguo caizheng nianjian 2013 中国财政年鉴 2013 [In China Fiscal Year Book 2013]. Zhongguo caizheng zazhishe 中国财政杂志社 China State Finance Magazine Press: Beijing, 2013.

Cunningham, Edward A. 2009. "A Portfolio Approach to Energy Governance: State Management of China's Coal and Electric Power Supply Industries." Massachusetts Institute of Technology, 2009. 
Dabla-Norris, Era. 2005. Issues in Intergovernmental Fiscal Relations in China. International Monetary

Fund. https://www.imf.org/external/pubs/ft/wp/2005/wp0530.pdf. Accessed in June 2012.

Devold, Havard. 2013. Oil and Gas Production Handbook: An Introduction to Oil and Gas Production, Transport, Refining and Petrochemical Industry. 3.0 ed. Oslo: ABB Group, 2013.

Dittmer, Lowell. 2003. "Leadership Change and Chinese Political Development." The China Quarterly 2003, no. 176.

Dittmer, Lowell, and Guoli Liu. 2006. eds. China's Deep Reform: Domestic Politics in Transition. Oxford, UK: Rowman \& Littlefield Publishers, Inc., 2006.

Downs, Erica. 2008a. "China's New Energy Administration." China Business Review November-December 2008.

Downs, Erica. 2008b. China's Energy Policies and Their Environmental Impacts. USChina Economic \& Security Review Commission. http://www.brookings.edu/research/testimony/2008/08/13-china-downs. Accessed in April 2013.

Downs, Erica, and Michal Meidan. 2011. "Business and Politics in China." China Security 2011, no. 19: 3-21.

Downs, Erica S. 2004. "The Chinese Energy Security Debate." The China Quarterly 177, no. May: 21-41.

Downs, Erica S. 2006. The Energy Security Series: China. The Brookings Institution. Washington D.C., http://www.brookings.edu/reports/2006/12china.aspx. Accessed in April 2013.

Drejer, Ina. 2002. Input-Output Based Measures of Interindustry Linkages Revisited - a Survey and Discussion. Centre for Economic and Business Research, The Ministry of Economic and Business Affairs, Denmark. Copenhagen, http://iioa.org/conferences/14th/files/Drejer_pdf. Accessed in May 2013.

Duffield, John S., and Brian Woodall. 2011. "Japan’s New Basic Energy Plan." Energy Policy 2011, no. 39: 3741-3749. 
Eaton, Sarah. 2013. "Political Economy of the Advancing State: The Case of China's Airlines Reform." The China Journal 2013, no. 69: 64-86.

Edin, Maria. 2003. "State Capacity and Local Agent Control in China: Cep Cadre Management from a Township." The China Quarterly March 2003, no. 173: 3552 .

Edin, Maria. 1998. "Why Do Chinese Local Cadres Promote Growth? Institutional Incentives and Constraints of Local Cadres." Forum for Development Studies 1998, no. 1: 97-127.

EIA. 2013. "International Energy Data and Analysis: China". US Energy Information Administration, http://www.eia.gov/beta/international/analysis.cfm?iso=CHN. Accessed in August 2013.

EIA. 2013. International Energy Outlook 2013. Washington D.C.: US Energy Information Administration, 2013.

EIA. 2013. "International Energy Statistics." US Energy Information Administration, http://www.eia.gov/cfapps/ipdbproject/IEDIndex3.cfm. Accessed in May 2013.

Feng Fei, Zhou Fengqi, and Wang Qingyi 冯飞, 周凤起, 王庆一. 2004. "Zhongguo nengyuan fazhan zhanlve yu zhengce yanjiu baogao" 中国能源发展战略与政 策研究报告 [Report on China's Energy Development Strategy and Policy], Jingji yanjiu cankao 经济研究参考 [Review of Economic Research], 83, no. 2004.

Feng, Shiliang 冯世良. 2005. "Zhongguo shihua gongye fazhan xianzhuang yu zhanwang" 中国石化工业发展现状与展望 [Current Development and Trend of China's Petrochemcial Industry], China Petrochemcial Industrial Association, 2005, http://www.shfe.com.cn/jrysp/22/16.pdf. Accessed in July 2013.

Fu, Weigang 傅蔚冈. September 6, 2014. "Guoziwei suoguan yangqi lirun san tong you zhan 7 cheng: jiu kao longduan qiye" 国资委所管央企利润三桶油占 7 成: 就 靠垄断企业 [The Three Nocs Contribute 70 Percent of Yangqi Profits by Monoplying the Market], Huaxia Times, September 6, 2014. 
Garnaut, Ross, Ligang Song, and Yang Yao. 2006. "Impact and Significance of StateOwned Enterprise Restructuring in China." The China Journal Jan., 2006, no. 55: 35-63.

Gerring, John. 2004. "What Is a Case Study and What Is It Good For?" American Political Science Review 98 2004, no. 02.

Gofas, Andreas, and Colin Hay. 2010. eds. The Role of Ideas in Political Science: A Portrait of Contemporary Debates. New York: Routledge, 2010.

Guo, Sujian. 2013. ed. Political Science and Chinese Political Studies: The State of the Field. Heidelberg, New York, Dordrecht, London: Springer, 2013.

Hall, Peter. 1993. "Policy Paradigms, Social Learning, and the State: The Case of Economic Policymaking in Britain." Comparative Politics 25, no. 3: 275-296.

Hall, Peter A., and Rosemary C. R. Taylor. 1996. "Political Science and the Three New Institutionalisms." Political Studies 44, no. 5: 936-957.

Hatch, M. T. 2003. "Chinese Politics, Energy Policy and the International Climate Change Negotiations." In Global Warming and East Asia: The Domestic and International Politics of Climate Change, edited by Paul G. Harris. London: Routledge.

He, Chibing 贺志兵. 1999. "Zhongguo gangtie gongye tizhi yanbian he qiye gaige licheng" 中国钢铁工业体制演变和企业改革历程 [The Evolution of China's Insitution of Steel Industry and the Steel Soe Reform], yejin jingji yu guanli 冶 金经济与管理[Metallurgy Economics and Management], 1999, no. 6: 23-25.

Heberer, Thomas, and René Trappel. 2013. "Evaluation Processes, Local Cadres' Behaviour and Local Development Processes." Journal of Contemporary China 22, no. 84: 1084-1066.

Heggelund, Gorild, Steinar Andresen, and Inga Fritzen Buan. 2010. "Chinese Climate Policy: Domestic Priorities, Foreign Policy, and Emerging Implementation." In Global Commons, Domestic Decisions: The Comparative Politics of Climate Change, edited by Kathryn Harrison and Lisa McIntosh Sundstrom, 229-259. Cambridge, MA: MIT Press. 
Hirschman, Albert O. 1958. The Strategy of Economic Development. Vol. 10, Volume 10 of Yale Studies in Economics. New Haven, Connecticut: Yale University Press, 1958.

Hu, Angang. March 6, 2011. "9 Steps toward Building the 12th Five-Year Guideline". http://www.chinausfocus.com/political-social-development/9-steps-towardbuilding-the-12th-five-year-guideline/. Accessed in July 2013.

$\mathrm{Hu}$, Jintao 胡锦涛. October 15, 2007. "Hu Jintao zong shuji zai zhongguo gongchandang di shiqi ci quanguo daibiao dahui shang de baogao" 胡锦涛总书 记在中国共产党第十七次全国代表大会上的报告 [Cpc General Secretary's Report on the 17th National Party Congress], News of the Communist Party of China, October 15 , 2007 , http://cpc.people.com.cn/GB/64162/64168/106155/106156/6430009.html. Accessed in June 2013.

$\mathrm{Hu}$, Jintao 胡锦涛. November 18, 2012. "Hu Jintao zong shuji zai zhongguo gongchandang di shiba ci quanguo daibiao dahui shang de baogao" 胡锦涛总书 记在中国共产党第十八次全国代表大会上的报告 [Cpc General Secretary's Report on the 18th National Party Congress], News of the Communist Party of China, November 18, 2012, http://cpc.people.com.cn/n/2012/1118/c6409419612151.html. $\quad$ Accessed in June 2013.

$\mathrm{Hu}$, Jintao 胡锦涛. March 12, 2005. "Hu Jintao zai zhongyang renkou ziyuan huanjing gongzuo huiyi shang de jianghua" 胡锦涛在中央人口资源环境工作会议上的 讲话 [Hu's Speech on the Central Committe's Conference on Population, Resource and Environment], China Ministry of Environmental Protection Offical Website, March 12, 2005, http://www.zhb.gov.cn/ztbd/gzhy/zth/200503/t20050313_65068.htm. Accessed in June 2013.

$\mathrm{Hu}$, Jintao 胡锦涛. 2005. Shuli he luoshi kexue fazhan guan 树立和落实科学发展观 [On Building and Adopting a Scientific Development Concept]. Shiliu da yilai zhongyao wenxian xuanbian 十六大以来重要文献选编 [Review on the Key Party Documents since the 16th National Party Congress]. Zhongyang wenxian chubanshe 中央文献出版社 The Central Literature Press: Beijing, 2005. 
$\mathrm{Hu}$, Jintao 胡锦涛. 2006. Jiaqiang he gaishan hongguan tiaokong - Hu Jintao zong shuji zai 2004 nian zhongyang jingji gongzuo huiyi shang de jianghua 加强和 改善宏观调控 - 胡锦涛总书记在 2004 年中央经济工作会议上的讲话 [Strengthening and Improving Macro-Economic Adjustment Capacity - Hu Jintao's Speech on the 2004 Acewc]. Shiliu da yilai zhongyao wenxian xuanbian 十六大以来重要文献选编 [Review on the Key Party Documents since the 16th National Party Congress]. Zhongyang wenxian chubanshe 中央文献出版社 The Central Literature Press: Beijing, 2006.

Hu, Junfeng, Fredrich Kahrl, Qingyou Yan, and Xiaoya Wang. 2012. "The Impact of China's Differential Electricity Pricing Policy on Power Sector Co2 Emissions." Energy Policy 2012, no. 45: 412-419.

Huang, Xiaoming. 2009. Politics in Pacific Asia: An Introduction. New York: Palgrave Macmillan, 2009.

Huang, Yasheng. 1996. "Central-Local Relations in China During the Reform Era: The Economic and Institutional Dimensions." World Development 24, no. 4: 655672.

Huang, Yasheng. 2002. "Managing Chinese Bureaucracies: An Institutional Economics Perspective." Political Studies 50, no. 1: 61-79.

IIASA. 2012. The Global Energy Assessment. International Institute for Applied Systems Analysis. Laxenburg, Austria, http://www.globalenergyassessment.org/. Accessed in July 2014.

Jacobsen, John Kurt. 1995. "Much Ado About Ideas: The Cognitive Factors in Economic Policy." World Politics 47, no. 2: 283-310.

Jefferson, Gary H., and Thomas G. Rawski. 1994. "Enterprises Reform in Chinese Industry." The Journal of Economic Perspectives 8, no. 2: 47-70.

Jiang, Weiwei 蒋韡薇. March 5, 2004. "Cong GDP dao xingfu zhishu" 从 GDP 到幸福 指数 [From Gdp to 'Happiness Indicator' ], China Youth, March 5, 2004. 
Jiang, Julie, and Chen Ding. 2014. Update on Overseas Investments by China's National Oil Companies: Achievements and Challenges since 2011. International Energy Agency. Paris.

Jiang, Julie, and Jonathan Sinton. 2011. Overseas Investments by Chinese National Oil Companies: Assessing the Drivers and Impacts. International Energy Agency (IEA). Paris.

Jiang, Zemin 江泽民. November 8, 2002. "Jiang Zemin tongzhi zai dang de shiliu da shang suo zuo baogao quanwen" 江泽民同志在党的十六大上所作报告全文 [Cpc General Secretary's Report on the 18th National Party Congress], News of the Communist Party of China, November 8, 2002, http://cpc.people.com.cn/GB/64162/64168/64569/65444/4429125.html.

Accessed in April 2013.

Jin, Hehui, Yingyi Qian, and Barry R. Weingast. 2005. "Regional Decentralization and Fiscal Incentives: Federalism, Chinese Style." Journal of Public Economics 2005, no. 89: 1719-1742.

Kambara, Tatsu. 1992. "The Energy Situation in China." The China Quarterly 131, no. September 1992: 608-636.

Kambara, Tatsu, and Christopher Howe. 2007. China and the Global Energy Crises: Development and Prospects for China's Oil and Natural Gas. Northampton, MA: Edward Elgar Publishing, 2007.

Ke, Jing, Lynn Price, Stephanie Ohshita, David Fridley, Nina Zheng Khanna, Nan Zhou, and Mark Levine. 2012. "China's Industrial Energy Consumption Trends and Impacts of the Top-1000 Enterprises Energy-Saving Program and Theten Key Energy-Saving Projects." Energy Policy 2012, no. 50: 562-569.

Kennedy, Andrew B. 2010. "China’s New Energy-Security Debate." Survival 52, no. 3: 137-158.

Kong, Bo. 2005. An Anatomy of China's Energy Insecurity and Its Strategies. Pacific Northwest Center for Global Security. Seattle, WA, http://www.pnl.gov/main/publications/external/technical_reports/PNNL15529.pdf. Accessed in April 2012. 
Kong, Bo. 2011. "Governing China's Energy in the Context of Global Governance." Global Policy 2, no. SI. September 2011: 51-65.

Kong, Bo. 2006. "Institutional Insecurity." China Security, no. 3: 65-89.

Lan, Yong 兰勇. 2009. Woguo lv gongye zongxiang yitihua de xingcheng ji yingxiang yanjiu 我国铝工业纵向一体化的形成及影响研究 [Research on the Formation and the Influence of Vertical Integration of Chinese Aluminum Industry ]. Zhongnan daxue 中南大学 Central South University: Changsha, 2009.

Landry, Pierre F. 2008. Decentralized Authoritarianism in China: The Communist Party's Control of Local Elites in the Post-Mao Era Cambridge, UK: Cambridge University Press, 2008.

Lee, Hochul. 2010. "Political Institutionalization as Political Development in China." Journal of Contemporary China 19, no. 65: 559-571.

Lester, Richard, and Edward S. Steinfield. 2007. "China's Real Energy Crisis." Harvard Asia Pacific Review 9, no. 1: 35-38.

Li, Chen. 2015. China's Centralized Industrial Order: Industrial Reform and Rise of Centrally Controlled Big Business. Edited by Peter Nolan, Routledge Studies on the Chinese Economy. London and New York: Routledge, 2015.

Li, Cheng. 2012. "Leadership Transition in the Cpc: Promising Progress and Potential Problems " China: An International Journal 10, no. 2: 23-33.

Li, Hongbin, and Li-An Zhou. 2005. "Political Turnover and Economic Performance: The Incentive Role of Personnel Control in China." Journal of Public Economics 2005, no. 89: 1743-1762.

Li, Jianwen 李建文. 2008. "Guanyu woguo dianjielv gongye fazhan de yanjiu" 关于我 国电解铝工业发展的研究 [Review of China's Electrolytic Aluminium Industry Development], Jingji wenti 经济问题 [Economic Problems], 2008, no. 3: $124-126$.

Li, Lei 李镭. 1991. "Jihua bianzhi chengxu yu fangfa" 计划编制程序与方法[Standard Proccedure and Techniques of State Socio-Economic Planning], Zhongguo 
jihua guanli 中国计划管理 [China Planning Administration], 1991, no. 5: 3739.

Li, Peng 李鹏. 1995. "Zhonggong zhongyang guanyu zhiding jiuwu jihua jianyi de shuoming" 中共中央关于制定九五计划建议的说明 [Some Explanations on the Policy Suggestions of the Cpc Central Committe to the Making of the Nineth Fyp], People's Daily, 1995.

Li, Weiye, and Louis Putterman. 2008. "Reforming China's Soes: An Overview." Comparative Economic Studies 2008, no. 50: 353-380.

Li, Xinmin 李新民. Febuary 24， 2009. "Woguo xibu ba sheng qu youhui dianjia kaowen guojia dianjia zhengce" 我国西部八省区优惠电价拷问国家电价政策 [Differential Power Pricing Policy Challenged by Eight Provincial Governments], Jingji cankao bao,Febuary 2 , 2009, http://jjckb.xinhuanet.com/cjxw/2009-02/24/content_145341.htm. Accessed in May 2013.

Li, Zhichuan 李志传. 2012. "Zhongguo minying shiyou qiye fazhan zhuangkuang he qianjing zhanwang" 中国民营石油企业发展状况和前景展望 [The Development and Outlook of China's Private Oil Companies], Guoji shiyou jingji 国际石油经济 [Internaitonal Petroleum Economy], 2012, no. 4: 54-60.

Lieberman, Robert C. 2002. "Ideas, Institutions, and Political Order: Explaining Political Change." American Political Science Review 96, no. 4: 697-712.

Lieberthal, Kenneth G., and David M. Lampton. 1992. eds. Bureaucracy, Politics, and Decision Making in Post-Mao China. Berkeley, Los Angeles, Oxford: University of California Press, 1992.

Lieberthal, Kenneth, and Mikkal E. Herberg. 2006. "China's Search for Energy Security: Implications for US Policy." NBR Analysis 17, no. 1.

Lieberthal, Kenneth, and Michel Oksenberg. 1988. Policy Making in China: Leaders, Structures, and Processes. Princeton: New Jersey: Princeton University Press, 1988. 
Lim, Tai Wei. 2009. Oil in China: From Self-Reliance to Internationalization. Edited by Joseph Fewsmith and Yong-Nian Zheng, Series on Contemporary China, Vol. 18: World Scientific Books, 2009.

Lin, Cheng, and Wancheng Ling 林晨, 令完成. 1988. "Zouguo wunian lucheng zhi hou - zai fang zhongguo shiyou huagong zong gongsi zong jingli Chen Jinhua" 走 过五年路程之后-再访中国石油化工总公司总经理陈锦华 [After Five Years' Journey - Revisiting the General Manager of Sinopec Chen Jinhua], Xinhuashe 〈liawang zhougan> 新华社《瞭望周刊》[Xinhua News Agency Outlook Weekly], 1988, no. 28: 18-19.

Lin, Justin Yifu, Fang Cai, and Zhou Li. 2003. The China Miracle: Development Strategy and Economic Reform. 2 ed. Hong Kong: The Chinese University Press, 2003.

Lin, Justin Yifu, Fang Cai, and Zhou Li. 1998. "Competition, Policy Burdens, and State-Owned Enterprise Reform." The American Economic Review 88, no. 2: 422-427.

Lin, Justin Yifu, and Zhiqiang Liu. 2000. "Fiscal Decentralization and Economic Growth." Economic Development and Cultural Change 49, no. 1: 1-20.

Lin, Justin Yifu, and Yingyi Tsai. 2004. "Reform and Development in China: A New Institutional Economics Perspective." Seoul Journal of Economics 17, no. 3: 335-381.

Lin, Xiannuan. 1996. China's Energy Strategy: Ecnomic Structure, Techbological Choices, and Energy Consumption. Westport, CT: Praeger Publishers, 1996.

Lin, Z. Jun. 2001. "Recent Development of Tax System Reforms in China: Challenges and Responses." International Tax Journal 2001, no. 27: 90-102.

Liu, Zhiguang 刘志广. 2010. "Woguo difang zhengfu caizheng shouru laiyuan ji qi guimo" 我国地方政府财政收入来源及其规模 [The Sources and Scale of Chinese Local Government's Fiscal Revenue], Difang caizheng yanjiu 地方财 政研究 [Local Finance Review], 2010, no. 4. 
Liu, Zhiping, Jonathan E. Sinton, Fuqiang Yang, Mark D. Levine, and Michael K. Ting. 1994. Industrial Sector Energy Conservation Programmes in the People's Republic of China During the Seventh Five-Year Plan (1986-1990). Energy and Environment Division, Lawrence Berkeley Laboratory. Berkeley, CA.

Lu, Yinqiu, and Tao Sun. 2013. Local Government Financing Platforms in China: A Fortune or Misfortune? International Monetary Fund. Washington DC, https://www.imf.org/external/pubs/ft/wp/2013/wp13243.pdf. Accesed in May 2014.

Ma, Hengyun, Les Oxley, and John Gibson. 2009. "China's Energy Situation in the New Millennium." Renewable and Sustainable Energy Reviews 13, no. 8: 17811799.

Ma, Li, Li Huimin, and QI Ye 马丽, 李惠民, 齐晔. 2012. "Zhongyang - difang hudong yu 'shiyi wu' jieneng mubiao zeren kaohe zhengce de zhiding guocheng fenxi” 中央-地方互动与“十一五”节能目标责任考核政策的制定过程分析 [An Analysis on Central-Local Government Interaction and the Formulation of 11th Fyp's Energy Efficiency Target Responsibility System], Gonggong guanli xuebao 公共管理学报 [Journal of Public Management], 9, no. 1.

Ma, Linwei, Feng Fu, Zheng Li, and Pei Liu. 2012. "Oil Development in China:Current Status and Future Trends." Energy Policy 2012, no. 45: 43-53.

Ma, Xin. 2008. "National Oil Company Reform from the Prespective of Its Relationship with Governments: The Case of China." University of Dundee, 2008.

Mai, Yinhua. 2001. Can the New Chinese Oil Giants Compete after China's Wto Entry? East Asia Institute (EAI), National University of Singapore. Singapore.

March, James G., and Johan P. Olsen. 1984. "The New Institutionalism: Organizational Factors in Political Life." The American Political Science Review 78, no. 3: 734-749.

Maskin, Eric, Yingyi Qian, and Chenggang Xu. 2000. "Incentives, Scale Economics, and Organization Forms." Review of Economic Studies 2000, no. 67: 359-378. 
Mattlin, Mikael. 2009. Chinese Strategic State-Owned Enterprises and Ownership Control. Brussels Institute of Contemporary China Studies (BICCS). Brussels, Belgium.

Meidan, Michal, Philip Andrews-Speed, and Ma Xin. 2009. "Shaping China's Energy Policy: Actors and Processes." Journal of Contemporary China 18, no. 61: 591616.

Miller, Alice L. 2008. The Ccp Central Committee's Leading Small Groups. The Hoover Institution.

Stanford, http://www.hoover.org/sites/default/files/uploads/documents/CLM26AM.pdf. Accesed in June 2014.

MOF 财政部. December 31, 2010. "Caizhengbu: 2011 nian qi shidang tigao yangqi shangjiao 'hongli' bili" 财政部: 2011 年起适当提高央企上缴“红利”比例 [Mof: Yangqi Profit Remmittance Will Rise from 2011], China Ministry of Fiance Official Website, December 31, 2010, http://www.mof.gov.cn/zhengwuxinxi/caizhengxinwen/201012/t20101231_396 059.html. Accessed in May 2013.

Moffat, Andrew. July 10, 2014. "Timeline: China's 13th Five-Year Plan". www.chinadialogue.net/blog/7369-Timeline-China-s-13th-Five-Year-Plan/en. Accessed in July 2014.

Montinola, Gabriella, Yingyi Qian, and Barry R. WeingastSource. 1995. "Federalism, Chinese Style: The Political Basis for Economic Success in China." World Politics 48, no. 1: 50-81.

Moe, Terry M. 1984. "The New Economics of Organization." American Journal of Political Science 28, no. 4: 739-777.

Naughton, Barry. 2007. The Chinese Eoconomy: Transition and Growth. Cambridge: MA: The MIT Press, 2007.

Naughton, Barry. 1995. Growing out of the Plan: Chinese Economic Reform, 19781993. Cambridge, UK: Cambridge University Press, 1995.

Naughton, Barry. 2005. The New Common Economic Program: China's Eleventh Five Year Plan and What It Means. Hoover Institution. 
http://www.hoover.org/publications/china-leadership-monitor. Accessed in May 2012.

Naughton, Barry. 2008. Sasac and Rising Corporate Power in China. The Hoover Institution. Stanford, CA, http://www.hoover.org/research/sasac-and-risingcorporate-power-china. Accessed in June 2013.

NBS 国家统计局. 2013a. 3.Nengyuan shengchan tongji 3.能源生产统计 [Chapter 3. Energy Production Statistics], Zhongguo nengyuan tongji nianjian 2013 中国能 源统计年鉴 2013 [China Energy Statistical Year Book 2013]. Zhongguo tongji chubanshe 中国统计出版社 China Statistics Press: Beijing, 2013, 35-51.

NBS 国家统计局. 2013b. 4.Nengyuan xiaofei tongji 4. 能源消费统计 [Chapter 4. Energy Consumption Statistics], Zhongguo nengyuan tongji nianjian 2013 中国 能源统计年鉴 2013 [China Energy Statistical Year Book 2013]. Zhongguo tongji chubanshe 中国统计出版社 China Statistics Press: Beijing, 2013, 19-32.

NBS 国家统计局. 2009. Zhongguo tongji nianjian 2009 中国统计年鉴 2009 [China Statistical Year Book 2009]. Zhongguo tongji chubanshe 中国统计出版社 China Statistics Press: Beijing, 2009.

NBS 国家统计局. 2014. Sanci chanye dui guonei shengchanzongzhi de ladong baifenbi 三次产业对国内生产总值的拉动百分比 [Contribution of the Three Sectors to the Annual Growth of GDP], Zhongguo tongji nianjian 2014 中国统 计年鉴 2014 [China Statistical Year Book 2014]. Zhongguo tongji chubanshe 中国统计出版社 China Statistics Press: Beijing, 2014.

NBS 国家统计局. 2005. 3-8 San ci chanye gongxianlv 3-8 三次产业贡献率 [Contribution of Three Economic Sectors to the Growth of GDP], Zhongguo tongji nianjian 2005 中国统计年鉴 2005 [China Statsictical Year Book 2005]. Zhongguo tongji chubanshe 中国统计出版社 China Statistics Press: Beijing, 2005.

NBS 国家统计局. October 8, 2002. "Guoyou qiye gaige wenbu tuijin" 国有企业改革 稳步推进 [Soe Reform Advancing Steadily], China National Bureau of $\begin{array}{lll}\text { Statistics, } & \text { October } & \text { 2002, }\end{array}$ 
http://www.stats.gov.cn/ztjc/ztfx/yjsld/200210/t20021008_36049.html.

Accessed in July 2012.

NDRC 国家发改委. December 2, 2003. "'Shiyi wu' guihua yanjiu zhongbiao keti" “十 一五” 规划研究中标课题 [Policy Research Topics of the 11th Fyp], Chinanews.com, December 2, 2003, http://www.china.com.cn/chinese/PIc/452965.htm. Acessed in April 2013.

NDRC 国家发改委. 2004. "Dui liuge gaohaoneng hangye shixing chabie dianjia de tongzhi" 对六个高耗能行业试行差别电价的通知 [The Trial Implementation of Differential Pricing Policy in 6 High Energy-Intensive Industries], China National Development and Reform Commission Official Website, 2004, http://www.ndrc.gov.cn. Accessed in April 2013.

NDRC 国家发改委. 2005. "Chanye jiegou tiaozheng zhidao mulu 2005 nian ben" 产业 结构调整指导目录 2005 年本 [The 2005 Cataloge of State Industrial Adjustment], China National Development and Reform Commission Official Website, 2005. http://www.sdpc.gov.cn/fzgggz/fzgh/zcfg/200512/t20051222_65963.html. Acceseed in April 2013.

NDRC 国家发改委. December 10, 2006. "Qian jia qiye mingdan" 千家企业名单 [List of the 1,000 Enterprises by Sectors], The National Development and Reform Commission Offical Website, December 10, 2006, http://www.ndrc.gov.cn/rdzt/jsjyxsh/200604/W020060413525683315691.xls. Acceseed in April 2013.

NDRC 国家发改委. 2007[2655]. "Guanyu jinyibu guiche luoshi chabie dianjia zhengce youguan wenti de tongzhi" 关于进一步贯彻落实差别电价政策有关 问题的通知 [Notice on Improving the Differential Power Pricing Policy], China National Energy Administration Official Website, 2007, http://www.nea.gov.cn/2007-10/12/c_131215806.htm. Acessed in April 2013.

NDRC 国家发改委. 2007[3550]. "Guojia fazhan gaigewei、guojia dianjianhui guanyu quexiao dianjielv deng gaohaoneng hangye dianjia youhui youguan wenti de tongzhi" 国家发展改革委、国家电监会关于取消电解铝等高耗能行业电价 优惠有关问题的通知 [Mandate on Abolishing Local Power Sales Discount on 
Energy-Intensitve Industries Such as Electrolytic Aluminium], China National Development and Reform Commission Official Website, 2007, http://www.sdpc.gov.cn/zcfb/zcfbtz/2007tongzhi/t20080222_193192.htm.

Accessed in April 2013.

NDRC 国家发改委. 2010[978]. "Guanyu qingli dui gaohaoneng qiye youhui dianjia deng wenti de tongzhi" 关于清理对高耗能企业优惠电价等问题的通知 [Mandate on Abolishing Power Price Discount on Energy-Intensive Industries], Chinese Central Government Official Website, 2010, http://www.gov.cn/zwgk/2010-05/17/content_1607555.htm. Accessed in April 2013.

NDRC 国家发改委. 2010[1023]. "Guanyu liji zuzhi kaizhan quanguo dianli jiage da jiancha de tongzhi" 关于立即组织开展全国电力价格大检查的通知 [Mandate on Initiating National Power Price Inspection], Chinese Central Government Official Website, 2010, http://www.gov.cn/zwgk/201005/21/content_1611021.htm. Accessed in April 2013.

NDRC 国家发改委. 2011a. "Fagaiwei : 'shiyi wu' qian jia qiye chaoe wancheng jieneng renwu" 发改委: “十一五”千家企业超额完成节能任务 [NDRC: The Top-1000 Enterprises Overshot Energy Efficiency Target of 11th Fyp], China National Development and Reform Commission Official Website, 2011, http://www.ndrc.gov.cn/xwzx/.../t20110930_436609.html. Accessed in April 2013.

NDRC 国家发改委. 2011b. "Chanye jiegou tiaozheng zhidao mulu 2011 nian ben" 产 业结构调整指导目录 2011 年本 [The 2011 Cataloge of State Industrial Adjustment], China National Development and Reform Commission Official Website, 2011 , http://www.ndrc.gov.cn/zcfb/zcfbl/201302/W020130226380863208670.pdf.

Acceseed in April 2013.

NDRC 国家发改委. October 2012. "Wanjia qiye jieneng ditan xingdong shishi fang'an" 万家企业节能低碳行动实施方案 [Implementation Strategy for the Top-10, 000 Project], National Energy Adimistration of The National Development Reform Commission, 2012, http://www.nea.gov.cn/131335328 31n.pdf. Acceseed in April 2013. 
Nolan, Peter. 2001. China and the Global Business Revolution. New York: Palgrave Macmillan 2001.

Nolan, Peter. 2014. "Globalisation and Industrial Policy: The Case of China." The World Economy 37, no. 6: 747-764.

Nolan, Peter. 1996. "Large Firms and Industrial Reform in Former Planned Economies: The Case of China." Cambridge Journal of Economics 1996, no. 20: 1-29.

NPC 全国人大. 2006. "Zhonghua renmin gongheguo guomin jingji he shehui fazhan di shiyi ge wu nian guihua gangyao" 中华人民共和国国民经济和社会发展第十 一个五年规划纲要 [The Eleventh-Five Year Programme for the National Scocio-Economic Development], The Information Centre of the National People's Congress, 2006, http://www.npc.gov.cn/wxzl/gongbao/200603/18/content 5347869.htm. Acceseed in June 2012.

NPC 全国人大. 1996. "Zhonghua renmin gongheguo guomin jingji he shehui fazhan 'jiuwu' jihua he 2010 nian yuanjing mubiao gangyao" 中华人民共和国国民经 济和社会发展“九五”计划和 2010 年远景目标纲要 [The 9th-Five Year Plan for the National Scocio-Economic Development, the Programme for the LongTerm Objectives by 2010 and the Report on the Programme], The Information Centre of the National People's Congress. 1996, http://www.npc.gov.cn/wxzl/gongbao/2001-01/02/content_5003506.htm. Acceseed in June 2012.

NPC 全国人大. 2001. "Zhonghua renmin gongheguo guomin jingji he shehui fazhan di shi ge wunian jihua gangyao" 中华人民共和国国民经济和社会发展第十个五 年计划纲要 [The 10th-Five Year Plan for the National Scocio-Economic Development], The Information Centre of the National People's Congress, 2001, http://www.npc.gov.cn/wxzl/gongbao/2001-03/19/content_5134505.htm.

Acceseed in June 2012.

NPC 全国人大. 2011. "Zhonghua renmin gongheguo guomin jingji he shehui fazhan di shi'er ge wunian guihua gangyao" 中华人民共和国国民经济和社会发展第十 二个五年规划纲要 [The Twelfth-Five Year Programme for the National Scocio-Economic Development], The Information Centre of the National 
People's Congress, 2011, http://www.npc.gov.cn/wxzl/gongbao/201108/16/content_1665636.htm. Acceseed in June 2012.

O'Leary, Zina. 2004. The Essential Guide to Doing Research. London: SAGE Publications Ltd., 2004. Reprint, 2007.

OECD. 2009. State Owned Enterprises in China: Reviewing the Evidence. OECD Working Group on Privatisation and Corporate Governance of State Owned Assets. Paris.

OECD/IEA. 2006. China's Power Sector Reforms: Where to Next? Paris: International Energy Agency, 2006.

OECD/IEA. 2007b. Energy Security and Climate Policy: Assessing Interactions. International Energy Agency. Paris.

OECD/IEA. 2007a. World Energy Outlook 2007: China and India Insights. Edited by International Energy Agency, World Energy Outlook. Paris: International Energy Agency, 2007a.

OECD/IEA. 2008. Worldwide Trends in Energy Use and Efficiency: Key Insights from Iea Indicator Analysis. Paris: International Energy Agency, 2008.

Oi, Jean C. 1992. "Fiscal Reform and the Economic Foundations of Local State Corporatism in China." World Politics 45, no. 1: 99-126.

Owen, A.D., and Penelope N. Neal. 1989. "China's Potential as an Energy Exporter." Energy Policy 1989, no. 17: 485-500.

Pan, Rulong 潘如龙. 2005. Dangdai zhongguo shiyou gongyingshi yanjiu - yi Zhejiang wei ge'an 当代中国石油供应史研究一以浙江为个案 [The History of Oil Supply in Contemporary China - the Case of Zhejiang Province]. Zhejiang daxue 浙江大学 Zhejiang Univerisity: Zhejiang, 2005.

Park, Albert, Scott Rozelle, Christine Wong, and Changqing Ren. 1996. "Distributional Consequences of Reforming Local Public Finance in China." The China Quarterly September 1996, no. 147: 751-778. 
Party Literature Research Center eds. 党的文献研究中心编. 2005. Shiliu da yilai zhongyao wenxian xuanbian (shang ce) 十六大以来重要文献选编(上册) [Review on the Key Party Documents since the 16th National Party Congress. Vol. I. ]. Zhongyang wenxian chubanshe 中央文献出版社 The Central Literature Press: Beijing, 2005.

Party Literature Research Center eds. 党的文献研究中心编. 2006. Shiliu da yilai zhongyao wenxian xuanbian (zhong ce) 十六大以来重要文献选编(中册) [Review on the Key Party Documents since the 16th National Party Congress. Vol. II. ]. Zhongyang wenxian chubanshe 中央文献出版社 The Central Literature Press: Beijing, 2006.

Pearson, Peter, and Jim Watson. 2012. Uk Energy Policy 1980-2010: A History and Lessons to Be Learnt. The Parliamentary Group for Energy Studies. London.

Peng, Wuyuan. 2009. The Evolution of China's Coal Institutions. Freeman Spogli Institute for International Studies, Staford University. Stanford, CA, http://iisdb.stanford.edu/pubs/22612/PESD_WP_86.pdf. Accessed in August 2013.

People's Daily 人民日报. November 29, 1959. "Xiao lianyouchang da you qiantu" 小 炼油厂大有前途 [China's Promising Small Oil-Refiners], People's Daily, November 29, 1959.

People's Daily 人民日报. August 1, 2007. "Youqi chanliang wu dazeng zhonghaiyou ligong shihua xiayou yewu chao shangyou" 油气产量无大增 中海油力攻石化 下游业务超上游 [Cnooc's Downstream Business Exceedes Upstream Business]. People's Daily Website, August 1, 2007, http://finance.people.com.cn/GB/1038/59942/59945/6055832.html. Accessed in August 2014.

People's Daily 人民日报. May 18, 2010. "Zhonghaiyou zhongbiao misang youtian zhongguo san da youqi qiju yilake" 中海油中标米桑油田 中国三大油企齐聚 伊拉克 [Cnooc Wins Contract in Iraq Misson Field, All Three Chinese Nocs in Iraq Now], People's Daily Website, May 18, 2010, http://finance.people.com.cn/GB/11621831.html. Accessed in October 2015. 
People's Daily 人民日报. Feburary 10, 2012. "Caizhengbu: quanmian quexiao yusuan wai zijin zhengfuxing shouru quanbu naru guanli" 财政部: 全面取消预算外 资金 政府性收入全部纳入管理 [Mof: Abolishing the Ebfs and Put All Governmental Revenue into Budgeting System], People's Daily Website, Feburary 10, 2012, http://politics.people.com.cn/GB/1027/17072863.html. Accessed in June 2014.

People's Daily 人民日报. October 12, 2007. "Fagaiwei fabu tongzhi chabie dianjia shouru you zhongyang huagui difang" 发改委发布通知差别电价收入由中央 划归地方 [NDRC Decides Differential Power Pricing Revenue Goes to Local Government Coffers]. People's Daily Website, October 12, 2007, http://finance.people.com.cn/GB/6371648.html, Accessed in May 2013.

People's Daily 人民日报. 2012. "Renminwang caijing pindao zhuanti: jiedu zhongyang jingji gongzuo huiyi" 人民网财经频道专题: 解读中央经济工作会议 [Special Topic: The Central Economic Working Conference Review], People's Daily Website, 2012, http://finance.people.com.cn/GB/jinji/222/2322/. Accessed in July 2013.

People's Daily 人民日报. October 19, 1984. "Jinyibu tuixing gaige tigao jingji xiaoyi Guowuyuan pizhuan shihua zonggongsi de gaige fang'an" 进一步推行改革提 高经济效益 国务院批转石化总公司的改革方案 [State Council's Mandate on Pushing Reform on Sinopec and Enhance Its Economic Efficiency], People's Daily Website, $\quad$ October $\quad 19, \quad 1984$, http://rmrbw.net/simple/index.php?t672601.html. Accessed in March 2013.

Pierson, Paul, and Theda Skocpol. 2002. "Historical Institutionalism in Contemproary Political Science." In Political Science: The State of the Discipline, edited by Ira Katznelson and Helen V. Milner, 693-721. New York: W.W. Norton \& Company.

PIW. Janurary 7, 2013. CNPC Overtakes Pdv in Latest Petroleum Intelligence Weekly Top 50 Oil Company Rankings. Petroleum Intelligence Weekly. http://www.energyintel.com/ /_layouts/EIG/samples/2013Jan_PIW-top50PressRelease.pdf. Accessed in May 2014. 
Platts. July 31, 2015. "Global Petrochemical Prices Continued to Advance". Platts McGraw Hill $\quad$ Financial, http://www.platts.com/newsfeature/2015/petrochemicals/pgpi/index. Accessed in August 2015.

Porter, Michael E. 1985. Competitive Advantage: Creating and Sustaining Superior Performance. New York, NY: The Free Press, 1985.

Price, Alan H., Timothy C. Brightbill, Christopher B. Weld, and Tessa V. Capeloto. October 2010. The Reform Myth: How China Is Using State Power to Create the World's Dominant Steel Industry. Wiley Rein LLP. Washington DC.

Price, Lynn, Mark D. Levine, Nan Zhou, David Fridley, Nathaniel Aden, Hongyou Lu, Michael McNeil, Nina Zheng, Yining Qin, and Ping Yowargana. 2011. "Assessment of China's Energy-Saving and Emission-Reduction Accomplishments and Opportunities During the 11th Five Year Plan." Energy Policy 39, no. 4: 2165-2178.

Price, Lynn, and Xuejun Wang. 2007. Constraining Energy Consumption of China's Largest Industrial Enterprises through the Top-1000 Energy-Consuming Enterprise Program. Environmental Energy Technologies Division, Ernest Orlando Lawrence Berkeley National Laboratory. http://eetd.lbl.gov/sites/all/files/publications/lbl-62874-top1000-programjune2007.pdf. Accessed in May 2014.

Qi, Dianbin 齐殿斌. 2006. "Guoqi zhengcexing pochan 'daxian' daojishi" 国企政策性 破产“大限”倒记时 [Counting Down to the Soe Reform Deadline], Renmin ribaoshe 《dadi zhoukan》人民日报社《大地周刊》 [The Earth Weekly], 06, no. 6 .

Qian, Yingyi, and Barry R. Weingast. 1997. "Federalism as a Commitment to Perserving Market Incentives." The Journal of Economic Perspectives 11, no. 4: 83-92.

Qian, Yingyi, and Chenggang Xu. 1993. "Why China's Economic Reforms Differ: The M-Form Hierarchy and Entry/Expansion of the Non-State Sector." eConomics of Transition 1, no. 2: 135-170. 
Qiu, Wangjun 仇王君. 2006. "Wang You :wei minying shiyou qiye hecai" 王勇: 为民 营石油企业喝彩 [Rooting for Private Oil Companies - an Interview with the Chairman of Ccpi Mr. Wang Yong], People's Daily Website, 2006 http://www.people.com.cn/GB/paper2515/16879/1482985.html. Accessed in March 2014.

Rabinovitch, Simon. November 11 2012. "Private Sector Battles March of Chinese State". Financial Times Website, http://www.ft.com/cms/s/0/eb5687c0-2bed11e2-a91d-00144feabdc0.html\#axzz3pAKeYF87. Accessed in March 2013.

Roberts, Clayton. 1996. The Logic of Historical Explanation. University Park: Pennsylvania State University Press, 1996.

Rocha, Euan. Feburary 5, 2013. "Cnooc Closes \$15.1 Billion Acquisition of Canada's Nexen". $\quad$ http://www.reuters.com/article/2013/02/25/us-nexen-cnoocidUSBRE9101A4201302. Accessed in March 2013.

Rogers, Simon. 2010. "How China Overtook the Us in Renewable Energy". The Guardian, http://www.theguardian.com/news/datablog/2010/mar/25/chinarenewable-energy-pew-research. Accessed in June 2012.

Rosen, Daniel H., and Trevor Houser. 2007. China Energy: A Guide for the Perplexed. A Joint Project by the Center for Strategic and International Studies and the Peterson Institute for International Economics. http://www.iie.com/publications/papers/rosen0507.pdf. Accessed in July 2014.

Sabatier, Paul A. 1991. "Toward Better Theories of the Policy Process." PS: Political Science and Politics 24, no. 2: 147-156.

Saich, Tony. 2004. Governance and Politics of China. 2nd ed. New York: Palgrave MacMillan, 2004.

Sano, Tadakatsu, Jones Day, and Mikiko Fujiwara. 2007. "Japan's Energy Policy: From Anti-Pollution to Energy Saving and Efficiency for Environmental Conservation." In Shaping China's Energy Security: The inside Perspective, edited by Michal Meidan, 194-216. Paris: Asia Centre-Centre études Asie.

SASAC 国务院国资委. June 25, 2007. "Chen Tonghai ciqu zhongshihua dongshizhang zhiwu Su Shulin jiren" 陈同海辞去中石化董事长职务 苏树林继任 [Chen 
Tonghai Resigned from Sinopec, Su Shulin Took over His Position], China.org.cn, June 25, 2007, http://www.china.com.cn/policy/txt/200706/25/content_8434570.htm. Accessed in October 2013.

SASAC 国务院国资委. September 25 2014. "Qiye jieneng jianpai cutui jiegou tiaozheng yu zhuanxing shengji" 企业节能减排促推结构调整与转型升级 [How Energy Efficiency Policy Promotes Structural Adjustment and Industrial Upgrade], State Council SASAC, September 252014 , http://www.sasac.gov.cn/n1180/n1271/n20515/n2697175/16067477.html. Accessed in Janurary 2015.

SASAC 国务院国资委. October 17，2007. "Li Rongrong: zhongshihua yuan dongshizhang Chen Tonghai bei shuanggui"李荣融: 中石化原董事长陈同海 被双规 [Li Rongrong Says Chen Tonghai Is under the Party Discipline Department's Control], China.org.cn, October 17, 2007, http://www.china.com.cn/17da/2007-10/17/content_9069796.htm. Accessed in May 2013.

SAT 国家税务总局. 1998[147]. "Guojia shuiwu zongju guanyu shiyou shihua qiye suodeshui de tongzhi" 国家税务总局关于石油石化企业所得税的通知 [State Administration of Taxiation's Notice on the Issue of Petrochemical Enterprises' Income Tax], China State Administration of Taxiation Official Website, 1998, http://www.chinatax.gov.cn/n810341/index.html. Accessed in March 2013.

Shambaugh, David. 2008. China's Communist Party: Atrophy and Adaptation. Berkeley: UC Press, 2008.

Shanghai PetroChemical Industry Editorial Committee. 1997. The History of Shanghai Gaoqiao Petrochemical Plant. Shanghai: Shanghai Academy of Social Science Press, 1997.

Shen, Chunli, Jing Jin, and Heng-fu Zou. 2012. "Fiscal Decentralization in China: History, Impact, Challenges and Next Steps." Annals of Economics and Finance 13, no. 1: 1-51.

Shen, Liren, and Yuanchen Dai 沈立人, 戴园晨. 1990. "Woguo 'zhuhou jingji' de xingcheng ji qi biduan he genyuan" 我国“诸侯经济”的形成及其弊端和根源 
[The Emergence of China's "Dukedom Economy", Its Ngative Impacts and Origins], Jingji yanjiu 经济研究 [Economic Research Journal], 1990, no. 3: 1219.

Shirk, Susuan L. 1993. The Political Logic of Economic Reform in China. Berkeley, Los Angeles, London: University of California Press, 1993.

Sieminski, Adam. 2014. Outlook for US Shale Oil and Gas. Philadelphia, PA, http://www.eia.gov/pressroom/presentations/sieminski_01042014.pdf. Accessed in July 2014.

Simon, Herbert A. 1955. "A Behavioral Model of Rational Choice." The Quarterly Journal of Economics 69, no. 1: 99-118.

Sinopec 中国石化. June 5, 2013. "Xintizhi gei qiye zhuru huoli" 新体制给企业注入活 力 [New Institution Brings New Energy to Enterprise], Sinopec News Website, June 5, 2013, http://www.sinopecnews.com.cn/news/content/201306/05/content_1302368.shtml. Accesed in March 2014.

Sinton, Jonathan E., Marck D. Levine, and Qingyi Wang. 1998. "Energy Efficiency in China: Accomplishments and Challenges." Energy Policy 26, no. 11: 813-829.

Sinton, Jonathan E., and Mark D. Levine. 1994. "Changing Energy Intensity in Chinese Industry: The Relatively Importance of Structural Shift and Intensity Change." Energy Policy 22, no. 3: 239-255.

Smil, Vaclav. 1990. China's Energy - Report Prepared for the US Congress. Office of Technology Assessment, US Congress. Washington DC.

Somekh, B., and C. Lewin. 2005. Research Methods in the Social Sciences. Thousand Oaks, Calif: SAGE Publications, 2005.

Song, Liang, and Wing Thye Woo. 2008. eds. China's Dilemma: Economic Growth, the Environment and Climate Change: Brookings Institution Press, 2008.

Song, Ligang, and Haimin Liu. 2012. "Steel Industry Development and Transformation in China: An Overview." In The Chinese Steel Industry's Transformation: Structural Change, Performance and Demand on Resources, edited by Ligang 
Song and Haimin Liu. Cheltenham, UK; Northhampton, MA: Edward Elgar Publishing Inc.

Song, Qun, and Liang Li 宋群, 李量. 1991. " Woguo muqian de jihua guanli lizhi" 我 国目前的计划管理体制 [China's Current Socio-Economic Planning System], Zhongguo jihua guanli 中国计划管理[China Planning Administration], 1991, no. 20: 37-40.

State Council 国务院. December 15, 1993. Guowuyuan guanyu shixing fenshuizhi caizheng guanli tizhi de jueding 国务院关于实行分税制财政管理体制的决 定 [State Council's Mandate on Reforming the Fiscal System], Shisida yilai zhongyao wenxian xuanbian 十四大以来重要文献选编 [Review on the Key Party Documents since the 14th National Party Congress], Zhangyang wenxian chubanshe 中央文献出版社 The Central Literature Press: Beijing, 2011.

State Council 国务院. 1996[48]. "Guowuyuan guanyu zujian guojia dianli gongsi de tongzhi" 国务院关于组建国家电力公司的通知 [State Council Mandate on Establishing State Power Corporation], 1996 , http://www.cpicorp.com.cn/zcfg/gfxwj/ywlx/dl/xzgz/201211/P02012111239825 7184691.pdf. Accessed in May 2013.

State Council 国务院. 1998[14]. "Guanyu zujian zhongguo shiyou tianranqi jituan gongsi he zhongguo shiyou huagong jituan gongsi youguan shiyou gongsi huazhuan wenti de tongzhi" 关于组建中国石油天然气集团公司和中国石油 化工集团公司有关石油公司划转问题的通知 [Mandate on Transferring Oil Marketing Companies to the CNPC and Sinopec Group], Chinese Central Government Offical Website, 1998, http://www.gov.cn/xxgk/pub/govpublic/mrlm/201011/t20101117_62831.html. Accessed in March 2013.

State Council 国务院. 1998[38]. "Guanyu qingli zhengdun chengpinyou liutong qiye he guifan chengpinyou liutong zhixu de yijian" 关于清理整顿成品油流通企业和 规范成品油流通秩序的意见 [Mandate on Adjusting Petroleum Products Market Order and Regulating Petroleum Product Enterprises], State Administration for Industry \& Commerce Website, 1998, 
http://www.saic.gov.cn/zcfg/xzgzjgfxwj/199907/t19990707_46549.html.

Accessed in July 2013.

State Council 国务院. 2001[72]. "Guanyu jinyibu zhengdun he guifan chengpinyou shichang zhixu yijian de tongzhi" 关于进一步整顿和规范成品油市场秩序意 见的通知 [Mandate on Further Regulating Petroleum Products Market], Chinese Central Government Official Website, 2001, http://www.gov.cn/gongbao/content/2001/content_61131.htm. Accessed in June 2014.

State Council 国务院. 2002[5]. "Guowuyuan guanyu yinfa dianli tizhi gaige fang'an de tongzhi"国务院关于印发电力体制改革方案的通知 [State Council's Mandate on Power Sector Reform]. Official Website of Hunan Provincial Branch of China State Grid Company, 2002. http://www.chinalawedu.com/falvfagui/fg22016/11980.shtml. Accessed in October 2013.

State Council 国务院. 2003[103]. "Guowuyuan bangongting zhuanfa fazhan gaigewei deng bumen guanyu zhizhi gangtie dianjielv shuini hangye" 国务院办公厅转发 发展改革委 等部门关于制止钢铁电解铝水泥行业 盲目投资若干意见的通 知 [State Council's Mandate on Stopping Reckless Investments in Certain Industies Headed by Steel, Aluminium and Cement], Chinese Central Government Official Website, 2003, http://www.gov.cn/zhengce/content/200803/28/content_8139.htm. Accessed in May 2013.

State Council 国务院. 2005[33]. "Guowuyuan guanyu jiaqian guomin jingji he shehui fazhan guihua bianzhi gongzuo de ruogan yijian" 国务院关于加强国民经济和 社会发展规划编制工作的若干意见 [Decisions on Improving the Work of Five-Year Programme Making], State Council NDRC Official Website, 2005. http://ghs.ndrc.gov.cn/zcfg/200511/t20051102_48078.html. Accessed in May 2013.

State Council 国务院. 2006[28]. "Guowuyuan guanyu jiaqiang jieneng gongzuo de jueding" 国务院关于加强节能工作的决定 [State Council's Decision on Energy Conservation Work], Chinese Central Government Official Website, 
2006, http://www.gov.cn/zwgk/2006-08/23/content_368136.htm. Accessed in May 2013.

State Council 国务院. 2006[77]. "Guowuyuan bangongting zhuanfa fazhan gaigewei guanyu wanshan chabie dianjia zhengce yijian de tongzhi" 国务院办公厅转发 发展改革委关于完善差别电价政策意见的通知 [Mandate on Improving the Differential Power Pricing System], Chinese Central Government Official Website, 2006, http://www.gov.cn/zwgk/2006-09/22/content_396258.htm. Accessed in June 2012.

State Council 国务院. 2006[97]. "Guanyu tuijin guoyou ziben tiaozheng he guoyou qiye zhongzu zhidao yijian" 关于推进国有资本调整和国有企业重组指导意 见 [Guiding Opinion on Promoting the Adjustment of State-Owned Capital and the Reorganization of State-Owned Enterprises], the State Council SASAC Official Website, 2006 http://www.sasac.gov.cn/n1180/n1566/n258252/n258644/11663621.html. Accessed in May 2013.

State Council 国务院. 2007[15]. "Guowuyuan guanyu yinfa jieneng jianpai zonghexing gongzuo fang'an de tongzhi" 国务院关于印发节能减排综合性工作方案的通 知 [State Council's Solution on the Comprensive Implementation of Energy Conservation and Emmisson Reduction], Chinese Central Government Official Website, 2007, http://www.gov.cn/jrzg/2007-06/03/content_634545.htm. Accessed in May 2013.

State Council 国务院. 2007[36]. "Guowuyuan pizhuan jieneng jianpai tongji jiance ji kaohe shishi fang'an he banfa de tongzhi" 国务院批转节能减排统计监测及考 核实施方案和办法的通知 [State Council's Mandate on Local Energy Efficiency Work Implementation and Monitor Sytem], Chinese Central Government Offical Website, 2007, http://www.gov.cn/zwgk/200711/23/content 813617.htm. Accessed in May 2012.

State Council 国务院. 2009[38]. "Guowuyuan pizhuan fazhan gaigewei deng bumen guanyu yizhi bufen hangye channeng guosheng he chongfu jianshe yindao chanye jiankang fazhan ruogan yijian de tongzhi" 国务院批转发展改革委等部 门关于抑制部分行业产能过剩和重复建设引导产业健康发展若干意见的 
通知 [Mandate on Constraining over-Capacity and Repeated-Construction in Some Industries], Chinese Central Government Official Website, 2009, http://www.gov.cn/zwgk/2009-09/29/content_1430087.htm. Accessed in August 2014.

State Council 国务院. 2012. "Zhongguo shiyou: 2012 nian woguo youqi duiwai yichundu jixu shangsheng" 中国石油：2012 年我国油气对外依存度继续上 升 [China's Oil \& Gas Dependence Continues to Rise in 2012], Chinese Central Government Official Website, 2012, http://www.gov.cn/jrzg/201301/30/content_2323461.htm. Accessed in January 2013.

Steinmo, Sven, Kathleen Thelen, and Frank Longstreth. 1992. eds. Structuring Politics: Historcial Institutionalismin Comparative Analysis. Cambridge: UK: Cambridge University Press, 1992.

Streeck, Wolfgang, and Kathleen Thelen. 2005. "Introduction: Institutional Change in Advanced Political Economies." In Beyond Continuity: Institutional Change in Advanced Political Economies, edited by Wolfgang Streeck and Kathleen Thelen. Oxford: UK: Oxford University Press.

$\mathrm{Su}$, Fubing, Ran Tao, and Dali L. Yang. forthcoming. eds. Rethinking the Institutional Foundations of China's Hyper Growth: Official Incentives, Institutional Constraints, and Local Developmentalism. Edited by Carol Lancaster and Nicholas van de Walle, The Oxford Handbook on the Politics of Development. Oxford, UK: Oxford University Press, forthcoming.

Sun, Yongsheng 孙永生. 1997. "Zhongguo shiyou gongxu xianzhuang he shiyou liutong tizhi biange" 中国石油供需现状和石油流通体制变革 [China's Oil Balance and Reform on the Distribution System], Guoji shiyou jingji 国际石油 经济[Internaitonal Petroleum Economy], 5, no. 5: 34-45.

Sutherland, Dylan. 2003. China's Large Enterprises and the Challenge of Late Industrialization. Vol. 5, Routledgecurzon Studies on the Chinese Economy: Routledge, 2003.

Szamosszegi, Andrew, and Cole Kyle. 2011. An Analysis of State-Owned Enterprises and State Capitalism in China. Capital Trade, Inc. Washington DC, 
http://www.uscc.gov/sites/default/files/Research/10_26_11_CapitalTradeSOESt udy.pdf. Accessed in April 2012.

Tang, Gongzhao 唐公昭. 1983. "'Tiaotiao' 'kuaikuai' yu dangqian de jihua guanli wenti" “条条”“块块”与当前的计划管理问题 [Tiaotiao Kuaikuai and Some Problems with the Administration of Economic Planning], Sichuan daxue xuebao zhexue shehui kexueban 四川大学学报哲学社会科学版 Journal of Sichuan University], 1983, no. 01.

Tao, Ran, and Dali Yang 陶然, 杨大力. 2009. "Caizheng shouru xuyao yu difang zhengfu zai zhongguo zhuangui he zengzhang zhong de zuoyong" 财政收入需 要与地方政府在中国转轨和增长中的作用 [Local Government's Fiscal Revenue Imperative and Its Role in China's Transition and Growth], Gonggong xingzheng pinglun 公共行政评论 [Public Administration Review], 08, no. 5.

Tao, Ran, and Dali Yang. 2008. "Revenue Imperative and the Role of Local Government in China's Transition and Growth." In University of Chicago Conference on China's Reforms. Chicago.

Taylor, Monique. 2014. The Chinese State Oil and Energy Security. Edited by Timothy M. Shaw, Palgrave Macmillan International Political Economy Series. London, New York: Palgrave Macmillan, 2014.

The Aluminium Dialogue. 2012. "Primary Aluminum Production". Association de l'aluminium du Canada, http://www.thealuminiumdialog.com/en/aluminium-2/production/primary-aluminum. Accessed in August 2013.

The New York Times. June 20, 2007. "China Overtakes US In Greenhouse Gas Emissions". http://www.nytimes.com/2007/06/20/business/worldbusiness/20ihtemit.1.6227564.html? r=0. Accessed in July 2012.

The World Bank. 2013. "Industiral Value-Added as Percentage of Gdp Worldwide." http://data.worldbank.org/indicator/NV.IND.TOTL.ZS. Accessed in July 2014.

Thomson, Elspeth. 2003. The Chinese Coal Industry: An Economic History. Edited by Peter Nolan and Dong Fureng, Routledgecurzon Studies on the Chinese Economy 2. London, New York: RoutledgeCurzon, 2003. 
Tordo, Silvana, Brandon S. Tracy, and Noora Arfaa. 2011. National Oil Companies and Value Creation. Washington DC: The World Bank, 2011.

Tsai, Kellee S. 2006. "Adaptive Informal Institutions and Endogenous Institutional Change in China." World Politics 59, no. 1: 116-141.

Tsai, Kellee S. 2004. "Off Balance: The Unintended Consequences of Fiscal Federalism in China." Journal of Chinese Political Science 9, no. 2: 7-26.

Tsui, Kai-yuen, and Youqiang Wang. 2004. "Between Separate Stoves and a Single Menu: Fiscal Decentralization in China." The China Quarterly 177, no. March 2004: 71-91.

USEPA. 2014. "Chapter 12: Metallurgical Industry." In Compilation of Air Pollutant Emission Factors. Washington DC: United State Environmental Protection Agency.

Vogel, Ezra F. 2013. Deng Xiaoping and the Transformation of China. Cambridge, MA: The Belknap Press, 2013.

Wang, Fengjun 王凤君. August 17, 2005. "Angang bengang hebing: san da nanti yici daijie" 鞍钢本钢合并: 三大难题依次待解 [The Merger of Anshan Steel and Benxi Steel - Three Obstacles Ahead]. People's Daily Website, August 17, 2005, http://finance.people.com.cn/GB/1039/3622994.html. Accessed in July 2014.

Wang, Haibo. 2010. Characteristics and Trends of China's Oil Demand. Research Institute of Economics and Technology, China National Petroleum Corporatoion. Beijing, http://www.indiaenergycongress.in/montreal/library/pdf/83.pdf. Accessed in June 2012.

Wang, Haijiang H. 1999. China's Oil Industry \& Market, Elsevier Global Energy Policy and Economics Series. Oxford, UK: Elsevier Science Ltd., 1999.

Wang, Jiming 王基铭. 2014. Lianhua gongye fazhan xianzhuang ji qushi 炼化工业发 展现状及趋势 [China's Refining \& Petrochemcial Industry Development]. Dangdai shiyou shihua 当代石油石化 [Petroleum \& Petrochemical Today], 2014, no. 6 . 
Wang, Yanjia, and William Chandler. 2010. "The Chinese Nonferrous Metals Industry — Energy Use and Co2 Emissions." Energy Policy 2010, no. 38: 6475-6484.

Wedeman, Andrew. 2000. "Budgets, Extra-Budgets, and Small Treasuries: Illegal Monies and Local Autonomy in China." Journal of Contemporary China 9, no. 25: 489-511.

Whiting, Susan H. 2000. Power and Wealth in Rural China: The Political Economy of Institutional Change. Cambridge, UK: Cambridge University Press, 2000.

Wong, Christine. 1985. "Material Allocation and Decentralization: Impact of the Local Sector on Industrial Reform." In The Political Economy of Reform in Post-Mao China, edited by Elizabeth J. Perry and Christine Wong, 268-275. Cambridge, MA: Harvard University Press.

Wong, Christine P. W. 1992. "Fiscal Reform and Local Industrialization: The Problematic Sequencing of Reform in Post-Mao China." Modern China 18, no. 2: 197-227.

Wong, Christine P.W. 2000. "Central-Local Relations Revisited: The 1994 Tax-Sharing Reform and Public Expenditure Management in China." China Perspectives 2000, no. 31 .

Woo, Pei Yee. 2005. China's Electric Power Market: The Rise and Fall of Ipps. Program on Energy and Sustainable Development, Stanford University. Stanford, CA, http://pesd.stanford.edu. Accessed in June 2013.

Worldsteel. December 2006. "Steel Statistical Yearbook 2006". World Steel Association, https://www.worldsteel.org/statistics/statistics-archive/yearbookarchive.html, Accessed in March 2015.

Worldsteel. December 2010. Steel Statistical Yearbook 2010. Brussels and Beijing: World Steel Association, December 2010.

Wu, Xinchun 吴新春. November 2010. Zhongguo gangtie gongye fazhan 中国钢铁工 业发展 [The Development of China's Steel Industry], Zhongguo gangtie gongye xiehui 中国钢铁工业协会 China Iron \& Steel Association: Beijing, 2010. 
Xing, Shaowen 邢少文. 2011. "4 yi dun gangtie weigui channeng quxiang" 4 亿吨钢铁 违规产能去向 [Where Shall China's 400 Million Tons Unlawful Iron-and-Steel Producitivity Go?], Nanfengchuang 南风窗[South Wind], 2011, no. 4.

Xinhua News Agency 新华社. May 9 2002. "Beijing jiang quexiao 21 xiang sheji guding zican touzi xiangmu shenpi shixiang" 北京将取消 21 项涉及固定资产 投资项目审批事项 [Beijing Local Government Will Abolish 21 Fixed-Asset Invesetment Review \& Approval Items], Xinhua News Agency, May 9 2002, http://news.xinhuanet.com/fortune/2002-05/09/content_386799.htm, Accessed in May 2012.

Xinhua News Agency 新华社. 1992. Zhongyang zhengfu jigou minglu 1992-1993 中央 政府机构名录 1992-1993 [The Central Government Departments Catalogue 1992-1993], Xinhua chubanshe 新华出版社 The Xinhua Press: Beijing, 1992.

Xinhua News Agency 新华社. December 18, 2006. "Woguo mingque qi da hangye jiang you guoyou jingji kongzhi" 我国明确七大行业将由国有经济控制 [China Announces That Seven Industries Are Going to Be Controlled by the State], Xinhua News Agency Website, December 18, 2006, http://news.xinhuanet.com/fortune/2006-12/18/content_5502762.htm, Accessed in June 2013.

Xinhua News Agency 新华社. December 14, 2006. "Zhongguo queding jieneng jianpai wei mingnian jingji jiegou tiaozheng shouyao renwu"中国确定节能减排为明 年经济结构调整首要任务 [China Confirms That Energy Efficiency Governance Will Be the Priority of Economic Structure Adjustment in the Coming Year], Xinhua News Agency Website, December 14, 2006, http://news.xinhuanet.com/environment/2006-12/14/content_5486281.htm, Accessed in Feburary 2012.

Xinhua News Agency 新华社. August 12, 2010. "Zhongguo zhongyang qiye guoyou ziben chaoguo 2 wan yi yuan" 中国中央企业国有资本超过 2 万亿元[Chinese Central Soes' Assets Exceed Rmb 2 Trillion], Xinhua News Agency Website, August $\quad 2010 . \quad$ http://news.xinhuanet.com/fortune/201008/12/c_12440586.htm, Accessed in May 2013. 
Xinhua News Agency 新华社. April 27, 2007. "'Chabie dianjia' nan’e gaohaoneng qiye taitou" "差别电价"难遏高耗能产业抬头 [Differential Power Pricing Hard to Contain Energy-Intensive Industries' Expansion], Xinhua News Agency Website, April 27, 2007, $\quad$ http://news.xinhuanet.com/fortune/200704/27/content_6034491.htm, Accessed in May 2013.

Xinhua News Agency 新华社. November 15, 2012. "Shiba ji yi zhong quanhui xuanju zhongyang zhengzhiju weiyuan" 十八届一中全会选举中央政治局委员 [The First Plenum of the 18th National Party Congress Elected Politburo Members], News of the Communist Party of China, November 15, 2012, http://cpc.people.com.cn/18/n/2012/1115/c350821-19590526.html. Accessed in Janurary 2013.

Xinhua News Agency 新华社. April 17, 2007. "Fazhan gaige wei xianqi jiaoting 14 ge shengfen gaohaoneng qiye youhui dianjia" 发展改革委限期叫停 14 个省份高 耗能企业优惠电价 [The NDRC Sets Dealine for Elimination of Power Price Discounts in 14 Provinces and Regions], Xinhua News Agency Website, April 17, 2007, http://news.xinhuanet.com/fortune/2007-04/17/content_5985871.htm, Accessed in June 2012.

Xinhua News Agency 新华社. October 31, 2007. "Fang 'youhuang' xu lishun chengpinyou dianjia jizhi" 防“油荒”须理顺成品油定价机制 [Petroleum Prodcuts Pricing Needs Reform to Aviod Fuel Shortage], Xinhua News Agency Website, October 31, 2007, http://news.xinhuanet.com/comments/200710/31/content_6976212.htm, Accessed in May 2013.

$\mathrm{Xu}$, Bing 徐斌. 2011. Zhongguo meidian zongxiang guanxi yanjiu: chongtu jili yu xietiao jizhi 中国煤电纵向关系研究: 冲突机理与协调机制 [The Vertical Relationship between China's Coal and Electric Power Industry: Mechanism of Confliction and Harmony]. Dongbei caijing daxue chubanshe 东北财经大学出 版社 Dongbei University Finance \& Ecnomics Press: Da Lian, 2011.

$\mathrm{Xu}$, Chenggang. 2011. "The Fundamental Institutions of China's Reforms and Development." Journal of Economic Literature 49, no. 4: 1076-1151.

Xu, Yi-Chong. 2008. China's Struggle for Power. The Griffith-Lowy Institute. 
Yan, Yilong, Shaoguang Wang, and Angang Hu 鄢一龙, 王绍光, 胡鞍钢. 2013. "Zhongguo zhongyang zhengfu juece moshi yanbian" 中国中央政府决策模式 演变 [The Evolution of Chinese Central Government's Decision-Making Model], Dangdai zhongguo shi yanjiu 当代中国史研究 [Contemporary China History Studies], 20, no. 4.

Yang, Dali. 2004. Remaking the Chinese Leviathan: Market Transition and the Politics of Governance in China. Stanford, CA: Stanford University Press, 2004.

Yang, Weicai, and Guangming Shi 杨伟才, 师广明. 1994. "Difang lianyou qiye de fazhan fangxiang" 地方炼油企业的发展方向 [Development Direction of China's Local Refineries], Zhongguo huagong 中国化工 [China Chemical Industries], 1994, no. 12: 17-18.

Yang, Xiaowu 杨晓武. 2005. "Xunzong dianjielv hangye hongguan tiaokong" 寻踪电 解铝行业宏观调控 [Tracking China's Macroeconomic Adjustment over the Electrolytic Aluminium Industry], Shijie youse jinshu世界有色金属 [Global NonFerrous Metal], 2005, no. 05: 10-14.

Yeoh, Boon-Siew, and Rajesh Rajaraman. 2004. "Electricity in China: The Latest Reforms." Electricity Journal 17, no. 3: 60-69.

Young, Jason. 2013. China's Hukou System: Markets, Migrants and Institutional Change. New York: Palgrave Macmillan, 2013.

Yuan, Gangming 袁钢明. 2007. "Zhongguo gangtie gongye一zai hongguan jingji biandong zhong fazhan" 中国钢铁工业一在宏观经济变动中发展 [China's Steel Industry: Development in Marco-Economic Changing]. Japan External Trade Organization, 2007. http://www.ide.go.jp/English/Publish/Download/Jrp/pdf/143_2.pdf. Accessed in June 2013.

Yuan, Xueliang, and Jian Zuo. 2011. "Transition to Low Carbon Energy Policies in China-from the Five-Year Plan Perspective." Energy Policy 39, no. 6: 38553859 . 
Zeng, Lin, Ming Xu, Sai Liang, SiyuZeng, and Tianzhu Zhang. 2014. "Revisiting Drivers of Energy Intensity in China During1997-2007: A Structural Decomposition Analysis." Energy Policy 2014, no. 67: 640-647.

Zeng, Peiyan 曾培炎. August 20, 2006. "Shenru xuexi Jiang Zemin tongzhi de jingji jianshe sixiang, cujin jingji shehui quanmian xietiao ke chixu fazhan" 深入学习 江泽民同志的经济建设思想，促进经济社会全面协调可持续发展[Studying Jiang Zeming's Economic Constrcution Ideas to Promote Comprehensive, Coordinated and Sustainable Development], People's Daily Website, August 20, 2006, http://politics.people.com.cn/GB/1026/4720751.html. Accessed in Janurary 2013.

Zha, Daojiong. 2006. "China's Energy Security: Domestic and International Issues." Survival 48, no. 1: 179-190.

Zha, Daojiong 查道炣. 2008. "Kuozhang zhongguo nengyuan anquan yanjiu de keti jichu" 扩展中国能源安全研究的课题基础 [Expanding the Research Area of Energy Security in China], Shijie jingji yu zhengzhi 世界经济与政治 [World Economics and Politics], 2008, no. 7.

Zha, Daojiong. 2010. "Oiling the Wheels of Foreign Policy? Energy Security and China's International Relations." Working Paper No.1, Asia Security Initiative Policy Series, RSIS Centre for Non-Tradtional Security (NTS) Studies, Nanyang Technological University.

Zha, Donglan, Dequn Zhou, and Ning Ding. 2009. "The Contribution Degree of SubSectors to Structure Effect and Intensity Effects on Industry Energy Intensity in China from 1993 to 2003." Renewable and Sustainable Energy Reviews 2009, no. 13: 895-902.

Zhang, Chi, and Thomas C. Heller. 2007. "Reform of Chinese Electric Power Market: Economics and Institutions." In The Political Economy of Power Sector Reform: The Experiences of Five Major Developing Countries, edited by David G. Victor and Thomas C. Heller. Cambridge, UK: Cambridge University Press.

Zhang, Jian. 2011. China's Energy Security: Prospects, Challenges and Opportunities. Center for Northeast Asia Policy Studies, The Brookings Institution. 
http://www.brookings.edu/research/papers/2011/07/china-energy-zhang.

Accessed in June 2012.

Zhang, Jin. 2004. Catch-up and Competitiveness in China. Edited by Peter Nolan and Dong Fureng, Routledgecurzon Studies on the Chinese Economy. London, New York: RoutledgeCurzon, 2004.

Zhang, Liang. 2010. "The Reformed Plan System: China's Electric Power Industry." PhD Thesis, Brunel University of West London, 2010.

Zhang, Xiangdong 张向东. October 23, 2009. "Gangtie wei pi xianjian channeng 5800 wan dun fagaiwei xiang 'yikanliaozhi"' 钢铁未批先建产能 5800 万吨发改委想 “一砍了之” [The NDRC Plans to Eliminate 58 Million Tons Illegal Iron-andSteel Productivity], China Economy Obersvation Website, October 23, 2009, http://www.eeo.com.cn/eeo/jjgcb/2009/10/26/153702.shtml. Accessed in May 2014.

Zhao, Suisheng. 2013. ed. China's Search for Energy Security: Domestic Sources and International Implications. New York: Routledge, 2013.

Zhao, Xiaofan, and Liang Wu 赵小凡, 邬亮. 2015. "Gongye qiye jienengliang jisuan yu mubiao kaohe" 工业企业节能量计算与目标考核 [2015 Annual Review of Low-Carbon Development in China], Brookings-Tsinghua Center for Public Policy, 2015, http://www.brookings.edu/zh-cn/research/papers/2015/06/17industry-energy-saving-zhao-wu. Accessed in August 2015.

Zhao, Xiaoli, Chunbo Ma, and Dongyue Hong. 2010. "Why Did China's Energy Intensity Increase During1998-2006: Decomposition and Policy Analysis." Energy Policy 2010, no. 38: 1379-1388.

Zhao, Ziyang 赵紫阳. 1982. "Guowuyuan zhongli zhaoziyang guanyu zhiding di liu ge wunian jihua de baogao" 国务院总理赵紫阳关于第六个五年计划的报告 [The State Council Premier's Report on the Implementation of the Sixth National Fyp Guideline], People's Daily Website, 1982, http://cpc.people.com.cn/GB/64184/64186/66678/4493887.html. Accessed in June 2013. 
Zhao, Ziyang 赵紫阳. 1985. "Guowuyuan zhongli zhaoziyang guanyu zhiding di qi ge wunian jihua de baogao" 国务院总理赵紫阳关于制定第七个五年计划的报告 [The State Council Premier's Report on the Making of the Seventh National Fyp Guideline], People's Daily Website, 1985, http://cpc.people.com.cn/GB/64184/64186/66678/4493887.html. Accessed in June 2013.

Zheng, Yu, and Regina Abrami. 2011. "The New Face of Chinese Industrial Policy: Making Sense of Antidumping Cases in the Petrochemical and Steel Industries." Journal of East Asian Studies 2011, no. 11: 373-406.

Zhou, Dequn, Donglan Zha, and Peng Zhou 周德群, 査冬兰, 周鹏. 2012. "Zhongguo nengyuan xiaolv yanjiu" 中国能源效率研究 [China Energy Efficiency Research]. Kexue chubanshe 科学出版社 Science Press : Beijing, 2012.

Zhu, Min 朱敏. Janurary 4, 2005. " Zhong huagongye dui jingji zengzhang de fumian yingxiang burong hushi" 重化工业对经济增长的负面影响不容忽视 [HeavyIndustrialisation's Negative Impacts to Economic Development Cannot Be Ignored], People's Daily Website, Janurary 4, 2005, http://theory.people.com.cn/GB/40540/3095846.html. Accessed in August 2015.

Zhu, Rongji 朱F基. 2000. "Zhonggong zhongyang guanyu zhiding guomin jingji he shehui fazhan di shi ge wunian jihua de jianyi" 中共中央关于制定国民经济和 社会发展第十个五年计划的建议 [Policy Suggestions of the Cpc Central Committe to the Making of the 10th Fyp], People's Daily Website, 2000, http://cpc.people.com.cn/GB/64162/71380/71382/71386/4837946.html.

Accessed in July 2014.

Zhu, Xufeng. 2013. The Rise of Think Tanks in China, Routledge China Policy Series. New York: Routledge, 2013.

Zweig, David, and Jianhai Bi. 2005. "China's Global Hunt for Energy." Foreign Affairs 84, no. 5: 25-38. 